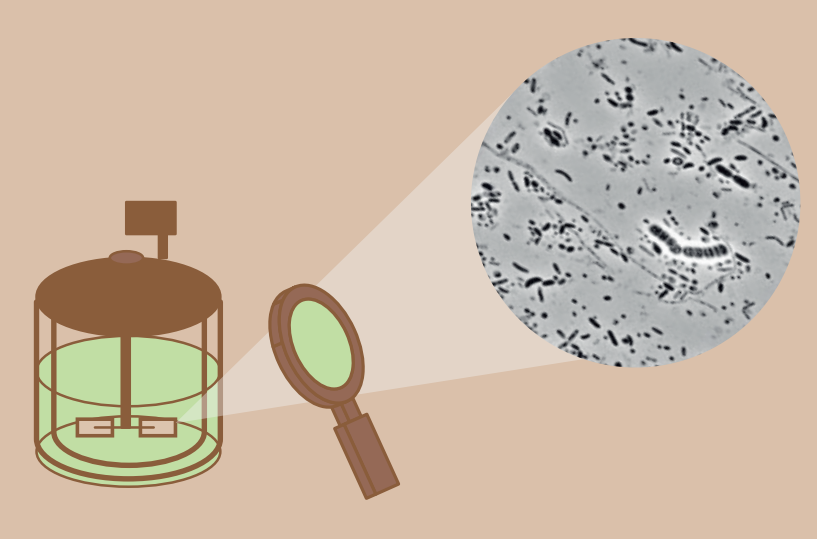

Organic acid production from starchy waste by gut derived microorganisms

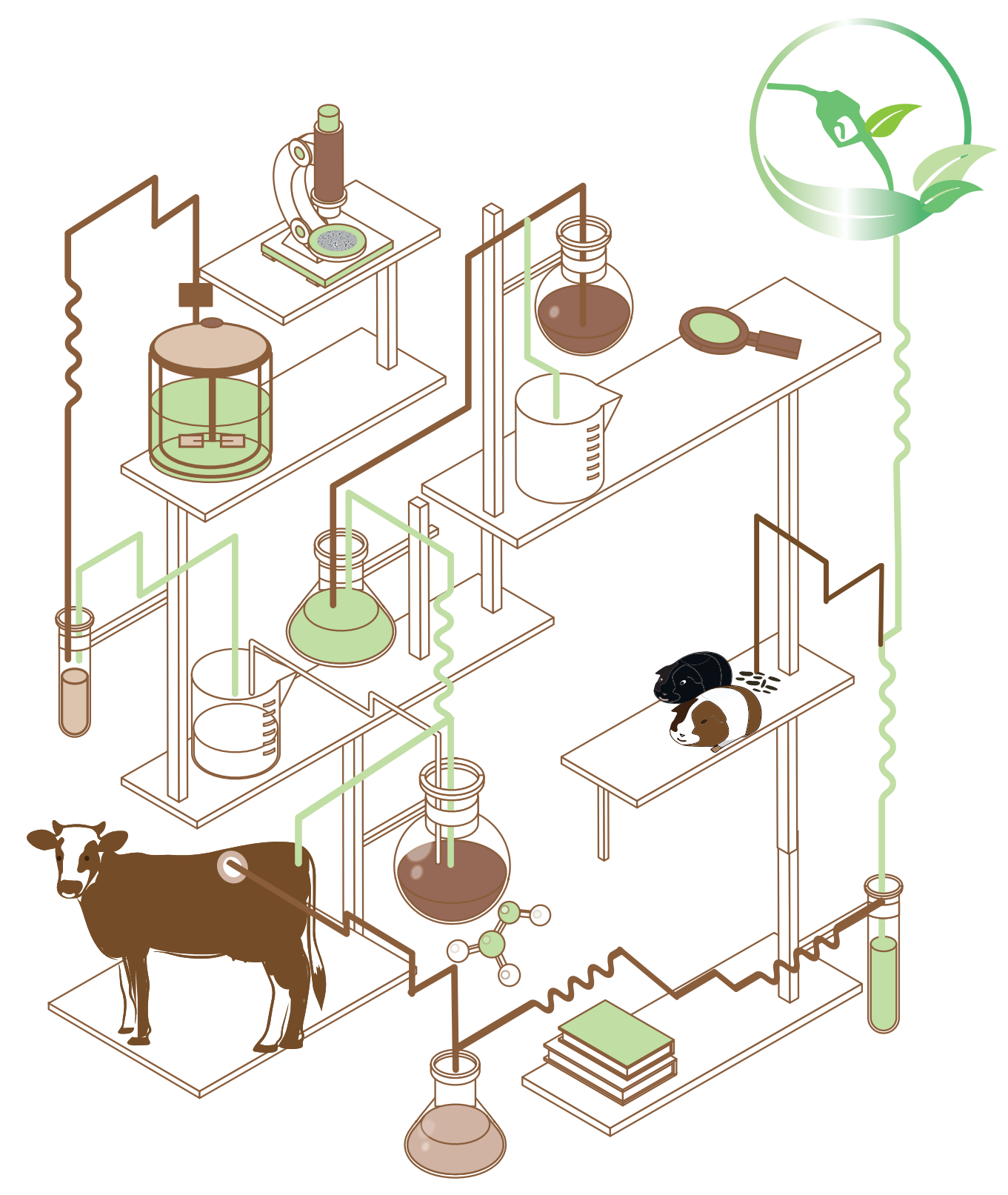




\section{Propositions}

1. Actinomyces succiniciruminis has potential for industrial succinate production from starchy waste

(this thesis)

2. Knowing the relative abundance of each microbial species in a mixed rumen inoculum does not help to predict the fermentation products (this thesis)

3. Phytoplanktons are the real-world savers for the global warming crisis as they are world's biggest oxygen producers and carbon sequesters

(Witman, S. (2017) World's biggest oxygen producers living in swirling ocean waters. Eos, 98)

4. The best way to protect endangered floras is to bring them into a commercial breeding system

5. Studying abroad elevates cooking skills to the master level

6. There is no real waste in our world

Propositions belonging to this thesis entitled:

"Organic acid production from starchy waste by gut derived microorganisms"

Susakul Palakawong Na Ayudthaya

Wageningen, 7 September 2018 
Organic acid production from starchy waste by gut derived microorganisms

Susakul Palakawong Na Ayudthaya 


\section{Thesis committee}

\section{Promotors}

Prof. Dr Alfons J.M. Stams

Personal chair at the Laboratory of Microbiology

Wageningen University \& Research

Prof. Dr Willem M. de Vos

Professor of Microbiology

Wageningen University \& Research

\section{Co-promotor}

Dr Caroline M. Plugge

Associate professor, Laboratory of Microbiology

Wageningen University \& Research

\section{Other members}

Prof. Dr Grietje Zeeman, Wageningen University \& Research

Dr Bundit Fungsin, Thailand Institute of Scientific and Technological Research, Pathum Thani, Thailand

Prof. Dr Gert-Jan W. Euverink, University of Groningen, The Netherlands

Dr Marieke E. Bruins, Wageningen University \& Research

This research was conducted under the auspices of the Graduate School for Socio-Economic and Natural Sciences of the Environment (SENSE). 


\title{
Organic acid production from starchy waste by gut derived microorganisms
}

\section{Susakul Palakawong Na Ayudthaya}

\author{
Thesis \\ submitted in fulfilment of the requirements for the degree of doctor \\ at Wageningen University \\ by the authority of the Rector Magnificus, \\ Prof. Dr A.P.J. Mol, \\ in the presence of the \\ Thesis Committee appointed by the Academic Board \\ to be defended in public \\ on Friday 7 September 2018 \\ at 11 a.m. in the Aula.
}


Susakul Palakawong Na Ayudthaya

Organic acid production from starchy waste by gut derived microorganisms, 220 pages.

$\mathrm{PhD}$ thesis, Wageningen University, Wageningen, the Netherlands (2018)

With references, with summary in English

ISBN: 978-94-6343-788-2

DOI: https://doi.org/10.18174/451805 
Table of Contents

$\begin{array}{lll}\text { Chapter } 1 & \text { General introduction and thesis outline } & \mathbf{7}\end{array}$

Chapter 2 Organic acid production from potato starch waste fermentation 27 by rumen microbial communities from Dutch and Thai dairy cows

Chapter 3 Actinomyces succiniciruminis sp. nov. and Actinomyces glycerinitolerans sp. nov., two novel organic acid-producing bacteria isolated from rumen

Chapter 4 Optimization of succinate production from potato starch waste by Actinomyces succiniciruminis strain $\mathrm{Am} 4^{\mathrm{T}}$

Chapter 5 Microbial diversity and organic acid production of guinea pig fecal samples

Chapter 6 Streptococcus caviae sp. nov., isolated from guinea pig fecal samples

Chapter 7 General discussion

Summary

References

List of publications

Co-author affiliations

About the author

Acknowledgements

SENSE Diploma 



\section{CHAPTER 1}

General introduction and thesis outline 


\section{Global energy consumption and waste streams}

Global energy consumption is steadily increasing. The transportation, chemical and many other industry sectors are largely relying on petroleum and fossil fuels as a primary source of energy. In 2015, fossil fuels comprised of oil (31.7\%), coal (28.1\%) and natural gas (21.6\%) contributed for more than $80 \%$ of the total energy supply $(13,647 \mathrm{Mt}$ ) (IEA, 2017). The rate at which worldwide fossil fuels are consumed is increasing due to world's population increase and the rise in living standards in parts of the world that had consumed very little energy in the past. Fossil fuel reserves are limited, and exploitation will become expensive. Besides, consumption of fossil fuels results in pollution and carbon dioxide formation, which contributes to global warming. Therefore, the search for other energy sources such as natural gas, wind, nuclear and renewable organics is essential to guarantee energy supply.

\section{Current bio-based economy prospective}

Fossil reserves are also important as chemicals precursors, including building blocks for the chemical industry. Hence, chemical technologies based on fossil (petroleum) resources are currently being replaced by green technologies that make use of alternative biobased resources, in the so called biorefinery concept. This is often relying on microbial fermentation and when compared to chemical refinery processes, it is more environmental friendly and more sustainable (less pollution and no net $\mathrm{CO}_{2}$ emission to the atmosphere). In Table 1 the chemical and the bio-fermentation routes are compared. One of the guideline principles of green chemistry defined by the US Environmental Protection Agency (EPA) is promoting the use of renewable feedstocks (http://www.epa.gov/) (Fiorentino and Ripa, 2017). 
Table 1. A general comparison between chemical and bio-fermentative routes.

(modified from Cukalovic and Stevens, 2008; Law and Mohammad, 2017)

\begin{tabular}{|c|c|c|}
\hline Parameter & $\begin{array}{c}\text { Chemical routes } \\
\text { Non-renewable feedstocks - } \\
\text { petrochemicals }\end{array}$ & $\begin{array}{c}\text { Fermentative routes } \\
\text { Biobased feedstock - carbohydrates }\end{array}$ \\
\hline Price considerations & $\begin{array}{l}\text { Still cheaper than the renewable } \\
\text { sources. }\end{array}$ & $\begin{array}{l}\text { Feedstock themselves do not contribute to } \\
\text { the price as much as downstream } \\
\text { processing }\end{array}$ \\
\hline Availability & $\begin{array}{l}\text { Availability expected to } \\
\text { decrease in time }\end{array}$ & Abundant and renewable \\
\hline Routes & $\begin{array}{l}\text { Developed routes, established } \\
\text { technologies }\end{array}$ & $\begin{array}{l}\text { Routes under constant improvement, young } \\
\text { technologies }\end{array}$ \\
\hline $\begin{array}{l}\text { Yields and } \\
\text { productivities }\end{array}$ & Generally high & $\begin{array}{l}\text { Sometimes a large number of side products, } \\
\text { diluted media, long reaction times }\end{array}$ \\
\hline Major disadvantages & $\begin{array}{l}\text { High energy demands (pressure } \\
\text { and temperature). Catalysts } \\
\text { disposal issues }\end{array}$ & $\begin{array}{l}\text { Sensitivity of microorganisms, nutrient } \\
\text { requirements, complicated product } \\
\text { recovery, large amounts of waste }\end{array}$ \\
\hline Environment effect & $\begin{array}{l}\text { Release } \mathrm{CO}_{2} \text { that contributes to } \\
\text { global warming }\end{array}$ & Consume $\mathrm{CO}_{2}$ via TCA cycle \\
\hline Public awareness & Decreasing popularity & $\begin{array}{l}\text { Increased interest in improving currently } \\
\text { applied routes and innovations }\end{array}$ \\
\hline
\end{tabular}

Current high costs of production prevent bio-based chemicals to be widely used. Thus, production processes from bio-based resources need to be developed and optimized. It is estimated that in 2050 approximately $30 \%$ (by weight) of chemicals will be obtained from renewable biomass (http://www.suschem.org) (Fiorentino and Ripa, 2017). Biomass is an abundant carbon-neutral renewable resource that can be used as a carbon source instead of fossil feedstocks (Fiorentino and Ripa, 2017). Production chains resulting from biomass are considered as "short-cycle carbon systems", which are more sustainable and preferable than those resulting from fossil resources, which are considered as "long-cycle carbon systems" (Kajaste et al., 2014; Fiorentino and Ripa, 2017).

The transition from fossil based to bio-based economy needs the development of innovative processes to exploit the potential of biomass (Pleissner et al., 2017). Thus, utilization of food wastes or biomass and their conversion into valuable products require more attention as the implementation of such system is not yet successfully guaranteed. However, many criteria need to be considered for 
biomass utilization in the context of efficient strategies, such as the amount of biomass available for energy and material uses and the positive environment from renewable organic materials and economic feasibility (Venus et al., 2018), as well as the factors presented in Table 1.

At present, three biorefinery platforms are known; i) the sugar platform: using purified enzymes to convert biomass into five- and six-carbon sugars and then further convert these into fuels and chemicals by fermentation; ii) the syngas platform: using thermochemical systems to convert biomass into synthesis gas (a mixture of $\mathrm{CO}, \mathrm{H}_{2}$ and $\mathrm{CO}_{2}$ ) and then further convert to fuels and chemicals by chemical or biological catalysts, and iii) the carboxylate platform: using hydrolysis and fermentation with often undefined mixed microorganisms to convert organic feedstocks into short chain carboxylates (Agler et al., 2011; Bosma et al., 2013). The differences between these platforms are largely based on the method of biomass conversion and the chemicals resulting from that. Methane is usually the expected product from anaerobic digestion process, however, not only methane is valuable, but the intermediate compounds as organic acids are also important.

\section{Abundance of organic waste streams}

On one hand, the increase of human population and the associated consumption of food and energy results in a steady increase of organic waste. Approximately one third of the global food production is discarded as waste per year according to the Food and Agriculture Organization of the United Nations (FAO). (http://www.unric.org/en/food-waste). Organic waste, such as food and fiber processing of fruit, vegetable waste, garbage, sewage sludge, cattle manure and/or industrial waste are abundant worldwide (Murto et al., 2004). The European Community Landfill Directive (EPA) has led to an increase in the costs of landfill and a reduction of places for landfill in many countries (EPA; http://ec.europa.eu/environment/waste/target_review.htm). Approximately 87.6 million tonnes per year of food waste are produced in Europe (Colombo et al., 2017; Stenmarck et al., 2016). It was predicted that the annually organic waste would be composed of 70,000 $t$ carbohydrates (including 50,000 $\mathrm{t}$ starch), 15,000 $\mathrm{t}$ lipids and 7,000 $\mathrm{t}$ proteins based on the present composition of 
food and the organic wastes in urban areas of Berlin (Venus et al., 2018). EU countries have announced the agreement on a Directive that sets a target for recycling approximately $65 \%$ of the municipal waste and to reduce landfilling to $10 \%$ of municipal waste by 2030 (EPA; http://ec.europa.eu/environment/waste/target_review.htm). With increasing disposal costs, alternative uses of wastes are increasingly being sought. Many waste products have the potential to provide new and natural sources of valuable products. The possibility of recovering the energy potential of biomass and wastes is a strong motivation for developing biological processes. Organic waste materials have no or low-value and do not compete with the food production chain (Ghaffar et al., 2014). Hence, notably organic waste is becoming an important source for producing novel or renewable energy to partially replace the use of fossil resources and closing the carbon cycle or reducing greenhouse gas emissions, as well as supply security, promoting rural development and projected long term economic savings (Clark et al., 2015; Keegan et al., 2013). Therefore, renewable alternative sources, such as organic waste, are of interest. Due to the huge availability of waste and agricultural residues, these were determined as high-potential feedstock for the sustainable biofuel and chemical production (Steinbusch et al., 2011). Therefore, bio-based processes should be further developed to conserve energy by turning waste and/or biomass into valuable products, such as organic acids, alcohols or methane. The organic acids for instance can be used as bio-based buildingblock chemicals to replace the use of fossil resources. This process is included in the carboxylate platform that uses mixed microbial cultures for the conversion of organic feeds into carboxylates via anaerobic digestion.

\section{Starch waste: a promising organic waste as substrate for organic acid production}

Starch is the second most abundant carbohydrate produced by plants after cellulose, resulting in a large amount of starchy waste or starchy residues worldwide (Sonnewald and Kossmann, 2013). For instance, in US Pacific Northwest, potatoes are a major crop with a harvest of $1.26 \times 10^{10} \mathrm{~kg}$ (in 2011) and about $40 \%$ of the potatoes are discharged (Liang et al., 2014; NPC, 2012). Approximately 
$8 \%$ of the potato weight or around $10^{9} \mathrm{~kg}$ was estimated to be lost as potato peel waste (Liang et al., 2014; NPC, 2012). Starch waste is abundant in many countries, including Thailand where potato and cassava are main agricultural crops. Such starch waste is used as animal feed or compost, but still much of it is discharged without further use (Suzuki et al., 2010). The amount of starch in raw materials is variable depending on the source (cassava, maize, potato, sweet potato and tapioca). Usually, dry starch waste contains more than $70 \%$ starch (Rakshit, 2004). Starch is mainly composed of amylose and amylopectin with $\alpha-1-4$ glycosidic linkages, which are relatively easily hydrolyzed. Thus, it has an advantage over cellulose with B-1-4 linkages that are more difficult to be broken down (Rakshit, 2004). As potato waste or starch waste mainly contains carbohydrates and less contribution of other compounds, this could lead to lower costs for downstream processing. Therefore, potato waste is a suitable substrate for microbial fermentation in the carboxylate platform, yielding organic acids, which can be converted to a variety of valuable chemicals and pharmaceuticals (Rakshit, 2004). This is so-called as the second-generation bio-based products, in which wastes, or by-products are utilized as raw material, whereas in the first-generation bio-based products, sugars and pure starch are utilized (Matsakas et al., 2014).

\section{Carboxylate platform for organic acids production}

The carboxylate platform is a possibility to conserve energy from waste and/or biomass using anaerobic mixed cultures to produce carboxylates, including organic acids (Tamis et al., 2015; Agler et al., 2011) (Fig. 1). Products from the carboxylate platform have a higher value and a better production efficiency than, for example, biogas (methane) formation (Tamis et al., 2015). The composition of the organic wastes varies depending on the source of the wastes. Agricultural wastes such as biomass or agro-food waste from industries, normally are composed of a complex mixture of cellulose, fibers, starch, protein and/or lipids. Normally, a physical and/or chemical pretreatment step is applied to make the organic wastes or biomass ready for fermenting microorganisms that is depending on the type of biomass. In the carboxylate platform (Fig. 1) there are mainly two steps; 
hydrolysis and acidogenesis (fermentation) that can be characterized into 1) separate enzymatic hydrolysis and fermentation (SHF) processes which complex organic matter or organic wastes is first hydrolyzed into soluble organic molecules (fermentable sugars) and then the soluble organic molecules are fermented into products (organic acids) in a separate reactor, 2) simultaneous saccharification and fermentation (SSF) processes where the organic matter is hydrolyzed into fermentable sugars and the sugars are fermented into products such as organic acids in one reactor (Kambam and Henson, 2010).

\section{Complex organic matter} Organic waste: starchy waste

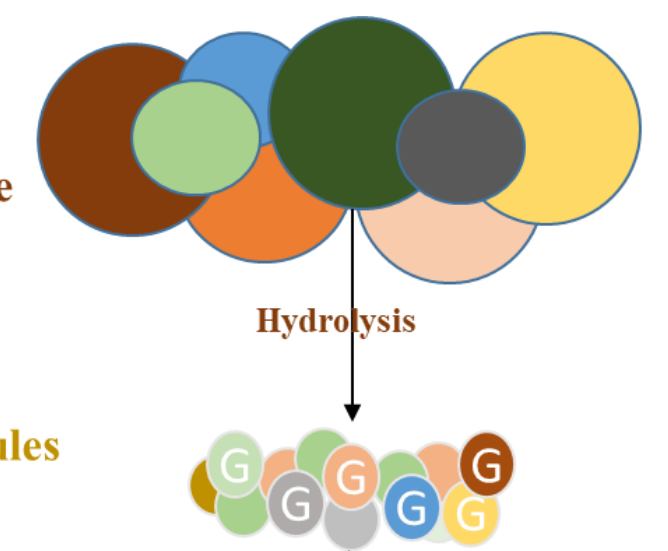

\section{Soluble organic molecules (glucose etc.)}

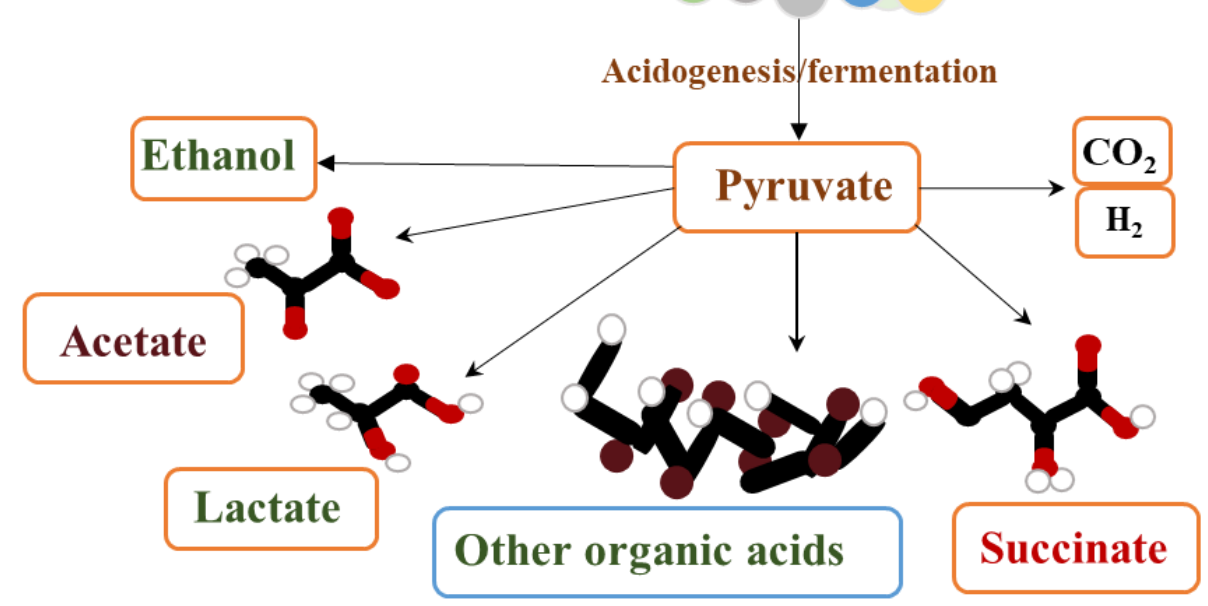

Fig. 1. Organic acid production from biobased feed stock in the carboxylate platform.

However, additional hydrolytic enzymes are required in both SHF and SSF processes, while in the consolidated bioprocessing (CBP), the most integrated variant, microorganisms produce all 
necessary enzymes to hydrolyze the pre-treated biomass without additional enzyme requirement (Bosma et al., 2013).

In anaerobic digestion, organic waste fermentation using undefined mixed microbes, such as activated sludge, manure or rumen, has an advantage in terms of high capacity to utilize various organic wastes without the addition of hydrolytic enzymes because the microbial consortia produce hydrolytic enzymes. Using undefined inocula is very challenging as it usually results in mixed organic acids and requires downstream product purification. Therefore, a strategic choice of substrate and/or inocula is important.

Organic acids can be used as biobased building-block chemicals (Agler et al., 2011; Sauer et al., 2008). Lactate, for instance, can be used in various applications such as an acidulant, chemicals, flavour enhancer or food preservative agent. As the organic acids can be applied in a broad range, lower market price of organic acids is desirable.

\section{Organic acid production and their market}

The market for organic acids is expanding and becomes important in chemical industry. For some organic chemicals more, knowledge of the microbes involved in their formation is required. Top 10 world chemicals are 1) succinic acid, 2) furanics, 3) hydroxypropionic acid, 4) glycerol, 5) sorbitol, 6) xylitol, 7) levulinic acid, 8) biohydrocarbons (such as isoprene, farnesene), 9) lactic acid and 10) ethanol (Sauer et al., 2008). Some acids such as citric, itaconic, gluconic and lactic acids are produced at large scale, and the microbial processes involved are well understood (Sauer et al., 2008). Beside from those category chemicals, five organic acids which have the potential to overcome the unsuccessful transferring from the pilot scale to commercial scale and serve as biobased materials to produce bioplastics and/or food additives and their application are presented in Table 2. These five organic acids, including lactic acid, acrylic acid, succinic acid, muconic acid and lactobionic acid are produced from renewable resources (Pleissner et al., 2017). 
Table 2. Organic acids obtained from renewable resources that can serve as bio-based materials (modified from Pleissner et al., 2017).

\begin{tabular}{|c|c|c|c|c|}
\hline $\begin{array}{c}\text { Number of } \\
\text { carbon } \\
\text { atoms } \\
\end{array}$ & Chemical name & $\begin{array}{l}\text { Chemical } \\
\text { formula }\end{array}$ & Producer (examples) & Use (examples) \\
\hline $\mathrm{C}_{3}$ & $\begin{array}{l}\text { Acrylic acid } \\
\text { (Prop-2-enoic acid) }\end{array}$ & $\mathrm{C}_{3} \mathrm{H}_{4} \mathrm{O}_{2}$ & $\begin{array}{l}\text { Lactobacillus plantarum, } \\
\text { Candida propionicum, } \\
\text { Pediococcus shermanii and } \\
\text { Rhodococcus rhodochrous }\end{array}$ & $\begin{array}{l}\text { For the formulation of } \\
\text { acrylate ester, detergents and } \\
\text { dispersants }\end{array}$ \\
\hline $\mathrm{C}_{3}$ & $\begin{array}{l}\text { Lactic acid } \\
\text { (2-Hydroxypropanoic acid) }\end{array}$ & $\mathrm{C}_{3} \mathrm{H}_{6} \mathrm{O}_{3}$ & $\begin{array}{l}\text { Lactobacilli, Bacillus, } \\
\text { Enterococcus, Lactococcus, } \\
\text { Pediococcus, Streptococcus, } \\
\text { Candida and Rhizopus } \\
\text { groups }\end{array}$ & $\begin{array}{l}\text { Food and beverages, } \\
\text { biodegradable } \\
\text { polymer production }\end{array}$ \\
\hline $\mathrm{C}_{12}$ & $\begin{array}{l}\text { Lactobionic acid } \\
\text { (4-O- } \beta \text {-galactopyranosyl-D- } \\
\text { gluconic acid) }\end{array}$ & $\mathrm{C}_{12} \mathrm{H}_{22} \mathrm{O}_{12}$ & Pseudomonas spp. & $\begin{array}{l}\text { For pharmaceutical, food, } \\
\text { cosmetic, and chemical } \\
\text { industries }\end{array}$ \\
\hline $\mathrm{C}_{6}$ & $\begin{array}{l}\text { Muconic acid } \\
((2 Z, 4 Z)-H e x a-2,4 \text {-dienedioic acid })\end{array}$ & $\mathrm{C}_{6} \mathrm{H}_{6} \mathrm{O}_{4}$ & $\begin{array}{l}\text { Arthrobacter sp. and } \\
\text { Pseudomonas sp. }\end{array}$ & $\begin{array}{l}\text { For formation of adipic acid } \\
\text { and nylon- } 6,6\end{array}$ \\
\hline $\mathrm{C}_{4}$ & $\begin{array}{l}\text { Succinic acid } \\
\text { (Butanedioic acid) }\end{array}$ & $\mathrm{C}_{4} \mathrm{H}_{6} \mathrm{O}_{4}$ & $\begin{array}{l}\text { Recombinant E. coli, } \\
\text { Actinobacillus succinogenes, } \\
\text { Mannheimia } \\
\text { succiniproducens, } \\
\text { Corynebacterium } \\
\text { glutamicum, Saccharomyces } \\
\text { cerevisiae, Yarrowia } \\
\text { lipolytica and Candida krusei }\end{array}$ & $\begin{array}{l}\text { Potential to replace maleic } \\
\text { anhydride, be converted to } \\
\text { 1,4-butanediol, manufacture } \\
\text { of tetrahydrofuran, polymers }\end{array}$ \\
\hline
\end{tabular}

Lactate and succinate are promising platform chemicals (Fiorentino and Ripa, 2017) and are currently produced biotechnologically at commercial scale (Table 2) (Pleissner et al., 2017). This thesis focuses on lactate and succinate production by mixed microbial communities using starch waste and other carbohydrates as substrates. 


\section{Bio-based lactate production}

As previously mentioned, lactate, or lactic acid $\left(\mathrm{C}_{3} \mathrm{H}_{6} \mathrm{O}_{3}\right)$ has various applications. In addition, lactate is the base chemical for production of biodegradable plastic: polylactic acid, which is composed of both poly D- and L-lactate (Okano et al., 2010; Hofvendahl and Hahn-Hägerdal, 2000). Due to the increase in demand, it was expected that the global market of lactate would exceed over 1-million-ton annual production by 2020, but this occurred already in 2010 (Taskila and Ojamo, 2013). The targeted cost of lactate at industrial scale should be less than $0.8 \mathrm{US} \$ . \mathrm{kg}^{-1}$ to serve the poly-lactic acid production. Thus, the selling price of bio-poly-lactic acid must be less than half of 2.2 SUS. $^{-1}$ to compete with the poly-lactic acid price derived from fossil-fuel-based plastics (Okano et al., 2010; Wee et al., 2006). Approximately 95\% of industrial lactate production derives from fermentation. Several bacteria, fungi and yeasts can produce lactate, for instance, Bacillus spp., Enterococcus spp., Lactococcus spp., Pediococcus spp., Streptococcus spp., Candida spp. and Rhizopus oryzae (Pleissner et al., 2017). Microbial lactate fermentation has an advantage over chemical lactate synthesis as a D- or an L-form can be preferentially produced. Chemical synthesis always results in a racemic mixture of D- and L-lactate (Ghaffar et al., 2014; Ryu et al., 2004). There are still some aspects that can improve the cost-efficiency of bio-lactate production such as the pretreatment cost of raw materials, the separation and purification processes of lactate after fermentation and fastidiousness of the lactic acid bacteria (LAB) (Okano et al., 2010). Bio-lactateproducing microorganisms are ideal for biotechnological application because they can cope with rough conditions such as high organic acid concentration at low pH value (Weusthuis et al., 2017). In 2010, Kovács and others have introduced Bacillus coagulans as a promising next-generation microbial production organism for building block chemicals or biofuels from renewable resources because it is a thermotolerant bacterium and is genetically accessible (Kovács et al., 2010). Recently, a new isolate of Bacillus coagulans MA-13 has been introduced as it has a potential for lactate production from lignocellulosic biomass (Aulitto et al., 2017). Weusthuis and others (2017) have first introduced a fungus; Monascus ruber as cell factory for lactate production at low $\mathrm{pH}$ with high 
lactate production (190 $\mathrm{g} \mathrm{l}^{-1}$ at $\mathrm{pH}$ 3.8) (Weusthuis et al., 2017). However, in their study glucose and/or xylose were used as substrate that have high costs in the overall production. Gao and others (2011) have claimed that the costs of substrate (carbon source) and the operation of the lactate fermentation are still the bottlenecks in the industrial scale. An alternative option to achieve the target cost of lactate is to reduce the production cost by either using low of zero cost substrate and/or processing. Lactate production by lactic acid producing bacteria has been studied using various substrates aiming to reduce the substrate cost (Table 3). For example, the maximum lactate production yield of $0.98 \mathrm{~g}$. $\mathrm{g}^{-1}$ has been achieved with Lactobacillus amylophilus BCRC 14055 (Yen and Kang, 2010) and Lactobacillus casei NRRL B-441, respectively (Table 3). Starchy materials are promising raw materials as they are relatively abundant and low in price. Using the amylolytic LAB (ALAB) such as the Lactobacillus amylophilum which have $\alpha$-amylase are able to produce lactate from starch materials is one of the strategies for the reduction of the pretreatment costs (Okano et al., 2010). 
Table 3. Examples of lactate production by microorganisms from different substrates (modified from Abdel-Rahman et al., 2013)

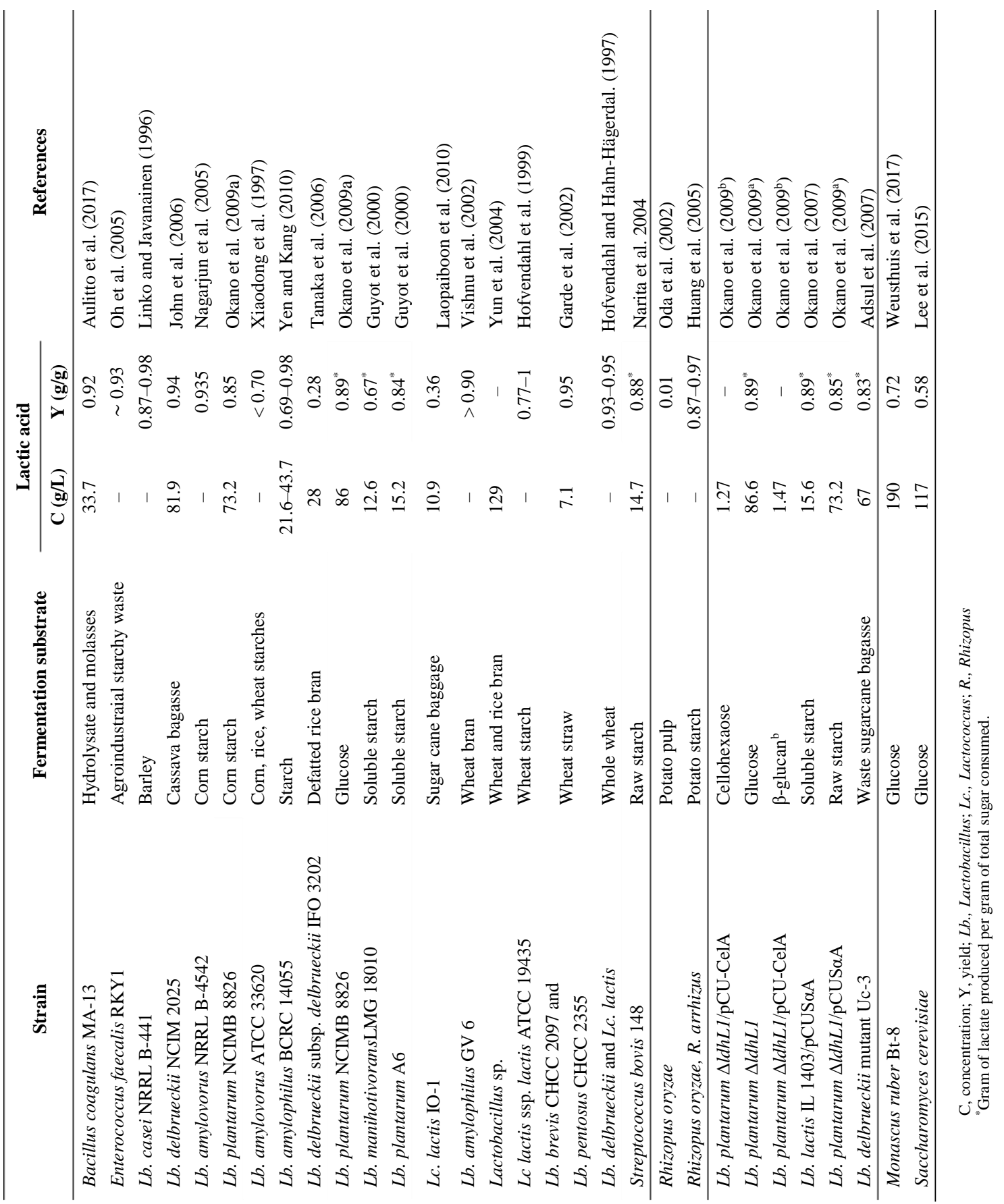




\section{Bio-based succinate production}

Succinate or succinic acid $\left(\mathrm{C}_{4} \mathrm{H}_{6} \mathrm{O}_{4}\right)$ is a 4-carbon dicarboxylic acid family and one of the intermediates in the anaerobic metabolism of various anaerobic and facultative microorganisms. Succinic acid has extensive range of applications such as in food industries as acidulant, as flavouring and antimicrobial agent, food supplement, or as building-block to produce fuel additives, and other products including plastics, paints, inks, resins, coatings and pigments (Pateraki et al., 2016; Salvachúa et al., 2016; Li et al., 2010; Cukalovic and Stevens 2008). Succinate is proposed as a biobased $\mathrm{C}_{4}$ platform chemical for the replacement of petrochemical building blocks such as maleic anhydride, an intermediate to produce many chemicals (Jang et al., 2012; Li et al., 2010 $)$. For instance, succinate and its derivatives adipic acid and 1,4 butanediol can be used to produce some of the biodegradable polymers such as polyamides and polyesters (Pateraki et al., 2016). Succinate is one of the "Top 10" bio-based products from biorefinery carbohydrates and the "Top 12" building block chemicals of the US Department of Energy's list (Bozell and Petersen, 2010; Meng et al., 2016; Fiorentino and Ripa, 2017). In 2013-2014, the annual bio-based succinate production was around $38,000 \mathrm{t}$ or about $49 \%$ of the total product market. It is expected to reach 600,000 t by 2020 (Pateraki et al., 2016). Currently, the bio-based marketing price is approximately $\$ 2.94$ per $\mathrm{kg}$, which is higher than the ideal cost (\$1 per $\mathrm{kg})$ based on the requirement to produce commodity chemicals by chemical production (Pateraki et al., 2016). Bio-succinate production in industrial fermentations mainly uses purified sugars or glucose syrup as carbon sources (Pateraki et al., 2016), which is costly and thus contributes to the overall succinate production price. In Table 4, the example of succinate production and productivity using a variety of substrates are listed. 
Table 4. Example of succinate production by microorganisms from different substrates (modified from Li and Xing, 2015)

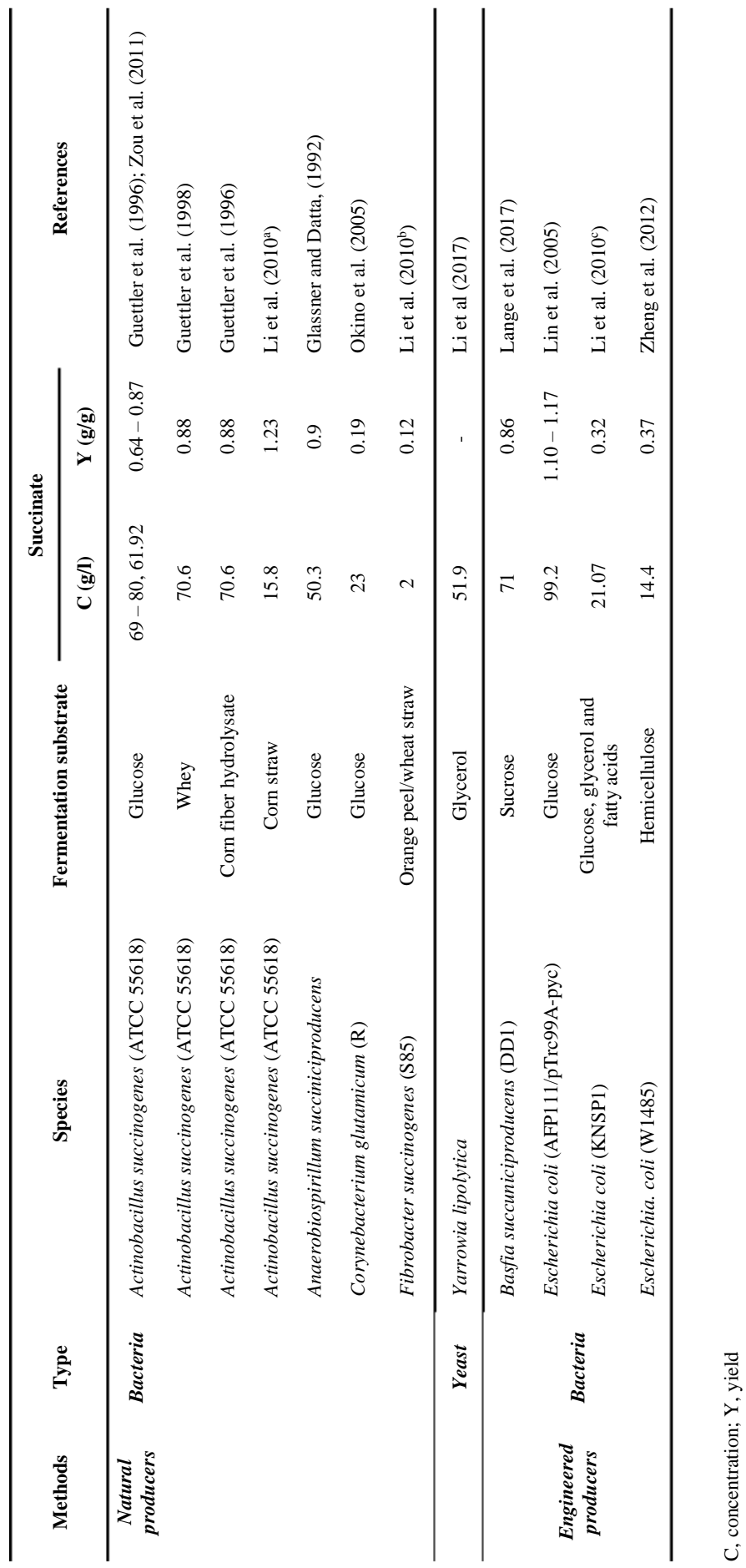




\section{Anaerobic digestion}

Anaerobic digestion is a well-known process that is catalyzed by mixed microbial communities. There are four main metabolic stages of anaerobic digestion of bio-waste; 1) Hydrolysis, where exo-enzymes hydrolyze complex molecules (polysaccharides, proteins, and lipids) into soluble oligo/monomeric compounds (such as sugars, amino acids, fatty acids and glycerol), 2) Acidogenesis, where the soluble organic substances and hydrolysis products are fermented to organic acids, alcohols, hydrogen, and carbon dioxide, 3) Acetogenesis, where larger volatile fatty acids and other organic acids are converted to acetic acid, hydrogen, and carbon dioxide, 4) Methanogenesis, where acetic acid, hydrogen, and carbon dioxide are converted to methane (Schink and Stams 2006; Veeken et al., 2000). The efficiency of the anaerobic digestion process relies on many factors such as chemical parameters ( $\mathrm{pH}$, nutrient content), physical parameters (temperature, mixing) and biological factors (biomass type) (Comparetti et al., 2013). Hydrolysis often considered as the rate-limiting step for bio-waste such as lignocellulosic biomass, primary sludge, industrial wastes and manure (Ma et al., 2013; Vavilin et al., 2008). Although much research has been performed to improve the understanding of the anaerobic digestion process, research on anaerobic hydrolysis and its microbiology is still poorly understood (Azman et al., 2015). Since the biogas yield is depending on the extent of hydrolysis, improvement of the hydrolysis step is required to enhance the overall anaerobic digestion. In the anaerobic digestion process, other intermediate products such as organic acids are also important, therefore, it is target not to convert everything to biogas. In these cases, the hydrolysis and fermentation steps need more attention to obtain a successful carboxylate process. Inoculum and the type of substrate as well as the understanding of interaction between these two parameters are important to steer anaerobic fermentation processes. Microorganisms are the drivers of the anaerobic digestion and research on the role of those microorganisms in the hydrolysis and fermentation steps is important. 


\section{Animal gut or rumen microorganisms and organic acid production}

The rumen, the first part of a ruminant stomach, is inhabited by complex microbiota consisting of bacteria, archaea, protozoa and anaerobic fungi, which interact with each other to break down plant derived compounds which constitute the feed of the ruminant.

The rumen is a living anaerobic "bioreactor", and an important environment to study the microbial biodiversity and it is a large source of enzymes and novel microorganisms to produce organic acids. The rumen contains a large number of microorganisms with enormous diversity. At least 50 bacterial genera $\left(10^{10}-10^{11}\right.$ cells ml $\left.{ }^{-1}\right), 25$ genera of ciliate protozoa $\left(10^{4}-10^{6}\right.$ cells $\left.\mathrm{ml}^{-1}\right), 6$ genera of fungi $\left(10^{3}-10^{5}\right.$ zoospores $\left.\mathrm{ml}^{-1}\right), 11$ genera of methanogenic archaea $\left(10^{9}\right.$ cells $\left.\mathrm{ml}^{-1}\right)$ and bacteriophages $\left(10^{8}-10^{9}\right.$ phages $\left.\mathrm{ml}^{-1}\right)$ are present in the rumen of ruminants (Cobellis et al., 2016; Paul et al., 2017). The microbial diversity composition also varies depending on the type of host and the environmental conditions, such as domestic or wild animals and their diets (Palakawong Na Ayudthaya et al., 2018).

Rumen microorganisms are naturally involved in the degradation of carbohydrates and lignocellulosic biomass to a variety of organic acids (Yue et al., 2013). Hydrolysis and acidification are important processes in the rumen. The product formation during anaerobic hydrolysis and acidification of especially carbohydrates and proteins is strongly influenced by the environmental conditions (Pitt, 1996). In the rumen, the activity of ruminal microorganisms is important to produce the energy and carbon sources for the ruminants. The microbial community can use various ruminal feedings, which can be divided in two main categories; low-grain diet and high-grain diet into organic acids. The low-grain diet such as hay, grasses etc. are composed of a high fiber portion whereas the high-grain diet such as wheat, corn etc., are high in carbohydrate and high energy sources that are composed of fiber, carbohydrate and/or protein (Krause et al., 1998; Krause et al., 2003). Exploring the gut or rumen biodiversity may yield dedicated microorganisms capable of producing organic acids, such as succinate or lactate. 
The rumen or other parts of the gut contains numerous and various of microorganisms which can be a good source for organic acid production. The product profile using the same inoculum may vary with the substrate type. The type of inoculum can affect the fermentation process and the microbial community that becomes abundant. Bacterial diversity in rumen according to its ability of substrate utilization is shown in Table 5 (Kamra, 2005; Puniya et al, 2015).

Table 5. Bacterial diversity of the rumen microbial ecosystem involved in complex substrate utilization

(adapted from Kamra, 2005; Puniya et al, 2015).

\begin{tabular}{ll}
\hline \multicolumn{1}{c}{ Substrate } & \multicolumn{1}{c}{ Bacteria } \\
\hline Cellulose & Butyrivibrio fibrisolvens, \\
& Clostridium cellobioparum, C. longisporum, C. lochheadii, \\
& Eubacterium cellulosolvens, \\
& Fibrobacter succinogenes, \\
& Ruminococcus flavefaciens, R. albus \\
\hline Hemicellulose & Butyrivibrio fibrisolvens, \\
& Prevotella ruminicola, \\
& Eubacterium xylanophilum, E. uniformis \\
\hline Pectin & Lachnospira multiparus, \\
& Treponema saccharophilum \\
\hline Starch & Streptococcus bovis, \\
& Ruminobacter amylophilus, \\
& Prevotella ruminicola \\
\hline Sugars/dextrins & Bifidobacterium globosum, B. longum, \\
& B. thermophilum, B. ruminale, B. ruminantium, \\
& Lactobacillus acidophilus, L. casei, \\
& L. fermentum, L. plantarum, L. brevis, L. helveticus, \\
& Selenomonas ruminantium, \\
& Succinivibrio dextrinosolvens, S. amylolytica \\
&
\end{tabular}

Rumen fluid has been used as an inoculum in biotechnological processes to improve municipal solid waste treatment in anaerobic digestion (Lopes and Leite, 2004) and to increase hydrolysis of cellulosic organic material (Barnes and Keller, 2004; Yan et al., 2014). Using a rumenderived inoculum, which harbours high hydrolytic activities, could reduce the pre-treatment costs in 
anaerobic digestion since there is little or no requirement to add hydrolytic enzymes (Thoetkiattikul et al., 2013).

In the monogastric herbivore such as guinea pigs of which cellulose-rich grass and hay is the main natural diet, Bacteroidetes and Firmicutes are the most abundant phyla (Hildebrand et al., 2012) as is the case for the rumen. The gastrointestinal microbiome of guinea pigs may be useful for studying organic acid production from plant material.

A continued effort to culture not-yet cultivated bacteria is useful to clarify gut microbial functions and to obtain insights on how the microbial diversity is associated with the metabolic processes that take place in those habitats. In addition, obtaining novel organic acid producing bacteria is a challenging and rewarding task, as they can be potential candidates for biotechnological processes of turning waste into the valuable products.

\section{Research aim and thesis outline}

This thesis aimed to investigate microbial diversity involved in the fermentation process of turning organic waste such as starchy waste into valuable products such as organic acids. We also aimed to reduce the operational cost by using undefine-mixed microorganisms derived from guts as well as to isolate novel organic acid producing bacteria that might be beneficial for biotechnology in the future.

In Chapter 2, starch waste from a potato factory was used as the substrate in an anaerobic bioreactor using rumen fluid as inoculum to produce organic acids. Two different sources of the inoculum, from cows in the Netherlands and Thailand, were compared and the microbial community composition during the fermentation in both reactors was investigated. In Chapter 3, two novel, organic-acid producing bacteria from two different ruminants-a dairy cow from the Netherlands and a sheep from the Slovak Republicwere characterized and compared. One was isolated from an 
enrichment with amylopectin and identified as Actinomyces succiniciruminis strain $\mathrm{Am} 4^{\mathrm{T}}$, originated from cow rumen fluid from the Netherlands. The other was isolated from an enrichment with $10 \%$ of glycerol, and preliminary identified as Actinomyces strain $\mathrm{G} 10^{\mathrm{T}}$, originated from sheep rumen fluid from Slovak Republic. Although the two strains were isolated from different ruminal animals and different places, they were phylogenetically closely related based on 16S rRNA gene sequence identity. Biochemical, physiological and phylogenetic characteristics were analyzed to distinguish these two species. Multiple features of the novel strains $A m 4^{\mathrm{T}}$ and $\mathrm{G} 10^{\mathrm{T}}$ were investigated, such as succinate production from poly-di saccharides and tolerance to oxygen and glycerol. A. succiniciruminis strain $\mathrm{Am} 4^{\mathrm{T}}$ was further studied aiming to produce succinate from starch waste at low costs as described in Chapter 4. In Chapter 5, a different source of gut microorganisms, fecal samples from guinea pigs, was used to investigate the microbial community and its potential to produce organic acids. Bacteria were enriched with different carbon sources such as cellulose, starch waste and dried grass. The microbial composition from selected secondary enrichments was analyzed. A novel species of the genus Streptococcus, S. caviae, was enriched with dried grass as substrate and the bacterium was further characterized in Chapter 6. In Chapter 7, results are intergrated and discussed and an outlook is presented. 



\section{CHAPTER 2}

Organic acid production from potato starch waste fermentation by rumen microbial communities from Dutch and Thai dairy cows

This chapter has been published as:

Susakul Palakawong Na Ayudthaya, Antonius H. P. van de Weijer, Antonie H. van Gelder, Alfons J. M. Stams, Willem M. de Vos and Caroline M. Plugge (2018) Organic acid production from potato starch waste fermentation by rumen microbial communities from Dutch and Thai dairy cows. Biotechnology for Biofules 11, 13. 


\begin{abstract}
Exploring different microbial sources for biotechnological production of organic acids is important. Dutch and Thai cow rumen samples were used as inocula to produce organic acid from starch waste in anaerobic reactors. Organic acid production profiles were determined, and microbial communities were compared using $16 \mathrm{~S}$ ribosomal ribonucleic acid gene amplicon pyrosequencing. In both reactors, lactate was the main initial product and was associated with growth of Streptococcus spp. (86\% average relative abundance). Subsequently, lactate served as a substrate for secondary fermentations. In the reactor inoculated with rumen fluid from the Dutch cow, the relative abundance of Bacillus and Streptococcus increased from the start, and lactate, acetate, formate and ethanol were produced. From day 1.33 to 2, lactate and acetate were degraded, resulting in butyrate production. Butyrate production coincided with a decrease in relative abundance of Streptococcus spp. and increased relative abundances of bacteria of other groups, including Parabacteroides, Sporanaerobacter, Helicobacteraceae, Peptostreptococcaceae and Porphyromonadaceae. In the reactor with the Thai cow inoculum, Streptococcus spp. also increased from the start. When lactate was consumed, acetate, propionate and butyrate were produced (day 34). After day 3, bacteria belonging to five dominant groups, Bacteroides, Pseudoramibacter_Eubacterium, Dysgonomonas, Enterobacteriaceae and Porphyromonadaceae were detected and these showed significant positive correlations with acetate, propionate and butyrate levels. The complexity of rumen microorganisms with high adaptation capacity makes rumen fluid a suitable source to convert organic waste into valuable products without the addition of hydrolytic enzymes. Starch waste is a source for organic acid production, especially lactate.
\end{abstract}




\section{Introduction}

Consuming fossil fuels has become a significant concern not only because resources are depleting but also because of the resulting pollution and carbon dioxide formation that contribute to global warming. However, there is also a worldwide increasing energy demand. Renewable instead of fossil sources for the production of energy and biochemical building blocks are thus of interest. Turning waste into energy carriers and valuable products is currently one of the promising sustainable options, especially since waste disposal requires energy (incineration) or space (landfills). Organic waste includes food and fiber processing by-products, fruit, vegetable waste, garbage, sewage sludge, cattle manure and/or industrial waste (Murto et al., 2004). All these materials have no or low-value and do not impact the food-value chain (Ghaffar et al., 2014). The possibility to conserve energy from waste and/or biomass is a strong motivation to further develop biobased processes and is in line with recently developed strategies that aim to use anaerobic mixed cultures for the conversion of organic feeds into carboxylates, including volatile fatty acids and/or organic acids (Tamis et al., 2015; Agler et al., 2011). Such a carboxylate platform may gain higher value of production efficiency than, for example, biogas (methane) formation (Tamis et al., 2015). Since volatile fatty acids and/or organic acids can be used as biobased building-block chemicals (Agler et al., 2011; Saucer et al., 2008). Demand for lactate, for instance, continuously increases due to its various applications as an acidulant, flavour enhancer or food preservative agent in addition to the production of base chemicals and for polymerization to biodegradable polylactic acid (PLA) (Okano et al., 2010; Hofvendahl and Hahn, 2000). PLA is a biodegradable plastic derived from lactate, and PLA is already available at the industrial scale. Microbial lactate fermentation has advantages over the chemical lactate synthesis in terms of obtaining purity where the chemical synthesis always results in a racemic mixture of lactate (Ghaffar et al., 2014; Ryu et al., 2004). It is important to select raw materials with suitable criteria such as high lactate production yield, rapid fermentation, low cost, low by-product formation and all-year-round availability for industrial 
lactate production (Ghaffar et al., 2014). As the world's second most abundant biopolymer, starch serves as food, feed and other industrial applications (Sonnewald and Kossmann, 2013), leading to a large amount of starch waste and starch residues. Starch residues from various sources, such as barley, cassava, corn and/or potato, can be used for volatile fatty acids and/or organic acid production (Ryu et al., 2004; Smerilli et al., 2015) and can meet industrial needs. Starch is the main component of the potato tuber with $80 \%$ of the dry solids and $20 \%$ of the total mass which can be used as a carbon source for microorganisms. Many studies have been conducted using potato starch and/or potato starch waste as a substrate in anaerobic digestion (Smerili et al., 2015; Parawira et al., 2004; Sreethawong et al., 2010; Zhu et al., 2008). Mostly, those studies use starch waste to produce biogas, organic acids or animal feed components. However, little attention has been paid to the microbial community involved in the organic acid production from starch waste.

The efficiency of the anaerobic digestion process (in terms of production and digestion yields) relies on many factors such as chemical parameters ( $\mathrm{pH}$, nutrient content), physical parameters (temperature, mixing) and biological factors (biomass) (Comparetti et al., 2013). The choice of inoculum is an important factor. Single or mixed cultures have been used in organic acid production; however, using pure culture mostly requires pre-treatment processing, including sterile operation, which increases the production costs.

Rumen fluid has been used as an inoculum in biotechnological processes to improve municipal solid waste treatment in anaerobic digestion (Lopes et al., 2004) and to increase hydrolysis of cellulosic organic material (Barnes and Keller, 2004; Yan et al., 2014). Using a rumen-derived inoculum, which harbours high microbial hydrolytic activities, could reduce the pre-treatment costs in anaerobic digestion since there is little or no requirement to add hydrolytic enzymes (Thoetkiattikul et al., 2013). The rumen contains a large number of microorganisms with enormous diversity, of which includes at least 50 bacterial genera $\left(10^{10}-10^{11}\right.$ cells $\left.\mathrm{ml}^{-1}\right), 25$ genera of ciliate protozoa $\left(10^{4}-10^{6}\right.$ cells $\left.\mathrm{ml}^{-1}\right), 6$ genera of fungi $\left(10^{3}-10^{5}\right.$ zoospores $\left.\mathrm{ml}^{-1}\right), 11$ genera of 
methanogenic archaea $\left(10^{9}\right.$ cells $\left.\mathrm{ml}^{-1}\right)$ and bacteriophages $\left(10^{8}-10^{9}\right.$ phages $\left.\mathrm{ml}^{-1}\right)($ Cobellis et al., 2016; Paul et al., 2017). Rumen microorganisms are naturally involved in the degradation of carbohydrates and lignocellulosic biomass to a variety of volatile fatty acids and organic acids (Yue et al., 2013). In this view, using rumen fluid as an inoculum is an attractive option for organic acid production.

The microbial community composition in the cow rumen depends on the feed composition (Thoetkiattikul et al., 2013). In tropical countries, such as Thailand, the feed mainly consists of crop residues, which can be lignocellulosic agricultural by-products of rice, corn, cassava, cereal straws, sugarcane, groundnut and/or pineapple processing industries (Kamra, 2005). On the other hand, cows in temperate countries, such as the Netherlands, are regularly fed with wheat and corn silage. Therefore, it is interesting to investigate and compare the organic acid production profiles and the microbial communities from both rumen inoculum sources.

We studied organic acid production from starch waste using rumen fluid as the inoculum and investigated the microbial composition shift during the process. Two different sources of rumen fluid obtained from fistulated cows in the Netherlands and Thailand were used.

\section{Material and methods}

\section{Reactor setup}

Fermentations were performed in batch mode using 1-liter dished-bottom reactors (Applikon, Delft, The Netherlands) with a working volume of 0.9 liters and controlled by an ADI 1010 Bio-controller and an ADI 1025 Bio-console (Applikon, Delft, the Netherlands). Temperature of both cow rumen-inoculated reactors was controlled at $39{ }^{\circ} \mathrm{C}$ to mimic conditions in the cow rumen. The $\mathrm{pH}$ was maintained at $7.0 \pm 0.4$ by automatic titration with a sterile solution of $3 \mathrm{M}$ 
$\mathrm{Na}_{2} \mathrm{CO}_{3}$. The stirrer speed was set at $120 \mathrm{rpm}$ to keep the starch waste homogeneous. The reactors were continuously sparged with $80: 20 \mathrm{~N}_{2} / \mathrm{CO}_{2}$ at a flow rate of $2.61 . \mathrm{h}^{-1}$ to ensure anaerobic conditions. Typically, the reactors were operated for 8 days and daily samples were taken during the fermentation.

\section{Inoculum}

Bovine rumen fluid $(500 \mathrm{ml})$ was collected from two fistulated Holstein cows from two different locations: The Netherlands and Thailand. The cows were aged between 4-5 years at the sampling period. The Dutch cows were fed with a high-grain diet with mainly corn (maize) and grass at Wageningen University's research farm in the Netherlands (Table S1). The Thai cows were fed with mainly pineapple peel at the Charoen Pokphand Test Farm, Chon Buri in Thailand (Table S1). After sampling, the rumen fluid was quickly filtered through two layers of cotton cloth in ambient air. The filtered rumen fluid was then transferred into a sterilised $\mathrm{CO}_{2}$-flushed anaerobic bottle and was kept at $4-10{ }^{\circ} \mathrm{C}$ until use. The Thai rumen fluid was shipped to the Netherlands in a cooled container at approximately $4{ }^{\circ} \mathrm{C}$. Samples of both rumen fluids were used to inoculate the reactors $\left(1 \% \mathrm{v} \mathrm{v}^{-1}\right)$.

\section{Medium composition}

A bicarbonate buffered anaerobic mineral medium (BM) was prepared as described by Plugge (2005) supplemented with $\left(1^{-1}\right): 0.1 \mathrm{~g}$ yeast extract, $0.005 \mathrm{~g}$ hemin, $0.05 \mathrm{~g}$ vitamin $\mathrm{K} 1$ and $0.5 \mathrm{~g}$ L-cysteine-hydrochloride (Plugge, 2005). Starch containing waste was obtained from an Avebé potato factory (Foxhol, The Netherlands) and was used as substrate. The starch waste was air dried at $80^{\circ} \mathrm{C}$ for $32 \mathrm{~h}$, crushed to small pieces and sieved with $1 \mathrm{~mm}$-pore size sieve. The dried starch waste contained $61 \%\left(\mathrm{w} \mathrm{w}^{-1}\right)$ starch according to the analysis of Nutricontrol (Veghel, The Netherlands) (Table S2). Dried starch waste $\left(7 \%, \mathrm{w} \mathrm{v}^{-1}\right)$ was added to the reactors as carbon and 
energy sources. After autoclaving, the sterile reactors with medium were continuously flushed with sterile $80: 20 \mathrm{~N}_{2} / \mathrm{CO}_{2}$.

\section{Sampling}

As starch waste has a high viscosity, the fermentation broth was pumped through a loop with a butyl-rubber stopper to facilitate anaerobic sampling. Ten-milliliter liquid samples were aseptically collected and transferred directly into sterile-anaerobic serum bottles. Each sample was divided into three portions. One portion of $6 \mathrm{ml}$ was transferred to a $10 \mathrm{ml}$-sterile-anaerobic serum bottle and stored at $-20{ }^{\circ} \mathrm{C}$ for molecular analysis. A second portion of $2 \mathrm{ml}$ was transferred to an Eppendorf tube for organic acid measurement. A third portion of $2 \mathrm{ml}$ was transferred to a sterile anaerobic serum bottle for CFU (colony-forming units) counts.

\section{Deoxyribonucleic acid (DNA) extraction}

Genomic DNA was extracted from the pelleted biomass using a Fast DNA Spin kit for soil (MP Biomedicals Santa Ana, CA) according to the manufacturer's instructions. DNA quantity of all samples was determined by a Nanodrop 1000 (Nanodrop Technologies, Wilmington, DE) and integrity was examined by gel electrophoresis on the $1 \%\left(\mathrm{w} \mathrm{v}^{-1}\right)$ agarose gel.

\section{Denaturing gradient gel electrophoresis (DGGE) analysis}

DGGE analysis was used to visualize the population dynamics in both reactors over time. Bacterial 16S rRNA V6-V8 regions were amplified with the universal bacterial primers GC-968F and 1401R (Nübel et al., 1996) using the Phire Hot start II Polymerase (Thermo Fisher Scientific, Waltham, MA). Bacterial amplicons were generated with a G-Storm cycler (G-storm, Essex, UK) using a pre-denaturing step at $95{ }^{\circ} \mathrm{C}$ for $5 \mathrm{~min}$, followed by 35 cycles at $95{ }^{\circ} \mathrm{C}$ for $20 \mathrm{~s}, 56{ }^{\circ} \mathrm{C}$ for 40 $\mathrm{s}, 72{ }^{\circ} \mathrm{C}$ for $40 \mathrm{~s}$ and a post-elongation step of $10 \mathrm{~min}$ at $72{ }^{\circ} \mathrm{C}$. The forward primer had a GC clamp of $40 \mathrm{bp}$ attached to the 5'-end as used by Yu et al. (Yu et al., 2008). DGGE analysis was performed 
as described by Martín et al. (Martín, 2007) in a DCode TM system (Bio-Rad Laboratories, Hercules, CA) at $60{ }^{\circ} \mathrm{C}$ for $16 \mathrm{~h}$ with a denaturing gradient of 30:60 percent gradients according to Yu et al. (2008). After electrophoresis, gels were silver-stained as described by Sanguinetti et al. (2011) and scanned.

\section{Pyrosequencing analysis}

Based on the bacterial DGGE profiles from both reactors, samples were selected to determine the relative abundance of the bacteria using 454-pyrosequencing analysis.

The genomic DNA obtained from the previous step was diluted to obtain DNA

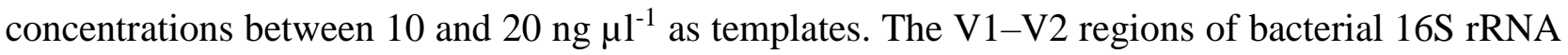
genes were amplified using forward primer 27F-DegS (Van et al., 2011) and an equimolar mix of two reverse primers: 338R-I and 338R-II (Daims et al., 1999). The forward primer was extended with titanium adapter $A$ and an eight-base specific barcode [30] at the $5^{\prime}$-end and the reverse primers were appended with titanium adapter $\mathrm{B}$ at the 5 '-ends. The polymerase chain reaction (PCR) amplification and the purification of the amplicons were performed as previously described by Timmers et al. (2015). The DNA concentration of all PCR products was measured using Qubit 2.0 Fluorometer (Thermo Fisher Scientific, Waltham, MA) and was then mixed together in equimolar amounts. Pooled samples were loaded on an agarose gel and bands were excised, purified and quantified using the protocol of Timmers et al. (2015). The purified pooled samples were sent to GATC Biotech Company (Konstanz, Germany) for pyrosequencing on the 454 Life Science GSFLX platform.

Pyrosequencing data were analyzed using a workflow based on Quantitative Insights into Microbial Ecology (QIIME) 1.7.0 pipeline (Caporaso et al., 2010). The reads were filtered and the Operational Taxonomic Units (OTUs) were identified with a cut-off value of $97 \%$ identity by USEARCH algorithm version 6.1 (Edgar, 2010). Representative sequences from OTUs were aligned 
using PyNAST (Caporaso et al., 2010) against with SILVA reference database version 118e (Kopylova et al., 2012) for taxonomic classification. Chimeric OTUs were identified and removed using QIIME's ChimeraSlayer method (Haas et al., 2011).

\section{Bacterial CFU counts during fermentation process and isolation of fermentative bacteria}

Total viable bacterial counts in both reactors were determined by colony-forming unit (CFU) plate counts over the entire incubation period. The samples were homogenised by vortexing. Next, tenfold dilutions in liquid Reinforced Clostridial Medium (RCM) in dilution $10^{-1}-10^{-10}$ and $20 \mu 1$ of each dilution was spread (in triplicate) on RCM agar plates (1.2\% agar). The plates were incubated in a jar containing AnaeroGen ${ }^{\mathrm{TM}}$ sachets (Oxoid-Thermo Scientific; Hampshire, UK) to create and maintain anaerobic conditions and incubated at $39{ }^{\circ} \mathrm{C}$ for $3-5$ days. After incubation, the colonies were counted and $\log _{10} \mathrm{CFUs} \mathrm{ml}^{-1}$ were calculated. Colonies with different morphology were selected and further purified using the streak plate technique on RCM agar plates until pure cultures were obtained. The pure cultures were then grown in the RCM liquid medium. Cell morphology of the cultures was observed using a light microscope (Leica DM 2000; Buffalo Grove, IL) to confirm the purity.

\section{Identification of the isolated bacteria}

Genomic DNA of each pure strain was isolated using the Fast Spin kit for soil (MP Biomedicals; Santa Ana, CA) following the manufacturer's instructions. The 16S rRNA gene of each isolate was amplified by PCR using bacterial-universal primers 27f and 1492r (Lane, 1991). PCR mixture contained: $2 \mu 1$ of DNA template, $0.25 \mu 1$ Gotaq DNA Polymerase Kit (Promega; Medison, WI), $1 \mu \mathrm{l}$ dNTPs, $1 \mu \mathrm{l}$ of each primer, $10 \mu \mathrm{l}$ PCR buffer and $34.75 \mu \mathrm{l}$ PCR water. The PCR programme was started with a denaturing step at $95{ }^{\circ} \mathrm{C}$ for $5 \mathrm{~min}$ and continued with 35 cycles consisting of $95{ }^{\circ} \mathrm{C}$ for $30 \mathrm{~s}, 52^{\circ} \mathrm{C}$ for $40 \mathrm{~s}$ and $72^{\circ} \mathrm{C}$ for $90 \mathrm{~s}$, and the last step of extension at $72{ }^{\circ} \mathrm{C}$ for 7 min. PCR products were purified and sequenced at GATC (Konstanz, Germany). The 16S 
rRNA gene sequences of the isolates were checked for reading errors, trimmed and aligned using the programme DNA Baser Sequence Assembler v4 (Heracle BioSoft S.R.L, Arges, Romania), and then the partial sequences of $16 \mathrm{~S}$ rRNA genes were blasted against the NCBI online database.

\section{Statistical analysis}

Principal Coordinate Analysis (PCoA) using weighted unifraction and Unweighted Pair Group Method with Arithmetic mean (UPGMA) were performed using the QIIME 1.7.0 pipeline to show the relationship of bacterial communities at different time points in the starch waste fermentation from both reactors. Multivariate analyzes were performed with the CANOCO V 5.0 software (Šmilauer and Lepš, 2014) using the pyrosequencing results and organic acid production profiles from both Dutch and Thai reactors. Organic acid production profiles were used as 'environmental' variables and the bacterial diversity (at genus-like level) as 'species' variables. First, principal component analysis (PCA) was used to visualise the overall correlation between all variables at different time points in both Dutch and Thai reactors, separately. Then, selected organic acids based on primary organic acids in each reactor were analyzed to reveal the relationship between variables using redundancy analysis (RDA). The significance test for RDA was performed by Monte Carlo permutation (499 times). The significant correlations between bacterial groups and operational conditions in each reactor were calculated with Ranked Spearman correlation by IBM SPSS Statistics version 23.

\section{Analytical methods}

During fermentations, off gas composition was automatically monitored every hour using a Compact GC (Interscience, Breda, The Netherlands), equipped with a Carboxen 1010 PLOT column and a Micro thermal conductivity detector, using helium with pressure flow $80.0 \mathrm{kPa}$ as a carrier gas to quantify $\mathrm{H}_{2}$ and $\mathrm{CH}_{4}$ production. The production of organic acids was quantified at $24 \mathrm{~h}$ intervals 
for over 16 days by HPLC (Thermo Scientific, Breda, The Netherlands), as described in (Van et al., 2012).

\section{Nucleotide sequence accession numbers}

The 16S rRNA gene sequences obtained from the isolates were deposited in the NCBI database and are available under Accession Numbers MF581503-MF581530. The 16S rRNA NGS sequences were deposited at the EMBL database and are available under accession numbers ERS1983120 - ERS1983133.

\section{Results and discussion}

\section{Starch waste fermentation in Dutch and Thai reactors}

The reactors were fed with starch waste and the fermentation process was followed for 16 days, with a focus on the first 8 days. In both reactors, lactate formation immediately started after inoculation with rumen fluid, and gradually changed to mixed acid fermentation after a few days (Fig. 1).

Lactic acid production is common and has been shown in many starch or starchy fermentation studies. For instance, lactate was the major product in potato peel waste fermentation (Liang et al., 2014) and lactate and acetate the main products in maize silage fermentation (Sträuber et al., 2012). Lactic acid producing bacteria are the first and the most rapidly growing microbes in the starch fermentation.

In the Dutch reactor, three stages could be identified in the fermentation (Fig. 1a and Table S3). During the first stage (day 0-1.33), lactate, acetate and ethanol rapidly accumulated to 148, 93 and $73 \mathrm{mM}$, respectively. In the second stage (day 1.33-2), lactate and a part of acetate were consumed and converted to butyrate $(112 \mathrm{mM})$. In the third stage (after day 2), butyrate and ethanol remained constant, whilst acetate increased further until $103 \mathrm{mM}$ (at day 8). Formate also increased 
from 22 (day 1) to $64 \mathrm{mM}$ (day 3) and then decreased again to about $10 \mathrm{mM}$ (day 8). Propionate increased from day 1 to 8 from 6 to $14 \mathrm{mM}$.
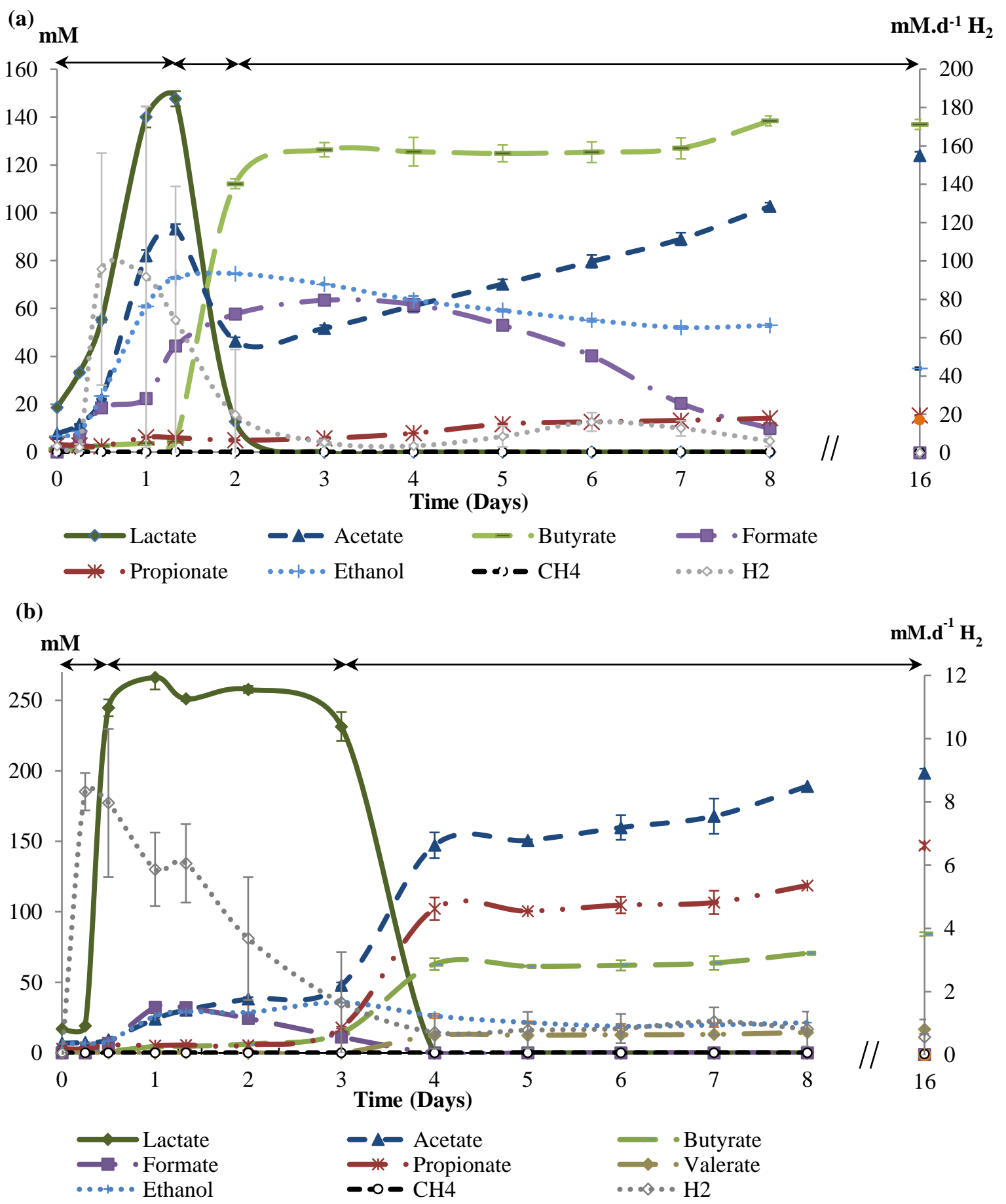

Fig. 1. Production profiles in starch waste fermentation using the Dutch (a) and Thai (b) rumen fluids as inoculum in anaerobic reactors. $\mathrm{H}_{2}$ is shown on the secondary axis. The arrows indicate three stages in the fermentation. 
Also, in the Thai reactor, three stages in the fermentation pattern could be identified (Fig. 1b and Table S4). During the first stage (day 0-0.5), lactate rapidly increased from 17 to $245 \mathrm{mM}$. In the second stage (day 0.5-3), lactate remained stable at $250 \pm 13 \mathrm{mM}$, whereas acetate, butyrate, propionate and ethanol increased further to $48,14,18$ and $36 \mathrm{mM}$, respectively. Formate increased from 7 (day 0.5 ) to 32 $\mathrm{mM}$ (day 1) and was completely consumed at day 3. In the early third stage (day $3-4)$, lactate (231 mM) was completely and ethanol $(10 \mathrm{mM})$ was partially consumed. Increasing the levels of acetate, propionate and butyrate detected on day 4, 147, 102 and $63 \mathrm{mM}$ respectively. From day 4 to day 16, the product pattern remained constant (Table S4).

The maximum yields of lactate were 0.3 (Dutch) and 0.6 (Thai) $\mathrm{g} \mathrm{g}^{-1}$ starch and the highest lactate concentrations were 13 and $25 \mathrm{~g} \mathrm{l}^{-1}$ (calculated using $90 \mathrm{~g} \mathrm{M}^{-1}$ as the MW of lactate) obtained from $42 \mathrm{~g}^{-1}$ of starch present in the starch waste. This gave 31 and $60 \%$ lactate yield at day 1.33 and 2 in the Dutch and Thai reactors, respectively. In the calculations, it was considered that starch waste contains $61 \%$ starch (Table S2). The lactate production that was observed from the Thai reactor was somewhat higher than that reported in a previous study which delivered $50 \%$ lactate yield (or the yield of lactate was $0.4 \mathrm{~g} \mathrm{~g}^{-1}$ starch present in cassava fibrous residue), where about $30 \mathrm{~g}$ of lactate was produced from $60 \mathrm{~g}$ of starch present in $100 \mathrm{~g}$ of cassava fibrous residue using a pure culture of Lactobacillus plantarum MTCC 1407 (2\% $\mathrm{vv}^{-1}$ of the inoculum) (Juturu and Wu, 2016; Ray et al., 2009). In another study in which an undefined mixed culture $\left(2 \% \mathrm{v} \mathrm{v}^{-1}\right.$ of inoculum) was used in potato peel waste fermentation with addition of hydrolytic enzymes, lactate production of $14.7 \mathrm{~g} \mathrm{l}^{-1}$ and a yield of $0.7 \mathrm{~g} \mathrm{~g}^{-1}$ starch (calculated with $34.3 \%$ starch in the initial substrate loading) were observed (Liang et al., 2014), which is higher than our yield. Our study was conducted based on using the ruminal mixed culture $\left(1 \% \mathrm{v} \mathrm{v}^{-1}\right.$ of inoculum) without adding any hydrolytic enzymes or performing a pre-treatment step. Notably, the production yield using different wastes cannot be accurately compared and additionally, the fermentation process has been influenced by other factors: fermentation conditions, type and amount of inoculum and the composition of the waste materials, for instance. However, this robust lactate production from starch waste challenges us to further optimise lactate 
production in the future. Natural producers of lactate are very efficient, but pure cultures and synthetic communities have drawbacks such as high nutrient requirement. Efforts to further improve lactate yield and engineer lactate production by redirecting the carbon flow for lactate production have been reported. Pyruvate is the end product of glycolysis and can be further metabolised either by a pyruvate dehydrogenase complex (Pdh, EC 1.2.4.1) to acetyl-coenzyme A or by pyruvate decarboxylase (Pdc, EC4.1.1.1) to acetaldehyde and subsequently to ethanol. In previous works, it has been shown that the expression of a heterologous lactate dehydrogenase (Ldh, EC 1.1.1.27) gene introduces a new and alternative pathway for $\mathrm{NAD}^{+}$regeneration, allowing a direct reduction of the intracellular pyruvate to lactate (Porro et al., 1995). CRISPR-Cas-based tools have been presented as the potential next-generation toolkit for prokaryotic metabolic engineering, for genome editing and expression control, and have enabled fast, easy and accurate strain development for established production platform organisms, such as Escherichia coli and Saccharomyces cerevisiae (Mougiakos et al., 2016). Future dedicated research could focus on development of the CRISPRCas-based tools for improved lactate production.

In both Dutch and Thai reactors, methane was not detected in the beginning of the fermentation process, but only appeared in trace amounts after 7 days in the headspace $(0.23$ and $0.018 \mathrm{mM} \mathrm{d}^{-1}$, respectively), whilst increasing after 2 weeks (4.4 and $11.1 \mathrm{mM}$ per day, respectively at day 16: data not shown). For hydrogen, 95.6 and $9.2 \mathrm{mM}$ per day out flow of the Dutch and Thai reactors, respectively were detected at the start (Day 0.5) of the fermentation process (Fig. 1). Notably, there was an unknown peak in our HPLC chromatogram (retention time 8.15), which was detected from both reactors and we could not identify the compound. 


\section{Bacterial CFUs and isolation of bacteria}

In both starch waste fermenting reactors, total bacterial counts increased up to $10.3( \pm 0.1) \log _{10}$ CFU ml ${ }^{-1}$ (standard deviation: SD) in $24 \mathrm{~h}$ (Table S5). From day 1 until 8, the average total bacterial counts were $7.6( \pm 1.1)$ and $8.6( \pm 1.1)\left[\log _{10} \mathrm{CFU} \mathrm{ml}^{-1}(\mathrm{SD})\right]$ and between day 8 and 16 , the total bacterial counts decreased to $4.8( \pm 0)$ and $6.4( \pm 0) \log _{10} \mathrm{CFU} \mathrm{ml}^{-1}$ for the Dutch and Thai reactors, respectively.

Ten different bacterial strains (28 in total) were isolated from both reactors based on different colony morphologies on RCM agar medium during the fermentation process (Table S6). Mainly, Streptococcus spp. were isolated from the first fermentation stage, and other fermentative bacteria (Enterococcus faecium, Enterococcus gallinarum, Escherichia fergusonii, Lactobacillus plantarum, Enterococcus durans, Clostridium sporogenes and Eubacterium limosum) were isolated from the second and third fermentation stages. Lactobacillus spp. were isolated only from the Thai reactor. The majority of these isolates are lactic acid bacteria (LAB). All of them were Gram-positive bacteria except Escherichia fergusonii, which was isolated at the third fermentation stage from the Dutch reactor. Lactate was the principal product of the first fermentation stage and is also known for its antibacterial properties. Lactate penetrates the cytoplasmic membrane, hence lowering the intracellular $\mathrm{pH}$ as well as disintegrating the outer-membrane in Gram-negative bacteria (Alakomi et al., 2000). Gram-positive bacteria have a thicker cell wall than Gram-negative bacteria, which enables them to sustain harsh conditions, such as high concentrations of lactate in the medium, which explains why mostly Gram-positive bacteria were isolated from this fermentation. 


\section{Bacteria (DGGE) profiles}

Bacterial DGGE profiles from the Dutch reactor could be grouped into three patterns (Fig. 2a). These patterns matched the three stages of the fermentation profiles (Fig. 1a). In the first stage (day 01.33), bands were visible with increasing intensity. The band pattern then shifted during stage 2 (day 1.332). Finally, in the third stage, the number of bands increased further, which indicated an increased bacterial diversity. Then, the microbial diversity remained stable until the end of the run (day 16).

Also in the Thai reactor, the bacterial DGGE profile could be grouped into three patterns that matched the three stages of the fermentation (Fig. 2b). In the first stage (day 0-0.5), one very dense band was visible amidst a variety of bands. In the second stage (day 0.5-3), banding patterns were less diverse, and one band appeared with high intensity (Fig. 2b). Finally, in the third stage, the number of bands increased, and then remained stable until the end of the run (day 16).

Notably, the intense bands from both reactors lined in the same position, which might possibly represent Streptococcus spp. since only this member shared the same OTU and was highly abundant during the fermentation process (Figure S1). 


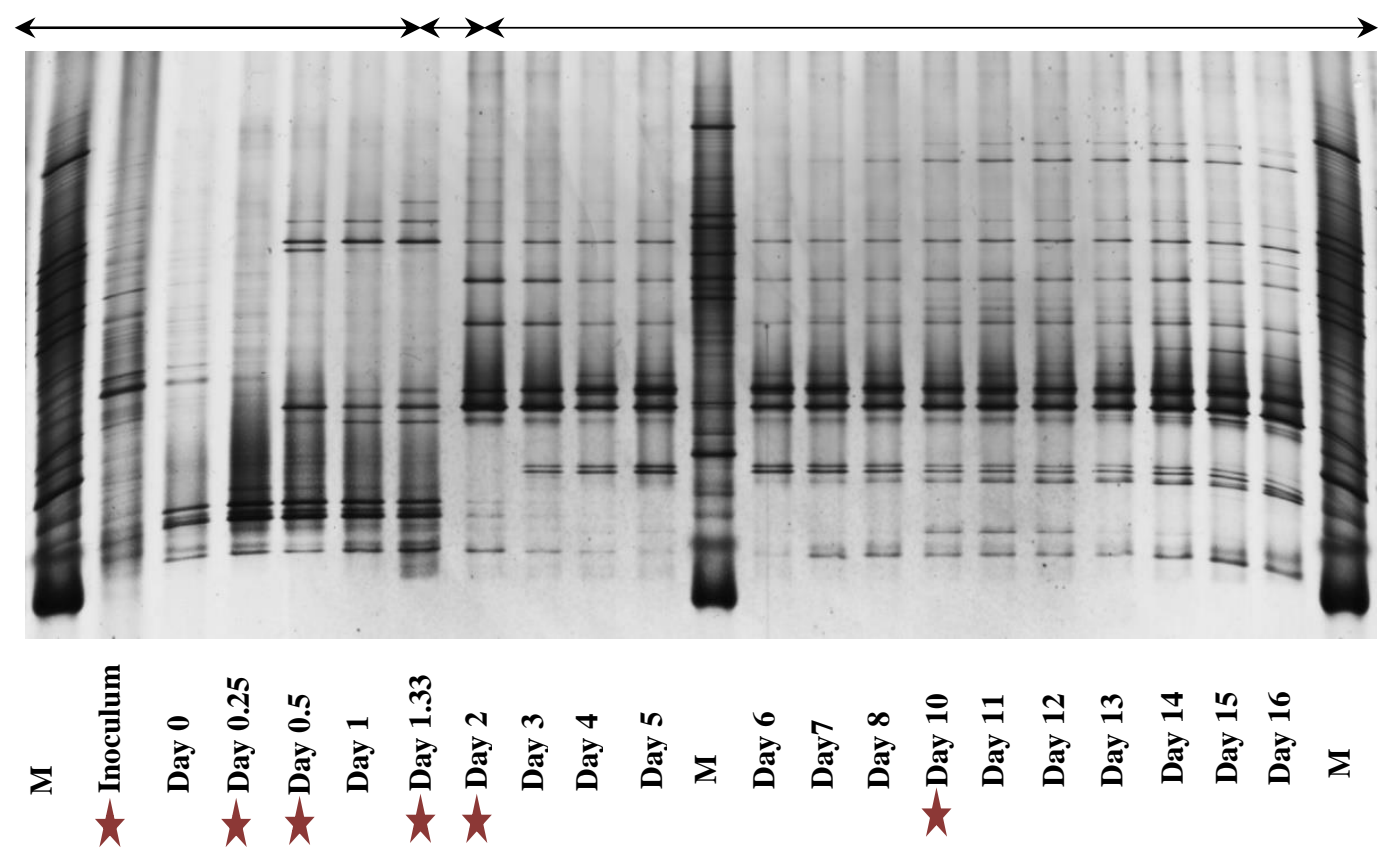

(a)

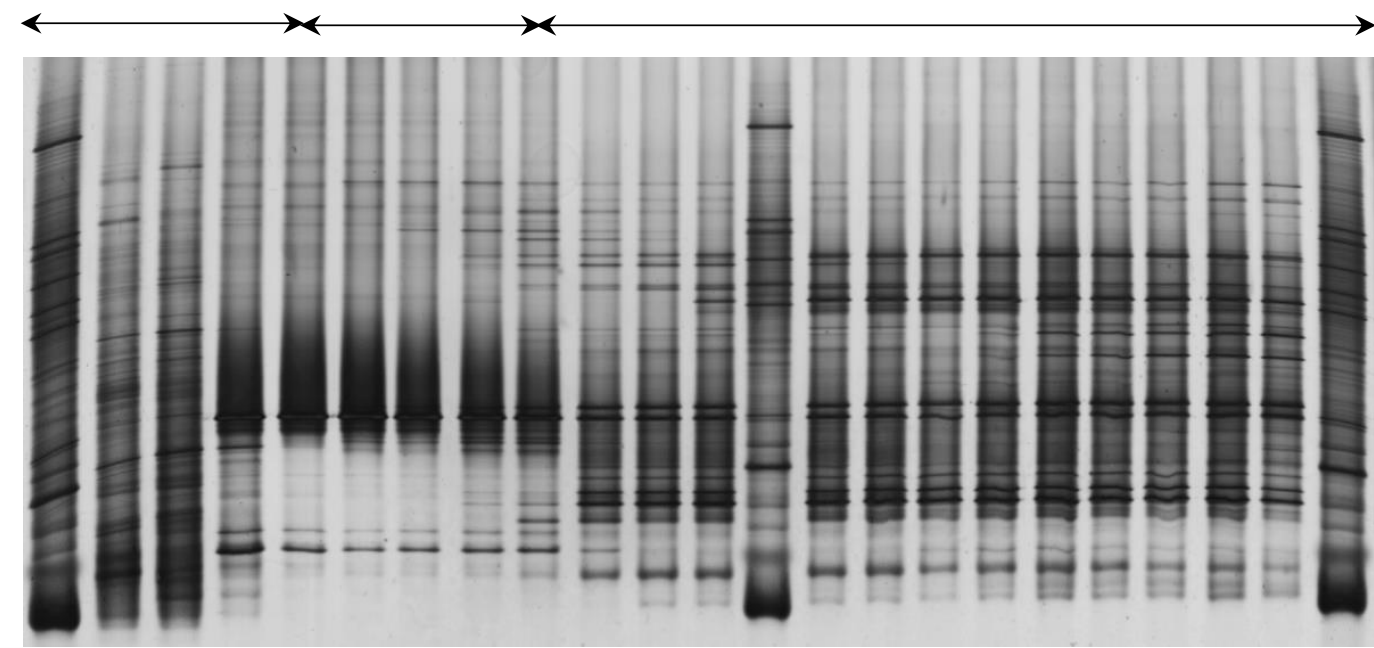

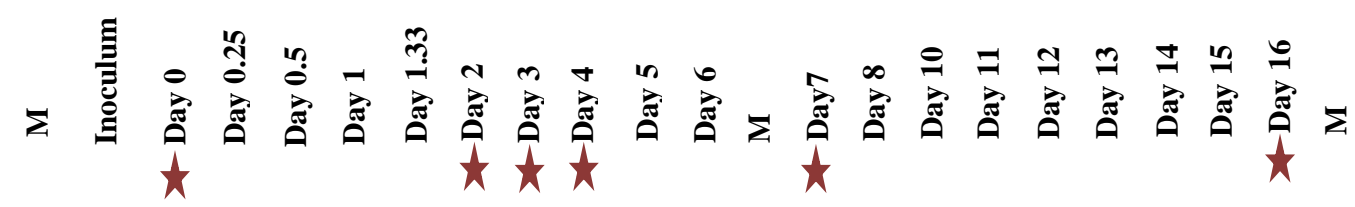

(b)

Fig. 2. 16 rRNA based DGGE profiles of bacteria involved in starch waste fermentation in reactors with a) Dutch and b) Thai cow rumen fluids. 'M' refers to marker. Asteriks $(\star)$ indicate samples that were used for NGS analysis. The arrows indicate three stages in the fermentation. 


\section{Bacterial community analysis}

16S rRNA gene amplicon pyrosequencing of the V1-V2 regions of the 16S rRNA gene of selected samples (based on the different pattern on DGGE profiles) from both reactors was used to analyze the bacterial communities during starch waste fermentation. After quality control, 228,106 sequence reads could be translated into 253 OTUs (Table S7). OTUs were then identified with a cutoff value of $97 \%$ identity and were assigned to 30 phyla, 53 classes, 101 orders, 155 families and 253 genera. Taxa with relative abundance $<1 \%$ and unclassified groups were termed as 'others'.

\section{Comparing the bacterial composition between two inocula}

At phylum level, Bacteroidetes was the most abundant (66\% relative abundance) in the Dutch rumen inoculum, followed with Firmicutes and Cyanobacteria (22 and 6\% relative abundances, respectively), whereas Firmicutes was the most abundant (41\% relative abundance) followed with Bacteroidetes and Proteobacteria (34 and 10\% relative abundances, respectively) in the Thai rumen inoculum (Figure S2).

At genus level, the microbial diversity in the Thai rumen inoculum was higher $(3$ orders, 7 families and 12 genera) compared to the Dutch rumen inoculum (1 phylum, 2 orders, 6 families and 7 genera) (Fig. 3). In Dutch rumen inoculum, Prevotella was the most abundant (58 relative abundance) followed by Ruminococcaceae and Clostridiales ( 8 and $7 \%$ relative abundance, respectively) (Fig. 3). In the Thai rumen inoculum, Prevotella was also the most abundant (20\% relative abundance) followed by members of Bacteroidales, Clostridiales and Lactobacillus (12, 10 and $10 \%$ relative abundance, respectively) (Fig. 3b). Notably, the relative abundance of Prevotella, which is commonly known as the dominant amylolytic species in rumen of the high-grain diet fed cows (Pitta et al., 2014), was rather different between Dutch and Thai inocula (58 and 20\% relative abundances, respectively). This can be explained by the difference in feed composition as the Dutch cows were fed $6.5 \mathrm{~kg}$ dry matter intake per day of maize silage, and no maize diet was fed to the 
Thai cows (Table S1). On the other hand, Lactobacillus and Acetobacter (10 and $6 \%$ relative abundances, respectively) were only detected in the Thai rumen inoculum, of which the cows were fed with $3.3 \mathrm{~kg}$ dry matter intake per day of pineapple peel (Fig. 3 and Figure S1). Indeed, Lactobacillus was only isolated from the Thai reactor. Various LAB, especially Lactobacillus were isolated from pineapple (Garcia et al., 2016) and one of the common diseases in pineapple is 'marbling disease' which is caused by acetic acid bacteria such as Acetobacter spp. (Sipes and Wang, 2017). These results show that the microbial community composition in the rumen is strongly dependent on the feed composition (Thoetkiattikul et al., 2013) and may affect the fermentation profiles in a reactor. 

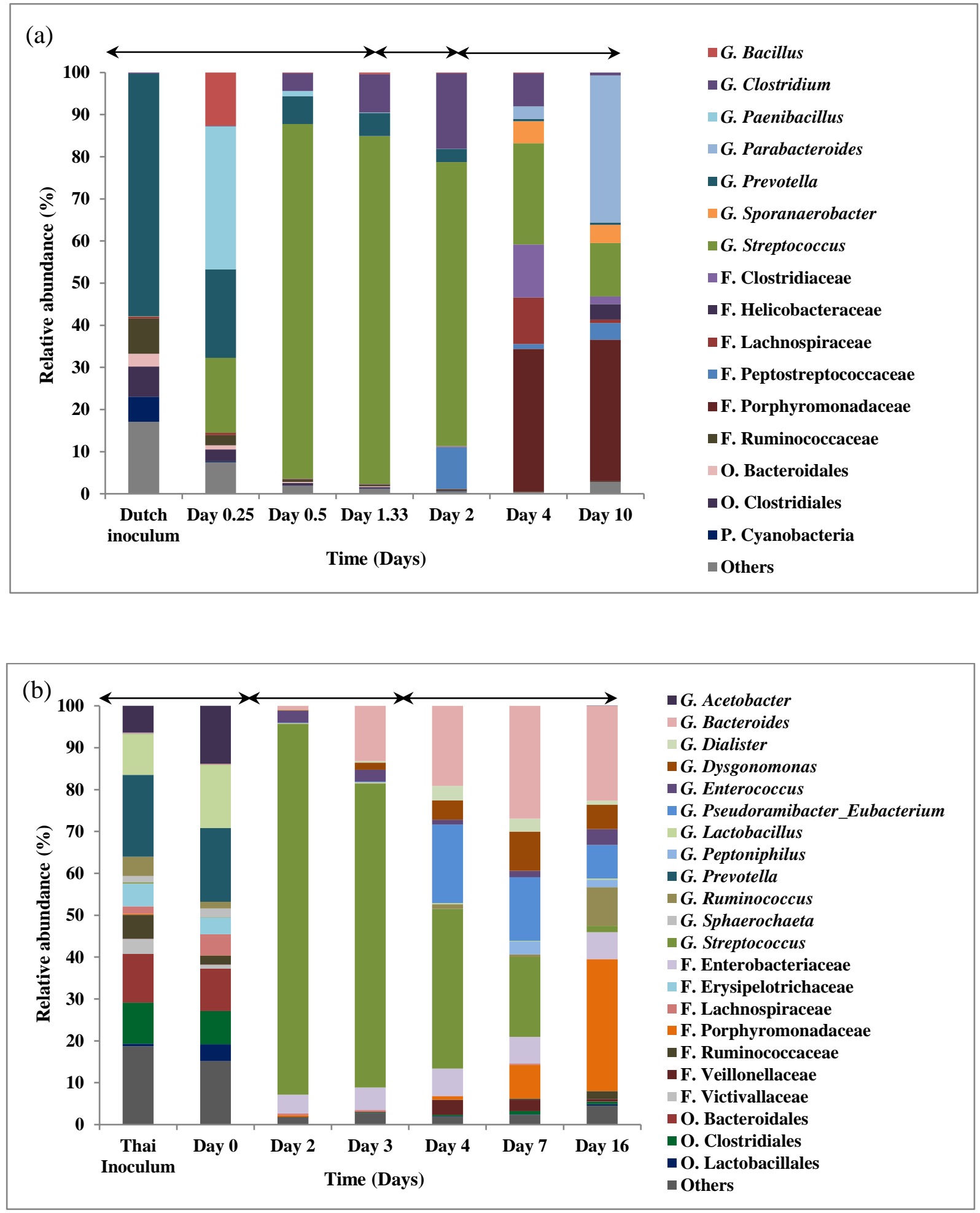

Fig. 3. Relative abundance of bacterial communities (genus-like level) in the starch waste fermentation using Dutch (a) and Thai (b) cow rumen. Taxa with relative abundance $<1 \%$ in all samples were grouped into the category 'others'. P; phylum, $\mathrm{O}$; order, $\mathrm{F}$; family, $G$; genus. The arrows indicate three stages in the fermentation. 


\section{Comparing the bacterial composition between the two reactors during the fermentation process}

The bacterial community composition at the phylum level from both reactors is shown in Figure S2. Bacteroidetes and Firmicutes were most represented in both communities. The work of Gou et al. (2016) revealed that in a starch-fed reactor, two bacterial phyla, Spirochaetes and Firmicutes (Streptococcus), were mainly responsible for starch degradation (Gou et al., 2016). Interestingly, in the Thai rumen community, Proteobacteria remained in the community throughout the reactor run. In the Dutch reactor, OTUs affiliated with Proteobacteria were detected in stage 3 (day 10), albeit at low levels.

\section{The Dutch reactor}

In the Dutch reactor, Prevotella spp. (58\% relative abundance) were dominant, but gradually decreased to less than $3 \%$ relative abundance at day 4 (Fig. 3a). At day 0.25, genus: Streptococcus (18\%), Paenibacillus (34\%) and Bacillus (13\%) increased in relative abundances, but after day 0.25 to 2 , Streptococcus spp. became dominant ( $\sim 80 \%$ relative abundance). From day 1.33 until day 2 (second stage), Streptococcus spp. decreased to 67\%, whereas the relative abundance of Clostridium and Peptostreptococcaceae (18 and 10\%, respectively) increased. In the third stage (day 4), the relative abundance of Clostridiales member remained stable with Clostridiaceae (13\%) and Clostridium (8\%). On day 4, Porphyromonadaceae appeared and remained until day 10 with 34\% relative abundance. From this family at genus level, Parabacteroides was also detected, and its relative abundance increased $3 \%$ at day 4 to $35 \%$ at day 10 . The remaining fraction of Porphyromonadaceae (35\% relative abundance) could not be identified to a deeper phylogenetic level.

\section{The Thai reactor}

As observed in the Dutch reactor, Prevotella (18\% relative abundance) members were also abundant in the Thai reactor at day 0 and decreased to less than $1 \%$ relative abundance at day 2 (Fig. 3b). At day 2, Streptococcus spp. ( $90 \%$ relative abundance) were highly abundant and remained 
dominant until day 4 (38\% relative abundance). At day 2, the second-most abundant group was members of Enterobacteriaceae (8\%), in which Enterococcus had 3\% relative abundance. From day 3 to 4, the relative abundance of Pseudoramibacter_Eubacterium spp. increased (19\%), whereas Streptococcus spp. gradually decreased (35\%) until day 16 (2\%). After day 4, Bacteroides (27\%), Pseudoramibacter_Eubacterium (15\%) and Porphyromonadaceae (17.4\%) became dominant. In the family Porphyromonadaceae, only one genus, Dysgonomonas, was identified and its relative abundance (9\%) was highest at day 7. Porphyromonadaceae members gradually increased and became the most abundant group (31\%) in the reactor at day 16.

\section{The relationship between starch waste fermentation and bacterial communities}

Organic acid production profiles mainly depend on the type of substrates and source of the microbial inoculum (Parawira et al., 2004; Liang et al., 2015). Using activated sludge from three different municipal wastewaters and potato peel wastes as substrates, lactate production was observed, and bacteria of the genus Lactobacillus prevailed (>96\%) in all three incubations, even though they were not abundant $(0.1 \%)$ in the seed sludges (Liang et al., 2015).

In our study, Streptococcus was detected only in small amounts in Dutch and Thai rumen inocula ( 0.03 and $0.3 \%$ relative abundances, respectively), but became highly abundant ( 84 and $89 \%$ relative abundances, respectively) during starch waste fermentation. Streptococcus was important for fast and efficient lactate (up to $250 \mathrm{mM}$ ) production during the first stage (0-1.33 days) in both reactors. Lactate was then the substrate for secondary fermentation to produce acetate, butyrate and propionate. Organic acid production profile and bacterial composition of both reactors were different in the second part of the fermentation.

Principal component analysis (PCA) using a weighted Unifrac plot and grouping tree analysis revealed that all time points separated the Dutch and Thai bacterial communities (Figure S3a). During the first stage of the fermentation process (day 0-2), the Dutch reactor communities 
clustered closely together. In stage 3 (day 4 and 10), they clearly developed into different communities. Communities from the Thai reactor directly separated from the inoculum and day 0 , indicating growth of a dedicated bacterial community after the starting point of the fermentation process (Figure S3b).

The abundance of the top 33 bacterial OTUs from the two reactors was also plotted in a heat map (Figure S1). Overall, the OTUs from both reactors were different and only the genera Prevotella and Streptococcus were shared. Prevotella members were abundant at the start of the fermentation and decreased in time. Members from three families: Porphyromonadaceae, Peptostreptococcaceae and Enterobacteriaceae were shared and became abundant in the last stage of both reactors.

The CANOCO (multivariate analysis) software programme was used to reveal the relation between the 16 most dominant bacteria (genus-like level) and the fermentation patterns in both reactors. First, PCA analysis (unweighted) was used to visualise the overall relationship of those in the Dutch and Thai reactors (Figure S4). Then, the relationship between those top 16 bacteria and main products during the fermentation was analyzed using RDA analysis and a correlation matrix (Spearman's Rank Order Correlations statistics) (Fig. 4, 5 and Table S8).

In the Dutch reactor, the relationship between the bacterial composition and lactate, acetate and butyrate could be explained by first two canonical differentiation axes with $69 \%$ of all total datasets $(p=0.04)$ (Fig 4). The results showed that in the first stage (day $0-1.33$ ), the relative abundance of Bacillus and Streptococcus positively correlated with increasing lactate concentration $(\mathrm{r}=0.860, p<0.05$ and $\mathrm{r}=0.778, p<0.05$, respectively). In the second stage (day 1.33-2) (Table S8a), lactate was consumed whilst butyrate was mainly produced. Mainly Streptococcus were present in this stage. The correlation results showed that Parabacteroides $(\mathrm{r}=0.883, p<0.01)$, Sporanaerobacter $(\mathrm{r}=0.867, p<0.05)$, Helicobacteraceae $(\mathrm{r}=0.802, p<0.05)$, Peptostreptococcaceae $(\mathrm{r}=0.852, p<0.05)$ and Porphyromonadaceae $(\mathrm{r}=0.867, p<0.05)$ positively correlated with butyrate production, whereas these members showed a negative correlation with 
lactate concentration (Fig. 1, 2, 4 and Table S8a). Moreover, members of Clostridiaceae, known as butyrate-producing bacteria, showed a significantly negative correlation with the lactate concentration $(\mathrm{r}=-0.889, p<0.01)$ and a positive correlation with the butyrate concentration $(\mathrm{r}=$ 0.607). In the late stage of the fermentation (day 4-10), acetate concentration increased and positively correlated with Parabacteroides $(\mathrm{r}=0.775, p<0.05)$ and this genus showed a positive correlation with butyrate as well (Fig. 4 and Table S8a). Members of the family Lachnospiraceae, known for their ability to convert lactate to butyrate or propionate (Flint et al., 2012), had a negative correlation $(r=-0.667)$ to lactate, but a positive correlation with butyrate $(r=0.393)$ and acetate $(r$ $=0.286)$ in the Dutch reactor.

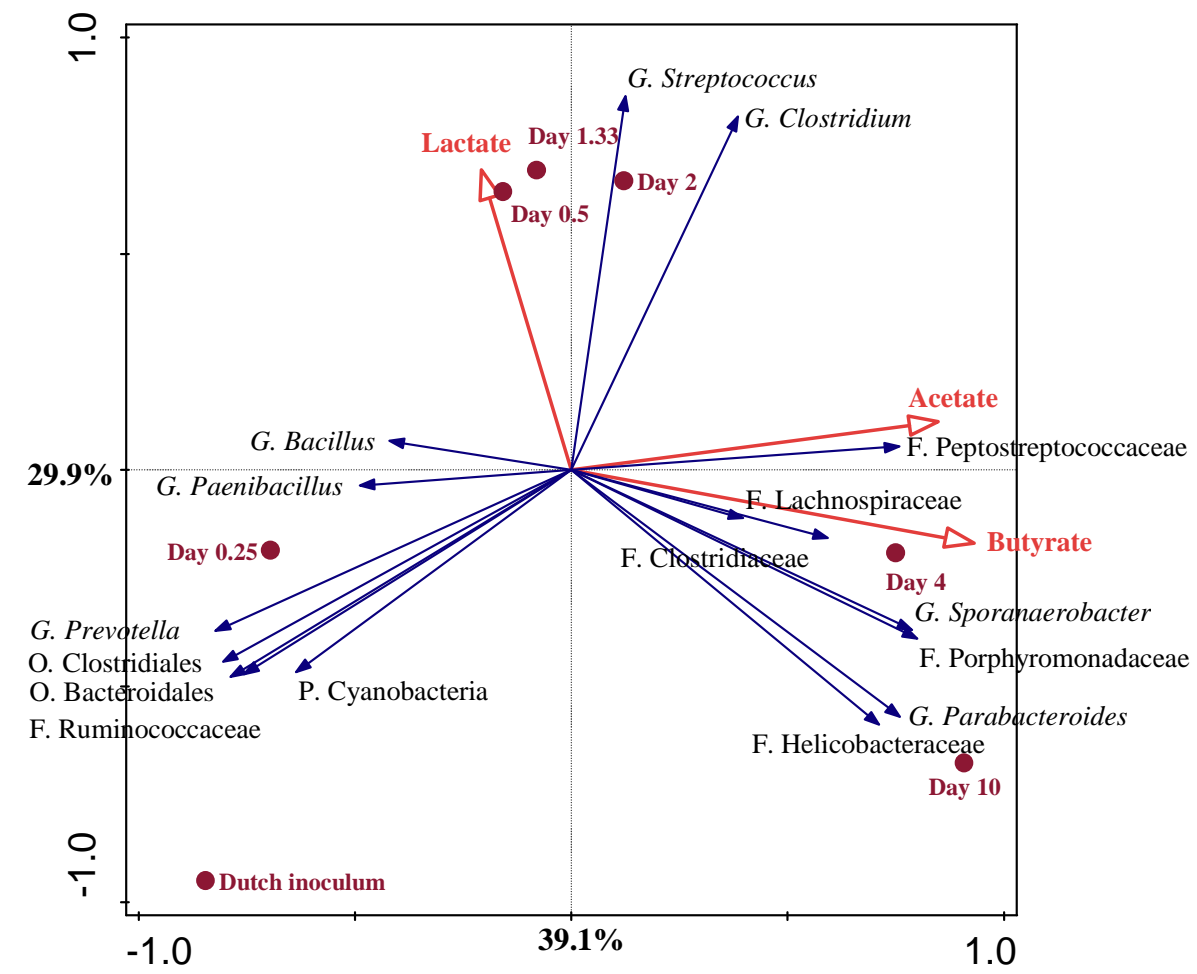

Fig. 4. Redundance analysis triplot showing the relationship between the top sixteen genus-like level phylogenetic groupings of the OTUs and the environmantal variables explaining the variance with time in the Dutch reactor. Sampling day are shown as fill circles $(\bullet)$. Environmental variables or selected fermentation products are represented by red arrows. Bacterial community at genus-like groups with the level, i.e. phylum $(\mathrm{P})$, order $(\mathrm{O})$, family $(\mathrm{F})$ or genus $(\mathrm{G})$ are represented as blue arrows. The arrows indicate the direction, in which the relative abundance increases. Length of arrows is measure of fit. The environmental variable arrows (in red) approximated the correlation between species and an environmental variable. The further a product falls in the direction indicated by an arrow, the higher the correlation. Both axes together explained $69 \%$ of the total variance in the dataset. 
In the Thai reactor, the relationship between the bacterial composition and lactate, acetate, propionate and butyrate were explained by two canonical differentiation axes with $91.8 \%$ of all total datasets $(p=0.01)$ (Fig. 5). The results revealed that in the first two stages: stage 1;0-0.25 and stage 2; 0.25-3 (day $0-3$ ), the relative abundance of genus Streptococcus increased in the same direction of increasing lactate. However, there was no significant correlation between bacterial community shift and lactate production (Table S8b). In the late stage of the fermentation (day 4-16), a variety of bacteria were involved in acetate, butyrate and propionate formation (Fig. 5). Members of the genera Bacteroides $(\mathrm{r}=$ 0.964, $p<0.01)$, Dysgonomonas $(\mathrm{r}=0.929, p<0.01)$ and Pseudoramibacter_Eubacterium $(\mathrm{r}=0.821$, $p<0.05)$, and families Enterobacteriaceae $(\mathrm{r}=0.857, p<0.05)$ and Porphyromonadaceae $(\mathrm{r}=0.821, p$ $<0.05$ ) had significantly positive correlations with acetate, butyrate and propionate production (Table $\mathrm{S} 8 \mathrm{~b})$. Members of Bacteroides in general are known to produce acetate, succinate and propionate (Macfarlane and Macfarlane, 1993). It was reported that the family Porphyromonadaceae, which includes the genus Dysgonomonas, possesses three butyrate synthesis pathways (Vital et al., 2014) and our findings support the relationship between this taxon and butyrate formation. Eubacterium spp. are known as butyrate-producing bacteria (Flint et al., 2012) and probably responsible for the conversion of lactate and acetate to butyrate. Remarkably, the Lachnospiraceae family had a negative correlation with lactate and a positive correlation with acetate and butyrate $(r=0.286$ and $r=0.393$, respectively $)$ in the Dutch reactor but a positive correlation $(r=0.473)$ with lactate and a negative correlation with acetate, butyrate and propionate $(r=-0.929, p<0.01)$ in the Thai reactor. In the Dutch reactor, Lachnospiraceae members may have been responsible for the conversion of lactate to acetate and/or butyrate. This is well known for bacteria from the Clostridium cluster XIVa group in the Lachnospiraceae family, which are acetate plus lactate-converting butyrate producers (Van et al., 2013). Besides, there are other Lachnospiraceae members such as Eubacterium rectale and Roseburia inulinivorans which are also known to produce butyrate, formate and lactate (Flint et al., 2015). The other, Eubacterium hallii consumed lactate and acetate and produced butyrate (Flint et al., 2015). In the Thai reactor, 
Pseudoramibacter_Eubacterium had 18\% relative abundance at day 4 and may also have been involved

in butyrate formation from lactate plus acetate.

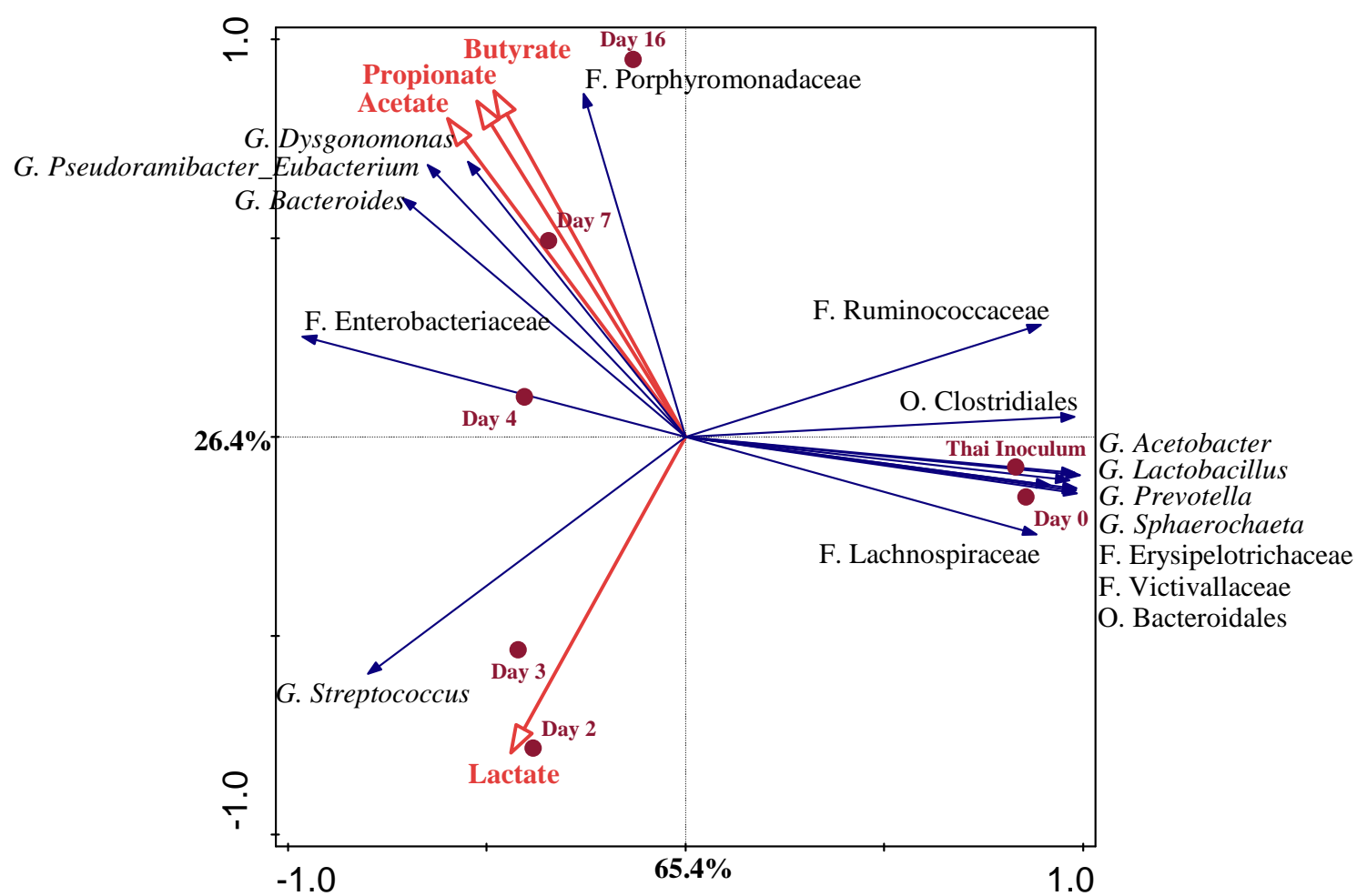

Fig. 5. Redundance analysis triplot showing the relationship between the top sixteen genus-like level phylogenetic groupings of the OTUs and the environmantal variables explaining the variance with time in the Thai reactor. Sampling day are shown as fill circles $(\bullet)$. Environmental variables or selected fermentation products are represented by red arrows. Bacterial community at genus-like groups with the level, i.e. phylum $(\mathrm{P})$, order $(\mathrm{O})$, family $(\mathrm{F})$ or genus $(\mathrm{G})$ are represented as blue arrows. The arrows indicate the direction, in which the relative abundance increases. Length of arrows is measure of fit. The environmental variable arrows (in red) approximated the correlation between species and an environmental variable. The further a product falls in the direction indicated by an arrow, the higher the correlation. Both axes together explained $91.8 \%$ of the total variance in the dataset.

Lactate is produced by a broad range of microorganisms such as bacteria and/or fungi. Currently, available lactate-producing strains still have advantages and disadvantages, for instance, the fungus Rhizopus oryzae is used to commercially produce L $(+)$ lactate because it can directly produce it from starch. However, its yield is lower compared to lactate produced by LAB and it has 
been reported that its mycelium caused turbidity and disturbed the reactor (Ghaffar et al., 2014). LAB produce lactate from glucose that mostly originate from corn syrup. As such, this feed stock competes with food and feed. Due to the increasing demand of lactate, further development of a lactate production platform is needed. As only a few LABs can meet the strict industrial requirements, such as capability to ferment low cost materials rapidly, less requirement of nitrogenous nutrients, and high yields with small amounts of other by-products, there is a need for novel strains (Ghaffar et al., 2014; Juturu and Wu, 2016).

Amylolytic lactic acid bacteria (ALAB) such as Enterococcus faecium, E. durans, Lactobacillus spp. and Streptococcus spp., which are capable of utilising starchy materials, are of biotechnological interest because of their potential to directly convert starchy biomass to lactate (Velikova et al., 2016; Reddy et al., 2008). This group (ALAB) produces lactate more effectively than LAB because they combine pre-treatment by enzymatic hydrolysis of carbohydrate and glucose fermentation to lactate in one step. In our study, various species of ALAB were detected and isolated from both reactors including Enterococcus faecium, E. durans and Lactobacillus plantarum (Table S6). The Streptococcus members were the most successful due to their rapid and high lactate production from starch waste fermentation, increasing in relative abundances (from <1\% up to $86 \%$ ) in both reactors. The majority of the isolates (D0, D0.25, D0.5, T0-3, T0.25, T0.5, T1 and T3-3) were Streptococcus members (Table S6) and their 16S rRNA gene sequences showed 100\% identity to the most abundant OTUs (pyrosequencing results), which play an important role in lactate production in both reactors. The BLASTN analysis of the 16S rRNA gene sequences of those isolates (ca. 1400 bp) showed ca. 99\% identity to Streptococcus lutetiensis, a strain able to degrade starch (Poyart et al., 2002; Schlegel et al., 2003). In 2013, Jiang et al. studied the fermentation of amylopectin and resistant starch (RS2) using colonic inocula of pigs and found that there was $4 \%$ relative abundance of $S$. lutetiensis detected from total lactic acid producing bacteria in the early stage of the fermentation (Jiang et al., 2013). This result together with our findings suggests that $S$. lutetiensis plays an important role in starch waste fermentation in our reactors. In general, using a 
single LAB strain for lactate production from glucose has some disadvantages because it lacks several biosynthetic pathways and therefore requires addition of costly nitrogen sources (yeast extract and/or peptone) and sterile conditions (Juturu and Wu, 2016). In this aspect, starchy waste as substrate becomes an advantage from an economical point of view because it contains crude proteins and various sources needed for the ruminal microorganisms and/or ALAB.

Importantly, using a rumen-derived inoculum, high concentrations of lactate and other organic acids can be reached from starch waste without the addition of hydrolytic enzymes. To produce other organic acids (acetate, butyrate and/or propionate), prolonged fermentation is required. Therefore, undefined mixed cultures originating from rumen are attractive for the production of organic acids, but specifically lactate, from starch waste.

\section{Conclusions}

Our study confirms that the substrate (waste) composition and source of inoculum play important roles in organic acid production, and the microbial community development in anaerobic digestion is reflected by changes in product profile. Starch waste or starchy materials are an alternative source for lactate production and Streptococcus spp. are key microorganisms in this context. Using rumen fluid or isolated ALAB such as Streptococcus spp. in starch waste-reactors to produce lactate is a promising approach. Different inoculum sources affected the secondary fermentation product profile. Rumen fluid is a suitable inoculum source because it contains various microorganisms with high capacity to convert organic waste to valuable products without the requirement of addition of hydrolytic enzymes. Due to the complexity of the rumen microbiota, it has also potential to produce products from other complex organic waste sources, such as kitchen waste and agricultural or industrial wastes containing cellulose and/or lignocellulosic materials. 


\section{Acknowledgements}

The authors thank Stang Pumisutapon at The Charoen Pokphand Group, Thailand and Rik Verkerk at the Department of Animal Sciences, Wageningen University for providing rumen fluids, Detmer Sipkema for his help with pyrosequencing analysis and Gerben Hermes for his support using the CANOCO program and Bart Nijsse for technical support. The first author was financially supported by a Royal Thai Government Scholarship, Thailand. Research of Alfons J. M. Stams is supported by ERC Grant project 323009. Alfons J. M. Stams and Willem M. de Vos are supported by Gravitation Grant project 024.002.002 from the Netherlands Ministry of Education, Culture and Science. 


\section{Supplementary data}

Table S1. Composition of the diets of Dutch and Thai cows

\section{Location of the cows}

Dutch cow: Carus house, Department of Animal Sciences, Bornse Weilanden 5, Wageningen University, Wageningen, 6708 WG The Netherlands

Thai cow: CP Test Farm Highway 3138 Road, Tambon Khlong Kio, Amphoe Ban Bueng, Chon Buri 20220, Thailand

\begin{tabular}{lc}
\hline Feed composition & $\begin{array}{c}\text { Dry matter intake } \\
\text { per cow per day (kg) }\end{array}$ \\
\hline Dutch cow & 7.0 \\
Pelleted feed (20\% protein; 25\% starch) & 6.5 \\
Maize silage (7-7.5\% protein; 35-40\% starch) & 6.5 \\
Grass silage (15\% protein; 0\% starch) & \\
\hline Thai cow & $3.52-4.40$ \\
Pelleted feed (14\% protein; 30\% starch) & 3.25 \\
Pineapple peel (0\% starch) & \\
\hline
\end{tabular}

Table S2. Composition of the dried starch waste used in this study

Starch waste was obtained from Avebe Potato factory (Foxhol, The Netherlands) and the starch waste composition was analyzed at Nutricontrol (Veghel, The Netherlands)

\begin{tabular}{lc}
\hline Composition & Percent $\left(\% \mathbf{~ w ~ w}^{-1}\right)$ \\
\hline Starch & 61 \\
Crude protein & 1.1 \\
Fiber & 0.8 \\
Crude ash & 0.4 \\
Sugar & 0.3 \\
Fat & 0.01 \\
Others & 36.39 \\
\hline
\end{tabular}


Table S3. Production profiles of starch waste fermentation using the Dutch rumen fluid as inoculum

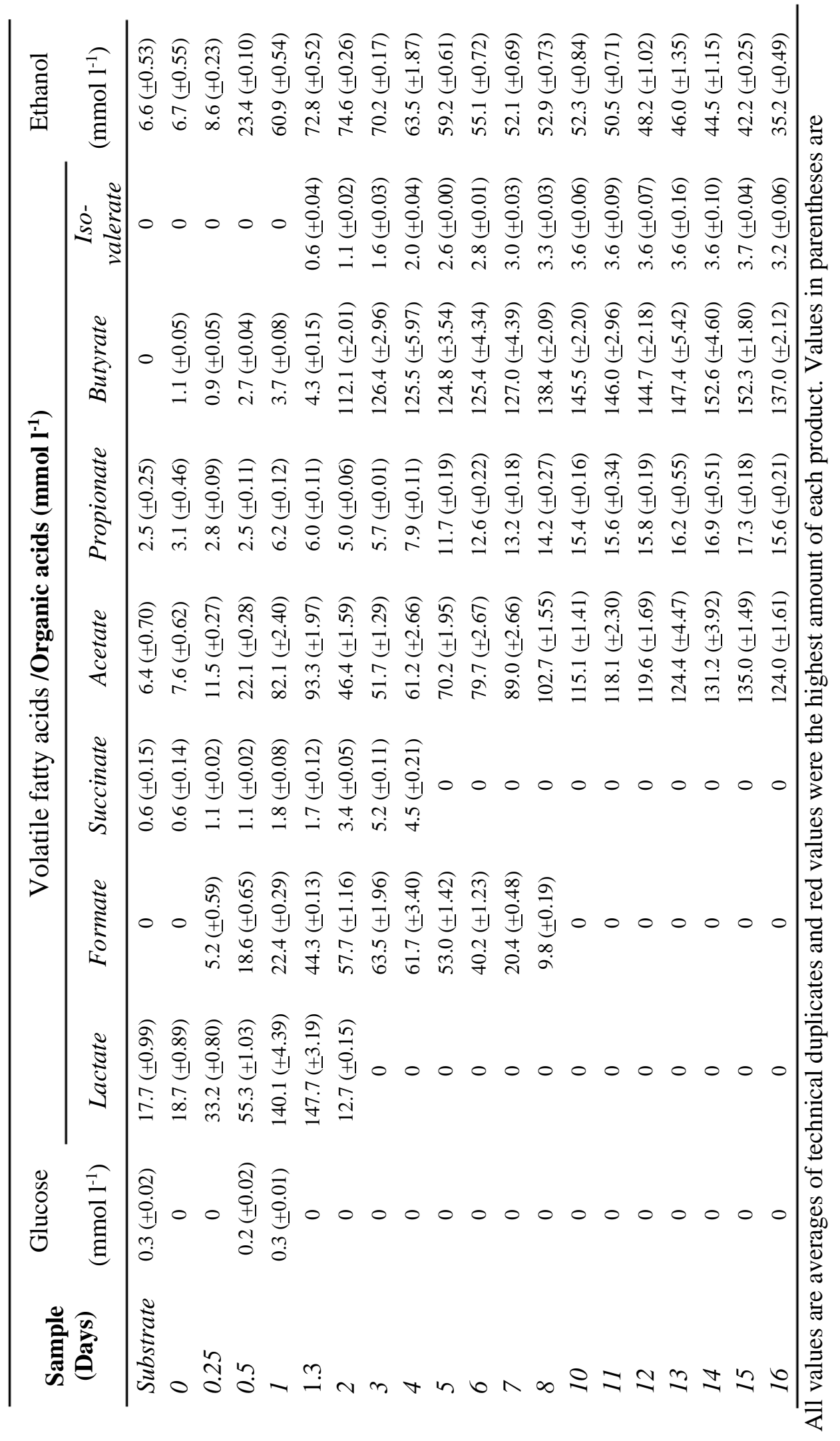


Table S4. Production profiles of starch waste fermentation using the Thai rumen fluid as inoculum

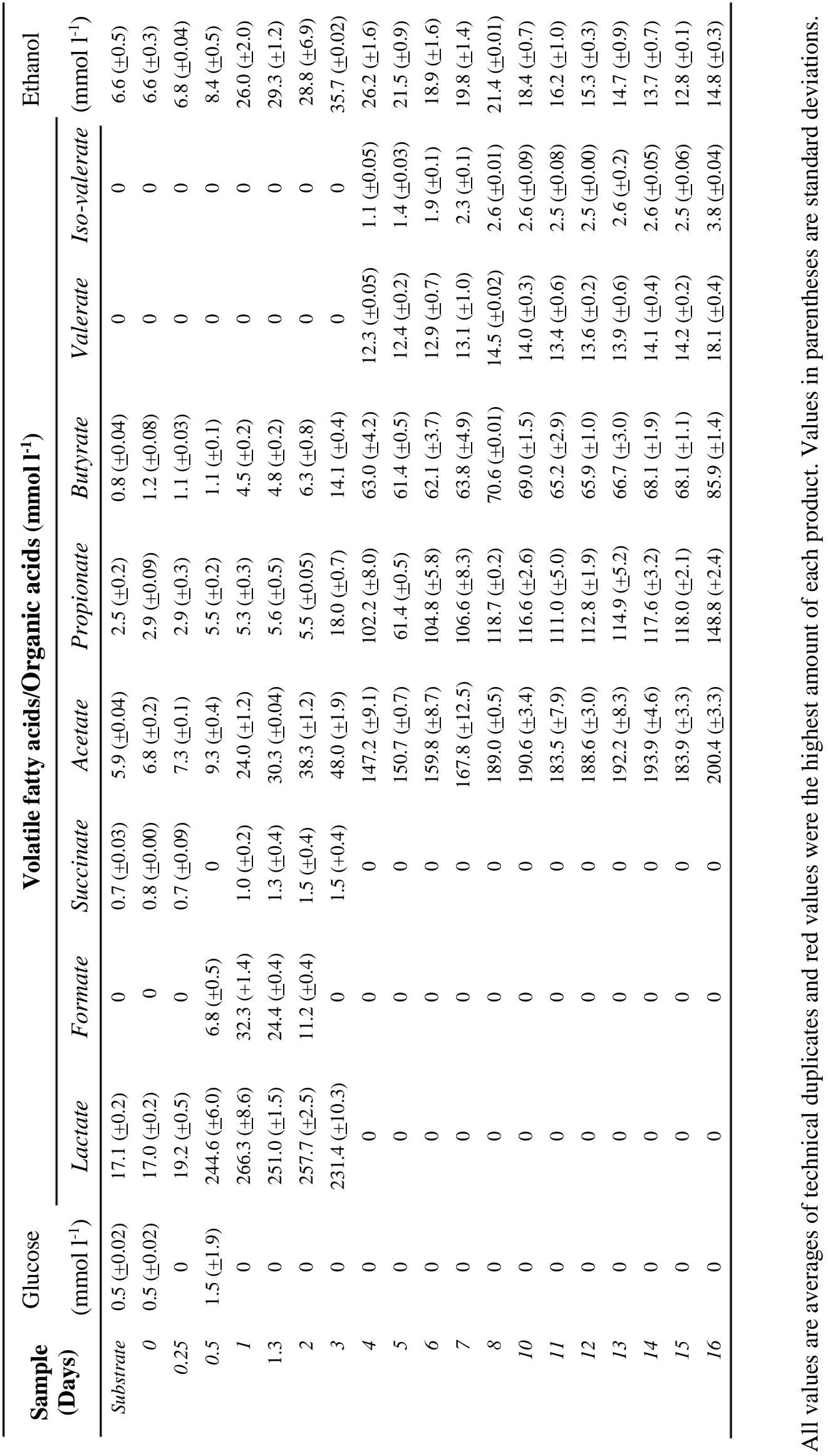


Table S5. Total bacterial counts $\left(\log _{10} \mathrm{CFU} / \mathrm{ml}\right)$ at different time point in during starch waste fermentation in the Dutch and Thai reactors

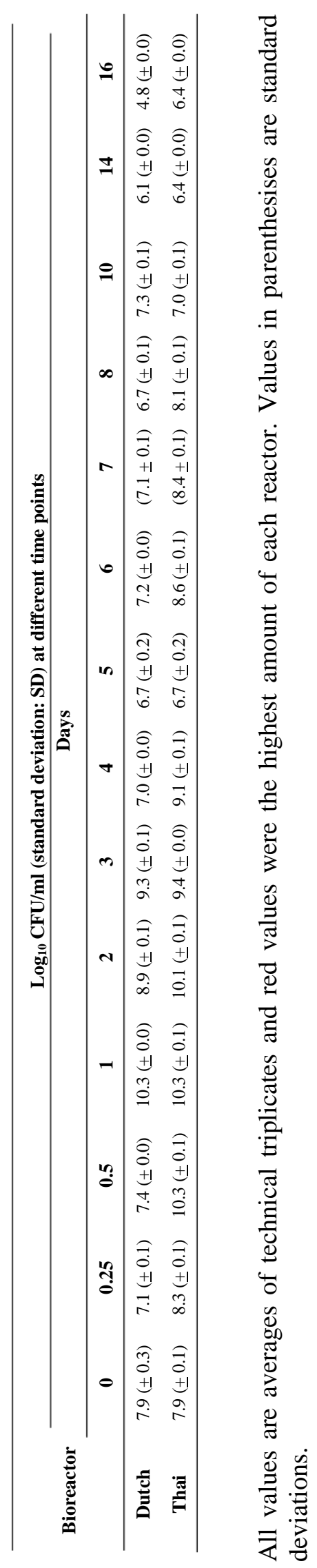


Table S6. Pure cultures isolated from the starch waste fermentation process. Ten different strains are in Bold.

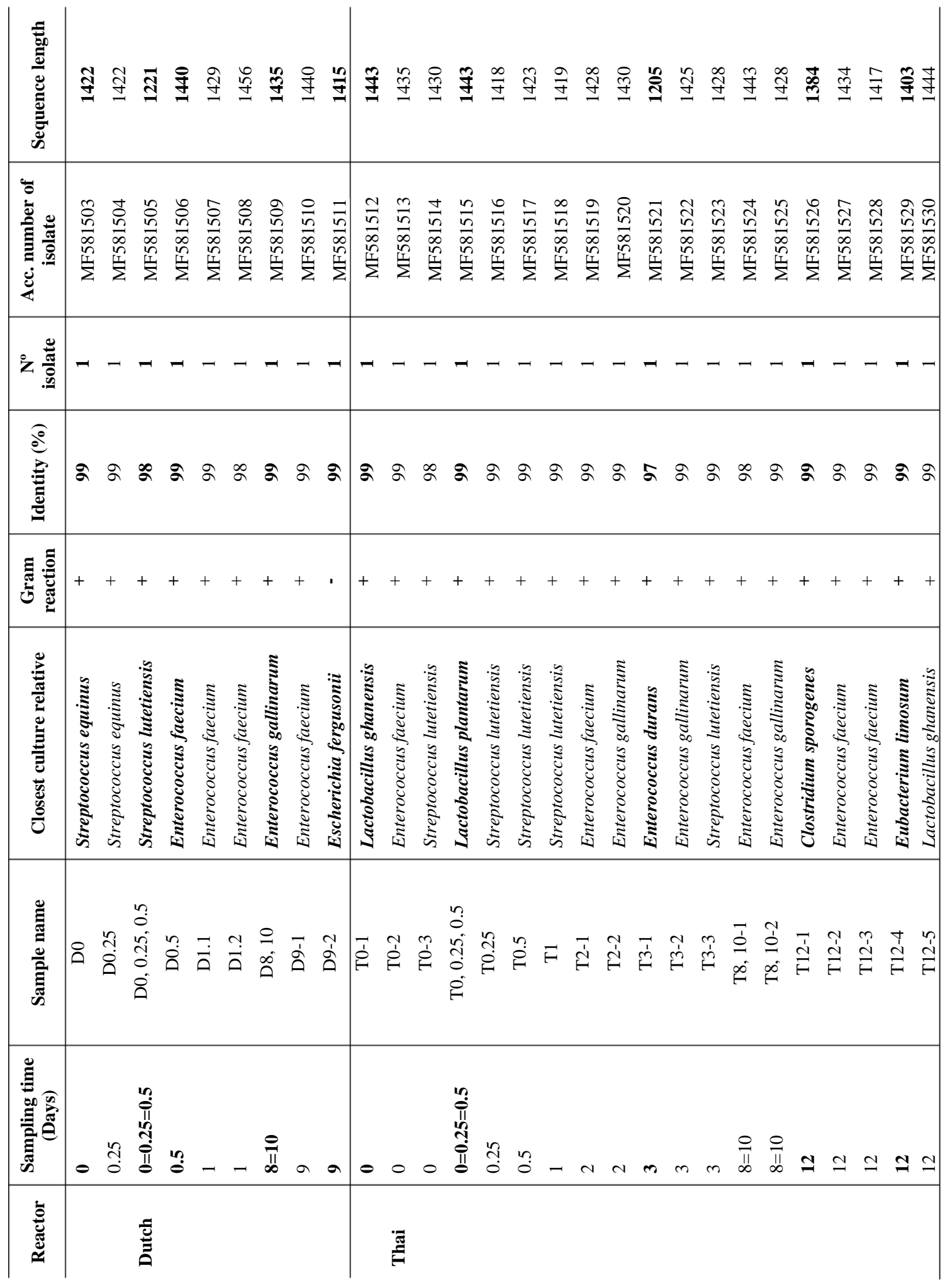


Table S7. The number of reads and OTUs per sample generated using 16S rRNA gene amplicon pyrosequencing from both reactors.

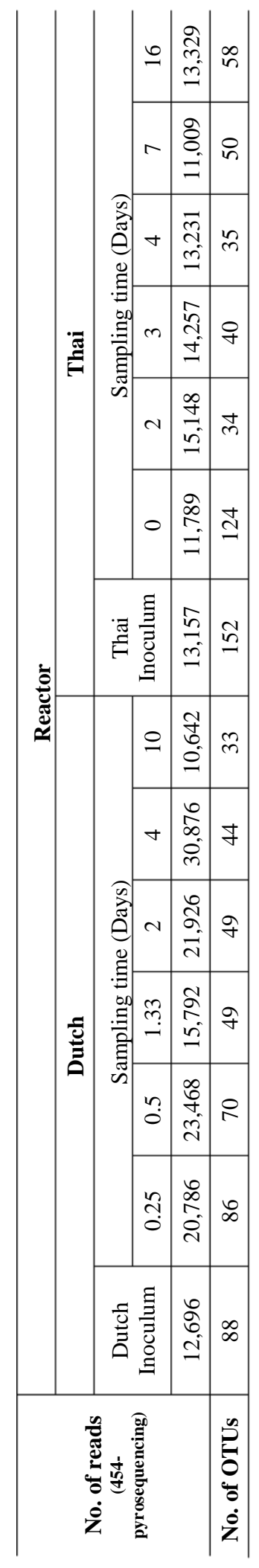


Table S8. Correlation matrix (Spearman's Rank Order Correlations statistics) between Bacterial OTUs at genus-like level and the operational data from the Dutch reactor (a) and Thai reactor (b). Green colors indicate positive correlations, whereas red colors indicate negative correlations. Correlation is significant at the $p=$ 0.05 level (2-tailed) for the groups in the solid parentheses, whereas the dashed parentheses indicate the significant correlations at $p=0.01$ (2-tailed) and both font types are italic.

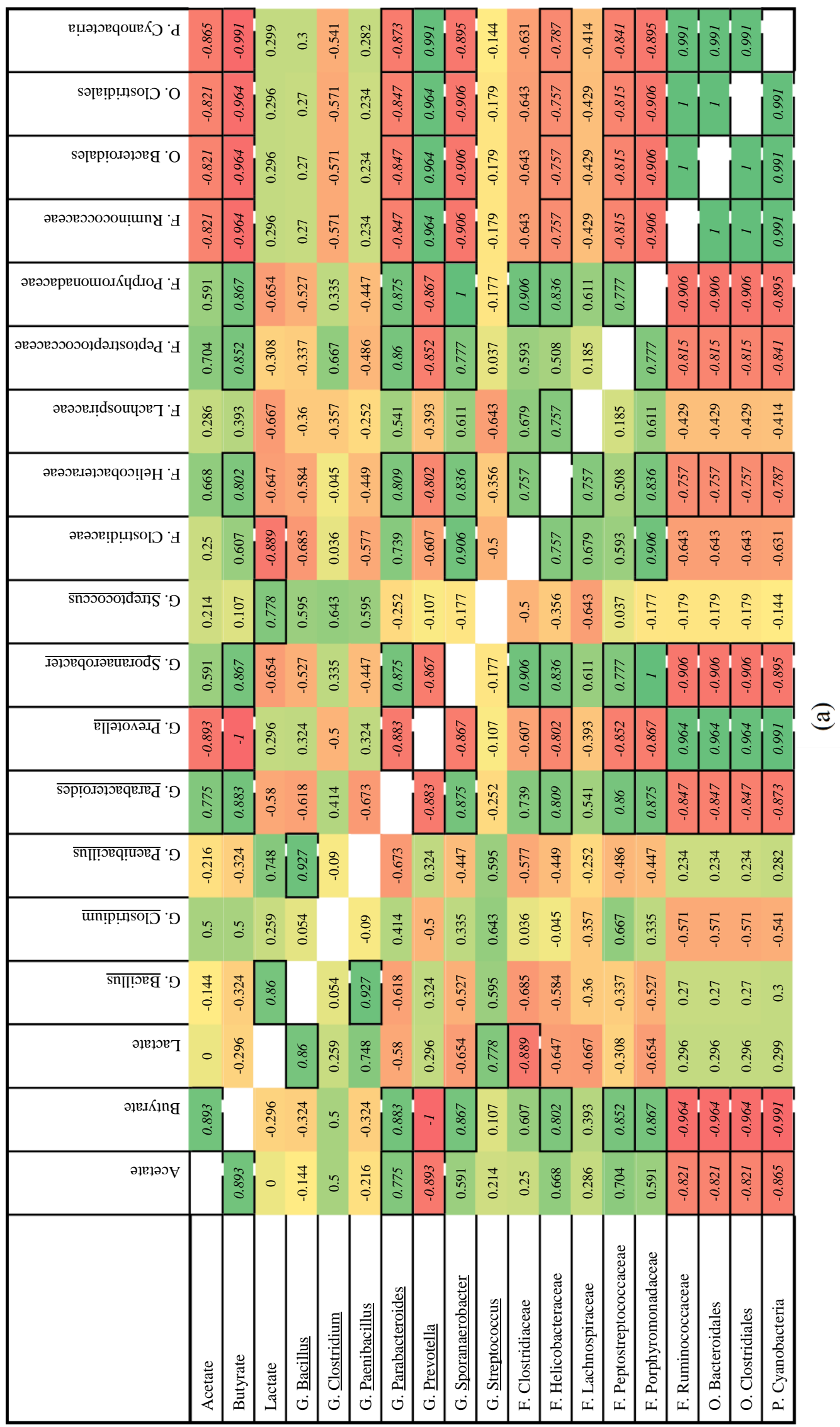




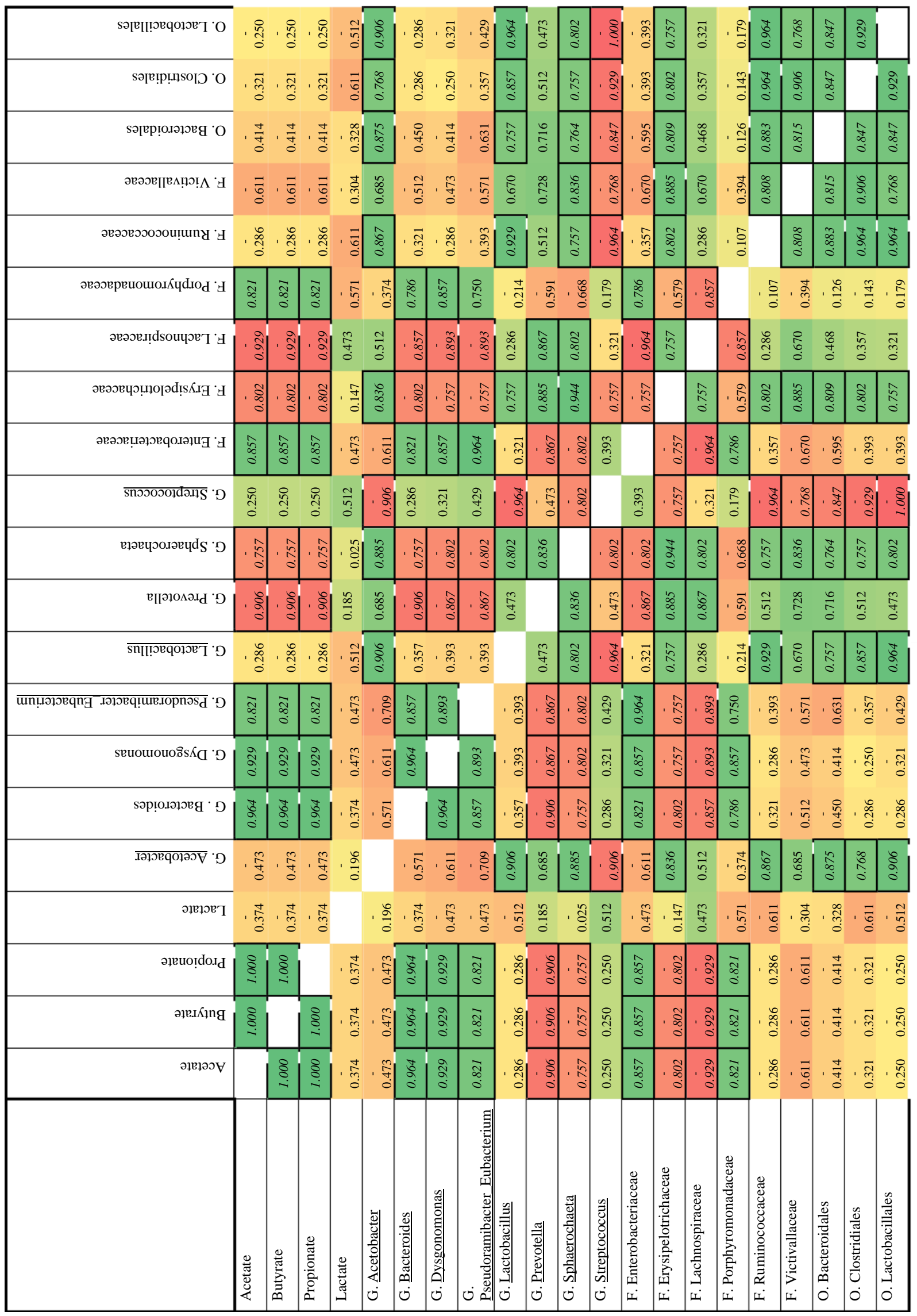




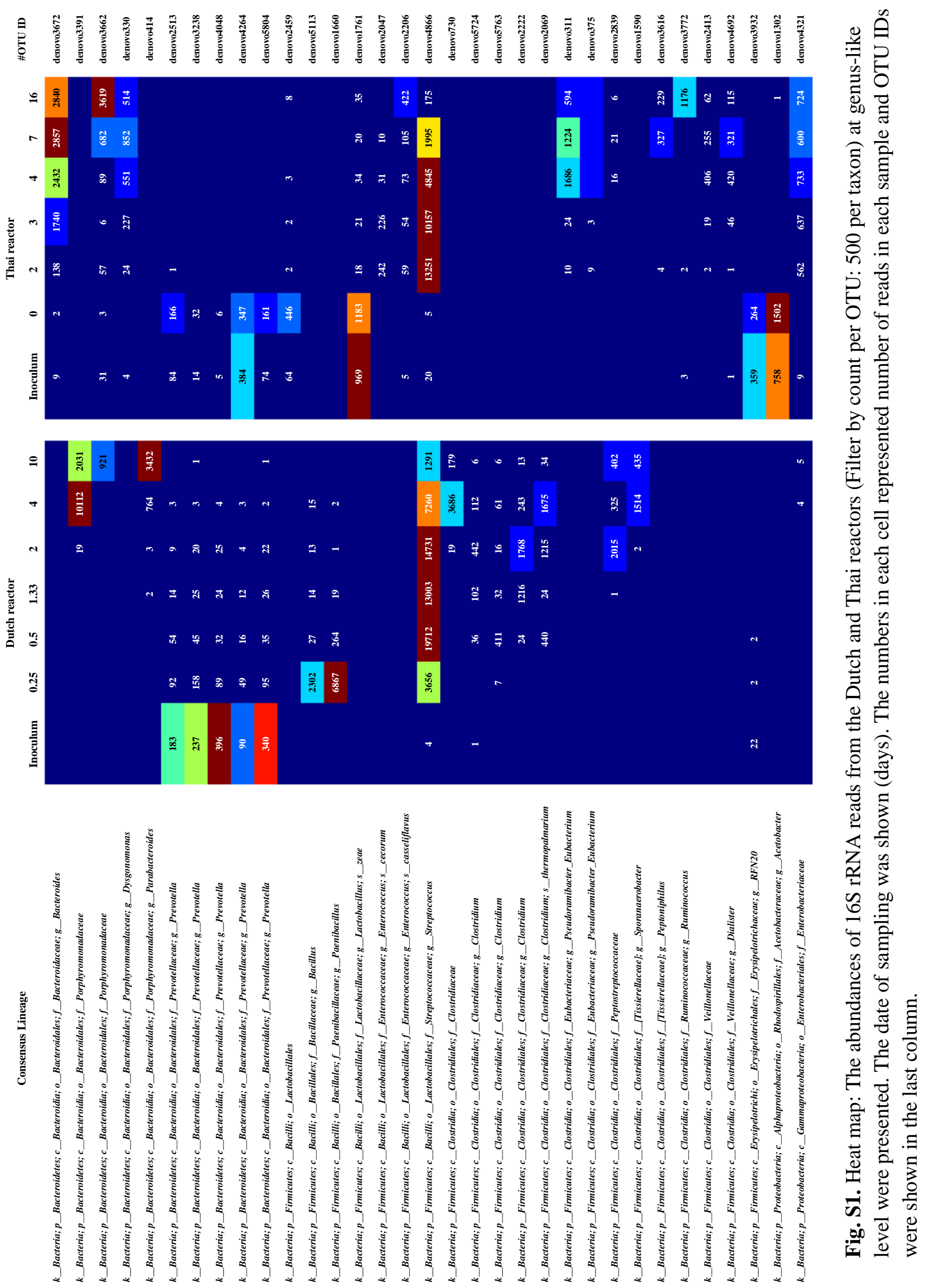




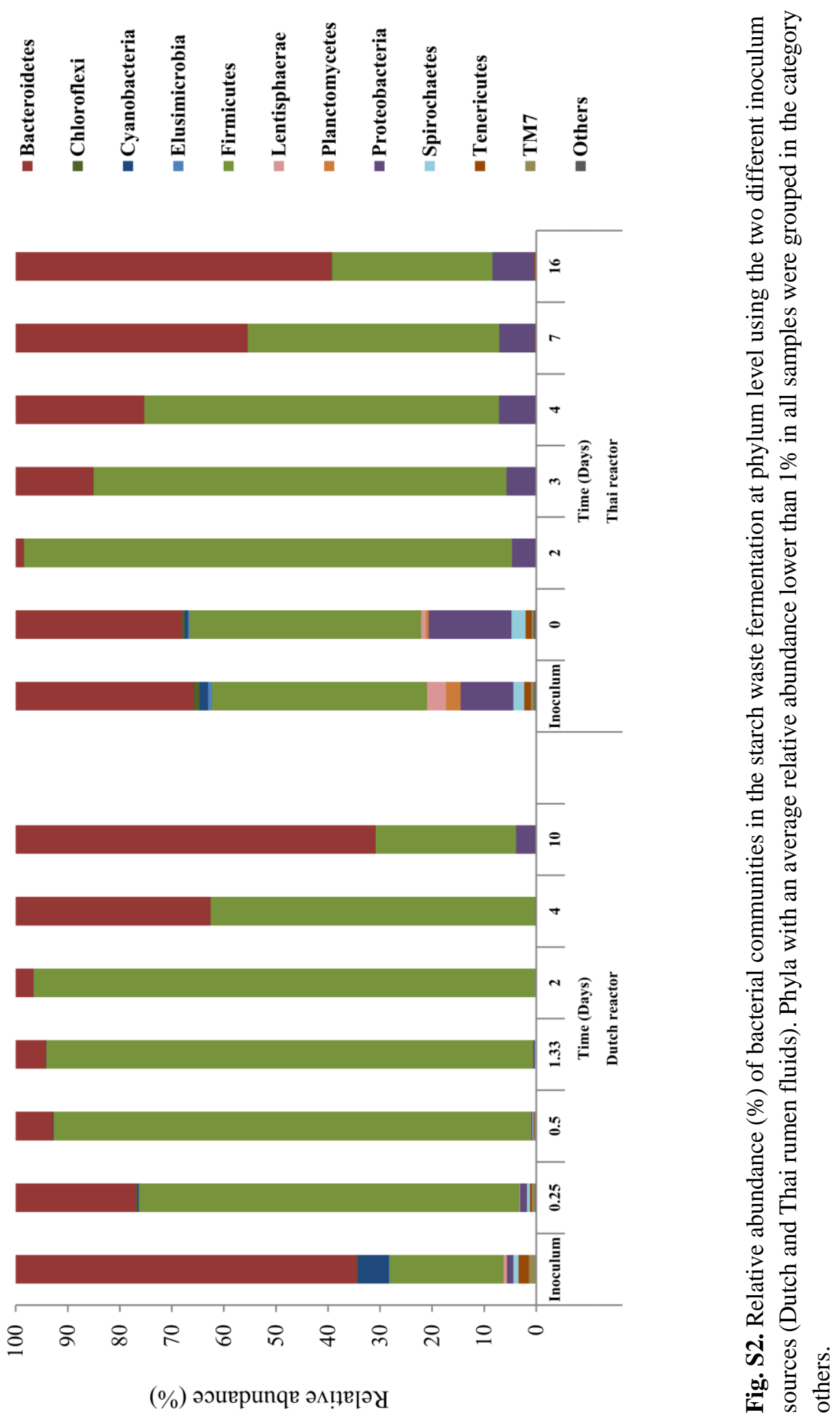




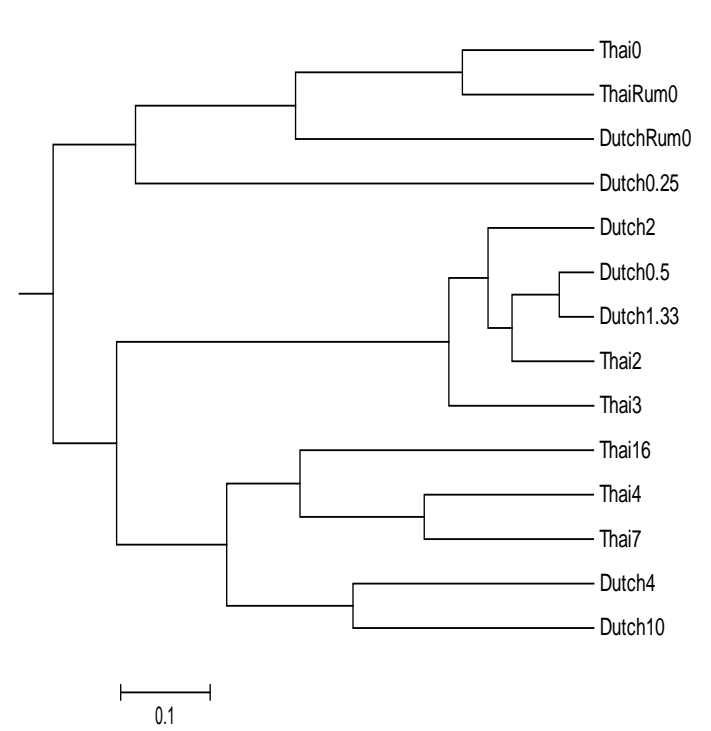

(a)

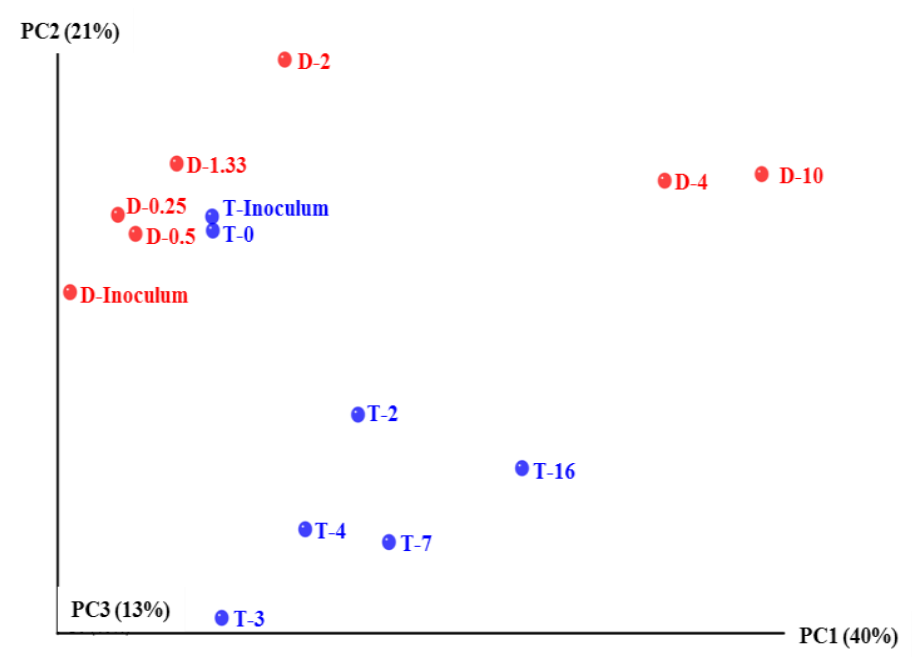

(b)

Fig. S3. Grouping tree of the bacterial communities from both reactors (a). PCA plot weighted unifraction of the relative abundance of the bacterial communities at different time points in the starch waste fermentation using the Dutch rumen fluid (red dots) and Thai rumen fluid (blue dots) (b). 

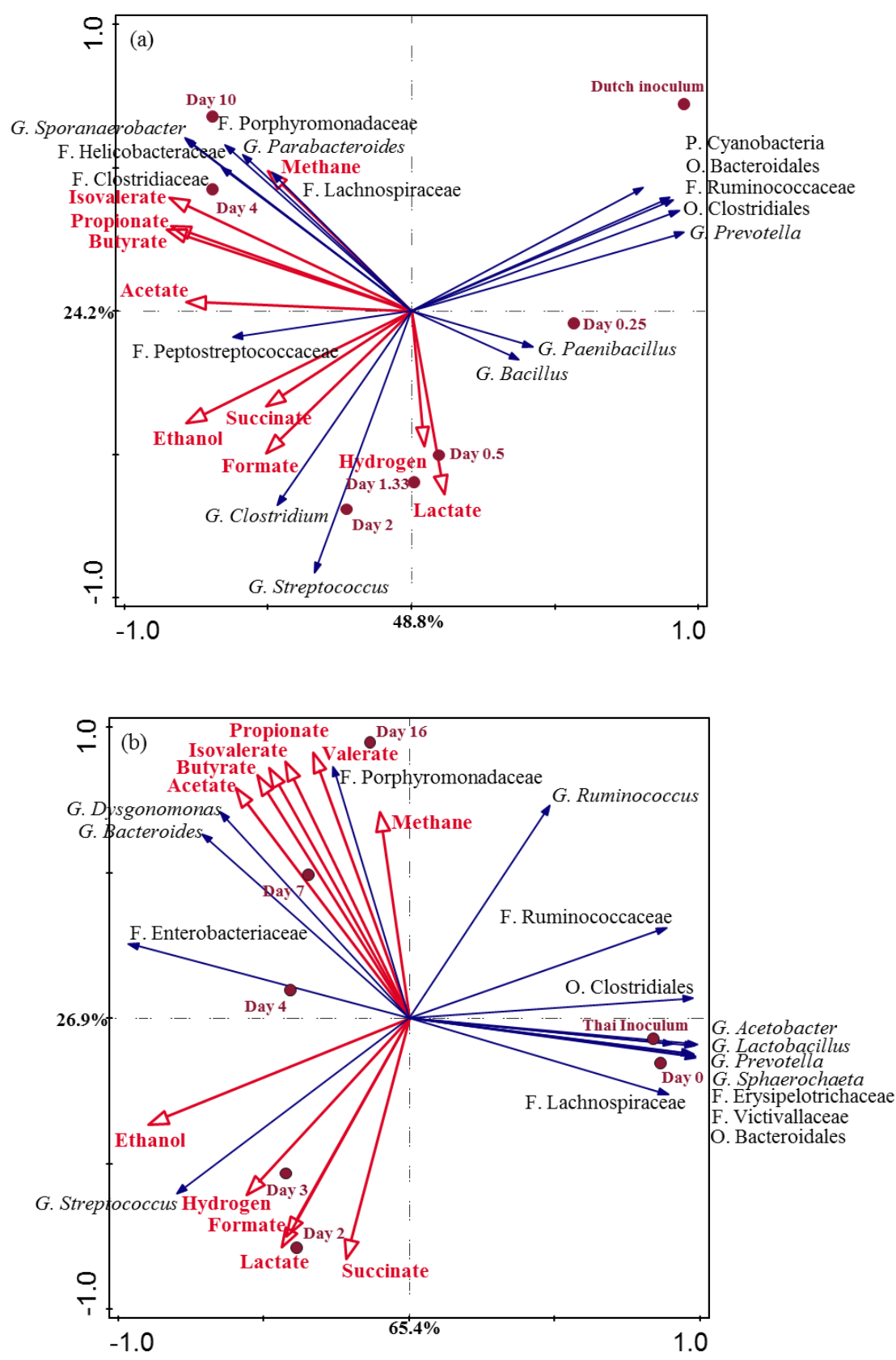

Fig. S4. Principal component analysis (PCA) with unconatrained ordination triplot between the top 16 genuslike level phylogenetic groupings of the OTUs and the environmantal variables explaining the variance with time in the Dutch (a) and Thai (b) reactors. Time points are indicated the sampling point (days) during the starch waste fermentation and shown as filled circles $(\bullet)$. Environmental variables or selected fermentation products are represented by red arrows. Bacterial community at genus-like groups with the level i.e. phylum $(\mathrm{P})$, order $(\mathrm{O})$, family $(\mathrm{F})$ or genus $(\mathrm{G})$ are represented as blue arrows. The direction of the species, in which the species abundance increases. Length of arrows is a measure of fit. The environmental variable arrows (in red) approximated the correlation between species and an environmental variable. The further a product falls in the direction indicated by arrow, the higher the correlation. Both axes together explained $73 \%$ and $92.3 \%$ of the total variances in the datasets from the Dutch (a) and Thai (b) reactors, respecitvely. 



\section{CHAPTER 3}

Actinomyces succiniciruminis sp. nov. and

Actinomyces glycerinitolerans sp. nov., two novel organic acidproducing bacteria isolated from rumen

This chapter has been published as:

Susakul Palakawong Na Ayudthaya, Peter Pristaš, Ludmila Hrehová, Peter Javorský, Alfons J.M. Stams and Caroline M. Plugge (2016) Actinomyces succiniciruminis sp. nov. and Actinomyces glycerinitolerans sp. nov., two novel organic acid-producing bacteria isolated from rumen. Systematic and Applied Microbiology 39, 445-452. 


\section{Abstract}

Two bacterial strains, Am4 and G10 were isolated from rumen fluid of different ruminants: cow (Holstein-Friesian) and sheep (Slovenskè merino), respectively. They were isolated from different hosts and regions but showed $99.2 \%$ similarity of the 16S rRNA genes. Both strains are versatile and ferment various sugars to mainly succinate and lactate and small amounts of acetate and formate. The $16 \mathrm{~S}$ rRNA sequences of Am4 and G10 revealed that they belonged to the genus Actinomyces and are related to Actinomyces ruminicola JCM $13352^{\mathrm{T}}$ with 97.0 and $97.4 \%$ similarity, respectively. DDH showed strain Am4 and G10 had only 55.8 and 43.3\% similarity with the Actinomyces ruminicola JCM $13352^{\mathrm{T}}$ and had $69.9 \%$ similarity among each other. Comparing strain Am4 and G10, gANI value and dDDH were 92.9 and 68.6\%, respectively. Additionally, AAI between the strains was $95.8 \%$. MLSA of housekeeping genes showed difference of met $G$ and pheS. The $\mathrm{G}+\mathrm{C} \%$ contents of strain Am4 and G10 were 69.8 and $68.5 \%$, respectively. MK-10(H4) was the principal quinone for strain Am4 (82\%) and G10 (91\%) with small amounts of MK-10(H $)$ and MK-10 $\left(\mathrm{H}_{6}\right)$ for both strains. Only MK-9 $\left(\mathrm{H}_{4}\right)$ was detected in strain Am4. MALDI-TOF analysis of protein profiles also revealed that Am4 and G10 are different from each other and from Actinomyces ruminicola JCM $13352^{\mathrm{T}}$.

Based on phylogenetic and physiological characteristics, together with genome comparison and MLSA we propose two novel species in the genus Actinomyces: Actinomyces succiniciruminis sp. nov. (type strain $\mathrm{Am} 4^{\mathrm{T}}=$ TISTR $2317^{\mathrm{T}}=\mathrm{DSM} 10376^{\mathrm{T}}$ ) and Actinomyces glycerinitolerans sp. nov. (type strain $\mathrm{G} 10^{\mathrm{T}}=$ TISTR $\left.2318^{\mathrm{T}}=\mathrm{DSM} 10377^{\mathrm{T}}\right)$.

In recent years, organic acids production by microbes has gained interest as organic acids can be used as building-blocks for chemicals and can be converted to biofuels to replace fossil fuel. Anaerobic digestion is a well-known fermentation process that is catalyzed by microorganisms. Various products, including organic acids such as lactate, acetate, butyrate, and succinate and the 
biofuel methane are formed in anaerobic digestion. Succinate is high in demand for chemical and industrial purposes as it is a precursor for several chemicals including butanediol, $\gamma$-butyrolactone, tetra-hydrofuran, and maleic anhydride, the latter being produced from petroleum and used in chemical synthesis processes (Sauer et al., 2008).

The rumen is an anaerobic "bioreactor", containing a multitude of microorganisms that efficiently converts complex organic compounds. Polymeric compounds are first hydrolyzed and then further digested to organic acids. Therefore, exploring the rumen biodiversity may yield dedicated microorganisms capable of producing certain organic acids, such as succinate, which is an important fermentation product in the rumen.

Actinomyces is an important genus within the order Actinomycetales, class Actinobacteria, and phylum Actinobacteri (Schaal and Yassin, 2012). This genus currently contains 47 recognized species and 2 subspecies (see http://www.bacterio.net/a/actinomyces.html: 17-07-2016). Characteristics are high $\mathrm{G}+\mathrm{C}$ content, Gram-positive, pleomorphic, varying from coccoid, diphtheroid-like to long branched filaments with swollen ends, non-motile and anaerobic, facultative anaerobic or aerotolerant (Schaal and Yassin, 2012). Actinomyces are widely distributed in nature such as in the mucous membranes of humans, animals, and intestinal guts, including rumen. They naturally produce organic acids such as acetate, formate, lactate, and/or succinate from glucose fermentation (Skyes and Skinner, 1973). This characteristic makes Actinomyces species interesting candidates for dedicated organic acid production (Saini et al., 2015). To date, most species in this genus were isolated from mucosal surfaces of animals and humans, except Actinomyces naturae CCUG $56698^{\mathrm{T}}$, isolated from chlorinated solvent-contaminated groundwater (Rao et al., 2012), and only one strain, Actinomyces ruminicola $\mathrm{JCM} 13352^{\mathrm{T}}$ has been isolated from the rumen (An et al., 2006). 
Here, we describe the properties of two novel organic acid producing strains, G10 and Am4, originating from the rumen. Strain G10 was isolated from sheep rumen fluid (Slovenskè merino breed) as previously described by Vandžurová et al. (Vandžurová et al., 2013). Strain Am4 was isolated from rumen fluid of a fistulated Friesian Holstein cow housed at Wageningen University Research Farm, The Netherlands.

For isolation of strain Am4, bovine rumen fluid (500 ml) was sampled through the rumen fistula. The rumen fluid was collected in a sterilized $\mathrm{CO}_{2}$-flushed anaerobic bottle (Hijazin et al., 2012) and brought to the laboratory, where it was blended for $10 \mathrm{~s}$ using a sterile blender and filtered through two layers of sterile cotton cloth. The filtered fluid was injected in sterillized- $\mathrm{N}_{2}$-flushed anaerobic bottles and kept at $4{ }^{\circ} \mathrm{C}$ until use. Rumen fluid (1\%, v/v) was used as inoculum in a bicarbonate-buffered anaerobic medium (BM), which was prepared as previously described (Plugge, 2005). The medium was supplemented (per liter) with $0.1 \mathrm{~g}$ yeast extract, $5 \mathrm{mg}$ hemin, $0.1 \mathrm{ml}$ vitamin $\mathrm{K}_{1}$, and $0.5 \%$ (w/v) amylopectin was added as carbon source. The final liquid volume was $50 \mathrm{ml}$ in $117 \mathrm{ml}$ serum bottles sealed with butyl rubber stopper containing 80:20 (v/v) $\mathrm{N}_{2} / \mathrm{CO}_{2}$ at $1.7 \mathrm{~atm}(172 \mathrm{kPa})$ gas phase. The $\mathrm{pH}$ of the medium was 7.2 . The primary enrichments were incubated while shaking $(50 \mathrm{rpm})$ at $39^{\circ} \mathrm{C}$ in the dark. Further enrichment was performed by consecutive transfers to the same medium and isolation was by serial dilution using Reinforced Clostridial Medium (RCM), and finally plating on BMY (BM with $0.1 \mathrm{~g} \mathrm{l}^{-1}$ yeast extract), supplemented with $0.5 \%$ amylopectin, $5 \mathrm{mg}$ hemin, $0.1 \mathrm{ml}$ vitamin $\mathrm{K}_{1}$ and $1.5 \%(\mathrm{w} / \mathrm{v})$ agar. The plates were placed in an anaerobic jar, which was the pressurized with $\mathrm{N}_{2} / \mathrm{CO}_{2}$ to contain 80:20 (v/v) at 1.7 atm $(172 \mathrm{kPa})$ gas phase. Single colonies were further purified on the same agar medium by the streak plate method, followed by serial dilution in BM liquid medium as described above for three times to obtain a pure culture that was termed strain Am4.

Strains Am4 and G10 were routinely grown with $20 \mathrm{mM}$ glucose in a bicarbonate-buffered anaerobic medium (Plugge, 2005) supplemented (per liter) with $0.1 \mathrm{~g}$ yeast extract (BMY). The 
purity of strains Am4 and G10 were checked routinely by phase-contrast microscopy (Leica DM 2000; Wetzlar, Germany). Organic acids were determined by high-performance liquid chromatography (HPLC) and gas production by gas chromatography (GC) as described in (Gelder et al., 2012).

Genomic DNA of strain Am4 was isolated and purified from glucose grown cells (BMY with $20 \mathrm{mM}$ glucose) using the Fast DNA ${ }^{\mathrm{TM}}$ Spin Kit for Soil (MP Biomedicals, Santa Ana, CA) following the manufacturer's instruction. DNA was amplified to obtain almost full-length 16S rRNA gene sequences (1429 bp) by PCR with bacterial-universal primers $27 f \quad\left(5^{\prime}\right.$ AGAGTTGATCCTGGCTCAG-3') and 1492r (5'-TACCTTGTTACGACTT-3') (Lane et al., 1991). The PCR program was started with a denaturing step at $95{ }^{\circ} \mathrm{C}$ for $5 \mathrm{~min}$ and continued with 35 cycles consisting of $95{ }^{\circ} \mathrm{C}$ for $30 \mathrm{~s}, 52{ }^{\circ} \mathrm{C}$ for $40 \mathrm{~s}$, and $72{ }^{\circ} \mathrm{C}$ for $90 \mathrm{~s}$, and the last step of extension at $72{ }^{\circ} \mathrm{C}$ for 7 min. PCR products of strain Am4 were purified and sequenced at GATC Biotech Company (Konstanz, Germany). The DNA sequence was checked for reading errors and aligned using the program DNA Baser Sequence Assembler v4 (Heracle BioSoft S.R.L, Arges, Romania). The partial sequences were blasted with the NCBI online database. The 16S rRNA gene sequence of strain G10 (1519 bp.) was obtained from the NCBI website KC866613 (Vandžurová et al., 2013). The 16S rRNA gene sequences were checked for chimeras using DECIPHER's Find Chimeras web tool (Wright et al.,2012) before comparison with BLASTN search online program (http://blast.ncbi.nlm.nih.gov/Blast.cgi: 03-02-2016) and EzTaxon 2.1 (Chun et al., 2007) and EzTaxon-e server (Kim et al., 2012). The phylogenetic position of strain Am4 and G10 was studied by comparison with $16 \mathrm{~S}$ rRNA gene sequences of other related strains in the Actinomycesgenus, using Bifidobacterium bifidum ATCC $29521^{\mathrm{T}}$ as an out group, all obtained from NCBI online database. All 16S rRNA genes were aligned using a CLUSTAL_X program (Thompson et al., 2009) with Kimura's two-parameter model (Kimura, 1980). Then, a phylogenetic tree was constructed and implemented on the MEGA 5 programs (Tamura et al., 2011) using the neighbor- 
joining, maximum-parsimony (Saitou and Nei, 1987), and maximum-likelihood (Felsenstein, 1981) methods. Tree topologies were performed by using bootstrap analysis with 1000 repeats (Felsenstein, 1985) (Fig. 1). The 16S rRNA gene sequences of the Am4 and G10 strains revealed that they belonged to the genus Actinomyces with 97.0 and $97.4 \%$ similarity, respectively, to the closest cultured relative, Actinomyces ruminicola $\mathrm{JCM} 13352^{\mathrm{T}}$, and were $99.2 \%$ similar to each other. The tree showed that rumen Actinomyces are separated and phylogenetically different from other Actinomyces species, pointing at a correlation between phylogeny and origin of the strains.

As the 16S rRNA gene sequence similarity between strain Am4 and strain G10 was higher than 99\%, genome-based comparison tools (Rosselló-Móra and Amann, 2015) such as ANI and dDDH (in silico) were used to elucidate difference between the two strains. Genomic DNA of strain Am4 and G10 were extracted from glucose grown cells (BMY with $20 \mathrm{mM}$ glucose) using the MasterPure $^{\mathrm{TM}}$ Complete DNA and RNA Purification Kit (Epicenter, Madison, WI) following the manufacturer's instruction. The genome of strain Am4 and G10 were sequenced at GATC-Biotech, Konstanz, Germany. The draft genomes were assembled at WUR using in-house pipeline protocol (Strepis et al., 2016). The draft genomes (Am4 and G10) were then analyzed using gold standard analysis. 


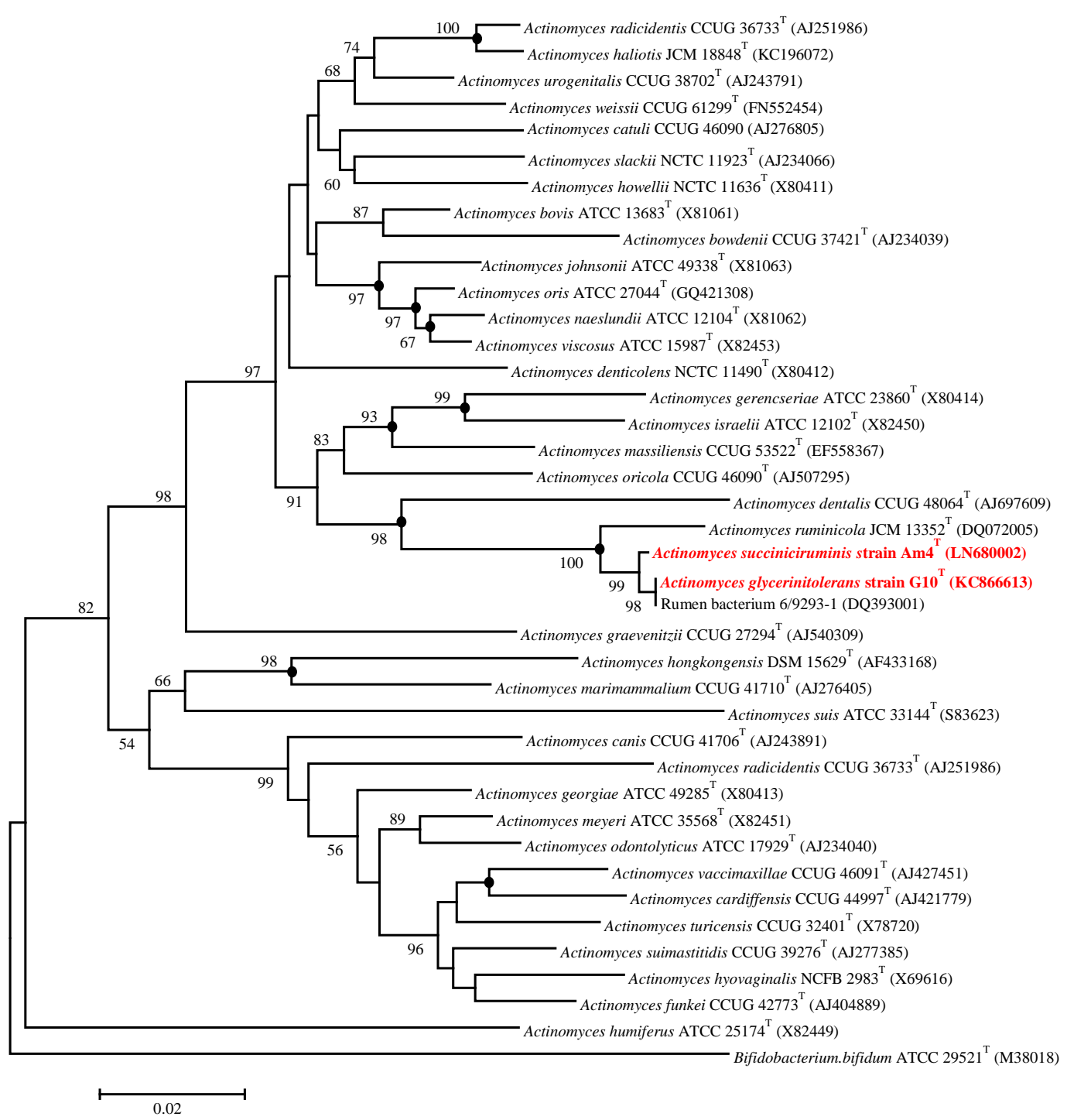

Fig. 1. Neighbour-joining tree, based on $16 \mathrm{~S}$ rRNA gene sequences, showing the phylogenetic relationship of strain Am4, strain G10, and related species in the genus Actinomyces. Bootstrap values, which were higher than $50 \%$ based on 1000 replications, are shown at the branching points. Bifidobacterium bifidum ATCC $29521^{\mathrm{T}}$ was used as an out group. Filled circles were used to indicate identical nodes generated by three methods (neighbor-joining, maximum-likelihood and maximumparsimony). In parentheses the Gen Bank accession number of each strain is listed. Bar $2 \%$ sequence divergence.

The ANI calculation was performed using MiSI (Microbial Species Identifier: MiSI) method version 0.3 from JGI website to calculate genome-wide Average Nucleotide Identity (gANI) complementary analysis with the fraction of orthologous genes (Alignment Fraction, AF) using threshold values of gANI and AF values with 96.5 and 0.6, respectively (Varghese et al., 2015). 
The average reciprocal values of gANI and AF values between strain Am4 and G10 were 92.94\% and 0.24, respectively, which were lower than the cut-off values $(96.5 \%$ and 0.6 , respectively). Other ANI methods were used: ANI BLAST (ANIb) and ANI MUMmer (ANIm) methods using JSpecies software tool (Richter and Rosselló-Móra, 2009) and Average Nucleotide Identity by Orthology (OrthoANI) measuring only orthologous fragment pairs between two fragmented genomes (Lee et al., 2016) (Table S1).

Average amino acid identity (AAI) between strain Am4 and G10 was also calculated by using AAI calculator at Kostas lab (http://enve-omics.ce.gatech.edu/aai/) and the AAI result was 95.8\% from 2249 proteins which was below the $96 \%$ threshold that was suggested to delineate Vibrio sp. (Thompson et al., 2009).

Recently, dDDH has been implemented by Genome Blast Distance Phylogeny (GBDP) and provides better correlation result than ANI (regarding to JSpecies) (Meier-Kolthoff et al., 2013). The dDDH comparing the whole genomes using Genome-to-Genome Distance Calculator (GGDC) web browser at DSMZ (Braunschweig, Germany) between strain Am4 and G10 was performed and compared with the wet-lab DDH results. The wet-lab DDH was done in parallel with their closest relative A. ruminicola JCM $13352^{\mathrm{T}}$ type strain (provided by Prof. Xiuzhu Dong, Chinese Academy of Sciences, Beijing, China via JCM-Japan Collection of Microorganisms) at the Deutsche Sammlung von Mikroorganismen und Zellkulturen GmbH (DSMZ) (Braunschweig, Germany) as described by De Ley et al. (1970) with modifications described by (Huss et al., 1983) using a model Cary 100 Bio UV/VIS-spectrophotometer equipped with a Peltier-thermostatted $6 \times 6$ multi cell changer and a temperature controller with in situ temperature probe (Varian, Inc., Palo Alto, CA). According to the recommendations by the ad hoc committee a threshold value of $70 \%$ DNA-DNA similarity of the definition of bacterial species is decisive to designate novel species (Rosselló-Móra and Amann, 2015; Wayne et al., 1987; Moore et al., 1987). The DNA-DNA hybridization result (wet-lab) confirmed that both strains (Am4 and G10) are different from A. ruminicola JCM $13352^{\mathrm{T}}$ 
with the average DDH values (mean value of two replications) between strain Am4 and $A$. ruminicola $\mathrm{JCM} 13352^{\mathrm{T}}$ was 55.8 and between strain $\mathrm{G} 10$ and $A$. ruminicola $\mathrm{JCM} 13352^{\mathrm{T}}$ were $43.3 \%$, respectively.

The mean value of DNA-DNA hybridization between Am4 and G10 from both digital and wet-lab were 68.6 and $69.9 \%$, respectively, which were lower than the threshold value of the $70 \%$ DNA-DNA similarity cut-off (Wayne et al., 1987). Additional genome-based comparison between strain Am4 and G10 is shown in Table S1.

Multilocus sequence analysis (MLSA) with ten housekeeping genes: atpA (ATP synthase F1, alpha subunit), atpD (ATP synthase beta chain), gltA (citrate synthase (si)), gyrA (DNA gyrase, subunit A), met $G$ (methionyl-tRNA synthetase), pheS (phenylalanyl-tRNA synthetase alpha chain), pgi (glucose-6-phosphate isomerase), rpoA (DNA-directed RNA polymerase alpha subunit), rроB (DNA-directed RNA polymerase beta subunit), and soda (superoxide dismutase $(\mathrm{Mn}))$ were also compared between strain Am4 and G10. Eight of the genes had only 1\% difference between the two strains using BLASTN analysis (Table S2). However, met $G$ and pheS had 3 and 4\% differences, respectively (Table S2). MLSA-based phylogenetic trees of metG (A) and pheS (B) genes revealed the relationship between strain Am4 and G10 and 17 other Actinomyces species in Fig. S1. All these genomes-based comparisons reveal that strain Am4 and G10 are different. However, additional chemotaxonomical, biochemical and physiological analysis were performed.

The DNA base composition $(\mathrm{G}+\mathrm{C}$ content) of strain Am4 and G10 was analyzed by HPLC (Tamaoka and Komagata, 1984) at the Identification Service of the DSMZ (Braunschweig, Germany). Strain Am4 and G10 were grown in modified BM with $20 \mathrm{mM}$ glucose and extra yeast extract $\left(5 \mathrm{~g} \mathrm{l}^{-1}\right)$ at $37^{\circ} \mathrm{C}$ for $48 \mathrm{~h}$. The cell biomass was harvested by centrifugation at $4{ }^{\circ} \mathrm{C}$ at $15,317 \times g$ for 10 min. The DNA G + C content of strain Am4 was 69.8 and $68.5 \%$ for strain G10. The $\% \mathrm{G}+\mathrm{C}$ content of the strain Am4 and G10 obtained from genome calculation (JSpecies tool) 
was 68 and $66.88 \%$, respectively. These values are in line (55-71\%) with that of known species within the genus Actinomyces.

Fatty acid and quinone composition of the cell wall of strain Am4 and strain G10 were also carried out at the DSMZ. The cultures and the cell biomass were obtained as described above for the $\mathrm{G}+\mathrm{C}$ content analysis. The fatty acid composition of the closest relative, Actinomyces ruminicola JCM $13352^{\mathrm{T}}$, was grown and analyzed in parallel with the two strains. The cellular fatty acids of strain Am4 were mainly composed of (>10\% of the total) $\mathrm{C}_{16: 0}$ FAME (40.06\%), $\mathrm{C}_{18: 1} \mathrm{CIS}_{9}$ FAME (31.20\%) and $\mathrm{C}_{18: 1} \mathrm{CIS}_{9}$ DMA (8.49\%), and those of strain G10 were $\mathrm{C}_{16: 0}$ FAME (38.02\%), $\mathrm{C}_{18: 1} \mathrm{CIS}_{9}$ FAME (33.53\%), and $\mathrm{C}_{18: 1} \mathrm{CIS}_{9}$ DMA (6.99\%), and were different from the fatty acids composition of Actinomyces ruminicola $\mathrm{JCM} 13352^{\mathrm{T}}$ (Table S3). The respiratory quinones of strain Am4 and strain G10 were mainly unsaturated tetrahydrogenated menaquinones

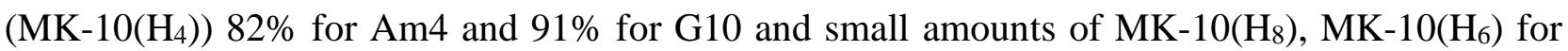
both strains, but only MK-9(H) was found in strain Am4. Actinomyces ruminicola JCM $13352^{\mathrm{T}}$ contained only MK-10 (70\%) and MK-9 (30\%) as shown in Table S4. These characteristics of the strains Am4 and G10 are similar to the principal respiratory quinones of other species in genus Actinomyces, that have menaquinones with eight, nine, ten or eleven isoprene units (MK-8, MK-9, MK-10, and MK-11), tetrahydrogenated menaquinones with nine [MK-9( $\left.\left.\mathrm{H}_{4}\right)\right]$ or ten [MK10( $\left.\mathrm{H}_{4}\right)$ ] isoprene units (Schaal and Yassin, 2012). The quinones of $A$. ruminicola $\mathrm{JCM} 13352^{\mathrm{T}}$ were quite different between strain Am4 and G10, however, inconsistant quinones systems from four Actinomycetes (A. viscosus, A. israelii, A. bowdenii and A. ruminicola) were reported (Hijazin et al., 2012). The first three strains contained dominantly MK-10( $\left.\mathrm{H}_{4}\right)$ whereas $A$. ruminicola contained MK-10 and MK-9 (7:3) (Hijazin et al., 2012). Moreover, Hijazin and coworkers also reported the different major quinone was found in the same species of A. bovis (Hijazin et al., 2012). A. bovis DSM $43014^{\mathrm{T}}$ contained mainly MK-9 quinone, which was different from the 
previous report of Hess et al., that the major quinone of A. bovis CCUG 1430 was MK-10 (Hijazin et al., 2012; Hess et al., 1979).

MALDI-TOF-MS is a rapid and simple method used to identify bacteria mainly of clinical importance (Schumann and Maier, 2014; Biswas and Rolain, 2013). Recently, the method was successfully applied to identify oral Actinomyces species cultivated from subgingival biofilm as well (Stingu et al., 2015). Therefore, protein patterns of strain Am4 and G10 were analyzed using MALDI-TOF-MS, to further study the similarities between the two strains. In parallel, related type strains Actinomyces ruminicola JCM $13352^{\mathrm{T}}$, A. oricola CCUG $46090^{\mathrm{T}}$, A. massisliensis CCUG $53522^{\mathrm{T}}$, and A. dentalis CCUG $48064^{\mathrm{T}}$ (all obtained from DSMZ, Braunschweig, Germany) were included. Biomass for the MALDI-TOF analysis of all strains was grown in BM with $1 \mathrm{~g} 1^{-1}$ yeast extract and $20 \mathrm{mM}$ glucose at $37^{\circ} \mathrm{C}$ for $48 \mathrm{~h}$. The cultures were harvested by centrifugation at $13,000 \times g$ for 2 min and the pellets were washed with PBS buffer and dissolved in $300 \mu$ sterile de-ionized $\mathrm{H}_{2} \mathrm{O}$ before adding $900 \mu \mathrm{l}$ of absolute ethanol to precipitate the proteins. The mixture was centrifuged at $13,000 \times g$ for $2 \mathrm{~min}$ and the supernatant was discarded. Thirty microlitre of formic acid $(70 \% \mathrm{v} / \mathrm{v})$ was added to the pellet and thoroughly mixed by pipetting before addition of $30 \mu \mathrm{l}$ of acetonitrile to the mixture. The mixture was centrifuged at $13,000 \times g$ for $2 \mathrm{~min}$ and the supernatant was analyzed as previous described (Ferreira et al., 2011) using a Microflex LT instrument (Bruker Daltonics GmbH, Leipzig, Germany) with FlexControl software (version 3.0) as described in (Ferreira et al., 2011). The raw spectra obtained for each isolate were imported into BioTyper software-version 3.0 (Bruker Daltonics GmbH, Leipzig, Germany, database version 3.3.1.0) and analyzed by standard pattern matching with default settings. High quality spectra were obtained for all Actinomyces species tested. The normalized spectra were different for $A$. ruminicola JCM $13352^{\mathrm{T}}$, Am4 and G10 isolates (Fig. S2) indicating that Am4 and G10 are different from other Actinomycesspecies. While A. ruminicola JCM $13352^{\mathrm{T}}$ and strain G10 showed well defined spectra with over 40 peaks in $m / z$ ratios from 3,000 to 15,000, strain Am4 had a very simple 
spectrum with a dominant peak at $\mathrm{m} / \mathrm{z}$ ratio 4,093. Each MALDI-TOF MS spectrum obtained was matched against all spectra of the analyzed set and a matrix of matching scores was calculated. Dendrograms were calculated using the Biotyper MSP dendrogram creation standard method using the MALDI Biotyper 3.0 software (Fig. 2). The spectra comparison placed Am4 and G10 in a separate branch along with $A$. ruminicola $\mathrm{JCM} 13352^{\mathrm{T}}$.

All rumen Actinomyces species separated well from mainly oral Actinomycetes and the comparison indicated that Am4 and G10 isolates differ significantly from A. ruminicola JCM $13352^{\mathrm{T}}$. A distance level over 250 was observed between strains Am4 and G10. For the delineation of species using MALDI-TOF-MS, a distance level 500 is arbitrary set as a distance limit for the secure species identification (Saucer et al., 2008). For closely related species however, lower distance limits have been observed (Christensen et al., 2012). In a recent paper (Vanikova et al., 2015), distance levels as low as 50 were observed between closely related Microbacterium spp. belonging to the Actinomycetales order. The MALDI-TOF-MS analyzes indicate that Am4 and G10 are different species.

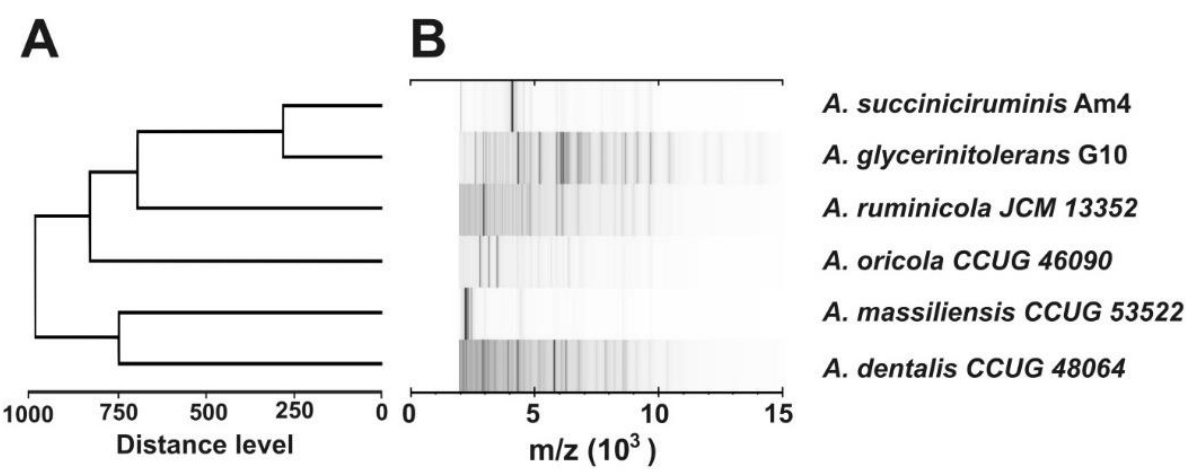

Fig. 2. Relationship between strain Am4, strain G10, and related Actinomyces sp. in a dendrogram of similarity (A) and MALDI-TOF MS spectra (B).

Both strains grew well on $1.5 \%$ RCM agar medium and colonies of both strains were round, with smooth margins, and convex with ivory color and reached a size of $0.1-0.2 \mathrm{~mm}$ after 3 days. 
Am4 and G10 cells were non-motile, pleomorphic, branched, with swollen ends, and commonly present as rods with size of $0.2-0.5 \mu \mathrm{m}$ by $0.9-2.8 \mu \mathrm{m}$ (Am4) and $0.4-0.6 \mu \mathrm{m}$ by $1.5-7 \mu \mathrm{m}$ (G10) (Fig. 3). Gram staining was examined using standard methods (Plugge et al., 2005). Spore formation was determined with Schaeffer and Fulton Spore Stain Kit (04551) following the manufacturer's instructions (Sigma-Aldrich Chemie GmbH, St. Louis, MS). Both strains were Gram positive, nonspore-forming bacteria and catalase, oxidase, and acid-fast negative.

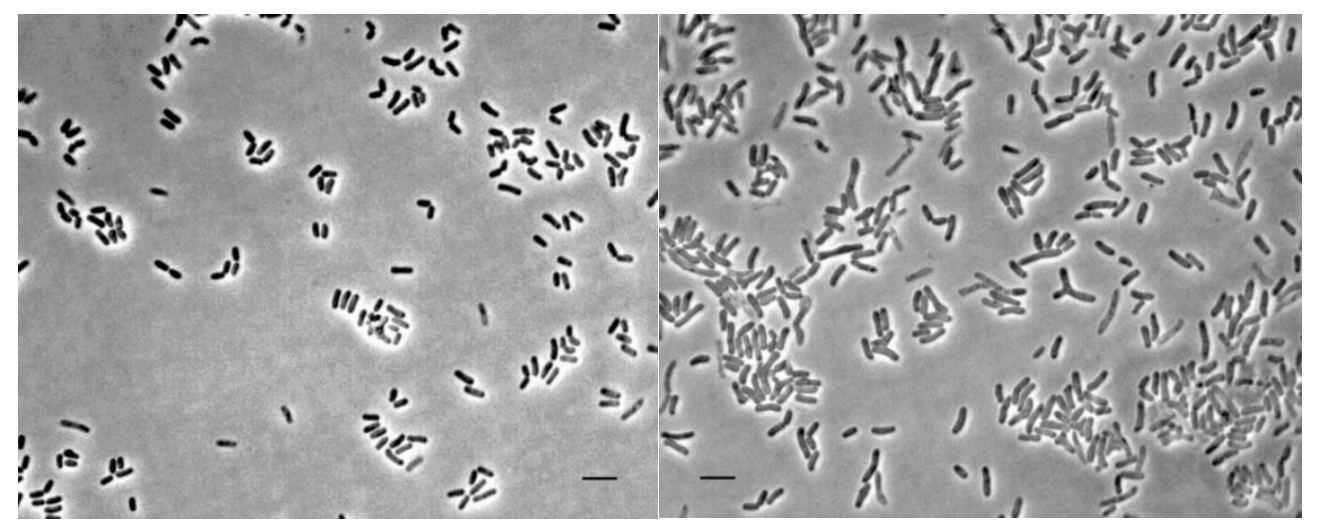

(A)

(B)

Fig. 3. Micrograph of Actinomyces strain Am4 (A) and Actinomyces strain G10 (B) using phasecontrast microscopy. Cells were grown for $24 \mathrm{~h}$. in BMY with $20 \mathrm{mM}$ glucose. Bar represents $2 \mu \mathrm{m}$.

The optimum conditions for growth of strain Am4 and G10 were determined using turbidity measurements for 4 weeks. The optimum pH was tested in Wilkins-Chalgren Broth (Oxoid) and the $\mathrm{pH}$ values of the medium were adjusted with $\mathrm{NaOH}$ and/or $\mathrm{HCl}$. Duplicate bottles were used and incubated at $37{ }^{\circ} \mathrm{C}$ at a $\mathrm{pH}$ range of $4.0-12.0$ at intervals of 0.5 . The optimum temperature was determined in BMY containing $20 \mathrm{mM}$ of glucose at temperature range of $4-65{ }^{\circ} \mathrm{C}$ at intervals of $5{ }^{\circ} \mathrm{C}$, including $37^{\circ} \mathrm{C}$. Strain Am4 and strain G10 could grow between pH 5.5 and 8.5, with an optimum at 7.5. Both strains could grow between 25 and $45^{\circ} \mathrm{C}$ but their optimal temperature was different $30^{\circ} \mathrm{C}(\mathrm{G} 10)$ and $37{ }^{\circ} \mathrm{C}(\mathrm{Am} 4)$.

Yeast extract $(0.1 \mathrm{~g})$, L-cysteine $(0.5 \mathrm{~g})$, hemin $(5 \mathrm{mg})$, vitamin $\mathrm{K}_{1}(0.1 \mathrm{ml})$ per liter were separately tested as a growth factor for strains Am4 and G10 in BM with $20 \mathrm{mM}$ glucose at $37^{\circ} \mathrm{C}$ 
for 14 days in duplicated bottles. Both strain Am4 and G10 could grow without L-cysteine, hemin and vitamin $\mathrm{K}_{1}$ but not without yeast extract.

The generation time of the strains when grown in BMY with $20 \mathrm{mM}$ glucose at $37{ }^{\circ} \mathrm{C}$ and $\mathrm{pH} 7.2$ was $5.3 \mathrm{~h}$ for Am4 and $7.0 \mathrm{~h}$ for G10.

Fermentation products and carbon balances were determined for both strains growing on BMY with $20 \mathrm{mM}$ glucose.

The glucose fermentation stoichiometry of strain Am4 was:

1 glucose $+0.7 \mathrm{CO}_{2} \rightarrow 0.7$ succinate +0.7 lactate +0.3 acetate +0.2 formate

For strain G10 the stoichiometry was:

1 glucose $+0.7 \mathrm{CO}_{2} \rightarrow 0.7$ succinate +0.7 lactate +0.2 acetate +0.2 formate

No $\mathrm{H}_{2}$ gas was detected. The redox balance was used to calculate the $\mathrm{CO}_{2}$. The calculated carbon recoveries, without biomass, were $85 \%$ and $82 \%$ for strain Am4 and strain G10, respectively. Oxygen-tolerance of strain Am4, G10 and Actinomyces ruminicola $\mathrm{JCM} 13352^{\mathrm{T}}$ was determined by growing them in BMY with $20 \mathrm{mM}$ glucose without reducing agent. Sterile oxygen was injected in the head space to provide $20 \%$ of oxygen. Two percent of each active inoculum was added and incubated at $37^{\circ} \mathrm{C}$. Growth was monitored using turbidity $\left(\mathrm{OD}_{600}\right)$ measurements. All three strains grew well in the medium, indicating that Am4, G10, and Actinomyces ruminicola $\mathrm{JCM} 13352^{\mathrm{T}}$ can be termed oxygen-tolerant, as they could grow with $\geq 5 \%$ oxygen as described by Tally et al. (Tally et al., 1975).

As strain G10 was described to be glycerol tolerant (Vandžurová et al., 2013), this characteristic was tested for both strains and Actinomyces ruminicola JCM $13352^{\mathrm{T}}$. All strains were grown in BMY with $20 \mathrm{mM}$ glucose at $37{ }^{\circ} \mathrm{C}$ for 30 days in the presence of various concentrations 
of glycerol $(0,5,7.5,12.5,25$ and $50(\%$ w/v $))$ and triplicate bottles were tested. Growth was measured by increase in turbidity at $600 \mathrm{~nm}$. Actinomyces ruminicola $\mathrm{JCM} 13352^{\mathrm{T}}$ could grow in the presence of up to $12.5 \%$ glycerol. Strain Am4 and G10 could grow in the presence of glycerol up to $25 \%$, but not at $50 \%$. Strain G10 could grow in the presence up to $25 \%$ glycerol after 14 days and was slower than strain Am4 (growth was observed within 7 days). Only succinate and lactate were formed when glycerol was present. Glycerol tolerance was recently reviewed by Sharma (Sharma, 2014), describing that Actinomycetes have the capability to live in oily environments, typical high in glycerol. This feature is an advantage when using these two strains to produce organic acids at high glycerol concentrations.

Physiological and biochemical characteristics of strain Am4 and G10 were determined and compared with closely related Actinomyces: A. ruminicola JCM $13352^{\mathrm{T}}$, A. oricola $\mathrm{CCUG}$ $46090^{\mathrm{T}}$, A. massisliensis CCUG $53522^{\mathrm{T}}$ and A. dentalis CCUG $48064^{\mathrm{T}}$. All cultures were grown in BMY with $20 \mathrm{mM}$ glucose at $37{ }^{\circ} \mathrm{C}$ for $24 \mathrm{~h}$ before testing with commercial API identification (test kits) systems (bioMérieux, France). Carbon assimilation and acid production from different carbohydrates were examined using API 50 CHB and API 20A kits. Enzyme activities were assayed using API ZYM and API Rapid ID 32A kits. All tests were performed in duplicate following the manufacturer's instruction. Selected results that differentiate the strains are shown in Table 1. Additionally, D-arabinose, D-arabitol, cellobiose, D-glucose, D-mannose, D-mannitol, 2-methyl glucopyranoside, potassium gluconate, D-ribose, D-sorbitol, sodium pyruvate, amylopectin, cellulose, inulin, pectin, soluble starch and xylan were tested under growing conditions in liquid cultures with BMY medium to confirm the results from API test kits. 
Table 1. Selected characteristics that differentiate strain Am4 and strain G10 from Actinomyces ruminicola $\mathrm{JCM} 13352^{\mathrm{T}}$, A. oricola CCUG $46090^{\mathrm{T}}$, A. massiliensis CCUG $53522^{\mathrm{T}}$ and $A$. dentalis CCUG $48064^{\mathrm{T}}$

\begin{tabular}{|c|c|c|c|c|c|c|}
\hline Characteristic & $\begin{array}{c}\text { Strain } \\
\text { Am4 }\end{array}$ & Strain G10 & $\begin{array}{l}\text { A. } \\
\text { ruminicola }\end{array}$ & A. oricola & A. massiliensis & A. dentalis \\
\hline Origin & $\begin{array}{l}\text { Cow } \\
\text { rumen }\end{array}$ & $\begin{array}{l}\text { Sheep } \\
\text { rumen }{ }^{\mathrm{a}} \uparrow\end{array}$ & $\begin{array}{c}\text { Cattle } \\
\text { rumen }^{\mathrm{b}} \uparrow\end{array}$ & $\begin{array}{l}\text { Human } \\
\text { teeth }^{\mathrm{c}} \uparrow\end{array}$ & Human blood $\mathrm{d}_{\uparrow}$ & $\begin{array}{c}\text { Human } \\
\text { dental } \\
\text { abscess }+\end{array}$ \\
\hline Gram reaction & + & $++^{\mathrm{a}} \uparrow$ & $t^{b_{\dagger}}+$ & $++^{\mathrm{c}} \dagger$ & $+{ }^{\mathrm{d}} \uparrow$ & $+{ }^{\mathrm{e}}+$ \\
\hline Cell size $(\mu \mathrm{m})$ & $\begin{array}{l}0.2-0.5 \mathrm{x} \\
0.9-2.8\end{array}$ & $\begin{array}{c}0.4-0.6 \mathrm{x} \\
1.5-7.0\end{array}$ & $\begin{array}{l}0.5-1.0 \mathrm{x} \\
2.5-4.0^{\mathrm{b}}+\end{array}$ & NR & $\begin{array}{c}0.35-0.74 \times 0.5- \\
1.7^{\mathrm{d}}+\end{array}$ & NR \\
\hline $\begin{array}{l}\text { Temperature range/ } \\
\text { Optimum }\left({ }^{\circ} \mathrm{C}\right)\end{array}$ & $25-45 / 37$ & $25-45 / 30$ & $20-55 / 46^{\mathrm{b}} \dagger$ & NR & $25-50 / 37^{\mathrm{d}} \uparrow$ & NR \\
\hline $\mathrm{pH}$ range/ Optimum & $5.5-8.5 / 7.5$ & $5.5-8.5 / 7.5$ & $\begin{array}{l}6.5-9.0 / 8.0- \\
8.5^{\mathrm{b}}+\end{array}$ & $\mathrm{NR} / \mathrm{NR}$ & $\mathrm{NR} / \mathrm{NR}$ & NR/NR \\
\hline $\mathrm{G}+\mathrm{C}$ content $(\%)$ & 69.8 & 68.5 & $68.06^{\mathrm{b}} \uparrow$ & NR & NR & $62^{\mathrm{e}} \uparrow$ \\
\hline $\begin{array}{l}\text { Fermentation products from } \\
\text { glucose }^{\#)}\end{array}$ & $\mathrm{S}, \mathrm{L}, \mathrm{a}, \mathrm{f}$ & $\mathrm{S}, \mathrm{L}, \mathrm{f}, \mathrm{a}$ & $\mathrm{S}, \mathrm{l}, \mathrm{a}, \mathrm{f}$ & $\mathrm{s}, \mathrm{L}, \mathrm{f}$ & $\mathrm{s}, \mathrm{L}, \mathrm{a}, \mathrm{f}$ & $\mathrm{L}$ \\
\hline Nitrate reduction & + & - & + & + & + & - \\
\hline Urease & - & - & + & - & - & - \\
\hline $\begin{array}{c}\text { Growth in present of } 25 \% \\
\text { glycerol }\end{array}$ & + & $\mathrm{W}+$ & - & ND & ND & ND \\
\hline \multicolumn{7}{|c|}{ Assimilation of substrates: } \\
\hline Myo-Inositol & + & - & + & ND & ND & ND \\
\hline D-Mannitol & + & $\mathrm{W}+$ & - & - & + & - \\
\hline $\begin{array}{c}\text { Methyl-BD- } \\
\text { xylopyranoside }\end{array}$ & - & + & + & - & - & - \\
\hline $\begin{array}{l}\text { Methyl- } \alpha \mathrm{D}- \\
\text { glucopyranoside }\end{array}$ & - & + & + & ND & ND & ND \\
\hline Potassium gluconate & + & - & - & - & - & - \\
\hline $\begin{array}{l}\text { Potassium 5- } \\
\text { ketogluconate }\end{array}$ & + & - & - & - & + & - \\
\hline D-Raffinose & + & + & + & - & + & + \\
\hline D-Sorbitol & + & $\mathrm{W}+$ & - & - & + & - \\
\hline \multicolumn{7}{|c|}{ Enzyme activities: } \\
\hline Esterase (C4) & - & - & + & + & + & - \\
\hline Esterase lipase (C8) & - & - & + & + & + & - \\
\hline Lipase $(\mathrm{C} 14)$ & - & - & + & + & - & - \\
\hline Valine arylamidase & - & - & + & + & - & - \\
\hline B-Galactosidase & + & + & + & - & + & + \\
\hline$\alpha$-Glucosidase & - & + & - & + & + & + \\
\hline ß-Glucuronidase & + & + & $\mathrm{W}+$ & - & - & - \\
\hline
\end{tabular}

All data were obtained in this study except $\dagger$ ) taken from; a, (Vandzurová et al., 2013); b, (An et al., 2006); c, (Hall et al., 2003);

d, (Renvoise et al., 2009); e, (Hall et al., 2005).

+, positive; -, negative; $\mathrm{W}+$, weakly positive; ND, not determined; NR, not reported

\#) S, Succinate; L, Lactate; A, Acetate; F, Formate (small letter indicates minor amount) 
Strain G10 and strain Am4 converted a wide range of substrates including starch waste, obtained from a potato factory (Aviko-Rixona, Warffum, Groningen, the Netherlands), to mainly succinate and lactate and small amounts of acetate and formate. Both strains could grow on $20 \mathrm{mM}$ D-arabinose, $20 \mathrm{mM}$ D-arabitol, $20 \mathrm{mM}$ myo-inositol, $20 \mathrm{mM}$ D-mannitol, $20 \mathrm{mM}$ Dsorbitol, and $20 \mathrm{mM}$ D-ribose as well as amylopectin, soluble starch, pectin, inulin, and xylan. The organic acids produced differed depending on the substrates (Table S5) Strain Am4 could use potassium gluconate but could not use methyl- $\alpha$-D-glucopyranoside, whereas the strain G10 could utilize methyl- $\alpha$-D-glucopyranoside, but not potassium gluconate.

Based on the biochemical, physiological, chemotaxonomic, and phylogenetic characteristics (Table 1 and Table S1), strain Am4 and G10 can be distinguished from each other and other members of the genus Actinomyces. We propose strain Am4 and G10 as novel species in the genus Actinomyces, family Actinomycetaceae and order Actinomycetales and the name Actinomyces succiniciruminis and Actinomyces glycerinitolerans are proposed, respectively.

\section{Description of Actinomyces succiniciruminis sp. nov.}

Actinomyces succiniciruminis [suc.ci.ni.ci.ru'mi.nis. N.L. n. acidum succinicum, succinic acid; L. gen. n. ruminis, of the rumen; N.L. n. succiniciruminis originating from the rumen and producing succinic acid].

Cells are $0.2-0.5 \mu \mathrm{m}$ in diameter and $0.9-2.8 \mu \mathrm{m}$ long with pleomorphic forms: rod, branch, or irregularly shaped with sometimes showing swollen ends (Fig. 3A). Colonies on RCM agar medium are white, circular, smooth, and have convex margins with $0.1-0.2 \mathrm{~mm}$ in diameter after $72 \mathrm{~h}$ of growth. The strain is Gram positive, non-motile, non-spore-forming and catalase and oxidase negative. Strain Am4 can grow between $25-45^{\circ} \mathrm{C}$ (optimum at $37^{\circ} \mathrm{C}$ ) and $\mathrm{pH} 5.5-8.5$ (optimum at 7.5 ). The generation time of this strain when grown in $\mathrm{BMY}$ at $37^{\circ} \mathrm{C}$ and $\mathrm{pH} 7.2$ is $5.3 \mathrm{~h}$. The strain requires yeast extract 
$\left(0.1 \mathrm{~g} \mathrm{l}^{-1}\right)$ for growth. Strain Am4 is an oxygen-tolerant anaerobic bacterium, which can grow in the presence of oxygen up to $20 \%$.

Strain Am4 produced organic acids from amylopectin, D-arabinose, D-arabitol, Dcellobiose, D-glucose, myo-inositol, inulin, D-mannitol, D-mannose, pectin, potassium gluconate, Dribose, soluble starch, D-sorbitol, and xylan but could not use crystal cellulose, methyl- $\alpha$ Dglucopyranoside, sodium acetate and sodium pyruvate as substrates in anaerobic bottles (Table S5). Moreover, in the API $50 \mathrm{CHB}$ test kit, it could also use $\mathrm{N}$-acetyl glucosamine, amygdalin, Larabinose, arbutin, D-fructose, esculin, D-galactose, gentiobiose, glycogen, D-lactose, D-lyxose, Dmelibiose, D-maltose, D-melezitose, $\quad$ potassium 5-ketogluconate, D-raffinose, L-rhamnose, Dsaccharose, salicin, D-tagatose, D-treharose, D-turanose, xylitol, and D-xylose (Table S6). The esculin hydrolysis and nitrate reductase tests were positive. Enzyme activities in the API ZYM tests, strain (Am4) tested positive for $\beta$-glucosidase and leucine arylamidase and weak positive for, $\beta$ galactosidase, $\beta$-glucuronidase, and napthol-AS-BI-phosphohydrolase (Table S7). The DNA G + C of the type strain is $69.8 \mathrm{~mol} \%$.

The type strain, $\mathrm{Am} 4^{\mathrm{T}}\left(=\mathrm{TISTR} 2317^{\mathrm{T}}=\mathrm{DSM}=10376^{\mathrm{T}}\right)$ was isolated from the rumen of a Holstein-Friesian cow in the Netherlands.

\section{Description of Actinomyces glycerinitolerans sp. nov.}

Actinomyces glycerinitolerans [gly.cer.in.i.to'le.rans. N.L. n. glycerinum, glycerol; L. part. adj. tolerans, enduring, tolerating; N.L. part. adj. glycerinitolerans glycerol tolerating].

Cells are $0.4-0.6 \mu \mathrm{m}$ in diameter and 1.5-7 $\mu \mathrm{m}$ long with pleomorphic forms: rod, branch, irregularly shaped with sometimes swollen ends (Fig. 3B). Colonies on RCM agar medium are white, circular, smooth, and have convex margins with $0.1-0.2 \mathrm{~mm}$ in diameter after $72 \mathrm{~h}$ of growth. 
The strain is Gram positive, non-motile, non-spore-forming and catalase and oxidase negative. Strain G10 can grow between $25-45^{\circ} \mathrm{C}$ (optimum at $30^{\circ} \mathrm{C}$ ), and $\mathrm{pH} 5.5-8.5$ (optimum at 7.5). The generation time of this strain when grown in $\mathrm{BMY}$ at $37^{\circ} \mathrm{C}$ and $\mathrm{pH} 7.2$ was $7.0 \mathrm{~h}$. The strain requires yeast extract $\left(0.1 \mathrm{~g} \mathrm{l}^{-1}\right)$ for growth. Strain G10 is an oxygen-tolerant anaerobic bacterium, which can grow in the presence of oxygen up to $20 \%$.

Strain G10 could produce organic acids from amylopectin, D-arabinose, D-arabitol, Dcellobiose, D-glucose, inulin, D-mannose, methyl- $\alpha$ D-glucopyranoside, D-mannitol, pectin, Dribose, soluble starch, D-sorbitol, and xylan but could not use crystal cellulose, myo-inositol, potassium gluconate, sodium acetate and sodium pyruvate as substrates in anaerobic bottles (Table S5). Moreover, it could also utilize amygdalin, L-arabinose, arbutin, D-fructose, esculin, Dgalactose, gentiobiose, glycogen, D-lactose, D-lyxose, D-melibiose, D-maltose, D-melezitose, methyl- $\beta \mathrm{D}$-xylopyranoside, D-raffinose, L-rhamnose, D-saccharose, $\quad$ salicin, D-tagatose, Dtreharose, D-turanose, xylitol, and D-xylose in the API 50 CHB test kit (Table S6). The result of esculin hydrolysis was positive, but nitrate reductase was negative. Enzyme activities from API ZYM tests, the strain (G10) tested positive for $\beta$-galactosidase, $\alpha$-glucosidase, $\beta$-glucosidase, $\beta$ glucuronidase, leucine arylamidase, and napthol-AS-BI-phosphohydrolase, (Table S7). The DNA $\mathrm{G}+\mathrm{C}$ of the type strain is $68.5 \mathrm{~mol} \%$.

The type strain, G10 $\left(=\right.$ TISTR $\left.2318^{\mathrm{T}}=\mathrm{DSM}=10377^{\mathrm{T}}\right)$ was isolated from the rumen of sheep (Slovenské merino breed) in Slovak Republic (Vandžurová et al., 2013).

Strain Am4 was isolated from Holstein cow rumen at Carus houses; part of Department of Animal Sciences and Agro technology and Food Sciences Group, Wageningen University, the Netherlands, whereas the strain G10 was isolated from sheep (Slovenskè merino breed) rumen fluid (Vandžurová et al., 2013). Interestingly, both of them produce succinate from starch waste and can hydrolyze many complex substrates such as inulin, pectin, xylan, and starch. Succinic acid is 
one of the important organic acids used as a building block in the chemical industry that can generate standard substances such as butanediol, tetrahydrofuran, and g-butyrolactone as well as biodegradable aliphatic polyester bionolle (Saucer et al., 2008). Moreover, these novel strains are rather robust as they tolerate up to $20 \%$ of $\mathrm{O}_{2}$ and high level of glycerol (up to $25 \% \mathrm{w} / \mathrm{v}$ ). For that reason, stain Am4 and strain G10 are potential candidates in biotechnological process that convert waste to product such as succinic acid, which in the future partially can replace the use of fossil fuels.

\section{Acknowledgements}

The authors thank Prof. Xiuzhu Dong (Chinese Academy of Sciences, Beijing, China) for kindly providing Actinomyces ruminicola JCM $13352^{\mathrm{T}}$, Prof. W.M. de Vos for stimulating discussion, Bastian Hornung and Nikolaos Strepis for genome assembly and annotation, and A.H. van Gelder for technical support. Research of the first author was supported by a Royal Thai Government Scholarship, Thailand and the research of A.J.M. Stams is supported by ERC grant (project 323009) and Gravitation grant (project 024.002.002) of the Netherlands Ministry of Education, Culture and Science and the Netherlands Science Foundation (NWO). 


\section{Supplementary data}

Table S1: Characteristic comparison between Actinomyces strain Am4 and G10 (data from genomes in bold)

\begin{tabular}{|c|c|c|}
\hline Characteristics & $\begin{array}{c}\text { Actinomyces strain } \\
\text { Am4 }\end{array}$ & $\begin{array}{c}\text { Actinomyces strain } \\
\text { G10 }\end{array}$ \\
\hline Origin & Cow & Sheep \\
\hline Country & The Netherlands & Slovakia \\
\hline Cell size & $0.2-0.5$ by $0.9-2.8 \mu \mathrm{m}$ & $0.4-0.6$ by $1.5-7 \mu \mathrm{m}$ \\
\hline $\mathrm{G}+\mathrm{C}$ content $(\mathrm{DSMZ})$ & $69.8 \%$ & $68.5 \%$ \\
\hline G+C content (JSpecies) & $68 \%$ & $67 \%$ \\
\hline DDH (wet-lab: DSMZ) & \multicolumn{2}{|c|}{$69.9 \%$} \\
\hline dDDH (GGDC 2.1) (GLM-based) & \multicolumn{2}{|c|}{$\mathbf{6 8 . 6 \%}(65.6$ and reciprocal 71.4) } \\
\hline Genome size (bp.) & $3,336,700$ & $3,695,248$ \\
\hline (\%genome coverage) & $99.9 \%$ & $100 \%$ \\
\hline $\begin{array}{l}\text { Genome function analysis; genes present } \\
\text { in one genome but not in the other }\end{array}$ & 46 & 63 \\
\hline Ortho ANI (OAT version 0.93 ) & \multicolumn{2}{|c|}{$96.4 \%$} \\
\hline average ANIb with TETRA (JSpecies) & \multicolumn{2}{|c|}{ 96.26\% (96.19-96.32) with Tetra 0.99892} \\
\hline average ANIm (JSpecies) & \multicolumn{2}{|c|}{$96.6(96.6-96.6)$} \\
\hline average gANI (Threshold; 96.5\%) & \multicolumn{2}{|c|}{$\mathbf{9 2 . 9 \%}(89.7,96.9)$} \\
\hline AAI (Two-way; Kostas lab) & \multicolumn{2}{|c|}{$\mathbf{9 5 . 8 \%}$ (SD: $8.99 \%$ ), from 2249 proteins } \\
\hline Presence of quinone & $\mathrm{MK}-9\left(\mathrm{H}_{4}\right)$ & -4 \\
\hline Quinone cofactors & + & - \\
\hline $\begin{array}{l}\text { The CRISPR/Cas system } \\
\text { (CRISPR-Cas1, Cas2 and Cas3) }\end{array}$ & - & + \\
\hline Phages, Prophages & + & - \\
\hline MALDI-TOF analysis of protein profiles & Simple pattern & Complex pattern \\
\hline Distance level from MALDI-TOF MS & \multicolumn{2}{|l|}{$>250$} \\
\hline Optimal temperature (range) & $37^{\circ} \mathrm{C}\left(25-45^{\circ} \mathrm{C}\right)$ & $30^{\circ} \mathrm{C}\left(25-45^{\circ} \mathrm{C}\right)$ \\
\hline Nitrate reductase (nitrate to nitrite) & + & - \\
\hline $\begin{array}{l}\text { Nitrate reductase cluster genes } \\
\text { (NarG, NarH, NarJ, and NarI) }\end{array}$ & + & - \\
\hline Arylsulfatase and sialidase genes & - & + \\
\hline Growth in presence of $25 \%$ glycerol & + & Weak \\
\hline Myo-Inositol fermentation & + & - \\
\hline Inositol catabolism genes & + & - \\
\hline Methyl- $\alpha \mathrm{D}$-glucopyranoside fermentation & - & + \\
\hline Methyl-ßD-xylopyranoside fermentation & - & + \\
\hline Potassium gluconate fermentation & + & - \\
\hline Potassium 5- ketogluconate fermentation & + & - \\
\hline$\alpha$-Glucosidase & - & + \\
\hline
\end{tabular}

+ , positive; -, negative 
Table S2. Blastn and blastp of 10 housekeeping genes from Actinomyces strain Am4 and G10 (Genes that differed between Am4 and G10 in Bold)

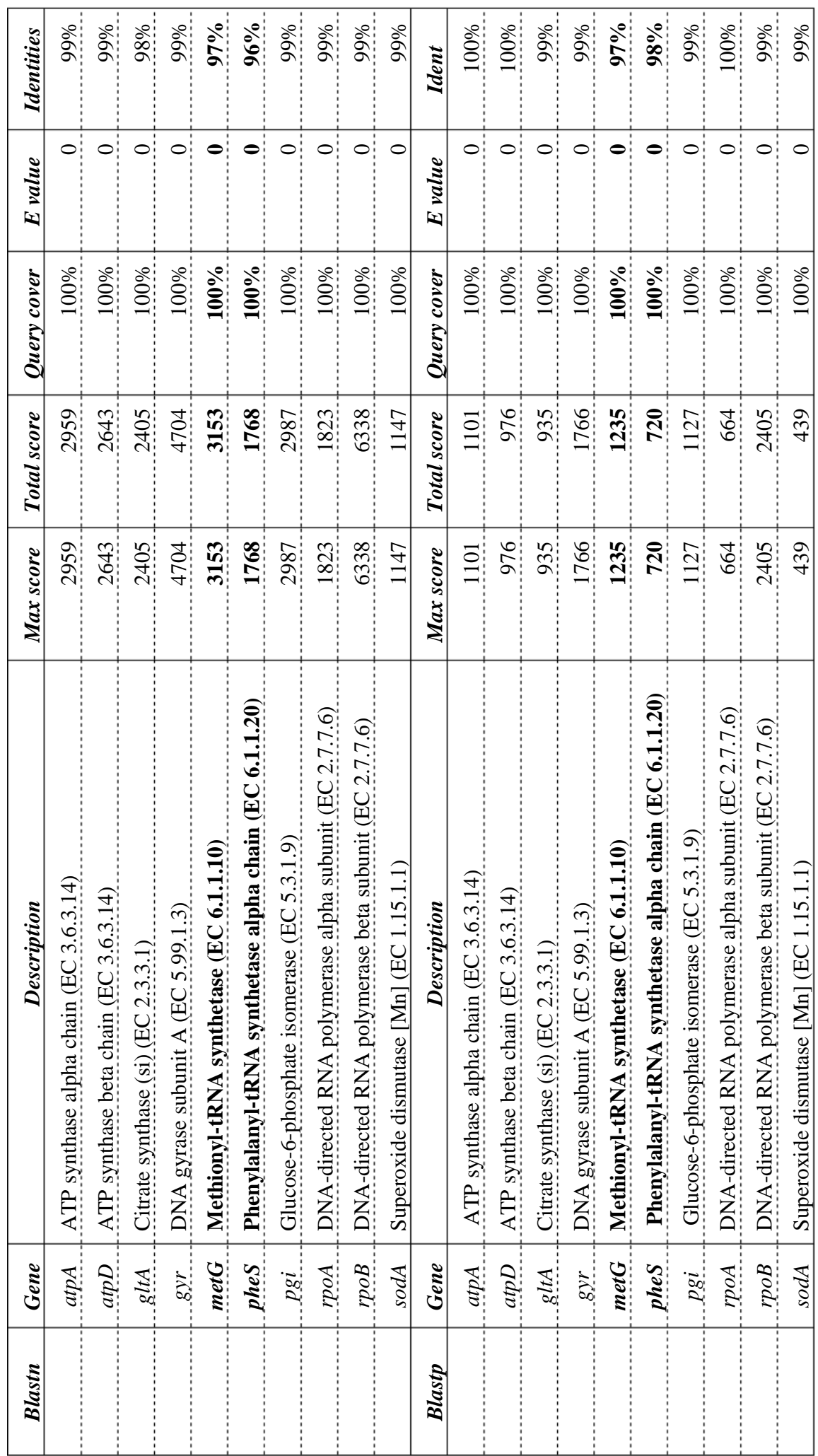


Table S3. Cellular fatty acid composition of strain Am4, strain G10 and Actinomyces ruminicola JCM $13352^{\mathrm{T}}$. Values are percentages of total fatty acids. Fatty acids present at less than $0.5 \%$ in all strains are not shown. Major fatty acids (>5\%) are in bold. FAME, fatty acid methyl ester; DMA, dimethyl acetal; ALDE, aldehyde

\begin{tabular}{lccc}
\hline Cellular fatty acids (\%) & Strain Am4 & Strain G10 & A. ruminicola \\
\hline Saturated acids & & & \\
C $_{10: 0}$ FAME & 1.28 & 2.89 & 1.93 \\
C $_{\mathbf{1 2 : 0}}$ FAME & 3.32 & 4.79 & $\mathbf{6 . 7 1}$ \\
C $_{14: 0}$ FAME & 3.35 & 4.43 & 3.45 \\
C $_{16: 0}$ FAME & $\mathbf{4 0 . 0 6}$ & $\mathbf{3 8 . 0 2}$ & $\mathbf{3 4 . 6}$ \\
$\mathrm{C}_{16: 0}$ DMA & 0.59 & 0.61 & 0.79 \\
$\mathrm{C}_{18: 0}$ FAME & 1.7 & 1.27 & 1.6 \\
$\mathrm{C}_{18: 0}$ DMA & 0.58 & 0.45 & 0.62 \\
Unsaturated acids & & & \\
$\mathrm{C}_{16: 1}$ CIS 7 FAME & 3.02 & 3.68 & 3.78 \\
C $_{\mathbf{1 8 : 1}}$ CIS 9 FAME & $\mathbf{3 1 . 2}$ & $\mathbf{3 3 . 5 3}$ & $\mathbf{3 7 . 9 7}$ \\
C $_{\mathbf{1 8 : 1}}$ CIS 9 DMA & $\mathbf{8 . 4 9}$ & $\mathbf{6 . 9 9}$ & $\mathbf{6 . 3}$ \\
$\mathrm{C}_{19}$ CYC 9,10/:1 FAME & 1.82 & 0.48 & - \\
$\mathrm{C}_{19}$ CYC 9,10/ DMA & 0.92 & 0.29 & - \\
Summed feature* & & & \\
7 & 2.12 & 1.63 & 1.57 \\
\hline
\end{tabular}

*Summed feature refers to chromatographic peaks of fatty acids groups that were not separated. Summed feature 7 contained $\mathrm{C}_{17: 2}$ FAME@ $16.760 / \mathrm{C}_{17: 1}$ CIS 8 FAME

Table S4. Respiratory quinones of strain Am4, strain G10, and Actinomyces ruminicola JCM $13352^{\mathrm{T}}$

\begin{tabular}{lcccccc}
\hline \multirow{2}{*}{ Strain } & \multicolumn{5}{c}{ Respiratory quinones (\%) } \\
\cline { 2 - 6 } & MK-9 & MK-10 & MK-9(H4) & MK-10(H4) & MK-10(H) & MK-10(H8) \\
\hline Strain Am4 & - & - & 6 & 82 & 2 & 2 \\
Strain G10 & - & - & - & 91 & 2 & 4 \\
A. ruminicola & $70^{*}$ & $30^{*}$ & - & - & - & - \\
\hline
\end{tabular}

*Data obtained from An et al., 2006 
Table S5. Organic acid production of strain Am4, strain G10 and Actinomyces ruminicola JCM $13352^{\mathrm{T}}$ from different substrates.

\begin{tabular}{llll}
\hline Characteristic / Strain & Strain Am4 & Strain G10 & A. ruminicola \\
\hline Amylopectin & $\mathrm{S}, \mathrm{l}, \mathrm{a}, \mathrm{f}$ & $\mathrm{S}, \mathrm{l}, \mathrm{a}, \mathrm{f}$ & $\mathrm{ND}$ \\
D-Arabinose & $\mathrm{S}, \mathrm{a}, \mathrm{f}$ & $\mathrm{S}, \mathrm{l}, \mathrm{a}, \mathrm{f}$ & $\mathrm{ND}$ \\
D-Arabitol & $\mathrm{S}, \mathrm{l}, \mathrm{a}, \mathrm{f}$ & $\mathrm{S}, \mathrm{l}, \mathrm{a}, \mathrm{f}$ & $\mathrm{A}$ \\
D-Cellubiose & $\mathrm{S}, \mathrm{L}, \mathrm{A}, \mathrm{f}$ & $\mathrm{S}, \mathrm{l}, \mathrm{a}, \mathrm{f}$ & $\mathrm{ND}$ \\
Cellulose & - & - & $\mathrm{ND}$ \\
D-Glucose & $\mathrm{S}, \mathrm{L}, \mathrm{a}, \mathrm{f}$ & $\mathrm{S}, \mathrm{L}, \mathrm{a}, \mathrm{f}$ & $\mathrm{S}, \mathrm{l}, \mathrm{a}, \mathrm{f}$ \\
Myo-inositol & $\mathrm{S}, \mathrm{a}, \mathrm{f}$ & - & $\mathrm{S}, \mathrm{a}$ \\
Inulin & $\mathrm{s}, \mathrm{l}, \mathrm{a}, \mathrm{f}$ & $\mathrm{S}, \mathrm{L}, \mathrm{a}, \mathrm{f}$ & $\mathrm{S}, \mathrm{l}, \mathrm{a}, \mathrm{f}$ \\
D-Mannitol & $\mathrm{S}, \mathrm{l}, \mathrm{a}, \mathrm{f}$ & $\mathrm{s}, \mathrm{a}$ & $\mathrm{S}, \mathrm{a}, \mathrm{l}$ \\
D-Mannose & $\mathrm{S}, \mathrm{L}, \mathrm{a}, \mathrm{f}$ & $\mathrm{S}, \mathrm{L}, \mathrm{a}, \mathrm{f}$ & $\mathrm{ND}$ \\
Methyl- $\alpha \mathrm{D}-$ & & & \\
glucopyranoside & - & $\mathrm{s}, \mathrm{l}, \mathrm{a}$ & $\mathrm{S}$ \\
Pectin & $\mathrm{s}, \mathrm{a}, \mathrm{f}$ & $\mathrm{s}, \mathrm{a}, \mathrm{f}$ & $\mathrm{ND}$ \\
Potassium gluconate & $\mathrm{S}, \mathrm{a}, \mathrm{f}$ & - & $\mathrm{S}$ \\
D-Ribose & $\mathrm{S}, \mathrm{a}, \mathrm{f}$ & $\mathrm{S}, \mathrm{a}, \mathrm{f}$ & $\mathrm{ND}$ \\
Sodium Acetate & - & - & $\mathrm{ND}$ \\
Sodium pyruvate & - & - & - \\
D-Sorbitol & $\mathrm{S}, \mathrm{l}, \mathrm{a}, \mathrm{f}$ & $\mathrm{s}, \mathrm{a}$ & $\mathrm{ND}$ \\
Soluble starch & $\mathrm{S}, \mathrm{l}, \mathrm{a}, \mathrm{f}$ & $\mathrm{S}, \mathrm{l}, \mathrm{a}, \mathrm{f}$ & $\mathrm{ND}$ \\
Starch waste & $\mathrm{S}, \mathrm{l}, \mathrm{a}, \mathrm{f}$ & $\mathrm{S}, 1, \mathrm{a}, \mathrm{f}$ & $\mathrm{ND}$ \\
Xylan & $\mathrm{S}, \mathrm{a}, \mathrm{f}$ & $\mathrm{S}, \mathrm{A}, \mathrm{f}$ & $\mathrm{ND}$ \\
& & & \\
\hline
\end{tabular}

All data were obtained in this study in duplication

+ , positive; -, negative; $\mathrm{W}+$, weakly positive; $\mathrm{ND}$, not determined

S; Succinate, L; Lactate, A; Acetate, F; Formate (small letter indicates minor amount of product) 
Table S6. Characteristics of strain Am4, strain G10, and related strains in the genus Actinomyces: A. ruminicola JCM $13352^{\mathrm{T}}$, A. oricola CCUG $46090^{\mathrm{T}}$, A. massiliensis CCUG $53522^{\mathrm{T}}$ and A. dentalis CCUG $48064^{\mathrm{T}}$

\begin{tabular}{|c|c|c|c|c|c|c|}
\hline Characteristic / Strain & Strain Am4 & Strain G10 & A. ruminicola & A. oricola & A. massiliensis & A. dentalis \\
\hline Catalase & - & $-{ }^{\mathrm{a}}$ & $-\mathrm{b}$ & $-^{c}$ & $-{ }^{d}$ & $-\mathrm{e}$ \\
\hline Nitrate reduction & + & - & + & - & + & - \\
\hline Esculin hydrolysis & + & + & + & + & + & + \\
\hline Starch hydrolysis & + & + & + & - & + & - \\
\hline Urease & - & - & + & - & + & - \\
\hline \multicolumn{7}{|l|}{ Assimilation of substrates: } \\
\hline D-Arabinose & - & - & - & - & W+ & - \\
\hline L-Arabinose & + & + & + & - & $\mathrm{W}+$ & - \\
\hline D-Arabitol & + & + & + & - & $\mathrm{W}+$ & - \\
\hline Amygdalin & + & + & + & + & - & + \\
\hline Arbutin & + & + & + & + & - & + \\
\hline D-Cellobiose & + & + & + & + & + & + \\
\hline D-Fructose & + & + & + & + & + & + \\
\hline D-Galactose & + & + & + & + & + & + \\
\hline D-Glucose & + & + & + & + & + & + \\
\hline Gentiobiose & + & + & + & + & + & + \\
\hline Glycogen & + & + & + & - & $\mathrm{W}+$ & - \\
\hline Inositol & + & - & + & - & + & - \\
\hline Inulin & + & + & + & - & + & - \\
\hline D-Lactose & + & + & + & - & + & - \\
\hline D-Lyxose & + & + & + & - & + & - \\
\hline D-Mannitol & + & $\mathrm{W}+$ & - & - & + & - \\
\hline D-Mannose & + & + & + & + & $\mathrm{W}+$ & + \\
\hline D-Maltose & + & + & + & - & + & + \\
\hline D-Melibiose & + & + & + & - & + & + \\
\hline D-Melezitose & + & + & + & - & + & - \\
\hline Methyl- $\alpha \mathrm{D}$-glucopyranoside & - & + & + & - & - & $\mathrm{W}+$ \\
\hline Methyl-ßD-xylopyranoside & - & + & + & - & - & - \\
\hline $\mathrm{N}$-acetylglucosamine & + & $\mathrm{W}+$ & - & - & - & - \\
\hline Potassium gluconate & + & - & - & - & - & - \\
\hline Potassium 5-ketogluconate & + & - & - & - & + & - \\
\hline D-Raffinose & + & + & + & - & - & + \\
\hline L-Rhamnose & + & + & + & - & W+ & $\mathrm{W}+$ \\
\hline D-Ribose & + & + & + & - & + & + \\
\hline D-saccharose & + & + & + & + & + & + \\
\hline Salicin & + & + & + & + & + & + \\
\hline Sodium pyruvate & - & - & - & ND & ND & ND \\
\hline D-Sorbitol & + & $\mathrm{W}+$ & - & - & + & - \\
\hline D-Tagatose & W+ & $\mathrm{W}+$ & - & - & $\mathrm{W}+$ & - \\
\hline D-Treharose & + & + & + & + & + & + \\
\hline D-Turanose & + & + & + & + & + & + \\
\hline Xylitol & + & + & - & - & - & - \\
\hline D-Xylose & + & + & + & - & + & - \\
\hline
\end{tabular}

All data were obtained in this study in duplicate except the data were taken from: ${ }^{\text {a }}$ (Vandžurová et al., 2013), b (An et al., 2006),

c (Hall et al., 2003), ${ }^{\mathrm{d}}$ (Renvoise et al., 2009), ${ }^{\mathrm{e}}$ (Hall et al., 2005)

+ , positive, -; negative, $\mathrm{W}+$; weakly positive, ND; not determined 
Table S7. Overview of biochemical characteristics and enzyme activities of strain Am4, strain G10 and related type strains in the genus Actinomyces: A. ruminicola JCM $13352^{\mathrm{T}}$, A. oricola CCUG $46090^{\mathrm{T}}, A$. massiliensis CCUG 53522 ${ }^{\mathrm{T}}$ and $A$. dentalis CCUG $48064^{\mathrm{T}}$

\begin{tabular}{|c|c|c|c|c|c|c|}
\hline Characteristic / Strain & $\begin{array}{c}\text { Strain } \\
\text { Am4 }\end{array}$ & $\begin{array}{c}\text { Strain } \\
\text { G10 }\end{array}$ & A. ruminicola & A. oricola & A. massiliensis & A. dentalis \\
\hline \multicolumn{7}{|l|}{ API ZYM: } \\
\hline Esterase $\left(\mathrm{C}_{4}\right)$ & - & - & + & + & + & \\
\hline Esterase Lipase $\left(\mathrm{C}_{8}\right)$ & - & - & + & + & + & - \\
\hline$\alpha$-Galactosidase & - & - & + & + & - & + \\
\hline ß-Galactosidase & + & + & + & + & + & + \\
\hline$\alpha$-Glucosidase & - & + & - & + & + & + \\
\hline B-Glucosidase & + & + & + & + & - & + \\
\hline B-Glucuronidase & $\mathrm{W}+$ & + & $\mathrm{W}+$ & - & - & - \\
\hline Lipase $\left(\mathrm{C}_{14}\right)$ & - & - & + & + & - & - \\
\hline Leucine arylamidase & + & + & + & + & + & + \\
\hline $\begin{array}{l}\text { Napthol-AS-BI- } \\
\text { phosphohydrolase }\end{array}$ & $\mathrm{W}+$ & + & + & + & + & + \\
\hline Valine arylamidase & - & - & + & + & - & - \\
\hline \multicolumn{7}{|l|}{ Rapid API 32A: } \\
\hline $\mathrm{N}$-acetyl-B-glucosaminidase & - & - & - & - & - & - \\
\hline$\alpha$-Arabinosidase & + & + & + & - & - & + \\
\hline Arginine dihydrolase & - & - & + & + & + & - \\
\hline$\alpha$-Galactosidase & - & - & + & + & - & + \\
\hline B-Galactosidase & + & + & + & + & + & + \\
\hline B-Glucosidase & + & + & + & + & - & + \\
\hline B-Glucuronidase & $\mathrm{W}+$ & + & W+ & - & - & - \\
\hline Histamine arylamidase & - & - & - & - & - & + \\
\hline Raffinose fermentation & + & + & + & - & - & + \\
\hline Indole production & - & - & - & - & - & - \\
\hline
\end{tabular}

All data were performed in this study

+ , positive; -, negative; $\mathrm{W}+$, weakly positive 


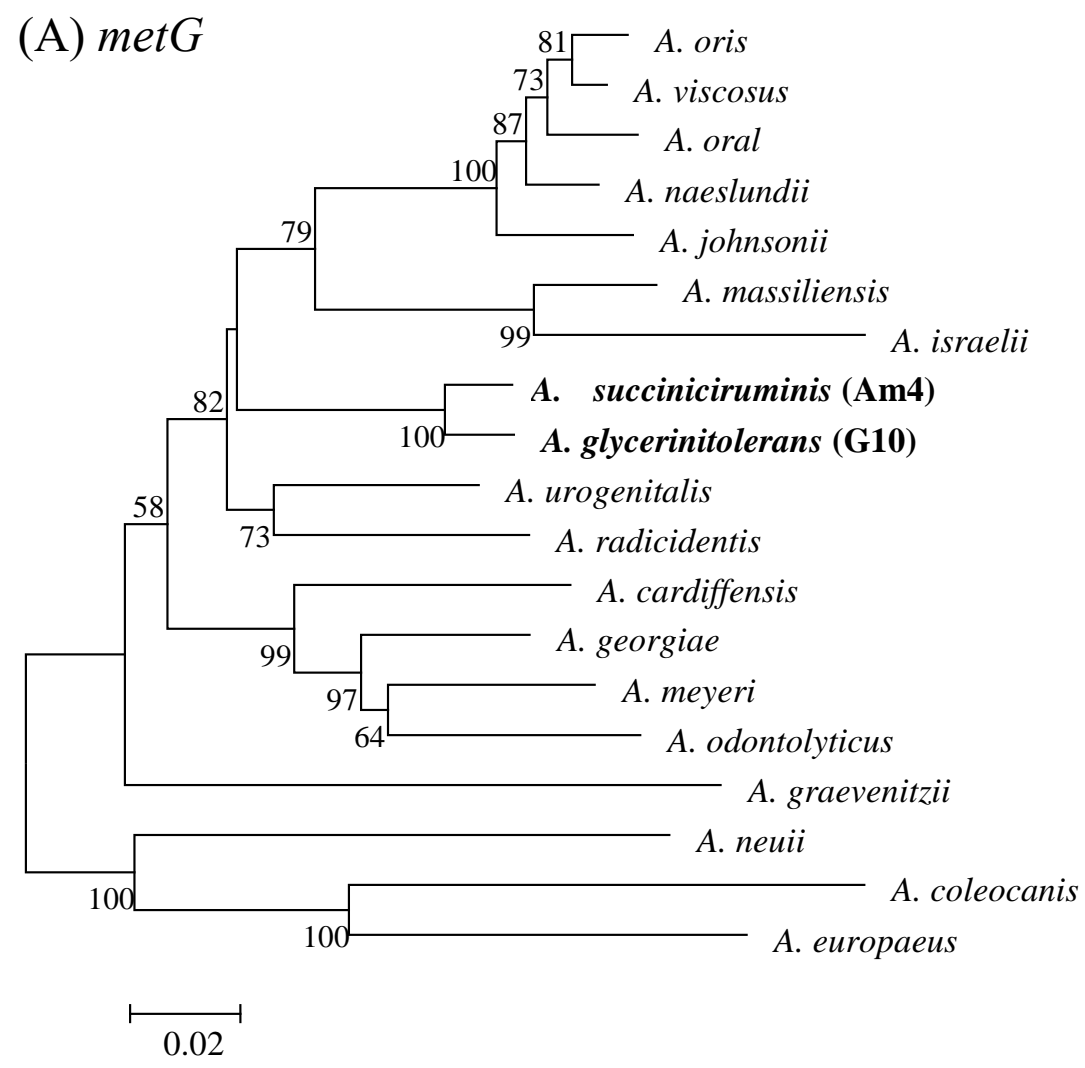

(B) phes

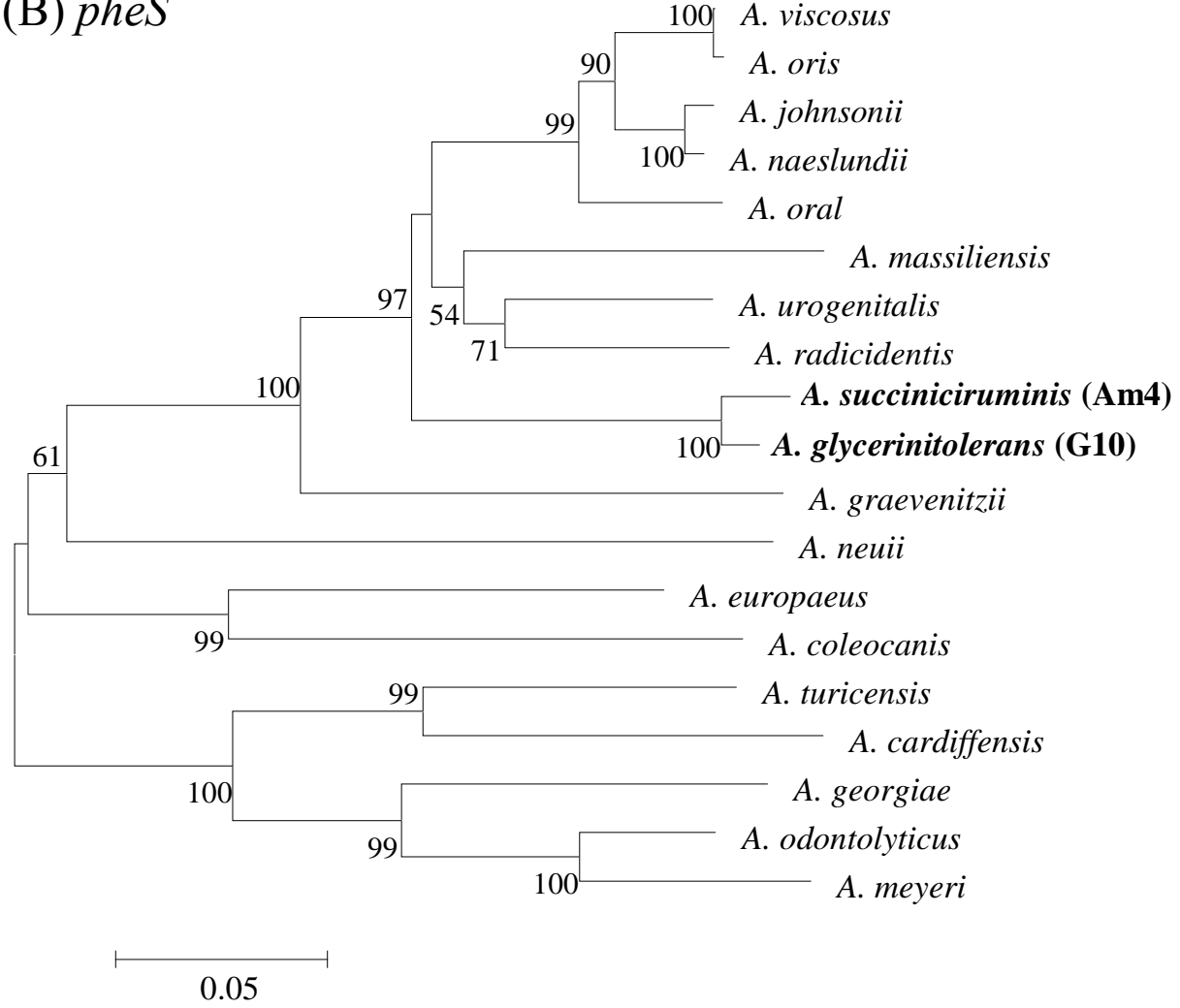

Fig. S1. Neighbour-joining trees, based on $m e t G$ gene sequences (A) and pheS gene sequences (B) showing the phylogeny of strain Am4, strain G10 and 17 other Actinomyces species. Bootstrap values, which were higher than $50 \%$ based on 1000 replications, are shown at the branching points. Bars indicate 2 and 5\% sequence divergence for $m e t G$ gene and $p h e S$ gene, respectively. 

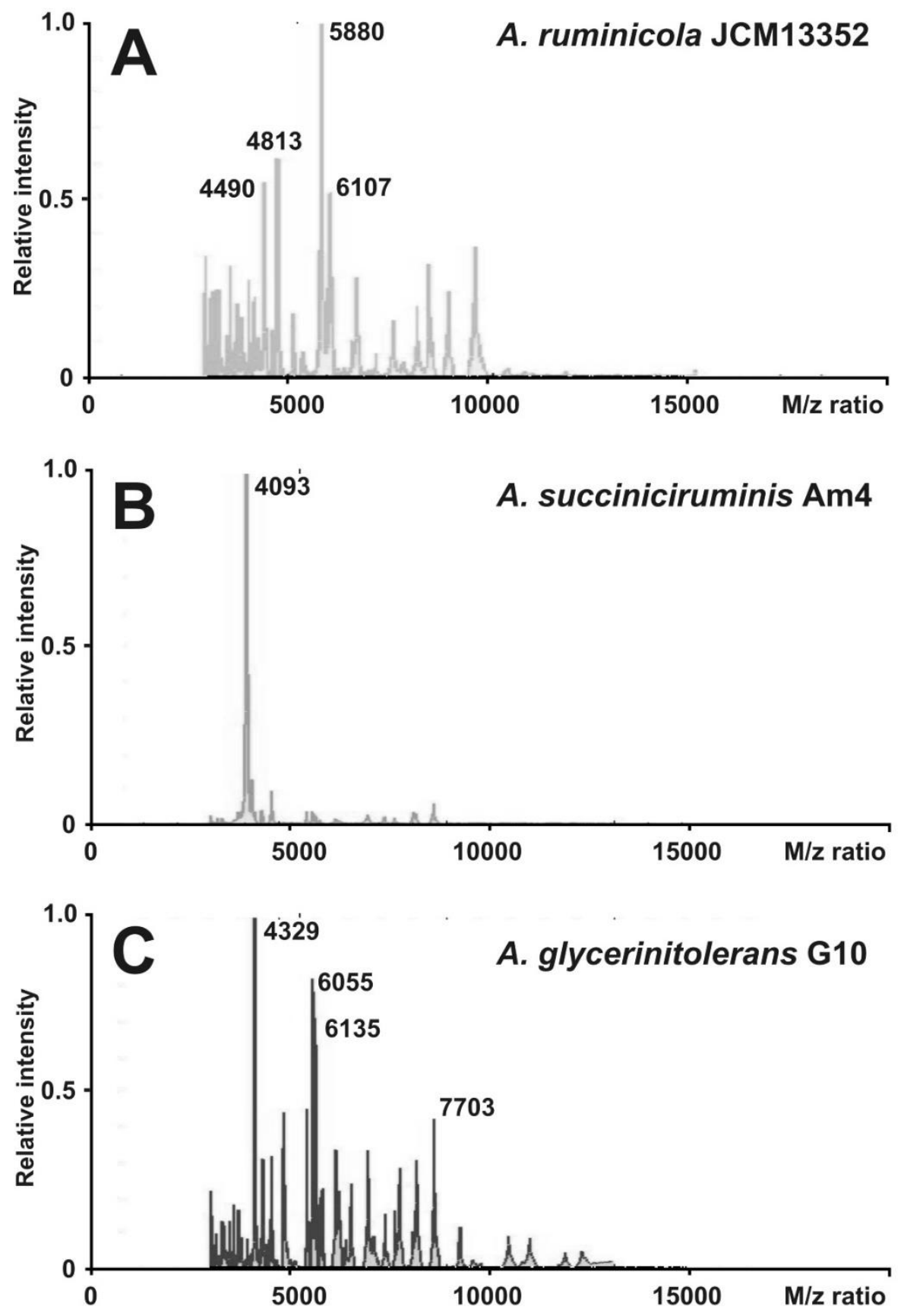

Fig. S2. Normalized MALDI-TOF-MS spectra of Actinomyces ruminicola JCM 13352 ${ }^{\mathrm{T}}$, strain Am4 and strain $\mathrm{G} 10$. The $\mathrm{m} / \mathrm{z}$ ratio of dominant peaks is shown. 


\section{CHAPTER 4}

Optimization of succinate production from potato starch waste by Actinomyces succiniciruminis strain Am4 ${ }^{\mathrm{T}}$

This chapter has been prepared by

Susakul Palakawong Na Ayudthaya, Xiaohan Guo and Caroline M. Plugge 


\section{Abstract}

Actinomyces succiniciruminis is a fast-growing fermentative succinate-producing bacterium that is tolerant to glycerol and oxygen. It can ferment a range of plant mono- and disaccharides, including starch. The optimization of succinate production from starch waste by A. succiniciruminis was studied in batch incubations in bottles and in bioreactors. Addition of phosphate and bicarbonate to the growth medium enhanced succinate production from starch waste. Oxygen, sulfate and nitrate did not affect the succinate yield. Nitrite had a negative effect on the succinate production. The succinate production was highest $(118 \mathrm{mM})$ in batch reactors with $8 \%(\mathrm{w} / \mathrm{v})$ dried starch waste in a mineral salt medium supplemented with $150 \mathrm{mM}$ bicarbonate, $12 \mathrm{mM}$ phosphate buffer, and $0.1 \mathrm{~g}$ $\mathrm{I}^{-1}$ yeast extract (as growth factor) and a headspace of $20 \% \quad \mathrm{CO}_{2}: 79 \% \quad \mathrm{~N}_{2}: 1 \% \quad \mathrm{O}_{2}$. The succinate production yield was highest (4.52 mmol succinate/ gram STARCH) (60\% Starch content in starch waste) in batch reactors with $4 \%(\mathrm{w} / \mathrm{v})$ dried starch waste in a mineral salt medium supplemented with $150 \mathrm{mM}$ bicarbonate, $30 \mathrm{mM}$ phosphate buffer, and $0.1 \mathrm{~g} \mathrm{l}^{-1}$ yeast extract (as growth factor) and a headspace of $20 \% \mathrm{CO}_{2}: 79 \% \mathrm{~N}_{2}: 1 \% \mathrm{O}_{2}$.

The high succinate yields indicate that A. succiniciruminis is a promising candidate for succinate production from organic waste.

\section{Introduction}

Succinate (SA) and its deprotonated form succinate has a range of applications as an acidulant in food industries, a flavoring and antimicrobial agent, and a food supplement, as well as in the production of other products, including plastics, paints, inks, resins, coatings, and pigments (Pateraki et al., 2016; Salvachúa et al., 2016; Li et al., 2010; Cukalovic and Stevens 2008; Zeikus et al., 1999). Succinate is proposed as a bio-based C4 platform chemical for the replacement of petrochemical building blocks such as maleic anhydride, the intermediate compound to produce 
many chemicals (Jang et al., 2012; Li et al., 2010). Succinate and its derivatives, such as adipic acid and 1,4 butanediol, can be used to produce biodegradable polymers, for example, polyamides and polyesters (Pateraki et al., 2016). Therefore, succinate is registered in the "Top 10" bio-based products from biorefinery carbohydrates and the "Top 12" building block chemicals of the US Department of Energy's list (Bozell and Petersen, 2010; Meng et al., 2016).

To date, succinate is produced chemically by the hydrogenation of maleic anhydride to form succinic anhydride, followed by hydration to succinate (Ventorino et al., 2017). However, succinate can also be produced by microbial fermentation, and this has advantages over chemical production since it can be produced by organic materials which are abundant and does not rely on fossil fuels. Moreover, the process of bio-based succinate fermentation consumes $\mathrm{CO}_{2}$ resulting in reduction of the greenhouse gas (Pateraki et al., 2016). In 2013-2014, the annual bio-based succinate production was around 38,000 $\mathrm{t}$ (about $49 \%$ of the total product market) and this is expected to reach $600,000 \mathrm{t}$ by 2020 (Pateraki et al., 2016). At present, the market price for both bio-based and chemical (fossil)based succinate is around $\$ 2.5$ per $\mathrm{kg}$, and the bio-based succinate alone is approximately $\$ 2.94$ per $\mathrm{kg}$, which it is still higher than the ideal cost $(\$ 1$ per $\mathrm{kg}$ ) based on the requirement to produce commodity products by the chemical industry (Pateraki et al., 2016).

Currently, succinate production in industrial fermentations mainly uses purified sugars or glucose syrup from corn as carbon sources (Pateraki et al., 2016). Turning agricultural by-products or organic waste (such as vegetable wastes or potato pulps) into valuable materials has been a particular focus of recent strategy developments (Dahiya et al., 2018). The use of by-products and waste does not interfere with food production and is environmentally friendly.

Starch is the world's second-most abundant sugar polymer, after cellulose. A large amount of starch waste or starch residues are available worldwide. Starch waste is used as animal feed or compost, but still much of it is discharged as waste (Suzuki et al., 2010). The amount of starch in raw materials is variable, depending on the source (maize, potato, tapioca, or sweet potato). 
Typically, starch waste contains more than $70 \%$ dry weight starch (Rakshit, 2004). Starch is mainly composed of amylose and amylopectin with $\alpha-1-4$ glycosidic linkages, which are easily hydrolyzed. This has an advantage over cellulose with B-1-4 linkages, which are more difficult to break down (Rakshit, 2004). Therefore, starch waste is a suitable substrate for microbial fermentation to produce organic acids (Rakshit, 2004).

Bio-based succinate is mostly produced in a monosaccharide-based biorefinery platform, using microorganisms such as Actinobacillus succinogenes, Anaerobiospirillum succiniciproducens, Mannheimia succiniciproducens, and a recombinant Escherichia coli strain (Bozell and Petersen, 2010; Li et al., 2010; Rakshit, 2004). Succinate production from cassava starch has been tested using metabolically-engineered Escherichia coli KJ122, but a biological pretreatment by adding hydrolytic enzyme was required (Khor et al., 2016). So far, succinate production from biomass-derived hydrolysates has not been established (Salvachúa et al., 2016). Some lactic acid bacteria can utilize starch through simultaneous saccharification by amylolytic enzymes (Rakshit, 2004). Microorganisms that have amylolytic activity are of interest in the carboxylate platform because they can directly convert carbohydrate materials to sugar and further fermentation to organic acids or volatile fatty acids without addition of enzymes.

More research on succinate biorefinery technology is needed to improve bioconversion of carbohydrates (Bozell and Petersen, 2010). Actinomyces succiniciruminis strain Am4, isolated from the cow rumen, is an efficient succinate producer (Palakawong Na Ayudthaya et al., 2016). A. succiniciruminis produces succinate from a wide range of carbon sources, including poly- and disaccharides (cellobiose, saccharose, inulin, pectin, xylan, starch, starch waste, etc.) as well as monosaccharides. The fermentation products of this strain from glucose are succinate, lactate, formate and acetate (Palakawong Na Ayudthaya et al., 2016). A. succiniciruminis tolerates oxygen (up to 20\%) and glycerol (up to 25\% (w/v)) (Palakawong Na Ayudthaya et al., 2016). These characteristics are valuable in anaerobic fermentation systems. Based on the genome of the $A$. 
succiniciruminis, succinate is produced via the reductive branch of the tricarboxylic acid cycle. Optimization of the dosing of chemicals and process parameters may increase succinate production rate and yield and/or production cost from starch waste fermentation (Palakawong Na Ayudthaya et al., $2017^{\mathrm{b}}$ ). In this research, we investigated the effect of various conditions on succinate production from starch waste by A. succiniciruminis.

\section{Material and methods}

\section{Organism growth conditions}

Actinomyces succiniciruminis strain Am4 (DSM 10376 ${ }^{\mathrm{T}}$ ) was routinely batch-cultured with $20 \mathrm{mM}$ glucose in a bicarbonate-buffered anaerobic medium supplemented with $0.1 \mathrm{~g} \mathrm{l}^{-1}$ yeast extract (BMY) without L-cysteine at 370 (Plugge, 2005; Stams et al., 1993). BMY medium with $20 \mathrm{mM}$ glucose (G) (BMY-G) or 0.5\% starch waste with a headspace of $\mathrm{CO}_{2}: \mathrm{N}_{2}$ of $20: 80 \%$ at $37^{\circ} \mathrm{C}$ were used as the control condition for all glucose or starch waste experiments. The strain was routinely checked to confirm the purity by phase-contrast microscopy (Leica DM 2000; Wetzlar, Germany). The strain was kept active by weekly sub-culturing in BMY-G medium. For all experiments, a $24 \mathrm{~h}$ pre-culture grown on BMY-G was used as inoculum.

Either glucose (Sigma) or starch waste (STW), obtained from a potato factory (AvikoRixona, Warffum, the Netherlands), was used as a substrate. The starch waste was air dried at $80^{\circ} \mathrm{C}$ for 32 hours, crushed to small pieces, and sieved with sieve with a pore size of $1 \mathrm{~mm}$. The dried starch waste contained $61 \%(\mathrm{w} / \mathrm{w})$ starch according the analysis of Nutricontrol (Veghel, The Netherlands) (Palakawong Na Ayudthaya et al., 2018). 


\section{Optimization of succinate production from glucose and/or potato starch waste}

An active strain Acitomyces succiniciruminis was first tested in batch experiments (anaerobic-serum bottles) using glucose and/or starch waste as substrate with various conditions such as the headspace gas, bicarbonate, phosphate, nitrate and sulfate as shown in Table 1. Later, the result from the batch experiments was analyzed and applied in the reactor experiments (Table $1)$.

\section{Batch experiments}

The following parameters were tested in $120-\mathrm{mL}$ serum bottles with 50-mL standard medium (BMY) and 67-mL (gas) headspace containing $\mathrm{CO}_{2}: \mathrm{N}_{2}$ of 20:80\%. All experiments were conducted in triplicate in $\mathrm{BMY}$ medium and incubated under anaerobic conditions at $37^{\circ} \mathrm{C}$, unless stated otherwise.

1.1 With (20 mM) glucose as carbon source

1.1.1) Substrate concentration: 10,15 and $30 \mathrm{mM}$ glucose.

1.1.2) Initial organic acid concentration: $5 \mathrm{mM}$ acetate, formate, lactate, and $10 \mathrm{mM}$ of lactate

1.1.3) Headspace composition: modified from $\mathrm{CO}_{2}: \mathrm{N}_{2}$ of 20:80\% (control)

1.1.3.1) $\mathrm{CO}_{2}: 0 \%\left(\mathrm{~N}_{2} 100 \%\right)$

1.1.3.2) $\mathrm{O}_{2}: 1$ and $5 \%$

Reducing agent $\left(\mathrm{Na}_{2} \mathrm{~S}\right)$ was omitted for the oxygen experiment.

1.1.4) Bicarbonate $\left(\mathrm{NaHCO}_{3}\right): 0,100$ and $150 \mathrm{mM}$

1.1.5) Phosphate $\left(\mathrm{KH}_{2} \mathrm{PO}_{4} / \mathrm{Na}_{2} \mathrm{HPO}_{4}\right): 30$ and $50 \mathrm{mM}$

1.1.6) Nitrate $\left(\mathrm{NaNO}_{3}\right): 5 \mathrm{mM}$

1.1.7) Nitrite $\left(\mathrm{NaNO}_{2}\right): 5 \mathrm{mM}$

1.1.8) Sulfate $\left(\mathrm{Na}_{2} \mathrm{SO}_{4}\right): 5 \mathrm{mM}$ (without addition of $\mathrm{Na}_{2} \mathrm{~S}$ )

1.2 With $0.5 \% \mathrm{w} / \mathrm{v}$ starch waste as carbon source 
1.2.1) Substrate concentration $0.25,1,2,3$ and $4 \%$ (w/v) starch waste.

1.2.2) Headspace composition: reducing agent $\left(\mathrm{Na}_{2} \mathrm{~S}\right)$ was omitted

- $\mathrm{O}_{2}: 1,5$, and $10 \%(\mathrm{v} / \mathrm{v})$

1.2.3) Phosphate $\left(\mathrm{KH}_{2} \mathrm{PO}_{4} / \mathrm{Na}_{2} \mathrm{HPO}_{4}\right): 12 \mathrm{mM}$

1.2.4) Yeast extract: without yeast extract

1.2.5) Nitrate $\left(\mathrm{NaNO}_{3}\right): 10 \mathrm{mM}$

1.2.6) Sulfate $\left(\mathrm{Na}_{2} \mathrm{SO}_{4}\right): 10 \mathrm{mM}$ (without addition of $\mathrm{Na}_{2} \mathrm{~S}$ )

1.2.7) Other compounds:

1.2.7.1) Na-Aspartate: $0.6 \mathrm{mM}$

1.2.7.2) Na-Glutamate: $10 \mathrm{mM}$

1.2.7.3) Dithiothreitol (DTT): 1,5 and $10 \mathrm{mM}$

1.3 Type of substrate

$0.5 \%(\mathrm{w} / \mathrm{v})$ soluble starch (Sigma) and $2 \%(\mathrm{w} / \mathrm{v})$ fresh starch waste (equal to

$0.5 \%(\mathrm{w} / \mathrm{v})$ dried starch waste) were tested on BMY medium.

\subsection{Medium composition:}

A. succiniciruminis was tested for its ability to grow on starch waste (dried and fresh) without mineral medium, vitamins and trace elements; only a buffering agent (50 $\mathrm{mM} \mathrm{NaHCO}$ ) was supplemented to the starch waste slurries.

\section{Sampling}

Two-mL liquid samples were aseptically collected and divided into two portions. One portion of $1 \mathrm{~mL}$ was transferred to an Eppendorf tube and stored at $-20^{\circ} \mathrm{C}$ for organic acid measurement. The second portion of $1 \mathrm{~mL}$ was used to determine $\mathrm{pH}$ and bacterial growth. 


\section{Reactor experiments}

Reactor experiments were performed on starch waste fermentation on BMY medium, unless stated otherwise, and incubated under the setting conditions at $37^{\circ} \mathrm{C}$.

\section{Reactor set-up}

The fermentations were performed in a batch mode using DASbox ${ }^{\circledR}$ Mini Bioreactor System (Eppendorf, Germany) with an 0.5-liter working volume controlled by DASWare Control 4.0 and DASGIP Control 4.0 (Eppendorf, Germany). Temperature was controlled at $37^{\circ} \mathrm{C}$. The $\mathrm{pH}$ was controlled at 7 or 7.5 by automatic titration with a sterile solution of $3 \mathrm{M}$ potassium hydroxide and $0.5 \mathrm{M}$ sulfuric acid. The stirrer speed was set at $200 \mathrm{rpm}$ to keep the starch waste homogeneous. The reactors were continuously sparged with 79:20:1 $\mathrm{N}_{2}: \mathrm{CO}_{2}: \mathrm{O}_{2}$ at a flow rate of $11 . h^{-1}$. The reactors were operated for 5 or 8 days and daily samples were taken.

\subsection{Substrate concentration}

$4 \%$ and $8 \%(\mathrm{w} / \mathrm{v})$ starch waste was used in modified BMY medium supplemented with 6 $\mathrm{mM} \mathrm{KH} 2 \mathrm{PO}_{4}, 6 \mathrm{mM} \mathrm{Na} 2 \mathrm{HPO}_{4} \cdot 2 \mathrm{H}_{2} \mathrm{O}$, and $150 \mathrm{mM} \mathrm{NaHCO}_{3}$ to study the effect of substrate concentration. The reactor was operated at $\mathrm{pH} 7.5$ for 8 days.

\subsection{Phosphate concentration}

$4 \%(\mathrm{w} / \mathrm{v})$ starch waste was used as the carbon source to investigate the effect of phosphate. 12 and $30 \mathrm{mM}$ phosphate was studied in the modified BMY medium supplemented with $150 \mathrm{mM}$ of bicarbonate. The reactor was operated at $\mathrm{pH} 7.0$ for 5 days. This experiment was performed in two runs as there was a second batch of starch waste used. Therefore, the runs with the new starch waste were done in duplicate reactors.

\section{Reactor sampling}

4-mL liquid samples were aseptically collected and stored at $-20^{\circ} \mathrm{C}$ for the organic acid measurement.

A summary of all experimental tests in this study is shown in Table 1. 
Table 1. Schematic overview of experiments with Actinomyces succiniciruminis strain Am4 ${ }^{\mathrm{T}}$

\begin{tabular}{|c|c|c|c|}
\hline Substrate & $\begin{array}{c}\text { Experiment } \\
\text { no. }\end{array}$ & Tested conditions & Medium \\
\hline \multicolumn{4}{|c|}{ Batch experiment: } \\
\hline \multirow{19}{*}{$\begin{array}{c}\text { Glucose } \\
20 \mathrm{mM} \\
\text { (unless otherwise stated) }\end{array}$} & 1.1.1 & Glucose concentration & BMY \\
\hline & & 10,15 and $30 \mathrm{mM}$ & \\
\hline & 1.1.2 & Initial organic acid concentration & BMY \\
\hline & & $5 \mathrm{mM}$ acetate & \\
\hline & & $5 \mathrm{mM}$ formate & \\
\hline & & 5 and $10 \mathrm{mM}$ lactate & \\
\hline & 1.1.3.1 & Headspace & BMY \\
\hline & & $\mathrm{CO}_{2} 0 \%\left(100 \% \mathrm{~N}_{2}\right)$ & \\
\hline & 1.1.3.2 & Initial $\mathrm{O}_{2}$ & BMY without $\mathrm{Na}_{2} \mathrm{~S}$ \\
\hline & & 1 and $5 \%(\mathrm{v} / \mathrm{v})$ & \\
\hline & 1.1.4 & Bicarbonate & BMY \\
\hline & & 0,100 and $150 \mathrm{mM} \mathrm{NaHCO}_{3}$ & \\
\hline & 1.1.5 & Initial phosphate & BMY \\
\hline & & 30 and $50 \mathrm{mM} \mathrm{KH} \mathrm{PO}_{4} / \mathrm{Na}_{2} \mathrm{HPO}_{4}$ & \\
\hline & & Nitrate and Nitrite & BMY \\
\hline & 1.1.6 & $5 \mathrm{mM} \mathrm{NaNO}_{3}$ & \\
\hline & 1.1.7 & $5 \mathrm{mM} \mathrm{NaNO}_{2}$ & \\
\hline & 1.1.8 & Sulfate & BMY without $\mathrm{Na}_{2} \mathrm{~S}$ \\
\hline & & $5 \mathrm{mM} \mathrm{Na}_{2} \mathrm{SO}_{4}$ & \\
\hline \multirow{19}{*}{$\begin{array}{c}\text { Dried STW* } \\
0.5 \%(\mathrm{w} / \mathrm{v}) \\
\text { (unless otherwise stated) }\end{array}$} & 1.2.1 & STW concentration & BMY \\
\hline & & $0.25,1,2,3$ and $4 \%(w / v)$ & \\
\hline & 1.2.2 & $\mathbf{O}_{2}$ & BMY without $\mathrm{Na}_{2} \mathrm{~S}$ \\
\hline & & 1,5 and $10 \%(\mathrm{v} / \mathrm{v})$ & \\
\hline & 1.2.3 & Phosphate (4\% STW) & BMY \\
\hline & & $12 \mathrm{mM} \mathrm{KH}_{2} \mathrm{PO}_{4} / \mathrm{Na}_{2} \mathrm{HPO}_{4}$ & \\
\hline & 1.2.4 & Without yeast extract & $\mathrm{BM}$ \\
\hline & & no yeast extract & \\
\hline & 1.2.5 & Nitrate and Nitrite & BMY \\
\hline & & $10 \mathrm{mM} \mathrm{NaNO}_{3}$ & \\
\hline & 1.2.6 & Sulfate & BMY without $\mathrm{Na}_{2} \mathrm{~S}$ \\
\hline & & $10 \mathrm{mM}$ of $\mathrm{Na}_{2} \mathrm{SO}_{4}$ & \\
\hline & & Other compounds & BMY \\
\hline & 1.2.7.1 & $0.6 \mathrm{mM}$ Na-aspartate & \\
\hline & 1.2.7.2 & $10 \mathrm{mM}$ Na-glutamate & \\
\hline & 1.2.7.3 & 1,5 and $10 \mathrm{mM}$ Dithiotreitol (DTT) & \\
\hline & 1.3 & Soluble starch versus dried STW & \\
\hline & & $0.5 \%(\mathrm{w} / \mathrm{v})$ soluble starch & BMY \\
\hline & & $0.5 \%(\mathrm{w} / \mathrm{v})$ dried STW & $\begin{array}{l}50 \mathrm{mM} \mathrm{NaHCO} \\
\text { BMY) } \\
\text { (no }\end{array}$ \\
\hline \multirow[t]{2}{*}{ Fresh STW } & 1.4 & $2 \%(\mathrm{w} / \mathrm{v})$ of fresh STW $(=0.5 \%$ dried STW $)$ & BMY \\
\hline & & $2 \%(\mathrm{w} / \mathrm{v})$ of fresh STW $(=0.5 \%$ dried STW $)$ & $\begin{array}{l}50 \mathrm{mM} \mathrm{NaHCO} \\
3 \text { (no } \\
\text { BMY) }\end{array}$ \\
\hline \multirow{5}{*}{ Dried STW } & & Reactor experiment: & \\
\hline & 2.1 & STW concentration & modified BMY (12 \\
\hline & & 4 and $8 \%(w / v)$ dried STW & $\begin{array}{l}\mathrm{KH}_{2} \mathrm{PO}_{4} / \mathrm{Na}_{2} \mathrm{HPO}_{4} \\
\text { and } 150 \mathrm{mM} \mathrm{NaHCO}{ }_{3}\end{array}$ \\
\hline & 2.2 & Phosphate (4\% STW) & $\begin{array}{l}\text { modified } \mathrm{BMY}\left(150 \mathrm{mM} \mathrm{NaHCO}_{3}\right)\end{array}$ \\
\hline & & 12 and $30 \mathrm{mM} \mathrm{KH} \mathrm{PO}_{4} / \mathrm{Na}_{2} \mathrm{HPO}_{4}$ & \\
\hline
\end{tabular}

*STW: starch waste 


\section{Analytical methods}

Fermentation products were quantified by high-performance liquid chromatography (Thermo Scientific, Breda, The Netherlands), as previously described (Van Gelder et al., 2012). The bacterial growth was monitored using turbidity measurements (Optical density at $600 \mathrm{~nm} .:$ OD) using a spectrophotometer (Hitachi U-1500, Japan) and pH was measured using a pH meter (Proline b210, Netherlands) for the batch cultures. In the reactor, off-gas composition was automatically monitored every hour using a Compact GC (Interscience, Breda, The Netherlands), equipped with a Carboxen 1010 PLOT column and a Micro-thermal conductivity detector, using helium with pressure flow $80.0 \mathrm{kPa}$ as a carrier gas to quantify $\mathrm{H}_{2}$ and $\mathrm{CH}_{4}$.

\section{Results}

Genome-based analysis

Using the genome of A. succiniciruminis (strain Am4) (Palakawong Na Ayudthaya et al., $2017^{\mathrm{b}}$ ) the metabolic pathways involved in succinate production and other organic acids were determined (Fig. 1). Compounds including phosphate, $\mathrm{CO}_{2}$ are involved in succinate production and may influence the succinate yield of the strain Am4.

\section{The effect of substrate concentration}

Different glucose concentrations $(10,15$ and $30 \mathrm{mM})$ and starch waste concentrations $(0.25$, 1 and 2\%) were tested. A. succiniciruminis was able to grow on all substrate concentrations of both glucose and starch waste.

Growth rates on 10,15 and $30 \mathrm{mM}$ glucose were similar $\left(0.042,0.051\right.$ and $0.045 \mathrm{~h}^{-1}$, respectively) compared with the $20-\mathrm{mM}$ control $\left(0.048 \mathrm{~h}^{-1}\right)$, but optical densities were different (Fig. 1a). Succinate production $(10.7 \mathrm{mM})$ in the control (20 mM glucose) was slightly higher than in the 
other incubations. The highest succinate yield $\left(0.8 \mathrm{~mol} \mathrm{~mol}^{-1}\right)$ was obtained with $10 \mathrm{mM}$ glucose (Table 2).

On starch waste, succinate increased when the \% starch waste increased $(0.25,0.5$ and $1 \%)$ (Table 3). After 10 days 1, 2, 3 and 4\% starch waste produced a similar amount of succinate (Table 3). The highest succinate yield (3.24 mmol succinate/ gram starch waste) was obtained when $0.25 \%$ starch waste was used, (Table 3). During fermentation, the $\mathrm{pH}$ had dropped to 5.0 with $4 \%$ starch waste at day 5 and 4.8 at day 10 (Figure 1c). 


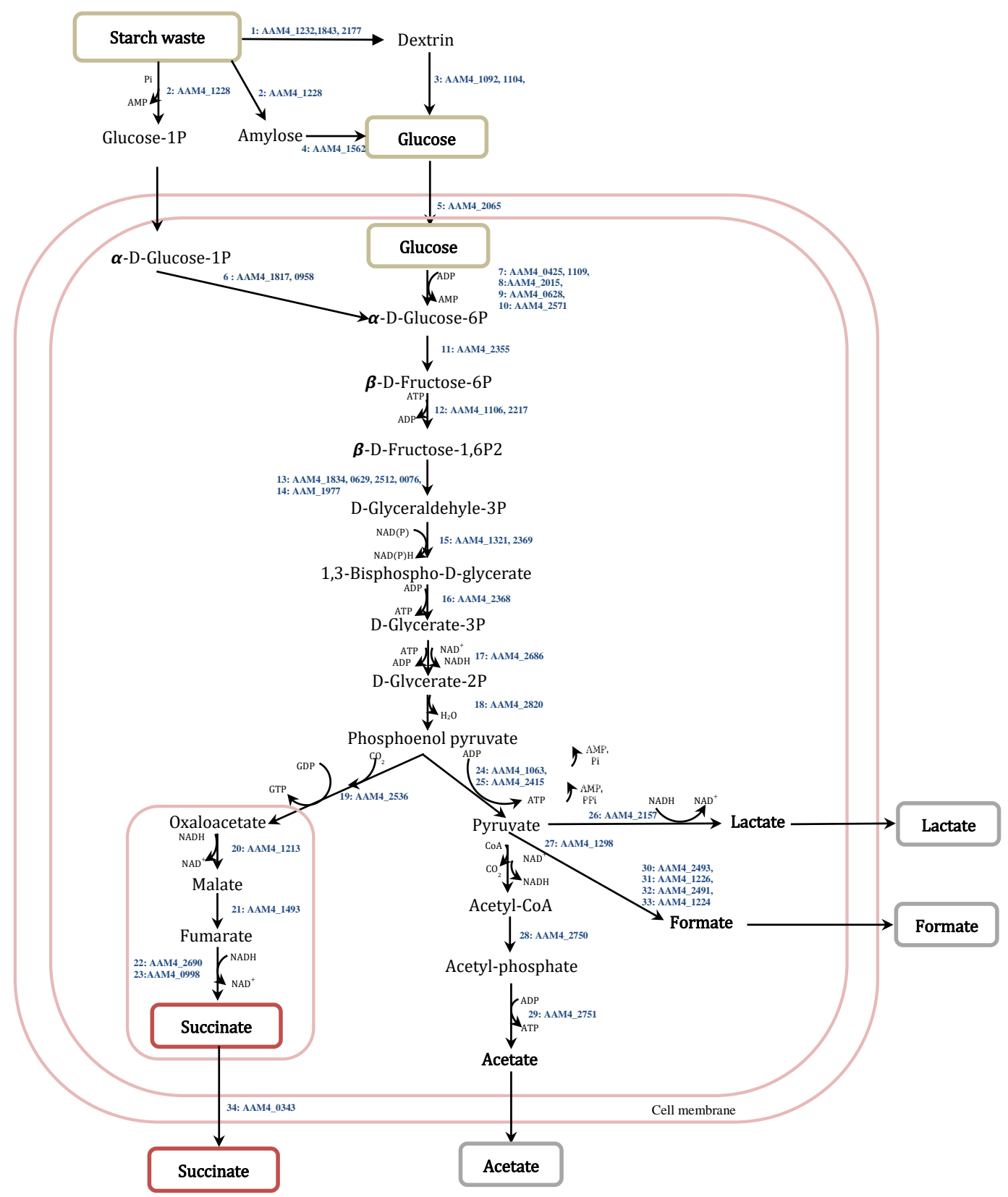

Fig. 1. Model for succinate production in A. succiniciruminis (Am4) 1: Beta/alpha-amylase (EC 3.2.1.1), 2: Glycogen phosphorylase (EC 2.4.1.1), 3: Oligo-1,6-glucosidase (3.2.1.10), 4:Glycogen debranching enzyme (EC 3.2.1.33, 2.4.1.25), 5: UDP-galactopyranose mutase (EC 5.4.99.9), 6: Phosphoglucomutase (EC 5.4.2.2) and Phosphoglucomutase-3 (EC 5.4.2.2 or 5.4.2.10),7: GlcK:Glucokinase (EC 2.7.1.2), 8: PPgK: Polyphosphate glucokinase (EC 2.7.1.63), 9: ADP-specific phosphofructokinase/glucokinase (EC 2.7.1.147), 10: Hexokinase, 1phosphofructokinase, 11: Pgi: Glucose-6-phosphate isomerase (EC 5.3.1.9), 12: PfK1: 6-phosphofructokinase (3) (EC 2.7.1.11), 13: FBA1:Fructose-bisphosphate aldolase class I (EC 4.1.2.13), 14: FBA_A:Fructose-bisphosphate aldolase, archaeal class I (EC 4.1.2.13), 15: Glyceraldehyde-3-phosphate dehydrogenase (EC 1.2.1.12), 16: PgK: Phosphoglycerate kinase (EC 2.7.2.3), 17: Phosphoglycerate mutase (EC 2.7.2.3), 18: EnO: Enolase (EC 4.2.1.11), 19: Phosphoenolpyruvate carboxykinase [GTP] (4.1.1.32), 20: Malate dehydrogenase (EC 1.1.1.37), 21: Fumarate hydratase class II, 22: Succinate dehydrogenase/fumarate reductase Fe-S protein, 23: Succinate dehydrogenase/fumarate reductase iron-sulfur subunit, 24: PpD: Pyruvate, phosphate dikinase (EC 2.7.9.1), 25: PyK: Pyruvate kinase (EC 2.7.1.40:AAM4_2415), 26: LDH: L-lactate dehydrogenase EC 2.3.1.54 (EC 1.1.1.27), 27: Pyruvate dehydrogenase E1 component (EC 1.2.4.1, 2.2.1.7), 28: PAT: Phosphate acetytransferase (EC 2.3.1.8), 29: ACK: Acetate kinase (EC 2.7.2.1), 30: Formate acetyltransferase 1, 31: Formate acetyltransferase 2 (EC 2.3.1.54), 32: Pyruvate formate-lyaseactivating enzyme (EC 1.97.1.4), 33: Pyruvate formate-lyase 2-activating enzyme, 34: Anaerobic C4-dicarboxylate transporter DcuA. 


\section{The effect of added organic acids}

Addition of acetate $(5 \mathrm{mM})$, formate $(5 \mathrm{mM})$, or lactate $(5$ or $10 \mathrm{mM})$ to the bottles prior to glucose fermentation showed no effect on succinate production compared with the control (20 mM glucose). The yields of succinate were not different from the control (Table 2). There was no effect on the $\mathrm{pH}$ and the growth performance.

The effect of $\mathrm{O}_{2}$ or $\mathrm{CO}_{2}$

One of the features of $A$. succiniciruminis is that it is not sensitive to $\mathrm{O}_{2}$, and therefore, the media for its growth are easier and less costly to prepare. Therefore, the effect of different percentages of oxygen in the headspace (1 and 5\%) on glucose and (1, 5 and 10\%) on starch waste fermentation was investigated. No clear effect on succinate production was observed when the concentration of oxygen was $1 \%$, both with glucose as well as with starch waste. Succinate yield decreased when $\mathrm{O}_{2}$ was higher (5 and 10\%) for both carbon sources (Table 2 and 3).

Omitting $20 \%$ carbon dioxide by supplying $100 \% \mathrm{~N}_{2}$ in the head space was tested to study its effect on succinate production from $20 \mathrm{mM}$ glucose. The results showed small differences in succinate production and yield between the bottle with $0 \% \mathrm{CO}_{2}$ and the $20 \% \mathrm{CO}_{2}$ as control (Table 2).

The effect of added bicarbonate $\left(\mathrm{NaHCO}_{3}\right)$

The effect of bicarbonate on succinate production with 0,50 (control), 100 and $150 \mathrm{mM}$ was tested without bicarbonate the succinate yield was considerably lower $(0.5 \mathrm{~mol} / \mathrm{mol})$ than when bicarbonate was added to the media. (Table 2).

The effect of different concentrations of phosphate

Two concentrations of phosphate $(30$ and $50 \mathrm{mM}$ ) were tested with $20 \mathrm{mM}$ glucose in BMY medium, compared to the control (6 $\mathrm{mM}$ of phosphate). An increased phosphate concentration had no effect on glucose conversion, but succinate production decreased when the phosphate 
concentration increased (Table 2). However, the succinate yield decreased slightly. Therefore, 12 $\mathrm{mM}$ of phosphate was further used in tests with $4 \%(\mathrm{w} / \mathrm{v})$ starch waste. Succinate production slightly increased when the phosphate concentration increased from 6 to $12 \mathrm{mM}$ for starch waste fermentation (Table 3). Yet, the succinate yield remained the same.

Table 2. Succinate production from glucose by A. succiniciruminis under different conditions in batch cultures

\begin{tabular}{|c|c|c|c|c|c|c|}
\hline $\begin{array}{c}\text { Experiment } \\
\text { no. }\end{array}$ & Tested conditions & Medium & $\begin{array}{l}\text { Fermentation } \\
\text { time (day) }\end{array}$ & $\begin{array}{l}\text { Succinate } \\
\quad(\mathbf{m M})\end{array}$ & $\begin{array}{c}\text { Succinate } \\
\text { yield (mol } \\
\text { mol-1 } \\
\text { glucose) }\end{array}$ & $\begin{array}{l}\text { SA:AA:FA:LA } \\
\text { (mol/mol*) }\end{array}$ \\
\hline \multirow[t]{4}{*}{ 1.1.1 } & Control (BMY-G) & \multirow{4}{*}{ BMY } & 8 & 10.7 & 0.6 & 1:0.6:0.7:0.9 \\
\hline & $10 \mathrm{mM}$ Glucose & & 8 & 6.9 & 0.8 & 1:0.6:0.6:0.7 \\
\hline & $15 \mathrm{mM}$ Glucose & & 8 & 9.2 & 0.7 & 1:0.5:0.4:0.7 \\
\hline & $30 \mathrm{mM}$ Glucose & & 8 & 10 & 0.6 & 1:0.4:0.4:0.8 \\
\hline \multirow[t]{5}{*}{ 1.1.2 } & Control (No addition) & \multirow{5}{*}{ BMY } & 10 & 3.6 & 0.7 & 1:0.6:0.6:0.8 \\
\hline & $5 \mathrm{mM}$ acetate & & 10 & 3.6 & 0.7 & 1:0.6:0.5:0.7 \\
\hline & $5 \mathrm{mM}$ formate & & 10 & 3.9 & 0.7 & 1:0.6:0.5:0.8 \\
\hline & $5 \mathrm{mM}$ lactate & & 10 & 3.4 & 0.7 & 1:0.7:0.5:0.9 \\
\hline & $10 \mathrm{mM}$ lactate & & 10 & 3.4 & 0.8 & 1:0.7:0.5:0.9 \\
\hline \multirow[t]{2}{*}{ 1.1.3.1 } & Control $\left(\mathrm{N}_{2} / \mathrm{CO}_{2} 80: 20 \%(\mathrm{v} / \mathrm{v}) ; \mathrm{BMY}-\mathrm{G}\right)$ & \multirow{2}{*}{ BMY } & 7 & 7.1 & 0.7 & $1: 0.2: 0.5: 0.2$ \\
\hline & $0 \% \mathrm{CO}_{2}(\mathrm{v} / \mathrm{v})\left(\mathrm{N}_{2} 100 \%(\mathrm{v} / \mathrm{v})\right)$ & & 7 & 6.6 & 0.9 & 1:0.2:0.4:0.3 \\
\hline \multirow[t]{3}{*}{ 1.1.3.2 } & Control $\left(0 \% \mathrm{O}_{2}(\mathrm{v} / \mathrm{v})\right)$ & \multirow{3}{*}{$\begin{array}{c}\text { BMY } \\
\text { without } \\
\mathrm{Na}_{2} \mathrm{~S}\end{array}$} & 7 & 6.6 & 0.9 & $1: 0.2: 0.5: 0.3$ \\
\hline & $1 \% \mathrm{O}_{2}(\mathrm{v} / \mathrm{v})$ & & 7 & 6 & 1 & 1:0.3:0.6:0.0 \\
\hline & $5 \% \mathrm{O}_{2}(\mathrm{v} / \mathrm{v})$ & & 7 & 3.2 & 0.6 & $1: 0.2: 0.5: 0.4$ \\
\hline \multirow[t]{4}{*}{ 1.1.4 } & Control (50 mM NaHCO ${ }_{3}$; BMY-G) & \multirow{4}{*}{ BMY } & 10 & 4.2 & 0.8 & 1:0.7:0.5:0.7 \\
\hline & $0 \mathrm{mM} \mathrm{NaHCO}_{3}$ & & 10 & 2.1 & 0.5 & $1: 0.7: 0.5: 2.1$ \\
\hline & $100 \mathrm{mM} \mathrm{NaHCO}_{3}$ & & 10 & 4.8 & 0.8 & 1:0.6:0.4:0.8 \\
\hline & $150 \mathrm{mM} \mathrm{NaHCO} 3$ & & 10 & 4.6 & 0.8 & 1:0.6:0.4:0.8 \\
\hline \multirow[t]{4}{*}{ 1.1.5 } & Control (6 mM KH $\mathrm{PO}_{4} / \mathrm{Na}_{2} \mathrm{HPO}_{4}$; BMY-G) & & 7 & 6.6 & 0.9 & $1: 0.2: 0.5: 0.3$ \\
\hline & $30 \mathrm{mM} \mathrm{KH}{ }_{2} \mathrm{PO}_{4} / \mathrm{Na}_{2} \mathrm{HPO}_{4}$ & BMY & 7 & 5.7 & 0.8 & 1:0.2:0.2:0.5 \\
\hline & $50 \mathrm{mM} \mathrm{KH}_{2} \mathrm{PO}_{4} / \mathrm{Na}_{2} \mathrm{HPO}_{4}$ & & 7 & 4.2 & 0.8 & 1:0.2:0.2:0.6 \\
\hline & Control BMY-G) & & 7 & 6.6 & 0.9 & 1:0.2:0.5:0.3 \\
\hline 1.1.6 & $5 \mathrm{mM}$ Na-nitrate & BMY & 7 & 6.2 & 0.8 & 1:0.3:0.5:0.1 \\
\hline 1.1 .7 & $5 \mathrm{mM}$ Na-nitrite & & 7 & 0 & 0 & 0 \\
\hline 1.1 .8 & $5 \mathrm{mM} \mathrm{Na}$-sulfate & $\begin{array}{c}\text { BMY } \\
\text { without } \\
\mathrm{Na}_{2} \mathrm{~S}\end{array}$ & 7 & 6.8 & 1 & 1:0.1:0.5:0.2 \\
\hline
\end{tabular}

*) SA: succinate; AA: acetate; FA: formate; LA: lactate 
The effect of nitrate, nitrite, or sulfate addition

No effect on the succinate and other organic acid production in the fermentation with glucose was observed when $5 \mathrm{mM}$ of sulfate or nitrate were added compared with the control (Table 2). Nitrite $(5 \mathrm{mM})$ was detected when nitrate was added. No organic acid production, no growth, and no $\mathrm{pH}$ change were observed when $5 \mathrm{mM}$ of nitrite was added.

Table 3. Succinate production from starch waste by A. succiniciruminis under different conditions in batch cultures

\begin{tabular}{|c|c|c|c|c|c|c|}
\hline $\begin{array}{l}\text { Experiment } \\
\text { no. }\end{array}$ & Tested conditions*)****) & $\begin{array}{c}\text { Medium } \\
\text { /substrate }\end{array}$ & $\begin{array}{l}\text { Succinate } \\
(\mathbf{m M})\end{array}$ & 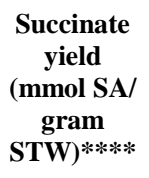 & $\begin{array}{c}\text { Succinate yield } \\
\text { (mmol SA/gram } \\
\text { STARCH) }(60 \% \\
\text { Starch content in } \\
\text { STW)**** }\end{array}$ & $\begin{array}{c}\text { SA:AA:FA:LA } \\
\left.(\mathrm{mol} / \mathrm{mol})^{* *}\right)\end{array}$ \\
\hline \multirow[t]{6}{*}{ 1.2.1 } & Control (0.5\% STW w/v) & \multirow{6}{*}{ BMY } & 15.7 & 3.14 & 5.23 & 1:0.8:0.8:0.0 \\
\hline & $0.25 \%$ STW (w/v) & & 8.1 & 3.24 & 5.4 & 1:0.8:0.7:0.0 \\
\hline & $1 \%$ STW (w/v) & & 18.7 & 1.87 & 3.12 & 1:0.8:0.8:0.3 \\
\hline & $2 \%$ STW (w/v) & & 17 & 0.85 & 1.42 & 1:0.9:0.8:0.6 \\
\hline & $3 \%$ STW (w/v) & & 18.2 & 0.61 & 1.01 & 1:0.9:0.8:0.8 \\
\hline & $4 \%$ STW $(w / v)$ & & 18 & 0.45 & 0.75 & 1:1.0:0.7:0.9 \\
\hline \multirow[t]{4}{*}{ 1.2.2 } & Control $\left(0 \% \mathrm{O}_{2} \mathrm{v} / \mathrm{v} ; 0.5 \% \mathrm{STW} w / \mathrm{v}\right)$ & \multirow{4}{*}{$\begin{array}{l}\text { BMY without } \\
\qquad \mathrm{Na}_{2} \mathrm{~S}\end{array}$} & 16.9 & 3.38 & 5.63 & 1:0.8:0.8:0.0 \\
\hline & $1 \% \mathrm{O}_{2}(\mathrm{v} / \mathrm{v})$ & & 17.2 & 3.44 & 5.73 & 1:0.8:0.7:0.0 \\
\hline & $5 \% \mathrm{O}_{2}(\mathrm{v} / \mathrm{v})$ & & 13.8 & 2.76 & 4.6 & 1:1.0:0.9:0.0 \\
\hline & $10 \% \mathrm{O}_{2}(\mathrm{v} / \mathrm{v})$ & & 11.5 & 2.3 & 3.83 & 1:1.1:0.9:0.1 \\
\hline \multirow[t]{2}{*}{1.2 .3} & Control $\left(6 \mathrm{mM} \mathrm{KH}_{2} \mathrm{PO}_{4} / \mathrm{Na}_{2} \mathrm{HPO}_{4}\right)$ & \multirow{2}{*}{$\begin{array}{l}\text { 4\% STW, } \\
\text { BMY }\end{array}$} & 17.8 & 0.45 & 0.74 & 1:0.4:0.8:1.0 \\
\hline & $12 \mathrm{mM} \mathrm{KH}_{2} \mathrm{PO}_{4} / \mathrm{Na}_{2} \mathrm{HPO}_{4}$ & & 18.7 & 0.47 & 0.78 & 1:0.4:0.8:0.9 \\
\hline \multirow[t]{2}{*}{ 1.2.4 } & Control ( $0.1 \mathrm{~g} \mathrm{l}^{-1}$ yeast extract $)$ & BMY & 12.1 & 2.42 & 4.03 & 1:0.1:0.9:0.1 \\
\hline & No yeast extract & $\mathrm{BM}$ & 13.4 & 2.68 & 4.47 & 1:0.2:0.9:0.1 \\
\hline & Control (0.5\% STW w/v) & \multirow{2}{*}{ BMY } & 16.6 & 3.32 & 5.53 & 1:0.8:0.8:0.0 \\
\hline 1.2.5 & $10 \mathrm{mM}$ Na-nitrate & & 6 & 1.2 & 2 & 1:1.2:0.8:1.1 \\
\hline \multirow[t]{2}{*}{ 1.2.6 } & $10 \mathrm{mM}$ Na-sulfate & $\begin{array}{l}\text { BMY without } \\
\qquad \mathrm{Na}_{2} \mathrm{~S}\end{array}$ & 16.5 & 3.3 & 5.5 & 1:0.8:0.8:0.1 \\
\hline & Control (0.5\% STW w/v) & \multirow{3}{*}{ BMY } & 14.2 & 2.84 & 4.73 & 1:0.4:0.7:0 \\
\hline 1.2.7.1 & $0.6 \mathrm{mM} \mathrm{Na}$-aspartate & & 12.9 & 2.58 & 4.3 & 1:0.4:0.7:0 \\
\hline 1.2.7.2 & $10 \mathrm{mM}$ Na-glutamate & & 13.4 & 2.68 & 4.47 & $1: 0.4: 0.7: 0$ \\
\hline \multirow[t]{4}{*}{ 1.2.7.3 } & Control (0.5\% STW w/v) & \multirow{4}{*}{ BMY } & 15.4 & 3.08 & 5.13 & 1:0.3:0.9:0.1 \\
\hline & 1 mM Dithiotreitol (DTT) & & 15.8 & 3.16 & 5.27 & 1:0.3:0.8:0.1 \\
\hline & 5 mM Dithiotreitol (DTT) & & 16.3 & 3.26 & 5.43 & 1:0.3:0.7:0.1 \\
\hline & 10 mM Dithiotreitol (DTT) & & 16.8 & 3.36 & 5.6 & 1:0.2:0.7:0.1 \\
\hline
\end{tabular}

*) Batches were incubated for 10 days at $37^{\circ} \mathrm{C}$

**) SA: succinate; AA: acetate; FA: formate; LA: lactate

***) Batches were incubated for 7 days at $37^{\circ} \mathrm{C}$

****) STW: starch waste 
No effect on succinate and other organic acid production was observed when $10 \mathrm{mM}$ of sulfate was added to the starch waste fermentation, but there was a negative effect on succinate production when $10 \mathrm{mM}$ nitrate was added (Table 3). Further, succinate, acetate and formate concentrations were lower in the presence of $10 \mathrm{mM}$ nitrate, whereas lactate production was higher than the control and nitrite was also detected (data not shown).

The effect of other compounds

Other compounds tested (aspartate, glutamate and dithiothreitol) had no significant effect on starch waste fermentation and succinate production. When yeast extract was omitted from the starch waste fermentation, succinate yield was not affected (Table 3).

The effect of substrate type (soluble starch, dried and fresh starch waste) (Experiment no. 1.3 and 1.4)

Dried and fresh starch waste and soluble starch were used to investigate growth and succinate and organic acid production of $A$. succiniciruminis. The strain could grow and ferment both starch sources (Figs. 2a, 2b and 2d). Succinate and organic acids were highest with fresh starch waste compared to dried starch waste and soluble starch (Figs. 2a, 2b and 2d).

A. succiniciruminis was also grown in fresh and dried starch waste without addition of mineral medium (BMY). Only $50 \mathrm{mM}$ bicarbonate $\left(\mathrm{NaHCO}_{3}\right)$ was added to a $0.5 \% \mathrm{w} / \mathrm{v}$ starch waste slurry (Figs. 2c and 2e). Here, succinate and organic acid production on fresh starch waste was higher than on the dried starch waste; the succinate yield was also higher (Figs. 2c and 2e). 


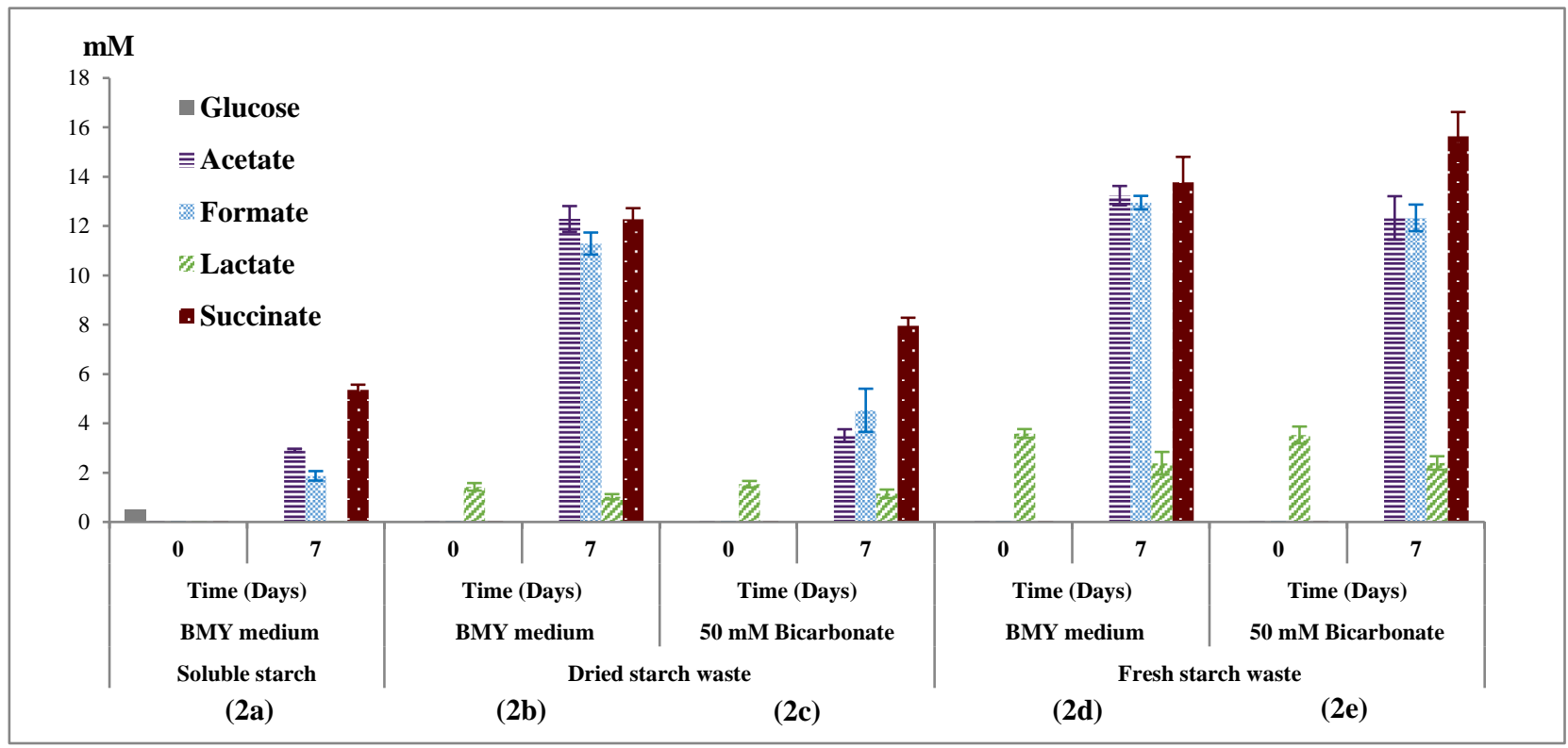

Fig. 2. Organic acid production by A. succiniciruminis in batch cultures from $0.5 \%$ (w/v) soluble starch (2a) $0.5 \%(\mathrm{w} / \mathrm{v})$ dried starch waste (2b), $0.5 \%$ (w/v) dried starch waste without BMY medium only supplemented with $50 \mathrm{mM} \mathrm{NaHCO} 3(2 \mathrm{c}), 0.5 \%$ (w/v based on dry weight) fresh starch waste (2d), and $0.5 \%$ (w/v based on dry weight) fresh starch waste (with equal final concentration) without BMY medium only supplemented with $50 \mathrm{mM}$ of $\mathrm{NaHCO}_{3}(2 \mathrm{e})$.

\section{Succinate production in reactor experiments}

Based on the results from the batch experiments, the factors that positively influenced succinate production, or made the fermentation conditions more robust, were tested in reactor experiments.

\section{Effect of substrate (starch waste) concentration}

Succinate was the major product in a $\mathrm{pH}$-controlled $(\mathrm{pH}=7.5)$ batch reactor from starch waste, followed by acetate, formate and lactate (Fig. 3, Table 4). Succinate production doubled (from $61 \mathrm{mM}$ up to $118 \mathrm{mM}$ ) when starch waste was increased from 4 to $8 \%(\mathrm{w} / \mathrm{v})$. The succinate yield, however, remained in the same range (2.46-2.55 mmol succinate/ gram starch) (Table 4). 
Table 4. Succinate production from starch waste by A. succiniciruminis under different conditions in a pHcontrolled reactor****)

\begin{tabular}{|c|c|c|c|c|c|c|}
\hline $\begin{array}{l}\text { Experiment } \\
\text { no. }\end{array}$ & Test conditions & Medium & $\begin{array}{l}\text { Succinate } \\
\quad(\mathrm{mM})\end{array}$ & $\begin{array}{c}\text { Succinate } \\
\text { yield (mmol } \\
\text { SA/gram } \\
\text { STW) }\end{array}$ & $\begin{array}{c}\text { Succinate yield } \\
\text { (mmol SA/ gram } \\
\text { STARCH) }(60 \% \\
\text { Starch content in } \\
\text { STW) }\end{array}$ & $\begin{array}{c}\text { SA:AA:FA:LA } \\
\left.(\mathrm{mol} / \mathrm{mol})^{* *}\right)\end{array}$ \\
\hline \multirow[t]{6}{*}{2.1} & $4 \%(w / v)$ dried STW & \multirow{6}{*}{$\begin{array}{c}\text { modified } \\
\text { BMY, pH = } \\
7.5,8 \text { days } \\
\text { fermentation }\end{array}$} & \multirow{3}{*}{61.3} & \multirow{3}{*}{1.53} & \multirow{3}{*}{2.55} & \multirow{3}{*}{ 1:0.1:0.5:0.6 } \\
\hline & $12 \mathrm{mM} \mathrm{KH}_{2} \mathrm{PO}_{4} / \mathrm{Na}_{2} \mathrm{HPO}_{4}$ & & & & & \\
\hline & $150 \mathrm{mM} \mathrm{NaHCO}_{3} ;$ & & & & & \\
\hline & $8 \%(w / v)$ dried STW & & \multirow{3}{*}{118} & \multirow{3}{*}{1.48} & \multirow{3}{*}{2.46} & \multirow{3}{*}{ 1:0.1:0.4:0.7 } \\
\hline & $12 \mathrm{mM} \mathrm{KH}_{2} \mathrm{PO}_{4} / \mathrm{Na}_{2} \mathrm{HPO}_{4}$ & & & & & \\
\hline & $150 \mathrm{mM} \mathrm{NaHCO} 3$ & & & & & \\
\hline \multirow[t]{12}{*}{2.2} & $4 \%(w / v)$ dried STW & \multirow{6}{*}{$\begin{array}{c}\text { modified } \\
\text { BMY, pH = } \\
7.0,5 \text { days } \\
\text { fermentation }\end{array}$} & \multirow{3}{*}{80} & \multirow{3}{*}{2} & \multirow{3}{*}{3.33} & \multirow{3}{*}{ 1:0.7:0.4:0.2 } \\
\hline & $12 \mathrm{mM} \mathrm{KH}_{2} \mathrm{PO}_{4} / \mathrm{Na}_{2} \mathrm{HPO}_{4}$ & & & & & \\
\hline & $150 \mathrm{mM} \mathrm{NaHCO}$ & & & & & \\
\hline & $4 \%(w / v)$ dried STW & & \multirow{3}{*}{108.4} & \multirow{3}{*}{2.71} & \multirow{3}{*}{4.52} & \multirow{3}{*}{ 1:0.6:0.4:0.4 } \\
\hline & $30 \mathrm{mM} \mathrm{KH}{ }_{2} \mathrm{PO}_{4} / \mathrm{Na}_{2} \mathrm{HPO}_{4}$ & & & & & \\
\hline & $150 \mathrm{mM} \mathrm{NaHCO}_{3}$ & & & & & \\
\hline & $\begin{array}{l}4 \%(\mathrm{w} / \mathrm{v}) \text { dried STW- } \\
\left.\mathrm{NEW}^{*}\right)\end{array}$ & \multirow{6}{*}{$\begin{array}{c}\text { modified } \\
\text { BMY, pH = } \\
7.0,5 \text { days } \\
\text { fermentation }\end{array}$} & \multirow{3}{*}{62} & \multirow{3}{*}{1.55} & \multirow{3}{*}{2.58} & \multirow{3}{*}{ 1:0.7:0.5:0.6 } \\
\hline & $12 \mathrm{mM} \mathrm{KH}_{2} \mathrm{PO}_{4} / \mathrm{Na}_{2} \mathrm{HPO}_{4}$ & & & & & \\
\hline & $150 \mathrm{mM} \mathrm{NaHCO}_{3}$ & & & & & \\
\hline & $\begin{array}{l}4 \%(\mathrm{w} / \mathrm{v}) \text { dried STW- } \\
\left.\mathrm{NEW}^{*}\right)\end{array}$ & & \multirow{3}{*}{95.4} & \multirow{3}{*}{2.39} & \multirow{3}{*}{3.98} & \multirow{3}{*}{$1: 0.6: 0.5: 0.1$} \\
\hline & $30 \mathrm{mM} \mathrm{KH}{ }_{2} \mathrm{PO}_{4} / \mathrm{Na}_{2} \mathrm{HPO}_{4}$ & & & & & \\
\hline & $150 \mathrm{mM} \mathrm{NaHCO} 3$ & & & & & \\
\hline
\end{tabular}

*) new batch of STW was used. Therefore, both runs were done in duplicate

**) SA: succinate; AA: acetate; FA: formate; LA: lactate

***) $60 \%$ Starch in STW)

****) STW: starch waste

\section{Effect of $p H$}

The succinate yield was affected when the $\mathrm{pH}$ of the reactor was changed from $\mathrm{pH} 7.5$ to $\mathrm{pH}$ 7.0 (4\% starch waste). Yields increased from 1.53 to $2.0 \mathrm{mmol}$ succinate/gram starch waste (2.55 to $3.33 \mathrm{mmol}$ succinate/ gram starch). 


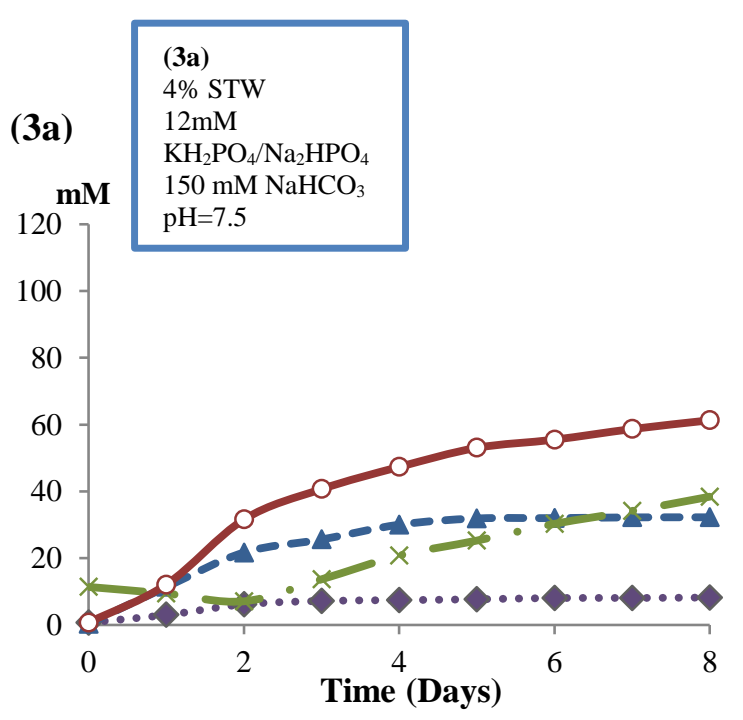

$\cdots \sim$ Acetate $\quad-\rightarrow-\cdot$ Formate

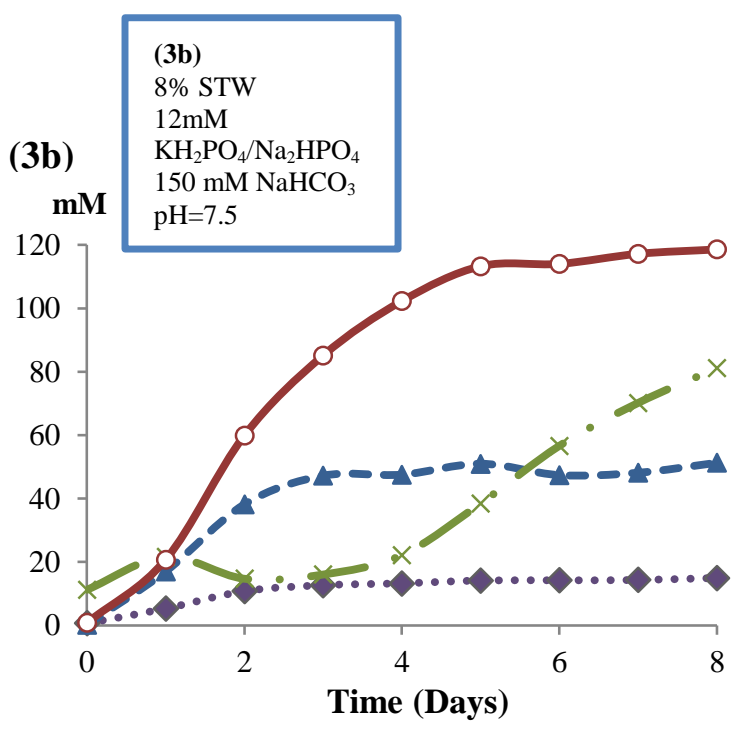

Lactate $\quad-$ Succinate

Fig. 3. Organic acid production from starch waste fermentation by A. succiniciruminis in a pH-controlled reactor. STW: starch waste

\section{Effect of phosphate concentration}

Succinate production from starch waste $(4 \% \mathrm{w} / \mathrm{v})$ increased when the concentration of phosphate increased from $12 \mathrm{mM}$ to $30 \mathrm{mM}$ in duplicate reactor runs (Figs. 4, Table 4). Succinate production increased rapidly after day 1 and increased until the end (day 5), along with acetate, formate and lactate production. The highest concentration of succinate was at day 5 , when $30 \mathrm{mM}$ of phosphate was provided in the modified BMY medium (150 mM bicarbonate) with $108 \mathrm{mM}$ and $95 \mathrm{mM}$ from the starch waste batch 1 (Fig. 4b) and 2 (Fig. 4d), respectively and succinate production increased ca. $45 \%$ (in average) when $12 \mathrm{mM}$ of phosphate was used, compared to $80 \mathrm{mM}$ and 62 mM from the starch waste batch 1 (Fig. 4a) and 2 (Fig. 4c), respectively. The succinate yield after 5 days fermentation was highest with $30 \mathrm{mM}$ phosphate (4.52 and $3.98 \mathrm{mmol}$ succinate/gram starch waste). 

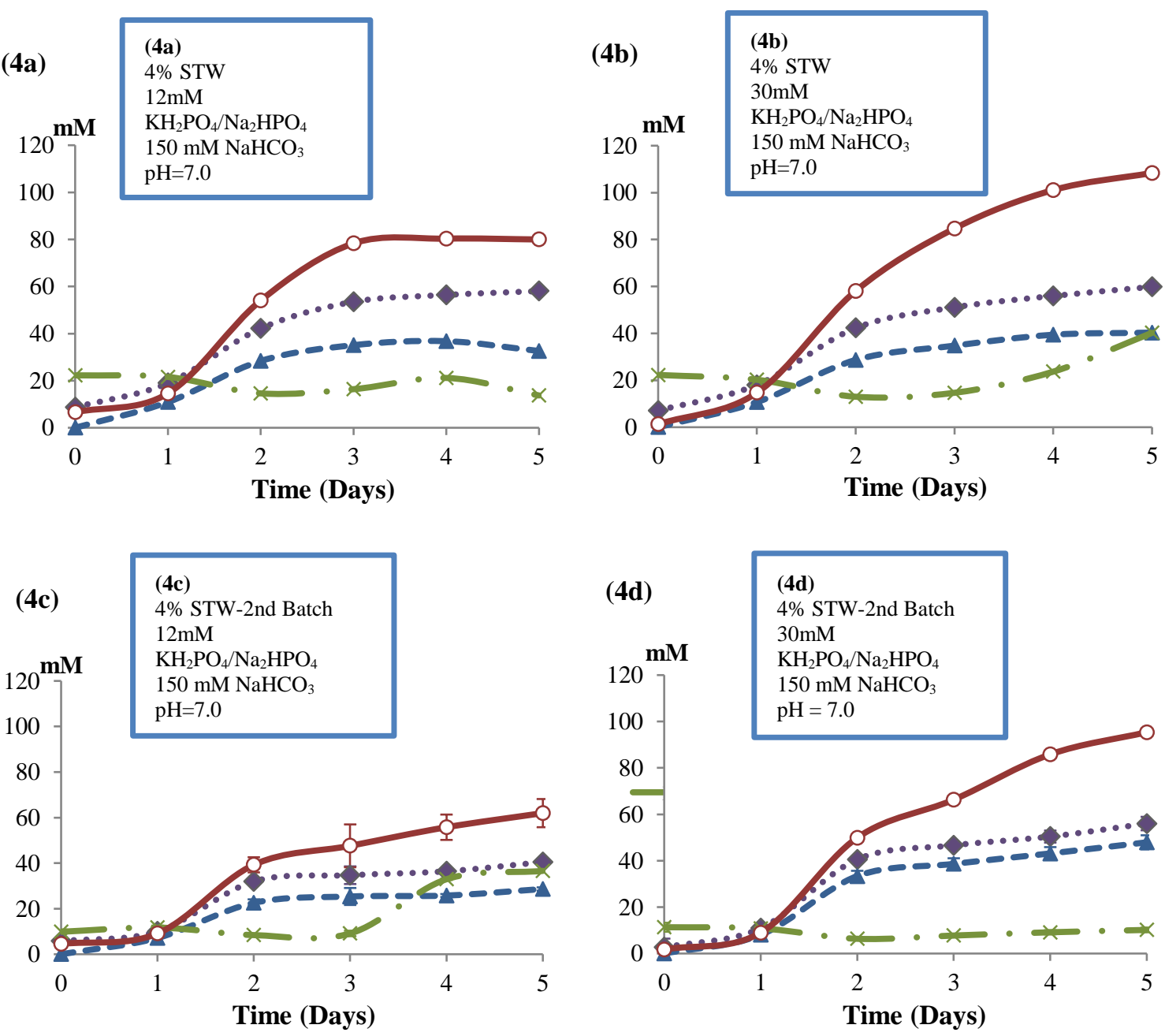

$\cdots \infty$ Acetate $\quad-\perp-$. Formate

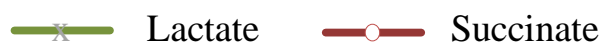

Fig. 4. Organic acid production by A. succiniciruminis from starch waste $4 \%(\mathrm{w} / \mathrm{v})$ fermentation in $\mathrm{pH}-$ controlled reactor 


\section{Discussion}

Succinate production from glucose by A. succiniciruminis strain Am4 differed, for instance, with respect to the ratio of production of succinate and the other products as well as the effect of process conditions on succinate production (Table 2 and 3). Bicarbonate showed a positive effect on succinate production in glucose fermentation (Table 2). The concentration of substrate, phosphate, dithiothreitol, with no addition of yeast extract and no medium, had a positive effect on succinate production from starch waste, but not directly on the succinate yield (Table 3). Based on this the effect of the substrate concentration, phosphate and bicarbonate on starch waste fermentation was further tested in a batch bioreactor.

Bicarbonate has a positive effect on succinate production because it provides the $\mathrm{CO}_{2}$ that is needed in the formation of succinate in the step from phosphoenolpyruvate to oxaloacetate (Fig. 1), which is in agreement with other studies (Tan et al., 2017; van der Werf et al., 1997; Ohta et al., 1989). Providing $\mathrm{CO}_{2}$ gas can be costly on an industrial scale. Instead, sodium bicarbonate or calcium carbonate, which are relatively cheap, can reduce the cost of succinate production. Increasing the amount of bicarbonate also increases the buffering capacity of the medium.

Succinate production and succinate yield did not increase when the phosphate concentration increased in the starch waste fermentation in the batch bottles. However, in the reactor experiment in which the $\mathrm{pH}$ was controlled, phosphate had a positive effect on succinate production. Therefore, our assumption is that phosphate may help in the starch waste degradation step that is involved in starch phosphorylase: $[\text { glucosyl }]_{\mathrm{n}}+$ phosphate $=[\text { glucosyl }]_{\mathrm{n}-1}+$ glucose-1-phosphate $($ Lamed and Zeikus, 1980) (Fig. 1). Genes encoding the starch phosphorylase enzyme (AAM4_1228: EC 2.4.1.1) and starch/glycogen debranching enzymes (AAM4_1562: EC 3.2.1.33 or EC 2.4.1.25) were detected in the A. succiniciruminis genome. The Am4 genome also contains the gene-encoding phosphoglucomutases (AAM4_1817 and 0958: EC 5.4.2.2), enzymes that convert glucose-1- 
phosphate into glucose-6-phosphate (Fig. 1). However, a high concentration of phosphate may also inhibit bacterial growth (Takahashi et al., 1995). Some bacteria, such as E. coli, use inorganic pyrophosphatase to decrease the pyrophosphate (PPi) level in their cells, while Actinomyces species remove the PPi by the coupling of PPi as a phosphoryl donor to glycolysis through phosphofructokinase (Takahashi et al., 1995), which probably helps Actinomyces to tolerate higher phosphate concentrations. The A. succiniciruminis genome also has genes encoding both inorganic pyrophosphatase (AAM4_1072; EC 3.6.1.1) and 6-phosphofructokinase (AAM4_1106, AAM4_2217; EC 2.7.1.11), which could help the strain to cope with high phosphate concentrations, because toxicity of phosphate was not observed. In batch experiment, $30 \mathrm{mM}$ phosphate showed a negative effect on succinate production in glucose fermentation. While, in the starch waste fermentation from reactor experiment, a positive effect on succinate production occurred when increasing the concentration of phosphate from $12 \mathrm{mM}$ to $30 \mathrm{mM}$ (Figs. $4 \mathrm{~b}$ and $4 \mathrm{~d}$, Table 4). A similar result was noted for substrate inhibition on succinate production that occurred during glucose fermentation, but not in the starch waste fermentation. Our hypothesis is that starch waste may contain some compounds that prevent this inhibition, or that the structure and viscosity of starch waste may prevent or decrease the toxicity of phosphate.

The two phosphate (12 and $30 \mathrm{mM}$ ) concentrations (Fig. 4) were tested in the reactor with two different batches of starch waste and the results were slightly different in terms of organic acid production. This is probably due to a small variation in the starch waste composition, because two batches of starch waste were collected and prepared in a different period (for the first batch, see Figs. 4a and 4b; for the second batch, see Figs. 4c and 4d).

The stoichiometry of glucose fermentation by A. succiniciruminis in BMY medium supplemented with L-cysteine was 1 glucose $+0.7 \mathrm{CO}_{2} \rightarrow 0.7$ succinate +0.7 lactate +0.3 acetate + 0.2 formate (Palakawong Na Ayudthaya et al., 2016). In this study, no L-cysteine $\left(0.5 \mathrm{~g} \mathrm{l}^{-1}\right)$ was added to the medium because preliminary experiments showed that succinate production increased 
when L-cysteine was not added to the medium (data not shown). However, in the absence of Lcysteine growth of strain Am4 was less (Palakawong Na Ayudthaya et al., 2016). L-cysteine is an amino acid, which is as a reducing agent and a sulfur source for bacteria, and this may explain the unfavorable effect on growth of strain Am4.

A small amount of oxygen (1\%) in the head space did not affect the succinate production of strain Am4. The genome of strain Am4 has genes coding for oxidative-stress enzymes, including superoxide dismutase (Mn) (AAM4_0808), NADH oxidase (AAM4_1060 and AAM4_1376), and NADH:flavin oxidoreductase/NADH oxidase (AAM4_1585). These genes were also found in other anaerobes such as Desulfovibrio, in $\delta$-Proteobacteria, and in other Actinomyces species such as $A$. naeslundii and A. odontolyticus and were reported to help these microorganisms to tolerate low oxygen levels (Gregory et al., 1978; Lin et al., 2004; Palakawong Na Ayudthaya et al., 2017 ${ }^{\text {b }}$.

An interesting characteristic of strain Am4 is that in the glycolytic pathway, instead of using ATP-dependent glucokinase to convert glucose into glucose-6-phosphate, a gene that encodes for an ADP-dependent glucokinase or ADPGK gene (AAM4_0628: EC 2.7.1.147) that uses ADP to convert glucose into glucose-6-phosphate (ADP + D-glucose $\Rightarrow$ AMP + D-glucose-6-phosphate) (Fig. 1). This gene so far has only been reported in archaea or eukaryotes and there is no report that it occurs in bacteria. Using ADPGK instead of ATPGK in this step may help the cell to conserve energy. 


\section{Conclusions}

A. succiniciruminis (Am4) is a fast-growing, natural succinate-producing bacterium that can tolerate oxygen. A. succiniciruminis can also ferment a broad range of plant mono- and disaccharides, including starch waste. The highest succinate production achieved was $118 \mathrm{mM}$, obtained in the fermentation of $8 \%(\mathrm{w} / \mathrm{v})$ of dried starch waste in a modified BMY medium without L-cysteine and sulfide, but supplemented with $150 \mathrm{mM}$ bicarbonate and $12 \mathrm{mM}$ phosphate and with 79:20:1 of $\mathrm{N}_{2}: \mathrm{CO}_{2}: \mathrm{O}_{2}$ at a flow rate of $11 . \mathrm{h}^{-1}$. The highest succinate yield obtained were $2.39-2.71$ mmol succinate/gram starch waste with $4 \%$ starch waste in the same conditions as above but supplemented with $30 \mathrm{mM}$ phosphate. When taken into account that the starch content of the starch waste is $60 \%$, succinate yields were $3.98-4.52 \mathrm{mmol}$ succinate/gram starch.

None of the in batch-tested compounds significantly increased the yield of succinate from glucose and starch waste. However, in the starch waste reactor fermentations with $1 \%$ oxygen, the yield did not decrease, nor was it affected when mineral salts, trace elements and vitamins were omitted from the culture fluid, indicating the robustness of strain Am4.

Based on the observed characteristics A. succiniciruminis strain Am4 may be an interesting candidate for succinate production in the carboxylate platform, particularly for starch waste degradation.

\section{Acknowledgements}

The authors thank Prof. A.J.M. Stams and Prof. W.M. de Vos for stimulating discussions and critical reading, A. H.P. van de Weijer and A.H. van Gelder for technical support. The first author was financially supported by a Royal Thai Government Scholarship, Thailand. 


\section{Supplementary data}
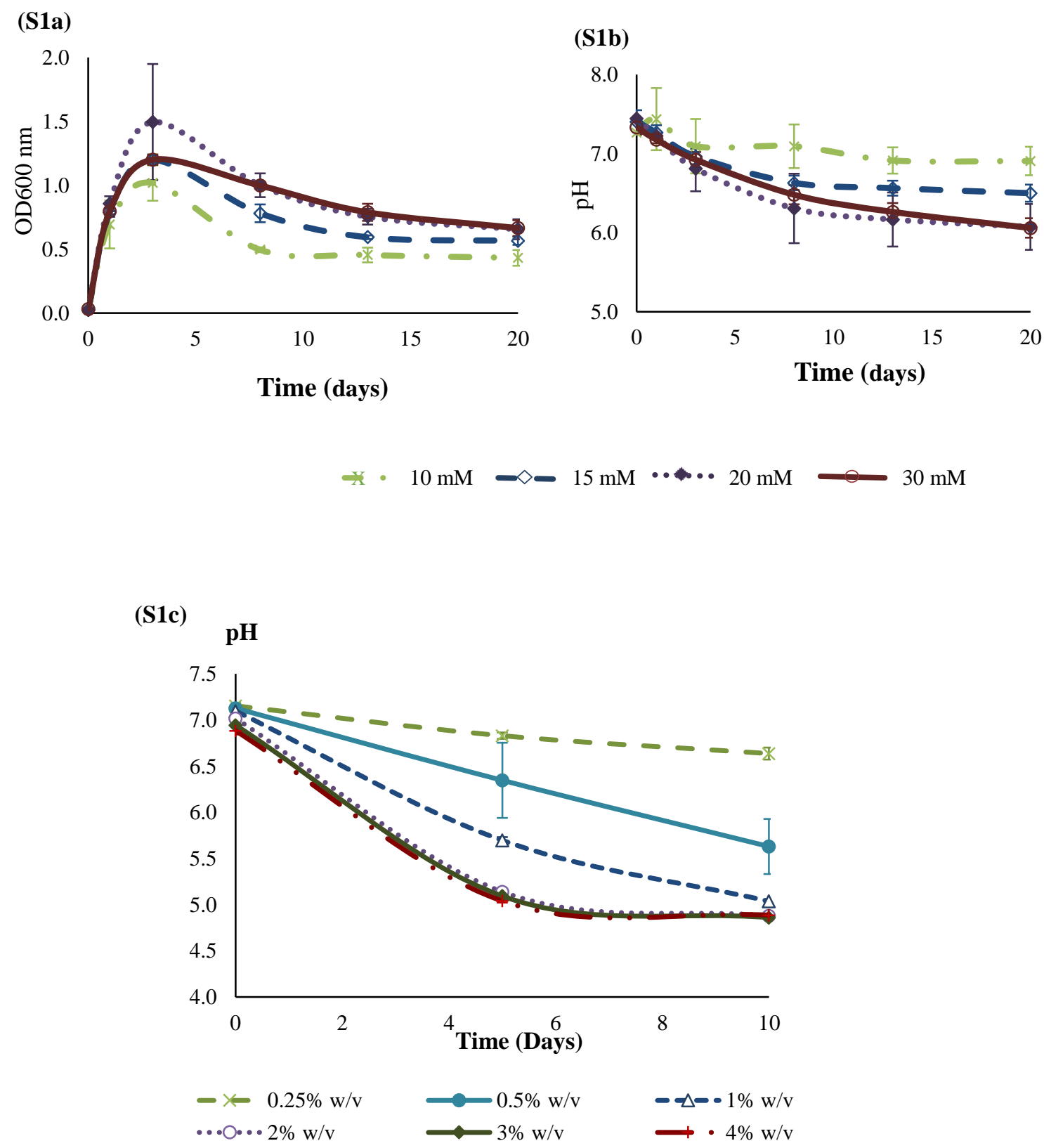

Fig. S1. Growth curves of A. succiniciruminis at different glucose concentration (S1a); pH profiles at different glucose concentration (S1b) and $\mathrm{pH}$ profiles at different starch waste concentration (S1c). 



\section{CHAPTER 5}

Microbial diversity and organic acid production

of guinea pig fecal samples

This chapter has been submitted and prepared by

Susakul Palakawong Na Ayudthaya, Hans van der Oost, John van der Oost,

Daan M. van Vliet and Caroline M. Plugge 


\begin{abstract}
The guinea pig (Cavia porcellus) or cavy is a grass-eating rodent. Its main diet consists of grass or hay, which comprises cellulose, hemicellulose, lignin and their derivatives. Here, the microbial diversity of fecal samples of two guinea pigs and microbial enrichments made with substrates, including starch waste and dried grass, were investigated along with organic acid production profiles. The microbial communities of the fecal samples were dominated by the phyla Bacteroidetes (40\%) and Firmicutes (36\%). Bacteroidales S24-7 (11\% in Cavy 1 and 21\% in Cavy 2) was the most abundant order. At genus level, many microorganisms remained unclassified. Different carbon-sources were used for organic acid production in fecal enrichments. The dominant bacterial groups in the secondary enrichments with dried grass, starch waste, and xylose were closely related to Prevotella and Blautia. Acetate was the predominant organic acid from all enrichments. The organic acid production profiles corresponded to a mixed acid fermentation but differed depending on the type of substrate. Eight phylogenetically different isolates were obtained, including a novel Streptococcus species, strain Cavy grass 6. This strain had a low abundance (1\%) in one of the fecal samples but was enriched in the dried grass enrichment (3\%). Cavy grass 6 is a fast-growing heterolactic bacterium that ferments cellobiose to lactate, acetate, formate and ethanol. Our results show that cavy fecal samples can be applied as the microbial source of microorganisms for organic acid production from complex organic substrates. The cavy gut contains many as-yet-uncultivated bacteria which may be appropriate targets for future studies.
\end{abstract}




\section{Introduction}

Guinea pigs (Cavia porcellus) are rodents belonging to the family Caviidae and are native to South America (Sakaguchi and Nabata, 1992). They are well known as experimental models for humans and have been used in medical research since the $19^{\text {th }}$ century (Hildebrand et al., 2012). In gastrointestinal research, guinea pigs are considered suitable models for humans because they have human-like E-cadherin on their intestinal surface (Hildebrand et al., 2012). To date, limited studies have been performed on the microbial composition of the guinea pig gut. In 2012, the intestinal microbiota of guinea pigs was studied using a metagenomic approach, revealing a higher abundance of Akkermansia spp. and methanogens (Methanobrevibacter spp.) compared to the human gut (Hildebrand et al., 2012). Recently, the microbial population from domesticated guinea pigs and rabbits was compared (Crowley et al., 2017). Differences were detected between samples from rabbit and guinea pig feces, suggesting that there is no a microbial community common in coprophagous (feces-eating) animals. Those animals eat their own feces to maintain their intestinal microbes and recover nutrients and vitamins (Richardson, 2000). Bacteroidetes and Firmicutes together formed most of the population in the guinea pig fecal samples, according the results of two studies (Crowley et al., 2017; Hildebrand et al., 2012). The two most abundant bacterial phyla in guinea pig guts relate to the typical vertebrate gut microbiome, including the human intestine. However, at genus level the microbiome composition was different between humans and guinea pigs (Hildebrand et al., 2012).

The guinea pig is a monogastric herbivore (Sakaguchi and Nabata, 1992) and its diet mainly consists of grass or hay of timothy, oat, wheat, pasture, meadow and/or ryegrass. Grass-eating rumen mammals such as cows and sheep have a long digestive tract or diet re-chewing system to digest and obtain nutrients, whereas guinea pigs have a relatively short digestive tract, therefore they maintain their vitamins and nutrition by re-eating their own feces. Consuming large quantities 
of plant polymers suggests that its gastrointestinal microbiome generates (hemi-) cellulolytic enzymes. The corresponding microbes may be useful for biotechnological applications.

The most abundant sources of organic carbon in global ecosystems are complex polysaccharides of plant cell walls that are difficult to degrade (Lewin et al., 2016). Cellulose degradation is usually driven by complex microbial communities such as bacteria and fungi, which use cellulolytic enzymes, 1,4- $\beta$-endoglucanase, 1,4- $\beta$-exoglucanase and/or $\beta$-glucosidase, that hydrolyse cellulose to cellobiose and/or to glucose which can then be further metabolized (Kumar et al., 2008). The microorganisms involved in cellulose degradation from the cavy gut are understudied (Lewin et al., 2016; Wilson, 2011).

Organic acids such as acetate, lactate and succinate are common fermentation products of plant polysaccharides. Organic acids can be used as biobased building-block chemicals in chemical and other industrial processes; therefore, the production of chemicals from renewable resources is considered an attractive green alternative (Agler et al., 2011; Sauer et al., 2008). Investigating the microbial diversity and organic acid production of guinea pig fecal samples could also be instrumental in revealing the mechanism of the guinea pig fiber digestion system and may lead to the discovery of novel bacteria capable of converting cellulose to organic acids. To date, no research has been performed using guinea pig fecal samples as a source for organic acid production.

In this study, the microbial diversity of guinea pig fecal samples was analyzed. Organic acid production profiles from cellulose, dried grass, glucose, starch waste, xylan and xylose by guinea pig fecal enrichment cultures were studied. Moreover, the microbial community composition of selected enrichments was revealed, and several pure cultures were isolated. 


\section{Material and Methods}

\section{Sampling, screening and enrichment of cavy fecal samples with various substrates}

A schematic overview of the experiments performed in this study is shown in Fig. 1.

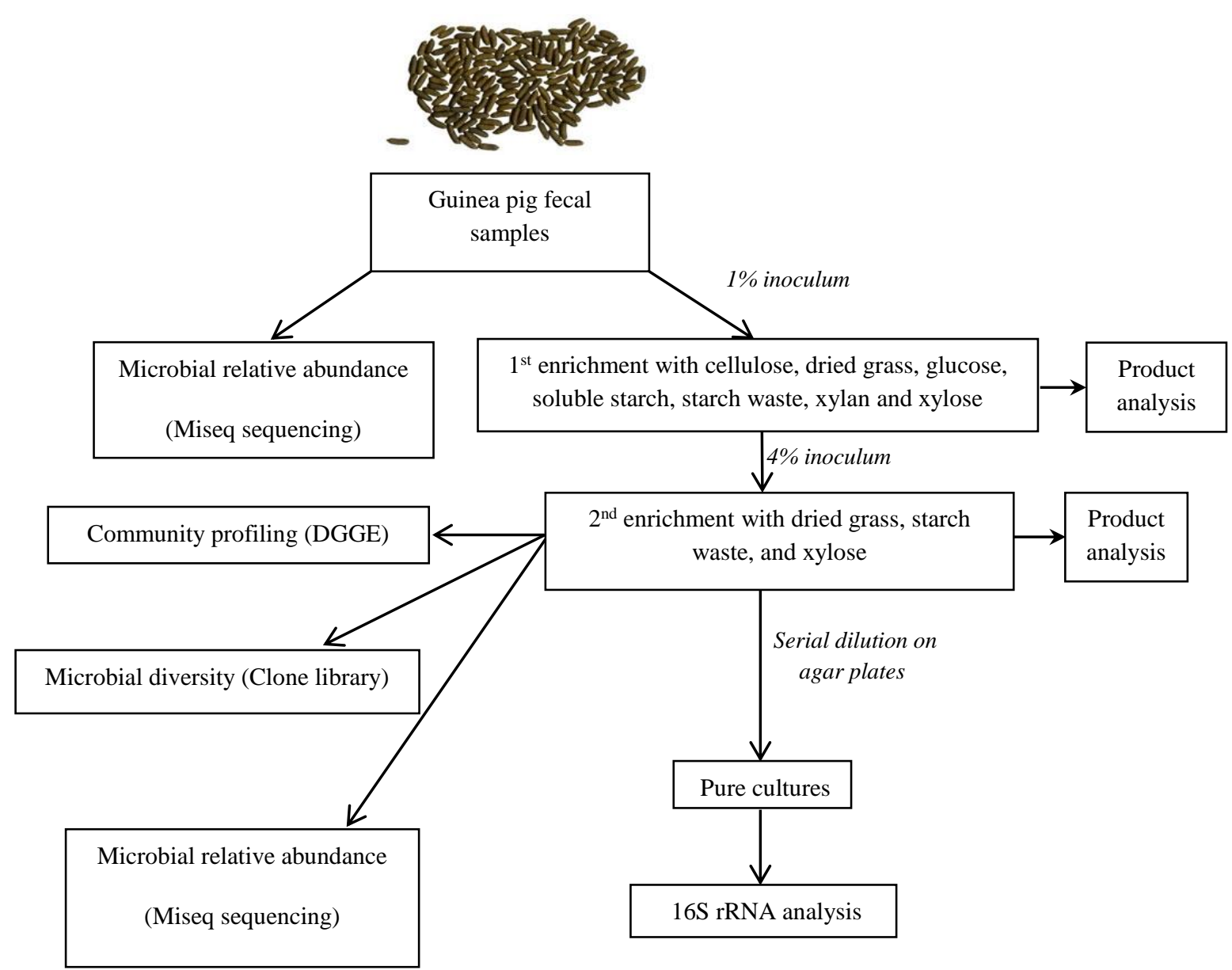

Fig. 1. Schematic overview of the experiments 


\section{Source of inoculum}

Fresh fecal droppings were collected from two adult-male pet guinea pigs (four- and threeyear-old; Cavy 1 and Cavy 2), in Renkum, The Netherlands. The fecal samples were placed into anaerobic sterile bottles and directly transferred to the Laboratory of Microbiology (Wageningen University \& Research, Wageningen, NL), where the entire experiment was performed. Approximately one gram of the fecal samples was dissolved in anaerobic phosphate buffered saline (PBS) using a sterile spatula and gentle vortexing in an anaerobic chamber. The guinea pig fecal slurry $(1 \% \mathrm{v} / \mathrm{v})$ was then used as an inoculum for enrichment with various substrates.

\section{Substrate preparation}

Cellulose, dried grass (commercial cavy grass feeding), glucose, soluble starch, starch waste, xylan and xylose $(0.5 \% \mathrm{w} / \mathrm{v})$ were used as carbon sources to selectively enrich bacteria from guinea pig feces. The dried grass was cut into small pieces using scissors $(1-3 \mathrm{~mm})$. The starch waste $(80 \%$ dry matter and 20\% water) obtained from Avebe Potato factory (Foxhol, The Netherlands) was air dried at $80{ }^{\circ} \mathrm{C}$ for $32 \mathrm{~h}$, crushed and sieved to obtain small pieces $(\leq 1 \mathrm{~mm})$. The composition of the starch waste containing $61 \%$ starch was analyzed at Nutricontrol (Veghel, The Netherlands) (Table S1).

\section{Medium composition and cultivation}

A bicarbonate-buffered anaerobic medium (BM) was used in this experiment and prepared as previously described (Plugge, 2005). The medium was supplemented (per liter) with $0.1 \mathrm{~g}$ yeast extract, $5 \mathrm{mg}$ hemin, $0.05 \mathrm{~g}$ vitamin $\mathrm{K}_{1}$ and $0.5 \mathrm{~g}$ L-cysteine-hydrochloride. Then, $0.5 \%(\mathrm{w} / \mathrm{v})$ of each substrate was added into serum bottles (duplicate bottles for each enrichment) before autoclaving. Bottles without substrate were used as controls. The final liquid volume was $50 \mathrm{ml}$ in $117 \mathrm{ml}$ serum bottles sealed with butyl rubber stoppers and aluminum crimp caps containing $\mathrm{N}_{2} / \mathrm{CO}_{2}$ $(80: 20 ; \mathrm{v} / \mathrm{v})$ and $1.7 \mathrm{~atm}(172 \mathrm{kPa})$ gas phase. The $\mathrm{pH}$ of the medium was 7.2. 
One percent $(\mathrm{v} / \mathrm{v})$ (pooled fecal samples) was inoculated in the anaerobic bottles and bottles were incubated at $37{ }^{\circ} \mathrm{C}$ in the dark for 14 days. Growth, $\mathrm{pH}$ and organic acid production of the enrichments were measured to determine microbial activity. The primary enrichments were transferred $(4 \% \mathrm{v} / \mathrm{v})$ to medium with the same substrate as previously described and termed secondary enrichments. After 5 days of incubation at $37{ }^{\circ} \mathrm{C}$, the secondary enrichments were used for further analysis.

\section{DNA extraction}

Genomic DNA from fresh feces of each guinea pig, from selected secondary enrichment samples and the isolates was extracted using Fast Spin kit for soil (MP Biomedicals; Santa Ana, CA) following the manufacturer's instructions. Genomic DNA yields were measured with a Nanodrop ND-1000 spectrophotometer (Nanodrop Technologies, Wilmington, DE). DNA quality was analyzed using OD 260/280 ratio and the integrity was determined by gel electrophoresis on a $1 \%$ (w/v) agarose gel. The extracted genomic DNA was then kept at $-20{ }^{\circ} \mathrm{C}$ for further analyzes.

\section{S rRNA amplicon sequencing analysis}

The extracted genomic DNA was diluted to obtain DNA concentration between $10-20 \mathrm{ng} / \mu \mathrm{l}$ as a template for PCR amplification. Microbial 16S rRNA V4 regions were amplified using a twostep PCR protocol. PCR amplifications were carried out in technical duplicates. The first PCR was performed with universal primers 515f (5'-GTGCCAGCMGCCGCGGTAA-3') and 806r (5'GGACTACHVGGGTWTCTAAT-3') (Caporaso et al., 2011) and the second PCR was carried out to extend eight-base specific barcodes to the amplicons as previously described (Hamady et al., 2008) using Phusion Hot Start II High-Fidelity DNA polymerase (Themo Fisher Scientific; Waltham, MA). PCR amplification was performed using a G-Storm cycler (G-storm; Essex, UK). The first PCR was performed in a total volume of $50 \mu 1$ containing $2.5 \mu 1$ of each forward and reverse primer, $0.5 \mu \mathrm{l}$ (2 unit) of the DNA polymerase, $10 \mu \mathrm{l}$ of 5 x HF-buffer, $1 \mu \mathrm{l}(200 \mu \mathrm{M}) \mathrm{dNTP}$ mix, 1 
$\mu 1$ of DNA template and $32.5 \mu 1$ of nuclease-free sterile water using the PCR program as follows: a pre-denaturing step at $98{ }^{\circ} \mathrm{C}$ for $3 \mathrm{~min}$, followed by 25 cycles at $98{ }^{\circ} \mathrm{C}$ for $10 \mathrm{~s}, 50{ }^{\circ} \mathrm{C}$ for $20 \mathrm{~s}, 72^{\circ} \mathrm{C}$ for $20 \mathrm{~s}$ and a post-elongation step of $10 \mathrm{~min}$ at $72{ }^{\circ} \mathrm{C}$. After amplification, the second PCR was done in $100 \mu$ l containing $10 \mu \mathrm{l}$ of the barcoded primer mix, $1 \mu \mathrm{l}$ (2 units) of the DNA polymerase, $20 \mu 1$ of 5 x HF-buffer, $2 \mu 1(200 \mu \mathrm{M})$ dNTP mix, $5 \mu 1$ of DNA template and $62 \mu 1$ of nuclease-free sterile water with the PCR program as follows: a pre-denaturing step at $98{ }^{\circ} \mathrm{C}$ for $30 \mathrm{~s}$, followed by 5 cycles at $98{ }^{\circ} \mathrm{C}$ for $10 \mathrm{~s}, 52{ }^{\circ} \mathrm{C}$ for $20 \mathrm{~s}, 72{ }^{\circ} \mathrm{C}$ for $20 \mathrm{~s}$ and a post-elongation step of $10 \mathrm{~min}$ at 72 ${ }^{\circ} \mathrm{C}$. The size of PCR products was expected to be $291 \mathrm{bp}$. Barcoded PCR products were examined for positive amplification on agarose gel and were then purified using the CleanPCR kit system according to the manufacturer's instruction (CleanNA Alphen aan den Rijn, The Netherlands). The DNA concentration was quantified using Qubit® dsDNA BR Assay Kit (Invitrogen) and DeNovix DS-11 FX Spectrophotometer/Fluorometer (DENovix Inc.; Wilmington, DE). All purified PCR products were pooled in equimolar amounts (200 ng of DNA per sample) to create a library which was then purified again with the CleanPCR kit to a final volume of $35 \mu$ l. The library was sent for paired-end Illumina MiSeq sequencing at GATC Biotech (Konstanz, Germany).

16S rRNA gene MiSeq sequencing data were analyzed with NG-Tax version 1.0 (RamiroGarcia et al., 2016) using default settings apart from a read length of $200 \mathrm{bp}$ and a $93 \%$ identity threshold for taxonomic assignment ('error correction' in NG-Tax). Paired-end libraries were filtered to obtain only read pairs with perfectly matching barcodes and those barcodes were then used to demultiplex reads by samples. Taxonomic assignment was performed with the SILVA 16S rRNA reference database (release version 128) using an open reference approach as described by Quast et al. (Quast et al., 2013).

\section{Denaturing gradient gel electrophoresis (DGGE) analysis}

DGGE was used to compare secondary enrichments. Bacterial 16S rRNA V6 - V8 regions were amplified with the DGGE Universal primers GC-968F (5'-CGCCCGGGGCGC 
GCCCCGGGCGGGGCGGGGGCACGGGGGGAACGCGAAGAACCTTAC-3') and 1401R (5'CGGTGTGTACAAGACCC-3') (Nübel et al., 1996) using the Phire Hot Start II High-Fidelity DNA Polymerase (Thermo Fisher Scientific; Waltham, MA). Bacterial amplicons were produced with a G-Storm cycler (G-storm; Essex, UK) using a pre-denaturing step at $95{ }^{\circ} \mathrm{C}$ for $5 \mathrm{~min}$, followed by 35 cycles at $95{ }^{\circ} \mathrm{C}$ for $20 \mathrm{~s}, 56{ }^{\circ} \mathrm{C}$ for $40 \mathrm{~s}, 72{ }^{\circ} \mathrm{C}$ for $40 \mathrm{~s}$ and a post-elongation step of $10 \mathrm{~min}$ at 72 ${ }^{\circ} \mathrm{C}$. The forward primer had a GC clamp of $40 \mathrm{bp}$ attached to the 5' end as used by Yu et al. (2008). DGGE analysis was performed as described previously (Martin et al., 2007) using a DCode TM system (Bio-Rad Laboratories; Hercules, CA) at $60{ }^{\circ} \mathrm{C}$ for $16 \mathrm{~h}$ with a denaturing gradient of 30:60 percent for bacterial profiles (Yu et al., 2008).

\section{Clone library construction}

The secondary enrichments (dried grass, starch waste and xylose) were further analyzed using a clone library approach. Almost full-length 16S rRNA genes were amplified using bacterialuniversal primers 27f (5'-AGAGTTTGATCCTGGCTCAG-3') and 1492r $\quad\left(5^{\prime}-\right.$ TACCTTGTTACGACTT-3') (Lane, 1991). PCR amplification was performed with the GoTaq Polymerase kit (Promega; Madison, WI) using a G-Storm cycler (G-storm; Essex, UK). The PCR program was started with a denaturing step at $95{ }^{\circ} \mathrm{C}$ for 5 min and continued with 35 cycles consisting of $95{ }^{\circ} \mathrm{C}$ for $30 \mathrm{~s}, 52{ }^{\circ} \mathrm{C}$ for $40 \mathrm{~s}$ and $72{ }^{\circ} \mathrm{C}$ for $90 \mathrm{~s}$ and the last step of extension at $72{ }^{\circ} \mathrm{C}$ for 7 min. PCR products were purified using the PCR Clean \& Concentrator kit (Zymo Research Corporation; Irvine, CA). Amplicons were ligated into a pGEM-T Easy vector kit (Promega; Madison, WI) and transformed into E. coli XL1-Blue Competent Cells (Agilent Technologies; Santa Clara, CA). Both ligation and transformation were conducted according to the manufacturer's instruction following the blue-white screening technique. White colonies were randomly selected and transferred to a 96-well Masterblock plate (Greiner Bio-One; Netherlands). 16S rRNA genes were sequenced using primer SP6 (5'-ATTTAGGTGACACTATAG-3') (Promega Corp.; Madison, WI) at GATC Biotech (Konstanz, Germany). DNA sequences were trimmed by removing the primer 
using the program DNA Baser Sequence Assembler v4 (Heracle BioSoft S.R.L; Arges, Romania). Chimeras were identified using DECIPHER's Find Chimeras web tool (Wright et al., 2012) and were removed. The $16 \mathrm{~S}$ rRNA sequences were blasted with the NCBI online database.

\section{Isolation and identification of fast-growing bacteria}

Each of the secondary enrichment was diluted 10-fold using liquid Reinforced Clostridial Medium (RCM) and plated on modified BMY (BM with $0.1 \mathrm{~g}^{-1}$ yeast extract), supplemented with $5 \mathrm{mg} \mathrm{l}^{-1}$ hemin, $0.05 \mathrm{~g} \mathrm{l}^{-1}$ vitamin $\mathrm{K}_{1}, 0.5 \mathrm{~g} \mathrm{l}^{-1}$ L-cysteine-hydrochloride and $15 \mathrm{~g} \mathrm{l}^{-1}$ agar (Difco) and the same carbon source as the original enrichment. The plates were incubated under anaerobic conditions with $\mathrm{N}_{2}-\mathrm{H}_{2}(96: 4 \mathrm{v} / \mathrm{v})$ gas at $37{ }^{\circ} \mathrm{C}$ for 5 days. Single colonies were picked and further purified on the same agar medium by the streak plate method, followed by serial dilution in the modified BMY liquid medium with the same substrate as described above for three times to obtain pure cultures. The pure cultures were grown in anaerobic bottles with BMY media with $20 \mathrm{mM}$ glucose and analyzed routinely by phase-contrast microscopy (Leica DM 2000; Wetzlar, Germany).

Genomic DNA of the isolated strains was amplified to obtain almost full-length 16S rRNA gene sequence using the same PCR primers and PCR protocol as previously described in the clone library analysis or by Palakawong Na Ayudthaya et al. $\left(2017^{\mathrm{a}}\right)$. 16S rRNA gene sequencing was performed at GATC Biotech (Konstanz, Germany). The 16S rRNA gene sequences were checked for reading errors and aligned using the program DNA Baser Sequence Assembler v4 (Heracle BioSoft S.R.L; Arges, Romania) and were then searched against the NCBI database using the BLASTN search online program (http://blast.ncbi.nlm.nih.gov/Blast.cgi: 21-12-2016)

\section{Analytical methods}

Growth was monitored by measuring the turbidity at $600 \mathrm{~nm}$ using a spectrophotometer for enrichments with soluble substrates (glucose and xylose). The organic acid production was measured by high-pressure liquid chromatography (HPLC) as previously described (Van Gelder et 
al., 2012). Methane and hydrogen were quantified using gas chromatography (GC) as described by Van Lingen et al. (Van Lingen et al., 2017).

\section{Nucleotide sequence accession numbers}

The 16S rRNA gene MiSeq sequences from the cavy fecal samples and the secondary enrichments and the 16S rRNA gene sequences of clone library from the secondary enrichments were deposited at the EMBL database and are available under accession numbers ERS1974899 ERS 1974908 (PRJEB21993) and LT708382 - LT08474, respectively. The bacterial 16S rRNA gene sequences of the isolates were deposited to NCBI and EMBL databases and are available under accession numbers MF579703-MF579713 and LT546457, respectively.

\section{Results and discussion}

\section{Microbial community composition of guinea pig fecal samples}

In total, 536,464 high-quality sequences were obtained from the fresh fecal samples of 'Cavy 1' and 'Cavy 2', which clustered into 78 operational taxonomic units (OTUs) at genus level. Of those 78 OTUs, 34 were shared between both animals and 44 were unique OTUs, distributed over 14 OTUs in Cavy 1 and 30 OTUs in Cavy 2. Numbers of OTUs for each sample at phylum level are shown in Table 1.

Table 1. Total number of OTUs detected in each Cavy fecal sample

\begin{tabular}{|c|c|c|c|c|c|c|c|c|c|c|c|c|}
\hline Sample & 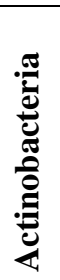 & 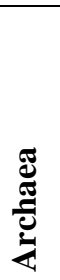 & 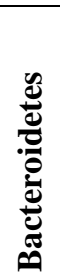 & 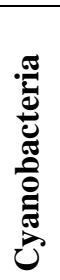 & 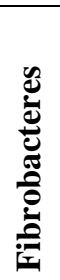 & & 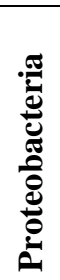 & 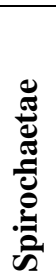 & 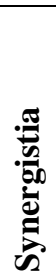 & 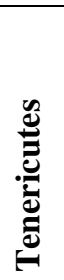 & 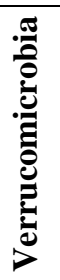 & 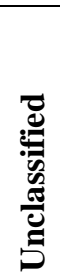 \\
\hline Cavy 1 & 5 & 1 & 13 & 2 & 0 & 16 & 2 & 1 & 1 & 2 & 6 & 1 \\
\hline Cavy 2 & 4 & 1 & 13 & 3 & 1 & 31 & 1 & 1 & 0 & 1 & 7 & 1 \\
\hline
\end{tabular}


The phyla Firmicutes (42\% and 31\%), Bacteroidetes (35\% and 45\%), Actinobacteria (13\% and $2 \%)$ and Verrucomicrobia (1\% and $9 \%$ ) had a high relative abundance in both fecal samples (Cavy 1 and 2, respectively) whereas Fibrobacteres, Cyanobacteria and Spirochaetae represented together around $11 \%$ in both samples (Data not shown). Concerning the phylum Fibrobacteres, our results are in agreement with previous work where this phylum was obviously detected in one of six guinea pigs (Crowley et al., 2017). However, the proportions of Bacteroidetes and Firmicutes in our cavy samples were different from the Crowley et al. study (Crowley et al., 2017). The Euryarchaeota phylum was detected in both samples with low relative abundance with Methanobrevibacter as the only archaeal representative detected (1.5 and 0.6\% in Cavy 1 and Cavy 2, respectively) (Fig. 2). The 16S rRNA gene sequence of this archaeon OTU showed 99\% identity to Methanobrevibacter smithii, a dominant archaeon in the human gut (Samuel et al., 2007).

The MiSeq sequencing result at genus-like level revealed a variety of bacteria, but most of them had low abundances $(<1 \%)$, as listed as in "others" (Fig. 2). Sequences that could not be assigned at six different identity-threshold levels (100, 98, 97, 95, 92 and 90\%) and two taxonomic (family and genus) levels as described by Ramiro-Garcia et al. (Ramiro-Garcia and Amann, 2015) were grouped as "Unclassified". On average, about 4\% of the total OTUs from both samples could not be assigned, indicative of an unknown microorganism as shown in 'unclassified' (Fig. 2). At family level (in both Cavy 1 and 2), Bacteroidales S24-7 group (11 and 21\%, respectively) was most abundant, followed by Prevotellaceae (5 and 11\%, respectively) (Fig. 2). In Cavy 1, the genus Allobaculum had a very high relative abundance (31\%), while only $1 \%$ was detected in the sample from the Cavy 2. Allobaculum spp. was previously identified as the most active glucose utiliser in mice (Herrmann et al., 2017). About 5.7\% relative abundance of Allobaculum was previously found in guinea pig gut (Neuendorf et al., 2015) and was also detected in other animals' guts, including in dogs Greetham et al., 2004), mice and hamsters (Martínez et al., 2009). Bifidobacterium, a probiotic species in the phylum Actinobacteria that is believed to be important to the host health, was highly abundant (12\% relative abundance) in Cavy 1 but not in Cavy 2 (1\% relative abundance). On the 
other hand, Fibrobacter, a fiber-degrading species, and Ruminococcus were found in Cavy 2 with relative abundances of 6 and 3\%, respectively, and were not detected in Cavy 1. Crowley et al. (2017) similarly reported that the genus Fibrobacter was detected in high abundance (11\%) in only one of six guinea pigs. The researchers suggested that in the cavy gut, organisms other than the Fibrobacteres must be responsible for fiber digestion (Crowley et al., 2017).

The results of both fecal samples suggested that each guinea pig has its own microbiome even when living together and eating the same diet (Fig. 2). Nguyen et al. (Nguyen et al., 2015) also reported that the core gut microbiota of mice accounted for only $13 \%$ of the genera (44 out of 352 genera) that were shared in three murine datasets. Moreover, about 68\% (in average or 57 and $78 \%$, respectively) from both cavy fecal samples could not be assigned at the genus level (Fig. 2). It seems a general observation in all cavy microbiome studies, including our study, that a substantial percentage of the population remains unclassified at the genus level, indicative of novel biodiversity (Neuendorf et al., 2015). 


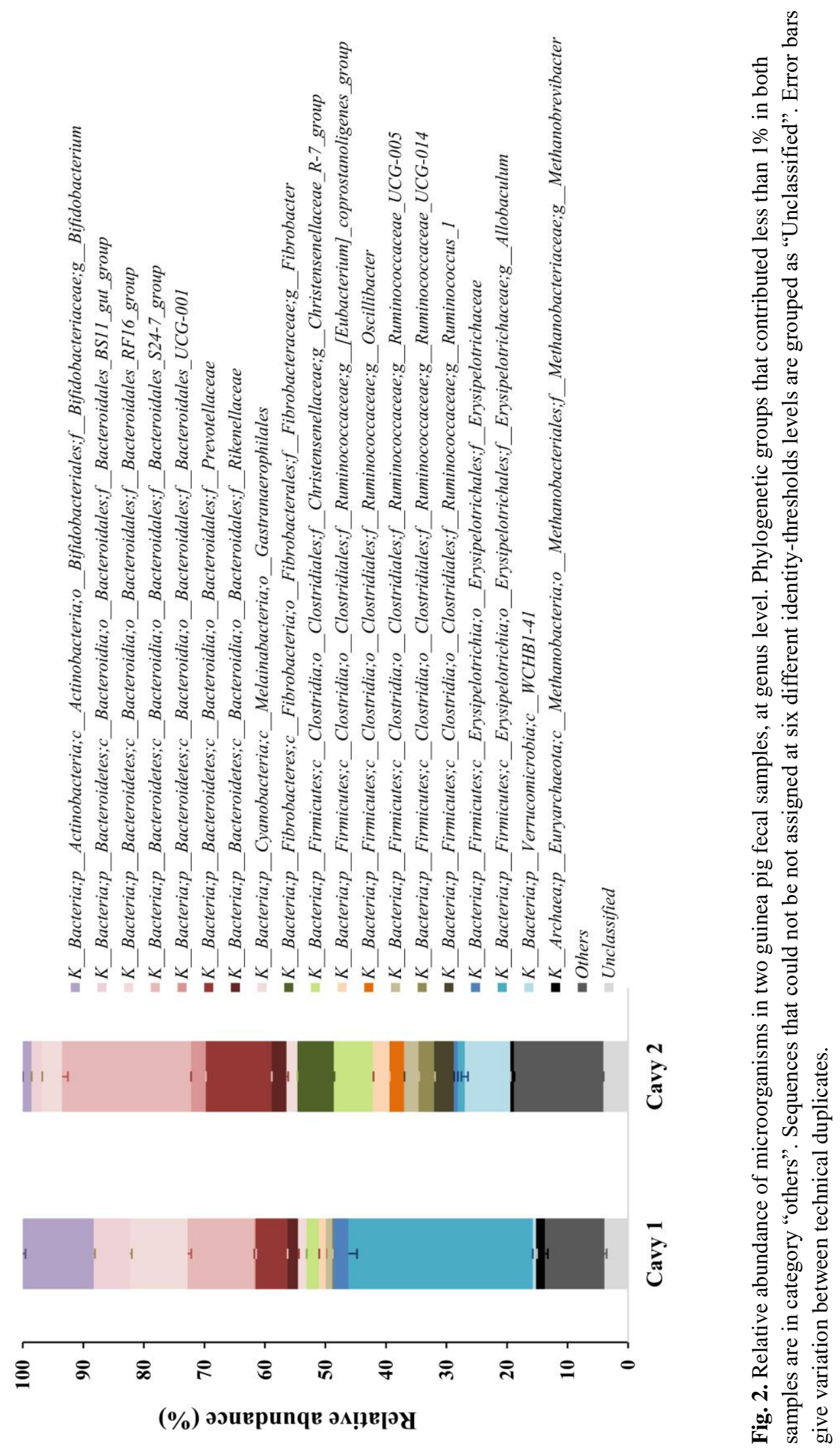




\section{Product profiles}

In all primary enrichments, mixed acid fermentation to acetate, butyrate, lactate, propionate, succinate and ethanol occurred with the following substrates; cellulose, dried grass, glucose, starch waste, xylan and xylose (Fig. 3). Glucose was degraded most rapidly (within one day; Fig. 3E) with simultaneous acidification (Fig. 3A), followed by starch waste, xylose, xylan, cellulose and dried grass (Fig. 3). The highest total organic acid production was reached at different time points depending on the substrate type. For instance, the maximum was reached at day 1 in the glucose enrichment (48 $\mathrm{mM}$ total organic acids), at day 3 in the starch waste enrichment (38 $\mathrm{mM})$ and at day 7 in the xylan and xylose enrichments (40 and $39 \mathrm{mM}$ ) (Fig. 3 and Table S2). Fermentation of cellulose and dried grass was slower with total organic acid production of $22 \mathrm{mM}$ and $31 \mathrm{mM}$ at day 9 and day 14, respectively. In general, acetate was the main product in all of the enrichments, with xylan yielding the highest acetate concentration (32 $\mathrm{mM}$ at day 7). The highest succinate concentration $(11 \mathrm{mM})$ was measured in the xylose enrichment (Fig. 3B $-3 \mathrm{H})$ and Table S2). Lactate was mainly formed during glucose and starch waste enrichments (11 and $5 \mathrm{mM}$, respectively) and trace amounts were detected with other substrates. organic acid concentration decreased by the end of the fermentation period, particularly in the case of succinate. As these were all primary enrichments, some or many bacteria (slow and fast growing) might have contributed to the dynamic fermentation (Fig. 3C, 3E, 3F, 3G and 3H and Table S2). 


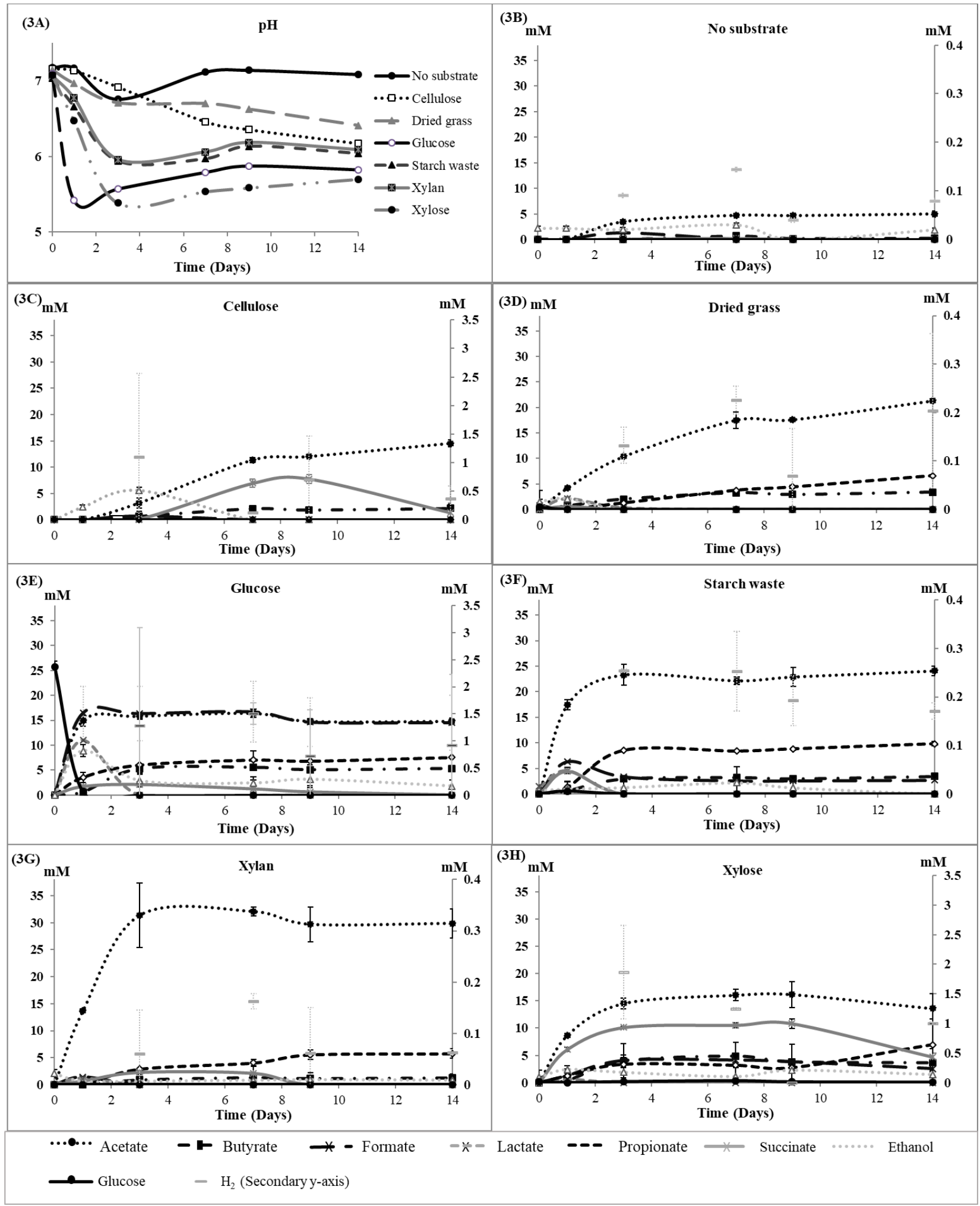

Fig. 3. $\mathrm{pH}$ profile of all fermentations in (3A). Guinea pig fecal slurry fermentation profiles from different carbon sources of the primary enrichments incubated at $37^{\circ} \mathrm{C}$ for 14 days $(3 \mathrm{~B}-3 \mathrm{H})$. The error bars indicate the standard deviation. 
In the secondary enrichments, mixed acid fermentation again occurred, and acetate, butyrate and propionate were produced with all substrates (dried grass, starch waste and xylose). Formate, lactate, succinate and/or ethanol were produced in some substrates, indicating that different microbial communities developed (Table S3). Acetate was still the primary fermentation product from all substrates, being the highest in the xylose enrichment with $27 \mathrm{mM}$ (Table S3). Butyrate was detected in small amounts $(0.5-1.8 \mathrm{mM})$ in all enrichments. Formate and lactate were detected only in the secondary enrichment of starch waste with 3.7 and $0.5 \mathrm{mM}$, respectively.

At the start of the primary enrichments, small amounts of hydrogen were detected with glucose, cellulose and xylose substrates with 1.3, 1.1 and $1.9 \mathrm{mM}$ (at day 3), respectively. In addition, traces of hydrogen were detected from dried grass, starch waste and xylan (Fig. 3). Although cavies are known to contain methanogens in their gut (Franz et al., 2011), methane has never been detected in any of the here-described incubations. From this, we concluded that methanogens were not active in the enrichments for organic acid production. Their absence could be explained by the rapidly decreasing $\mathrm{pH}$ (Fig. 3A), since most gut methanogens are neutrophilic (pH range 6.0-8.0) and sensitive to low pH (Serrano-Silva et al., 2014; Zhang et al., 2016)

Taken together, the different substrates yielded different mixed acid profiles, with acetate as the main product. All complex substrates (cellulose, dried grass and starch waste) were fermented by the microbial community from guinea pig fecal samples. Based on the organic acid production profiles, the succinate production and the efficiency of the substrate utilisation, dried grass, starch waste and xylose enrichments were selected for further analysis. 


\section{Microbial community profiling of secondary enrichments}

Major groups detected

Bacterial DGGE profiles of guinea pig fecal samples from the secondary enrichments of dried grass, starch waste and xylose are shown in Fig. S1. Based on the obtained DGGE profiles, three bacterial $16 \mathrm{~S}$ rRNA gene clone libraries were constructed to identify the phylogenetic affiliation of the dominant bacteria. Additionally, a microbial 16S rRNA gene MiSeq analysis was used to investigate the relative abundance of the microorganisms from the secondary enrichments. Three clone libraries of dried grass (38 clones), starch waste (37 clones) and xylose (20 clones) secondary enrichments were constructed. After chimera screening, 36, 37 and 20 clones passed the quality control and represented the bacterial community from the enrichments of dried grass, starch waste and xylose, respectively (Table 2). In the clone library of all enrichments, most of the clones were distantly related to cultured relatives and may represent novel genera or species, according to the respective 16S rRNA gene sequence identity thresholds of 94.5\% (Yarza et al., 2014) and 98.7\% (Stackebrandt and Ebers, 2006) respectively. About $60 \%$ of all clones had less than $94 \%$ identity to their closest cultured relative (Table 2), again indicative of the presence of multiple novel genera in the cavy gut. 
Table 2. Phylogenetic affiliation and frequency of cloned bacterial 16S rRNA gene amplicons ${ }^{\mathrm{a}}$ from the secondary enrichments of cavy fecal samples

\begin{tabular}{|c|c|c|c|c|}
\hline $\begin{array}{l}\text { Enrichment } \\
\text { (No. of clones) }\end{array}$ & Closest cultured relative & $\begin{array}{l}\text { No. of } \\
\text { clones }\end{array}$ & $\begin{array}{c}\text { Identity } \\
(\%)\end{array}$ & $\%$ \\
\hline \multirow{10}{*}{ Dried grass (36) } & Acetanaerobacterium elongatum & 1 & $93 \%$ & 3 \\
\hline & Anaerovorax odorimutans & 2 & $93 \%$ & 6 \\
\hline & Bacteroides xylanisolvens & 2 & $99 \%$ & 6 \\
\hline & Blautia marasmi & 4 & $98 \%$ & 11 \\
\hline & Blautia producta & 4 & $98 \%$ & 11 \\
\hline & [Clostridium] cochlearium & 1 & $99 \%$ & 3 \\
\hline & Clostridium fimetarium & 1 & $95 \%$ & 3 \\
\hline & Prevotella copri & 3 & $91 \%$ & 8 \\
\hline & Prevotella dentalis & 9 & $92-94 \%$ & 25 \\
\hline & Prevotella veroralis & 9 & $91-92 \%$ & 25 \\
\hline \multirow{15}{*}{$\begin{array}{c}\text { Starch waste } \\
\text { (37) }\end{array}$} & Bacteroides coprosuis & 1 & $89 \%$ & 3 \\
\hline & Bacteroides xylanisolvens & 1 & $99 \%$ & 3 \\
\hline & Blautia marasmi & 4 & $96-98 \%$ & 11 \\
\hline & Blautia producta & 5 & $98 \%$ & 14 \\
\hline & Clostridium cochlearium & 2 & $99 \%$ & 5 \\
\hline & [Clostridium] indolis & 2 & $95-99 \%$ & 5 \\
\hline & Defluviitalea saccharophila & 1 & $97 \%$ & 3 \\
\hline & Prevotella bryantii & 1 & $95 \%$ & 3 \\
\hline & Prevotella copri & 1 & $91 \%$ & 3 \\
\hline & Prevotella dentalis & 10 & $93-95 \%$ & 27 \\
\hline & Prevotella histicola & 2 & $91-92 \%$ & 5 \\
\hline & Prevotella maculosa & 1 & $91 \%$ & 3 \\
\hline & Prevotella veroralis & 4 & $91 \%$ & 11 \\
\hline & Ruminococcus gauvreauii & 1 & $96 \%$ & 3 \\
\hline & Sporanaerobacter acetigenes & 1 & $99 \%$ & 3 \\
\hline \multirow{12}{*}{ Xylose (20) } & Bacteroides coprosuis & 2 & $89 \%$ & 10 \\
\hline & Bacteroides eggerthii & 1 & $89 \%$ & 5 \\
\hline & Bacteroides xylanisolvens & 1 & $90 \%$ & 5 \\
\hline & Blautia marasmi & 3 & $98-99 \%$ & 15 \\
\hline & Blautia producta & 1 & $96 \%$ & 5 \\
\hline & Clostridium cochlearium & 3 & $99 \%$ & 15 \\
\hline & Defluviitalea saccharophila & 1 & $93 \%$ & 5 \\
\hline & Eubacterium oxidoreducens & 1 & $93 \%$ & 5 \\
\hline & Oscillibacter valericigenes & 1 & $92 \%$ & 5 \\
\hline & Prevotella dentalis & 2 & $94 \%$ & 10 \\
\hline & Prevotella veroralis & 2 & $91 \%$ & 10 \\
\hline & Ruminococcus gauvreauii & 2 & $96-98 \%$ & 10 \\
\hline
\end{tabular}

\footnotetext{
a 16S rRNA gene sequences were deposited in genbank with the accession numbers LT708382-LT0847
} 
The 16S rRNA gene MiSeq results revealed no archaea in the enrichments, confirming the earlier conclusion that methanogenic archaea were absent. The highest bacterial diversity was found in the dried grass enrichment while the lowest was detected in the xylose enrichment. These results were supported by the DGGE profiling as represented by the number of bands on the DGGE gel profiling (Fig. S1). These revealed and confirmed that the substrate not only drove the fermentation pattern profile (Fig. 3) but also the bacterial composition. Firmicutes were the most abundant in the dried grass enrichment with $67 \%$, whereas Bacteroidetes were the most abundant in the starch waste and xylose enrichments (61 and 64\%, respectively). Actinobacteria were detected in all enrichments with a low abundance ( $3 \%$ on average).

In the microbial community analyzes of the secondary enrichments, the two approaches (clone library and MiSeq sequencing analyzes) revealed slightly different compositions. This could be due to the different primers used and to the statistical power of the clone library analysis which may have been somewhat limited by the small library size (Dishaw et al., 2014; Kiely et al., 2011). Moreover, the different lengths of the amplified sequences from both methods resulted in varying $\%$ identification comparing to the database (200 bp was used for MiSeq and on average $721 \mathrm{bp}$ was used for the clone library). Both approaches detected Prevotella spp. in all enrichments (Table 2, Fig. 4). However, the clones were only distantly related to Prevotella spp. $(\leq 95 \%)$ and represent either novel genera or species. The two approaches revealed Prevotella as being the core of the microbial community in the secondary enrichments, although the proportion was different between the two methods. Therefore, our hypothesis is that the genus Prevotella may play an important role in the fiber degradation in the guinea pig gut since this genus was detected in both fecal samples and involved in fiber degradation in many organisms. Members of the genus Prevotella, known to carry genes for cellulose and xylan hydrolysis (Ivarsson et al., 2014), can efficiently convert xylan, xylose and/or carboxymethylcellulose into short-chain fatty acids (De Filippo et al., 2010). Prevotella enterotypes were also dominant in the gut of mice and humans that had carbohydrate- and fiber-rich 
diets (De Filippo et al., 2010; Nguyen et al., 2015). Prevotella spp. has also been reported to show a positive correlation with xylose in pig guts and it is known as an acetate-producing bacterium (Ivarsson et al., 2014). The Genus Prevotella is known as a dietary fiber-fermenting bacterium (Chen et al., 2017) and recently it was shown that it became dominant in the calve gut upon a change to fiber diets (Jami et al., 2013). Moreover, the phylum Bacteroidetes (Prevotella) was the most abundant group and is postulated to have a positive relationship with the diet containing fiber in guinea pigs (Crowley et al., 2017).

Blautia was the most abundant OTU ( $41 \%$ relative abundance) in the dried grass enrichment, while less than $1 \%$ was detected in the starch waste enrichment and it was not detected at all in the xylose enrichment (Fig. 4). However, Blautia was detected in all clone libraries of the three enrichments (dried grass, starch waste and xylose) with 22, 24 and 20\% abundances, respectively (Table 2). We conclude that Blautia is present in all secondary enrichments. Acetate was the main fermentation product of Blautia producta (formerly Ruminococcus productus) (Liu et al., 2008). In our study, B. producta related clones (96-98\% identity) were abundant in the dried grass (11\%), starch waste (14\%) and xylose (5\%) enrichments (Table 2). 


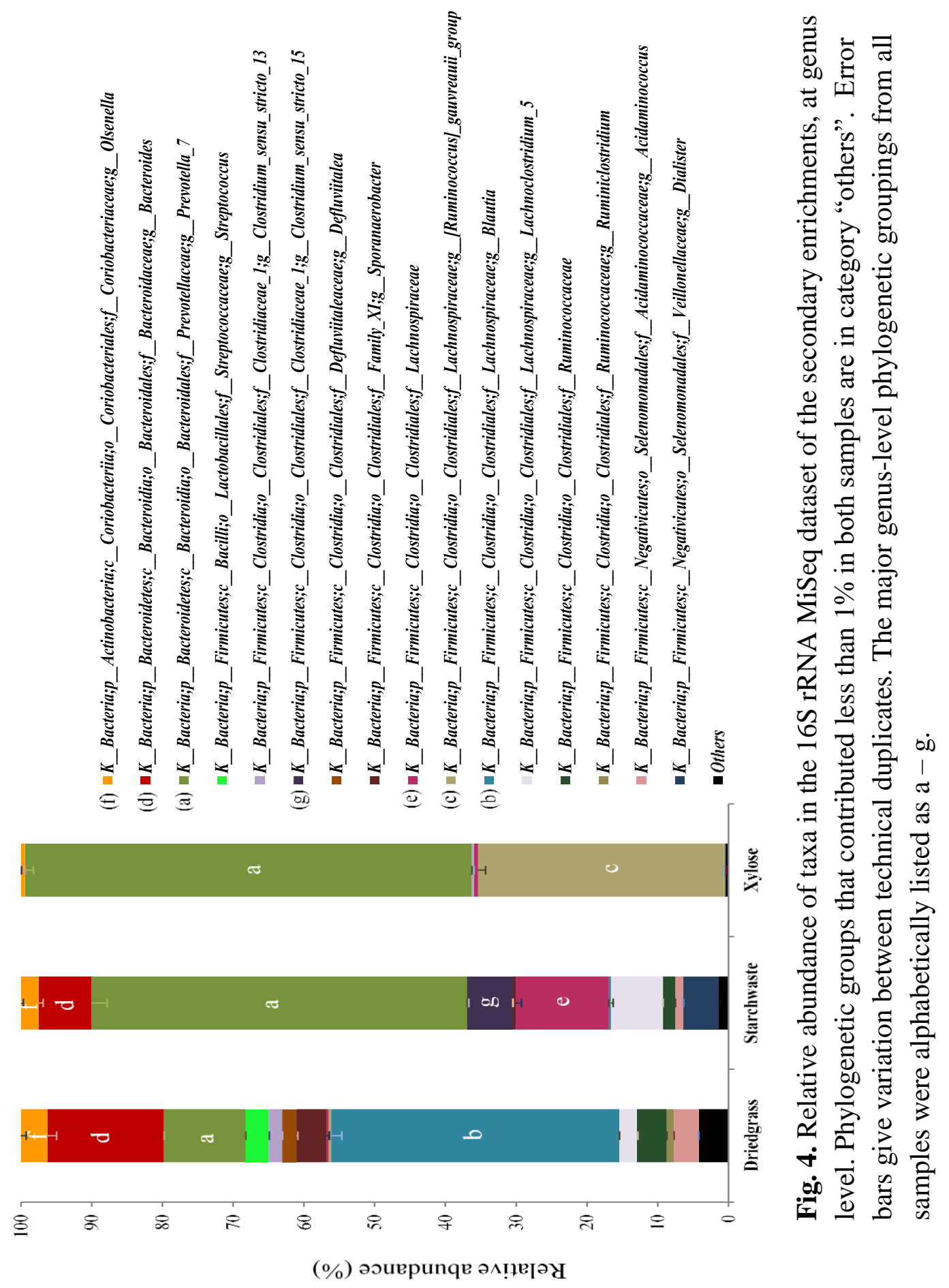


The second most abundant group in the dried grass enrichment by MiSeq sequencing analysis belonged to genus Bacteroides (16\% relative abundance). Bacteroides was also present in the enrichment of starch waste ( $8 \%$ relative abundance) but was not detected in the xylose enrichments. Bacteroides-related clones were detected in all enrichments. Clone sequences related to Bacteroides xylanisolvens (99\% 16S rRNA gene sequence identity) were detected in the enrichments of dried grass and starch waste with 6 and 3\% relative abundances, respectively, and the clone sequences related to B. xylanisolvens (90\% 16S rRNA gene sequence identity) were also detected with $5 \%$ relative abundance in the xylose enrichment. B. xylanisolvens is known to degrade xylan and xylose to mainly acetate, propionate and succinate, but cannot utilise starch (Chassard et al., 2008). The starch waste contains various compounds such as sugar, protein and/or other substances that bacteria can use for growth, as well as the benefit of mixed cultures in the enrichment that the bacteria can share their products. The 90-99\% 16S rRNA gene sequence identity points to the possibility of a different Bacteroides strain.

The second most abundant bacteria detected in the xylose enrichment by MiSeq sequencing analysis was related to Ruminococcus gauvreauii (35\% relative abundance). $R$. gauvreauii was mainly detected in the xylose enrichment and only less than $1 \%$ was found in the dried grass and was not detected in the starch waste enrichments. In the clone library, the sequences related to this member were detected in both in xylose and starch waste enrichments with 10 and $3 \%$ relative abundances with 96-98 and 96\% 16S rRNA identity, respectively (Table 2). Ruminococcus gauvreauii (CCRI-16110T) has been reported not to produce acid from L-xylose or starch (Domingo et al., 2008). However, in our experiment, we used D-xylose and starch waste in which the composition of xylose and starch were different from the previous study. Based on the 16S rRNA gene sequence identities of our clones (96-98\%) to that of $R$. gauvreauii CCRI-16110 ${ }^{\mathrm{T}}$, we enriched one or more novel species of the genus Ruminococcus. 


\section{Isolation and identification of fast-growing bacteria}

The secondary enrichments of dried grass, starch waste and xylose were selected to isolate potential novel species based on the organic acid profiles and the clone library results. A variety of isolates was obtained from dried grass (5), starch waste (6) and xylose (1) secondary enrichments. The 12 isolates were identified based on 16S rRNA gene sequence analysis which resulted in eight unique isolates (Table 3), from which four isolates belonged to genus Clostridium and the others belonged to genus Streptococcus, Actinomyces, Lactobacillus and Staphylococcus. Clostridium spp. were isolated from all enrichments and they are well known as acetate- and/or butyrate-producing bacteria. One of the isolates, strain Cavy grass 6, obtained from dried grass, had only $96 \% 16 \mathrm{~S}$ rRNA identity to Streptococcus devriesei CCUG $47155^{\mathrm{T}}$ (Table 3). Less than $1 \%$ of the OTU obtained from the Miseq sequencing approach belonged to the genus Streptococcus was detected in Cavy 2 and absent in Cavy 1 fresh fecal samples (data not shown). Streptococcus sp. strain Cavy grass 6 was enriched in dried grass and increased to $3 \%$ relative abundance in the secondary enrichment from which it was isolated (Fig. 2). Strain Cavy grass 6 is a novel species and it is a facultative anaerobe, fast-growing bacterium that converts cellobiose mainly to lactate (Palakawong $\mathrm{Na}$ Ayudthaya et al., $\left.2017^{\mathrm{a}}\right)$. 
Table 3. Pure cultures obtained from guinea pig fecal samples.

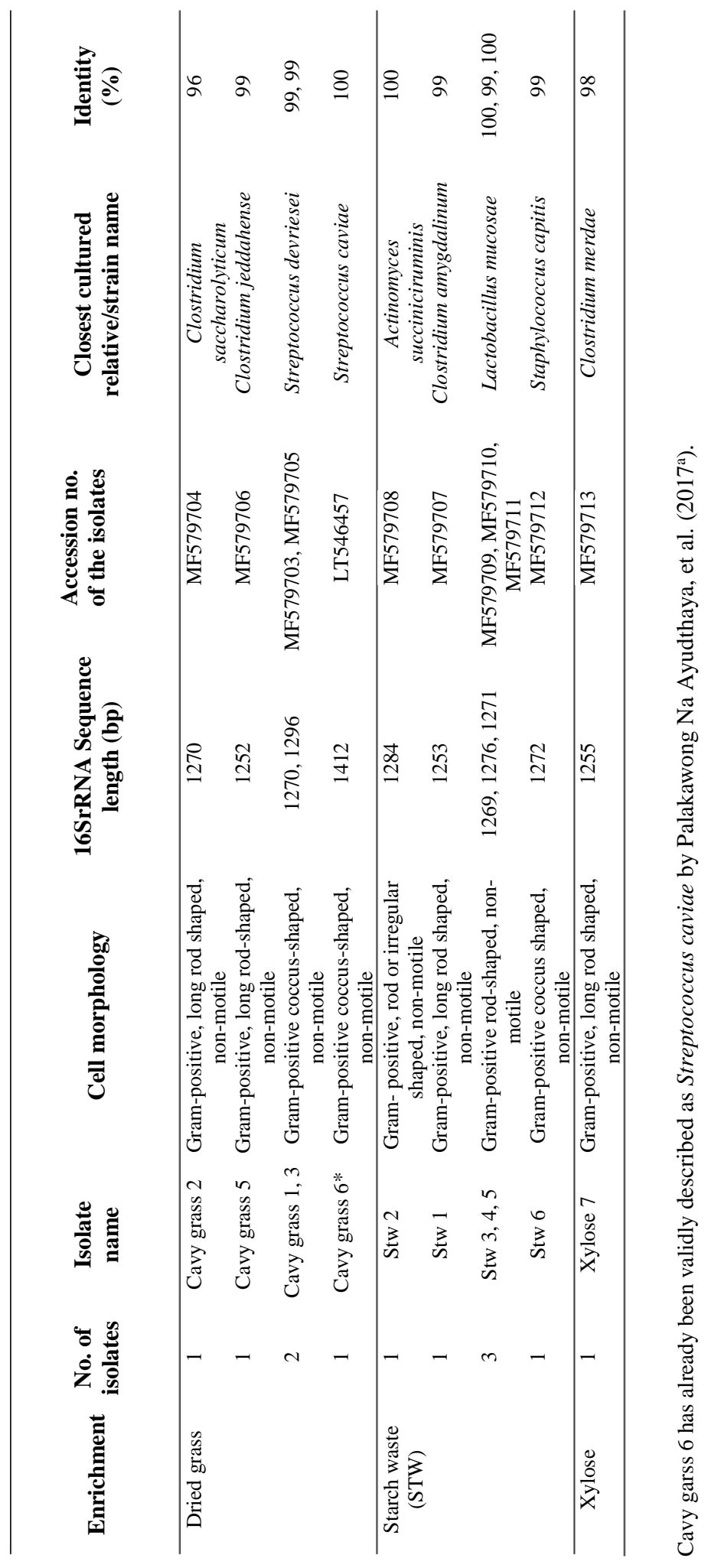




\section{Conclusion}

We investigated the microbial community of fecal samples from two domesticated guinea pigs using MiSeq sequencing analysis and found that $68 \%$ of the community could not be classified to genus level. The microbial composition of the two fecal samples was quite different at the genus level (Fig. 2), indicating that despite identical diets for several years, the two guinea pigs each have their own microbiomes.

This was the first study in which guinea pig fecal samples were used for organic acid production and microbial enrichments with various substrates. Acetate was the main organic acid produced from all substrates. Prevotella and Blautia were the most abundant microbial groups in the secondary enrichments of dried grass, starch waste and xylose. The microbial enrichment strategy is an efficient approach for obtaining novel organic acid-producing bacteria. The microbial diversity analysis of the guinea pig intestine has been reviewed, and many unknown bacteria are waiting to be cultured and characterized. Therefore, guinea pig fecal samples are an interesting source for further microbial exploration and could lead to the isolation of dedicated acetate or lactate producers and/or starch waste, grass or cellulose degraders in the future.

\section{Acknowledgments}

Prof. W. M. de Vos and Prof. A. J. M. Stams are gratefully acknowledged for stimulating discussions and W. M Akkermans-van Vliet, M. Jarzembowska and A. H. van Gelder for technical support. The first author was supported by a Royal Thai Government Scholarship, Thailand and D. M. van Vliet was supported by Gravitation grant project 024.002 .002 from the Netherlands Ministry of Education, Culture and Science. 


\section{Supplementary data}

Table S1. Composition of the dried starch waste used in this study

Starch waste was obtained from Avebe Potato factory (Foxhol, The Netherlands) and the starch waste composition was analyzed at Nutricontrol (Veghel, The Netherlands)

\begin{tabular}{lc}
\hline Composition & Percent $\left(\% \mathbf{w ~ w}^{-1}\right)$ \\
\hline Starch & 61 \\
Crude protein & 1.1 \\
Fiber & 0.8 \\
Crude ash & 0.4 \\
Sugar & 0.3 \\
Fat & 0.01 \\
Others & 36.4 \\
\hline
\end{tabular}


Table S2. Fermentation profiles in the primary enrichments

\begin{tabular}{|c|c|c|c|c|c|c|c|c|c|}
\hline \multirow{2}{*}{$\begin{array}{l}\text { Substrates } \\
(0.5 \% \text { w/v) }\end{array}$} & \multirow{2}{*}{$\begin{array}{l}\text { Incubation } \\
\text { time (days) }\end{array}$} & \multirow{2}{*}{ Glucose } & \multicolumn{7}{|c|}{ Products $\left(\mathrm{mmol} \mathrm{l}^{-1}\right)$} \\
\hline & & & Acetate & Butyrate & Formate & Lactate & Propionate & Succinate & Ethanol \\
\hline \multirow{6}{*}{ No substrate } & 0 & 0 & 0 & 0 & 0 & 0 & 0 & 0 & $2.2( \pm 0.0)$ \\
\hline & 1 & 0 & 0 & 0 & 0 & 0 & 0 & 0 & $2.2( \pm 1.7)$ \\
\hline & 3 & 0 & $3.5( \pm 0.4)$ & 0 & $1.3( \pm 0.0)$ & 0 & 0 & $0.2( \pm 0.2)$ & $2.0( \pm 0.6)$ \\
\hline & 7 & 0 & $4.7( \pm 0.2)$ & $0.7( \pm 0.0)$ & 0 & 0 & 0 & $0.3( \pm 0.0)$ & $2.8( \pm 0.4)$ \\
\hline & 9 & 0 & $4.7( \pm 0.4)$ & $0.2( \pm 0.3)$ & 0 & 0 & 0 & $0.1( \pm 0.2)$ & 0 \\
\hline & 14 & 0 & $5.0( \pm 0.6)$ & $0.2( \pm 0.3)$ & 0 & 0 & 0 & 0 & $1.9( \pm 2.7)$ \\
\hline \multirow{6}{*}{ Cellulose } & 0 & 0 & 0 & 0 & 0 & 0 & 0 & 0 & 0 \\
\hline & 1 & 0 & 0 & 0 & 0 & 0 & 0 & 0 & $2.5( \pm 0.4)$ \\
\hline & 3 & 0 & $3.2( \pm 1.0)$ & $0.7( \pm 1.0)$ & $0.7( \pm 1.0)$ & 0 & 0 & $0.2( \pm 0.2)$ & $5.6( \pm 0.5)$ \\
\hline & 7 & 0 & $11.4( \pm 0.4)$ & $2.1( \pm 0.5)$ & 0 & 0 & 0 & $7.0( \pm 0.8)$ & 0 \\
\hline & 9 & 0 & $12.0( \pm 0.1)$ & $1.9( \pm 0.4)$ & 0 & 0 & 0 & $7.9( \pm 0.8)$ & 0 \\
\hline & 14 & 0 & $14.5( \pm 0.7)$ & $2.7( \pm 0.9)$ & 0 & 0 & 0 & $1.3( \pm 1.9)$ & 0 \\
\hline \multirow{6}{*}{ Dried grass } & 0 & $0.5( \pm 0.0)$ & 0 & 0 & $0.8( \pm 1.2)$ & 0 & 0 & 0 & $1.5( \pm 2.2)$ \\
\hline & 1 & 0 & $4.2( \pm 0.1)$ & $0.8( \pm 0.1)$ & 0 & $2.1( \pm 0.1)$ & 0 & $0.6( \pm 0.1)$ & $2.2( \pm 0.1)$ \\
\hline & 3 & 0 & $10.4( \pm 0.1)$ & $2.1( \pm 0.3)$ & 0 & $0.3( \pm 0.0)$ & $1.3 \pm 0.1)$ & 0 & 0 \\
\hline & 7 & 0 & $17.5( \pm 1.6)$ & $3.3( \pm 0.0)$ & 0 & 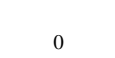 & $3.8( \pm 0.1)$ & 0 & 0 \\
\hline & 9 & 0 & $17.6( \pm 0.0)$ & $2.9( \pm 0.1)$ & 0 & 0 & $4.4( \pm 0.3)$ & 0 & 0 \\
\hline & 14 & 0 & $21.3( \pm 0.4)$ & $3.4( \pm 0.0)$ & 0 & 0 & $6.6( \pm 0.2)$ & 0 & 0 \\
\hline \multirow{6}{*}{ Glucose } & 0 & $\begin{array}{c}25.8( \pm \\
1.1)\end{array}$ & 0 & 0 & 0 & 0 & 0 & 0 & 0 \\
\hline & 1 & $0.7( \pm 1.1)$ & $14.9( \pm 1.1)$ & $0.7 \pm 0.1)$ & $16.5( \pm 5.4)$ & $11.0( \pm 3.0)$ & $3.0( \pm 1.0)$ & $1.7( \pm 0.0)$ & $8.9( \pm 1.6)$ \\
\hline & 3 & 0 & $15.8( \pm 0.6)$ & $5.3( \pm 0.9)$ & $16.3( \pm 5.4)$ & 0 & $6.0( \pm 0.1)$ & $2.1( \pm 0.3)$ & $2.9( \pm 2.8)$ \\
\hline & 7 & 0 & $16.4( \pm 0.9)$ & $5.6( \pm 0.5)$ & $16.7( \pm 6.1)$ & 0 & $7.0( \pm 1.8)$ & $1.2( \pm 1.8)$ & $2.4( \pm 0.8)$ \\
\hline & 9 & 0 & $14.8( \pm 0.6)$ & $5.1( \pm 0.5)$ & $14.6( \pm 4.9)$ & 0 & $6.8( \pm 0.8)$ & $0.6( \pm 0.9)$ & $3.2( \pm 2.7)$ \\
\hline & 14 & 0 & $14.8( \pm 0.7)$ & $5.4( \pm 0.1)$ & $14.5( \pm 5.5)$ & 0 & $7.6( \pm 0.0)$ & 0 & $1.8( \pm 2.6)$ \\
\hline \multirow{6}{*}{ Starch waste } & 0 & 0 & 0 & 0 & 0 & $1.5( \pm 0.1)$ & 0 & 0 & $0.7( \pm 1.0)$ \\
\hline & 1 & $0.5( \pm 0.3)$ & $17.5( \pm 1.0)$ & $0.7 \pm 0.1)$ & $6.3( \pm 0.8)$ & $4.6( \pm 0.6)$ & $1.4( \pm 1.1)$ & $4.4( \pm 0.0)$ & $1.0( \pm 1.4)$ \\
\hline & 3 & 0 & $23.3( \pm 2.0)$ & $3.0( \pm 0.2)$ & $3.4( \pm 0.2)$ & 0 & $8.6( \pm 0.2)$ & 0 & $1.3( \pm 1.8)$ \\
\hline & 7 & 0 & $22.2( \pm 0.8)$ & $3.2( \pm 0.1)$ & $2.6( \pm 0.5)$ & 0 & $8.4( \pm 0.1)$ & 0 & $2.2( \pm 3.1)$ \\
\hline & 9 & 0 & $22.9( \pm 1.9)$ & $3.0( \pm 0.2)$ & $2.6( \pm 0.4)$ & 0 & $8.8( \pm 0.3)$ & 0 & $1.2( \pm 1.7)$ \\
\hline & 14 & 0 & $24.1( \pm 0.9)$ & $3.4( \pm 0.3)$ & $2.7( \pm 0.7)$ & 0 & $9.8( \pm 0.4)$ & 0 & 0 \\
\hline \multirow{6}{*}{ Xylan } & 0 & 0 & 0 & 0 & 0 & 0 & 0 & 0 & $2.0( \pm 0.8)$ \\
\hline & 1 & 0 & $13.7( \pm 0.27)$ & 0 & $1.4( \pm 0.0)$ & $1.2( \pm 0.1)$ & 0 & $0.6( \pm 0.1)$ & $0.6( \pm 0.9)$ \\
\hline & 3 & 0 & $31.4( \pm 6.01)$ & $0.9( \pm 0.0)$ & 0 & 0 & $2.9( \pm 0.0)$ & $2.3( \pm 0.4)$ & $0.6( \pm 0.9)$ \\
\hline & 7 & 0 & $32.1( \pm 0.84)$ & $1.3( \pm 0.2)$ & 0 & 0 & $4.0( \pm 0.6)$ & $2.1( \pm 1.4)$ & $0.8( \pm 1.2)$ \\
\hline & 9 & 0 & $29.7( \pm 3.23)$ & $1.2( \pm 0.0)$ & 0 & 0 & $5.6( \pm 0.9)$ & 0 & $0.9( \pm 1.3)$ \\
\hline & 14 & 0 & $29.9( \pm 2.66)$ & $1.3( \pm 0.1)$ & 0 & 0 & $5.8( \pm 0.9)$ & 0 & $0.8( \pm 1.2)$ \\
\hline \multirow{6}{*}{ Xylose } & 0 & 0 & 0 & 0 & 0 & 0 & 0 & 0 & $1.0( \pm 1.4)$ \\
\hline & 1 & 0 & $8.7( \pm 0.40)$ & $0.5( \pm 0.1)$ & $1.3( \pm 1.8)$ & $0.6( \pm 0.0)$ & $1.2( \pm 0.0)$ & $6.1( \pm 0.3)$ & $2.4( \pm 0.1)$ \\
\hline & 3 & 0 & $14.5( \pm 0.98)$ & $3.9( \pm 1.1)$ & $4.0( \pm 3.1)$ & 0 & $3.4( \pm 0.5)$ & $10.1( \pm 0.1)$ & $1.9( \pm 2.7)$ \\
\hline & 7 & 0 & $16.1( \pm 1.03)$ & $4.9( \pm 0.2)$ & $4.1( \pm 3.2)$ & 0 & $3.2( \pm 0.1)$ & $10.6( \pm 0.5)$ & $1.1( \pm 1.6)$ \\
\hline & 9 & 0 & $16.2( \pm 2.37)$ & $3.8( \pm 0.2)$ & $3.8( \pm 3.2)$ & 0 & $2.7( \pm 0.4)$ & $10.8( \pm 0.9)$ & $2.3( \pm 0.0)$ \\
\hline & 14 & 0 & $13.6( \pm 2.74)$ & $3.7( \pm 1.0)$ & $2.6( \pm 3.6)$ & 0 & $7.0( \pm 4.7)$ & $4.7( \pm 5.9)$ & $1.5( \pm 2.1)$ \\
\hline
\end{tabular}


Table S3. Fermentation profiles in the secondary enrichments

\begin{tabular}{|c|c|c|c|c|c|c|c|c|c|}
\hline \multirow{2}{*}{$\begin{array}{l}\text { Substrates } \\
(0.5 \% \text { w/v })\end{array}$} & \multirow{2}{*}{$\begin{array}{c}\text { Incubation } \\
\text { time } \\
\text { (days) }\end{array}$} & \multirow{2}{*}{ Glucose } & \multicolumn{7}{|c|}{ Products (mmol $\left.\mathbf{l}^{-1}\right)$} \\
\hline & & & Acetate & Butyrate & Formate & Lactate & Propionate & Succinate & Ethanol \\
\hline Dried grass & 5 & 0 & $10.5( \pm 1.7)$ & $0.5( \pm 0.1)$ & 0 & 0 & $0.3( \pm 0.4)$ & $0.5( \pm 0.7)$ & $1.0( \pm 1.4)$ \\
\hline Starch waste & 5 & 0 & $17.0( \pm 1.9)$ & $1.5( \pm 0.5)$ & $3.7( \pm 5.2)$ & $0.5( \pm 0.6)$ & $10.1( \pm 1.9)$ & 0 & $5.0( \pm 0.9)$ \\
\hline Xylose & 5 & 0 & $27.0( \pm 19.4)$ & $1.8( \pm 0.7)$ & 0 & 0 & $2.3( \pm 3.2)$ & $10.9( \pm 1.4)$ & 0 \\
\hline
\end{tabular}

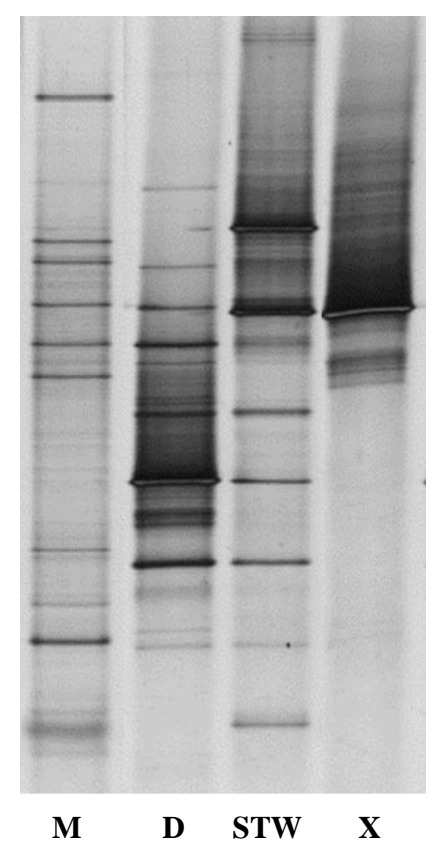

Fig. S1. Bacterial 16S rRNA-DGGE profiles of the secondary enrichments with dried grass (D), starch waste (STW), and xylose (X). M is the marker. 



\section{CHAPTER 6}

\section{Streptococcus caviae sp. nov., isolated from guinea pig fecal samples}

This chapter has been published as:

Susakul Palakawong Na Ayudthaya, Loes J Hilderink, John van der Oost, Willem M. de Vos and Caroline M Plugge (2017) Streptococcus caviae sp. nov., isolated from guinea pig fecal samples. International Journal of Systematic and Evolutionary Microbiology. 67, $1551-1556$. 


\section{Abstract}

A novel cellobiose-degrading and lactate-producing bacterium, strain Cavy grass $6^{\mathrm{T}}$, was isolated from fecal samples of guinea pigs (Cavia porcellus). Cells of the strain were ovalshaped, non-motile, non-spore-forming, Gram-stain-positive and facultatively anaerobic. The strain grew at 25-40 ${ }^{\circ} \mathrm{C}$ (optimum $37^{\circ} \mathrm{C}$ ) and $\mathrm{pH} 4.5-9.5$ (optimum 8.0). Phylogenetic analysis based on $16 \mathrm{~S}$ rRNA gene sequences showed that strain Cavy grass $6^{\mathrm{T}}$ belongs to the genus Streptococcus with its closest relative being Streptococcus devriesei CCUG $47155^{\mathrm{T}}$ with only $96.5 \%$ similarity. Comparing strain Cavy grass $6^{\mathrm{T}}$ and Streptococcus devriesei CCUG $47155^{\mathrm{T}}$, average nucleotide identity and level of digital DNA-DNA hybridization dDDH were only 86.9 and 33.3\%, respectively. Housekeeping genes groEL and gyrA were different between strain Cavy grass $6^{\mathrm{T}}$ and other streptococci. The $\mathrm{G}+\mathrm{C}$ content of strain Cavy grass $6^{\mathrm{T}}$ was $42.6 \pm 0.3 \mathrm{~mol} \%$. The major $(>10 \%)$ cellular fatty acids of strain Cavy grass $6^{\mathrm{T}}$ were $\mathrm{C}_{16: 0}, \mathrm{C}_{20: 1} \omega 9 \mathrm{c}$ and summed feature 8

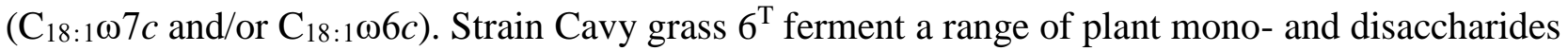
as well as polymeric carbohydrates, including cellobiose, dulcitol, d-glucose, maltose, raffinose, sucrose, 1-sorbose, trehalose, inulin and dried grass extract, to lactate, formate, acetate and ethanol. Based on phylogenetic and physiological characteristics, Cavy grass $6^{\mathrm{T}}$ can be distinguished from other members of the genus Streptococcus. Therefore, a novel species of the genus Streptococcus, family Streptococcaceae, order Lactobacillales is proposed, Streptococcus caviae sp. nov. (type strain Cavy grass $6^{\mathrm{T}}=$ TISTR $\left.2371^{\mathrm{T}}=\mathrm{DSM} 102819^{\mathrm{T}}\right)$.

Cellulose is a homo-polysaccharide with repetitive units of $\beta$ - $d$-glycopyranose that are coupled via $\beta$-glycosidic linkages and estimated to be the most abundant organic compound on earth (Kumar et al, 2008). It can be degraded by micro-organisms such as bacteria and fungi. Those microorganisms produce exocellular cellulolytic enzymes such as 1 , 4- $\beta$-endoglucanase, $1,4-\beta$ -

exoglucanase and/or $\beta$-glucosidase (cellobiase) that can hydrolyse cellulose to cellobiose and/or glucose, which can be further metabolized (Kumar et al, 2008). 
Guinea pigs (Cavia porcellus) are rodents located in the genus Cavia, family Caviidae, and native to South America (Sakaguchi and Nabata, 1992). The guinea pig is a monogastric herbivore and grass is its natural diet (Sakaguchi and Nabata, 1992). The fact that guinea pigs consume major quantities of plant polymers suggests that its large gastrointestinal microbiome makes it a useful model to study the production of organic acids, such as acetate, lactate and succinate. Comparative metagenome studies have shown that the most abundant bacterial phyla in the guinea pig gut are the Bacteroidetes and Firmicutes (Hildebrnd et al., 2012). Investigating the microbial diversity and organic acid production using guinea pig fecal samples could be instrumental in revealing the mechanism of fiber digestion in the guinea pig and leading to the discovery of novel bacteria that are capable of degrading cellulose or its components to valuable organic acids.

Currently, the genus Streptococcus includes 117 recognized species (www.bacterio.net/streptococcus.html) and this number is continuously increasing, for example with the recent addition of Streptococcus pantholopis DSM 102135 (Bai et al., 2016). Historically, the genus Streptococcus is one of the earliest groups of bacteria described and includes pathogens such as Streptococcus pyogenes and Streptococcus pneumoniae, reported by Rosenbach and Klein in 1884 (Clavel et al., 2013). Streptococcus species have been isolated from a broad range of habitats, including the gastrointestinal tracts of humans and animals. Streptococci are chemoorganotrophs with a fermentative metabolism and are often referred to as lactic acid (-producing) bacteria. Their nutritional requirements are complex and variable, they are mostly facultatively anaerobic, and some species require additional $\mathrm{CO}_{2}$ for growth (Whiley and Hardie, 2009). Streptococcus cells are normally spherical or ovoid shaped, less than $2 \mu \mathrm{m}$ in diameter and occur in chains or in pairs when grown in liquid medium. Cells are Gram-stain-positive, non-motile and nonspore forming. The optimum growth temperature is usually about $37^{\circ} \mathrm{C}$, but minimum and maximum growth temperatures vary among the species (Whiley and Hardie, 2009). 
In this work, we describe the isolation, phylogenetic analysis, phenotypic characterization and physiological properties of a novel lactic acid-producing strain, Cavy grass $6^{\mathrm{T}}$, originating from domestic guinea pig feces.

Approximately, $1 \mathrm{~g}$ of fresh fecal sample was dissolved in anaerobic PBS and used as an inoculum. Dried hay was cut with scissors into small pieces $(1-3 \mathrm{~mm})$ and $0.5 \%(\mathrm{w} / \mathrm{v})$ was used as the sole carbon source. The guinea pig fecal slurry $(1 \%, \mathrm{v} / \mathrm{v})$ was inoculated in a bicarbonatebuffered anaerobic medium (BM), which was prepared and supplemented as previously described by Plugge (2005) and Palakawong Na Ayudthaya et al. (2016). Further enrichment and pure culture isolation was performed as described previously using $0.5 \%(\mathrm{w} / \mathrm{v})$ dried grass as carbon source to obtain a pure culture that was termed strain Cavy grass 6 ${ }^{\mathrm{T}}$ (Palakawong Na Ayudthaya et al., 2016). Pyrosequencing results of the $16 \mathrm{~S}$ rRNA genes (data not shown) from two guinea pig fecal samples showed similar microbial profiles as reported previously with the most abundant phyla being the Bacteroidetes (41-50\%) and Firmicutes (42-37\%) (Hildebrand et al., 2012). The relative abundance of the genus Streptococcus in the guinea pig fecal samples was $<1 \%$.

Strain Cavy grass $6^{\mathrm{T}}$ was routinely grown with $20 \mathrm{mM}$ glucose in BM with $0.01 \%(\mathrm{w} / \mathrm{v})$ yeast extract (BMY-G). The purity of strain Cavy grass $6^{\mathrm{T}}$ was checked routinely by phase-contrast microscopy (Leica DM 2000). Production of organic acids was analyzed by HPLC and gas production by GC as described by van Gelder et al. (2012).

Genomic DNA of strain Cavy grass $6^{\mathrm{T}}$ was isolated and purified from glucose-grown cells (BMY-G) using the Fast DNA Spin Kit for Soil (MP Biomedicals) following the manufacturer's instructions. An almost full-length $16 \mathrm{~S}$ rRNA gene sequence (1412 bp) of strain Cavy grass $6{ }^{\mathrm{T}}$ was amplified by PCR using bacterial-universal primers $27 \mathrm{f}$ (5'-AGAGTTGATCCTGGCTCAG-3') and 1492r (5'-TACCTTGTTACGACTT-3') (Lane, 1991). The PCR programme was started with a denaturing step at $95^{\circ} \mathrm{C}$ for 5 min and continued with 35 cycles consisting of $95^{\circ} \mathrm{C}$ for $30 \mathrm{~s}, 52^{\circ} \mathrm{C}$ for $40 \mathrm{~s}$ and $72{ }^{\circ} \mathrm{C}$ for $90 \mathrm{~s}$, and the last step of extension at $72{ }^{\circ} \mathrm{C}$ for $7 \mathrm{~min}$. PCR products were 
purified and sequenced at GATC Biotech. The $16 \mathrm{~S}$ rRNA gene sequence of Cavy grass $6{ }^{\mathrm{T}}$ was checked for reading errors and aligned using the program DNA Baser Sequence Assembler v4 (Heracle BioSoft). The 16S rRNA gene sequence was used to search the DNA database employing the online blastn program, EzTaxon 2.1 (Chun et al., 2007) and EzTaxon-e server (Kim et al., 2012). The partial sequence of the 16S rRNA gene was blasted with the NCBI online database. The level of $16 \mathrm{~S}$ rRNA gene sequence similarity between strain Cavy grass $6^{\mathrm{T}}(1412 \mathrm{bp})$ and the closest strain Streptococcus devriesei CCUG $47155^{\mathrm{T}}(1439 \mathrm{bp})$, obtained from the NCBI database, was calculated using the Bioedit sequence alignment editor (version 7.2.5) program (Hall, 1999). The two sequences were then aligned based on 1000 replications of the neighbour-joining tree using the clustal w multiple alignment option (Thompson et al., 1994). Following this, the sequences were trimmed, and later, the curated sequences $(1387 \mathrm{bp})$ of both strains were used to calculate the sequence identity matrix, resulting in a $16 \mathrm{~S}$ rRNA gene sequence similarity of $96.5 \%$ to $\mathrm{S}$. devriesei. The phylogenetic position of strain Cavy grass $6^{\mathrm{T}}$ was studied by comparison with 16S rRNA gene sequences of related strains in the genus Streptococcus, using Enterococcus faecalis ATCC $19433^{\mathrm{T}}$ as an outgroup, all deposited in the NCBI database. The $16 \mathrm{~S}$ rRNA genes were aligned using the Clustal x program (Thompson et al., 1997) with Kimura's two-parameter model (Kimura, 1980). The phylogenetic tree based on 16S rRNA gene sequences was reconstructed and implemented in the mega 5 programme (Tamura et al., 2011) using the neighbour-joining, maximum-parsimony (Saitou ans Nei, 1987) and maximum-likelihood (Felsenstein, 1981) methods as shown in Fig. S1. Tree topologies were determined using bootstrap analysis with 1000 repeats (Felsenstein, 1985) (Figs. 1 and S1). 


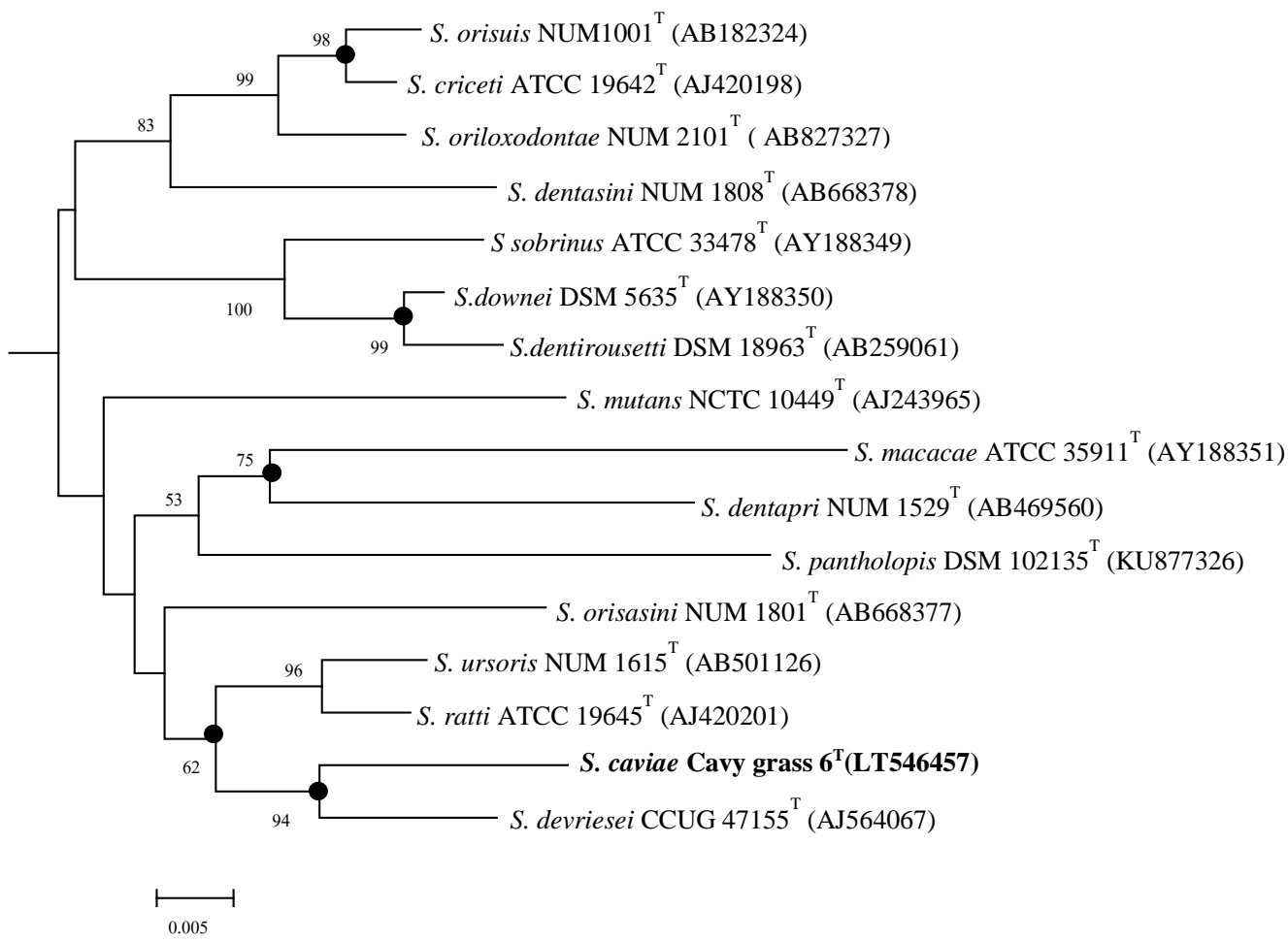

Fig. 1. Phylogenetic relationships between strain Cavy grass $6^{\mathrm{T}}$ and related species in the genus Streptococcus based on 16S rRNA gene sequences (approximately $1360 \mathrm{nt}$ ) by the neighbourjoining method. Bootstrap values, which were higher than $50 \%$ based on 1000 replications, are shown at branch points. Filled circles indicate identical nodes generated by three methods (neighbour-joining, maximum-likelihood and maximum-parsimony). GenBank accession numbers of each strain are given in parentheses. Bar, $0.5 \%$ sequence divergence. The tree presented is extracted from an extended version (Fig. S1).

Phylogenetic analysis based on 16S rRNA gene sequence characterization showed that strain Cavy grass $6^{\mathrm{T}}$ belongs to the genus Streptococcus with its closest relative being $S$. devriesei CCUG $47155^{\mathrm{T}}$ at only $96.5 \% 16 \mathrm{~S}$ rRNA gene sequence similarity, which was lower than the species delineation value of $98.65 \%$ (Kim et al., 2014).

Genome-based comparison tools (Rosselló-Móra and Amann, 2015) were applied to confirm the difference between strain Cavy grass $6^{\mathrm{T}}$ and the closest relative strain $S$. devriesei. We used the genome sequence of $S$. devriesei CCUG $47155^{\mathrm{T}}$ (Accession no. AUIN00000000) and the draft genome sequence of strain Cavy grass 6 ${ }^{\mathrm{T}}$ (Accession no. MOWR00000000).

ANI and dDDH values were calculated using the ANI and AAI calculators at http://enveomics.ce.gatech.edu/ani/ and Genome-to-Genome Distance Calculator (GGDC) web browser from 
the DSMZ (Braunschweig, Germany), respectively. The ANI and dDDH values between strain Cavy grass $6^{\mathrm{T}}$ and S. devriesei CCUG $47155 \mathrm{~T}$ were 86.8 and $33.3 \%$, lower than the cut-off values (95 and 70\%, respectively) for species delineation (Rosselló-Móra and Amann, 2015; Goris et al., 2007).

MLSA with two housekeeping genes, groEL (Chaperonin GroEL) and gyrA (DNA gyrase, subunit A), was performed between strain Cavy grass $6^{\mathrm{T}}$ and other Streptococcus species. MLSAbased phylogenetic trees of both groEL and gyrA genes revealed the relationship between strain Cavy grass $6^{\mathrm{T}}$ and other Streptococcus species (Figs S2 and S3). All these genome-based comparisons reveal that strain Cavy grass $6^{\mathrm{T}}$ can be differentiated from other Streptococcus species. However, additional chemotaxonomic, biochemical and physiological analysis were performed.

The DNA base composition $\left(\mathrm{G}+\mathrm{C}\right.$ content) of strain Cavy grass $6^{\mathrm{T}}$ was analyzed by HPLC (Tamaoka and Komagata, 1984) at the Deutsche Sammlung von Mikroorganismen und Zellkulturen $\mathrm{GmbH}$ (DSMZ). Strain Cavy grass $6^{\mathrm{T}}$ was grown in BMY-G at $37^{\circ} \mathrm{C}$ for $48 \mathrm{~h}$. Cell biomass was harvested by centrifugation at $4{ }^{\circ} \mathrm{C}$ at $15317 \mathrm{~g}$ for $10 \mathrm{~min}$. The DNA G+C content of strain Cavy grass $6^{\mathrm{T}}$ was $42.6 \pm 0.3 \mathrm{~mol} \%$. The DNA G $+\mathrm{C}$ content of strain Cavy grass $6^{\mathrm{T}}$ obtained from a genome calculation (RAST Server) was $42.3 \mathrm{~mol} \%$. This value lies within the range (33-46 mol\%) of DNA $\mathrm{G}+\mathrm{C}$ contents that have been described for other species within the genus Streptococcus (Whiley and Hardie, 2009).

Cellular fatty acid and quinone composition analyzes of the cell wall of strain Cavy grass $6^{\mathrm{T}}$ were also carried out at the DSMZ. The cultures and cell biomass were obtained as described above for the $\mathrm{G}+\mathrm{C}$ content analysis. The fatty acid composition of the closest relative, $\mathrm{S}$. devriesei CCUG $47155^{\mathrm{T}}$, was determined in parallel with Cavy grass $6^{\mathrm{T}}$. The predominant cellular fatty acids of strain Cavy grass $6^{\mathrm{T}}\left(>10 \%\right.$ of the total) were $\mathrm{C}_{16: 0}(32.5 \%)$, summed feature $8\left(\mathrm{C}_{18: 1} 107 c\right.$ and/or $\left.\mathrm{C}_{18: 1 \omega 6} c\right)(30.3 \%)$ and $\mathrm{C}_{20: 1} \omega 9 c(12.6 \%)$, similar to those of $S$. devriesei CCUG $47155^{\mathrm{T}}$ (Table S1). These patterns of major fatty acids were also found in other species of the genus such as Streptococcus downei and Streptococcus vestibularis (Whiley and Hardie, 2009). No respiratory 
quinones were detected in strain Cavy grass $6^{\mathrm{T}}$, which is also characteristic for the genus Streptococcus (Whiley and Hardie, 2009).

The strain grew well on Reinforced Clostridial Medium (RCM; Difco) agar (1.5\%,w/v) medium and colonies of the strain were white, round with smooth margins, convex and 1-2 mm in diameter after 2 days at $37^{\circ} \mathrm{C}$ under anaerobic conditions. Cell morphology was examined using phase-contrast microscopy (Leica DM 2000) and scanning electron microscopy (FEI Magellan 400). Cells were non-motile, oval-shaped and commonly present in pairs or chains, with single cells $0.5 \times 0.5-0.8 \mu \mathrm{m}$ in size (Fig. S4). Gram staining was examined using standard methods (Plugge et al., 2000). Spore formation was determined with a Schaeffer and Fulton Spore Stain Kit (SigmaAldrich) following the manufacturer's instructions. Cells of strain Cavy grass $6^{\mathrm{T}}$ were Gram-stainpositive and non-spore-forming.

To determine the optimum $\mathrm{pH}$, strain Cavy grass $6^{\mathrm{T}}$ was inoculated in Wilkins-Chalgren Broth (Oxoid) and the $\mathrm{pH}$ values of the medium were adjusted with $\mathrm{NaOH}$ and/or $\mathrm{HCl}$. Triplicate bottles were used and incubated at $37^{\circ} \mathrm{C}$ at a $\mathrm{pH}$ range of $4.0-10.0$ at intervals of $0.5 \mathrm{pH}$ units. Bottles were incubated for 2 weeks. The optimum temperature was determined in BMY-G at a temperature range of $4-60{ }^{\circ} \mathrm{C}$ with intervals of $5{ }^{\circ} \mathrm{C}$, including at $37^{\circ} \mathrm{C}$. Bottles were incubated for 2 weeks. Strain Cavy grass $6{ }^{\mathrm{T}}$ was able to grow between $\mathrm{pH} 4.5$ and 9.5 with an optimum at 8.0. The strain grew between 25 and $40{ }^{\circ} \mathrm{C}$ with an optimal temperature of $37^{\circ} \mathrm{C}$.

Yeast extract $\left(0.1 \mathrm{~g} \mathrm{l}^{-1}\right), 1$-cysteine $\left(0.5 \mathrm{~g} \mathrm{l}^{-1}\right)$, haemin $\left(5 \mathrm{mg} \mathrm{l}^{-1}\right)$ and vitamin $\mathrm{K}_{1}\left(0.05 \mathrm{~g} \mathrm{l}^{-1}\right)$ were tested separately as growth factors for strain Cavy grass $6^{\mathrm{T}}$ in $\mathrm{BM}-\mathrm{G}$ at $37^{\circ} \mathrm{C}$ for 14 days in duplicate bottles. Strain Cavy grass $6^{\mathrm{T}}$ grew without L-cysteine, haemin, vitamin $\mathrm{K}_{1}$ and yeast extract, but yeast extract at $0.1 \mathrm{~g}^{1^{-1}}$ accelerated growth. The generation time of the strain when grown in $\mathrm{BMY}-\mathrm{G}$ at $37^{\circ} \mathrm{C}$ and $\mathrm{pH} 7.2$ was $2.6 \mathrm{~h}$. 
Fermentation products and carbon balance were determined in cultures growing in BMY-G. The glucose fermentation molar stoichiometry of strain Cavy grass $6^{\mathrm{T}}$ was: 1 glucose $\rightarrow 1.1$ lactate +0.7 formate +0.3 acetate +0.4 ethanol [concentrations of reactants $(\mathrm{mM}): 19.1$ glucose $\rightarrow 21.2$ lactate +12.5 formate +5.7 acetate +6.8 ethanol]. Carbon recovery was $90 \%$ (without biomass). When calculating carbon recovery, we assumed no net $\mathrm{CO}_{2}$ is produced as the amount of formate matched the sum of acetate and ethanol. $\mathrm{No}_{2}$ gas was detected.

Oxygen tolerance was tested by growing strain Cavy grass $6^{\mathrm{T}}$ in BMY-G without reducing agent under aerobic conditions and with a cotton stopper. Two per cent of active inoculum (18-24 h) that was pre-grown in BMY-G was added and incubated at $37^{\circ} \mathrm{C}$. Growth was monitored using turbidity $\left(\mathrm{OD}_{600}\right)$ measurements. Strain Cavy grass $6^{\mathrm{T}}$ was able to grow under these aerobic conditions after 3 days. This was confirmed by growing the strain on RCM agar plates under aerobic conditions. After 5 days, colonies of strain Cavy grass $6^{\mathrm{T}}$ appeared, which indicated that the strain was able to grow under aerobic conditions but slower than under anaerobic conditions and no respiration occurred. Therefore, we conclude that strain Cavy grass $6^{\mathrm{T}}$ is a facultatively anaerobic bacterium, and this is a characteristic of most streptococci.

Salt tolerance of strain Cavy grass $6^{\mathrm{T}}$ was determined by growth in BMY-G with increasing salt concentrations of $0-7 \%(\mathrm{w} / \mathrm{v}) \mathrm{NaCl}$ at intervals of $0.5 \%$. The inoculated medium was incubated at $37^{\circ} \mathrm{C}$ and the experiment was performed in triplicate. Growth was monitored using turbidity $\left(\mathrm{OD}_{600}\right)$ and organic acid production. Strain Cavy grass $6^{\mathrm{T}}$ tolerated up to $4.5 \%(\mathrm{w} / \mathrm{v}) \mathrm{NaCl}$.

Haemolytic activity was determined on trypticase soy agar (TSA) medium supplemented with $5 \%$ sterile horse blood (added after autoclaving). A culture of strain Cavy grass $6^{\mathrm{T}}$ was tested and incubated under both aerobic and anaerobic conditions at $37^{\circ} \mathrm{C}$ for $2-5$ days. Colonies developed normally, and no haemolysis was observed. 
Lancefield grouping of streptococci was performed using PathoDxtra Strep Grouping Kit (Thermo Scientific) at Medisch Microbiologisch Laboratorium (MML) of Hospital 'de Gelderse Vallei' (Ede, The Netherlands). Strain Cavy grass $6^{\mathrm{T}}$ tested negative for all Lancefield group antisera (groups A, B, C, D, F and G). This negative result also confirmed that strain Cavy grass $6^{\mathrm{T}}$ does not belong to the beta-haemolytic streptococci.

The three most closely related species (based on 16S rRNA gene sequence comparisons), Streptococcus devriesei CCUG 47155' , Streptococcus ratti ATCC $19645^{\mathrm{T}}$ and

Streptococcus ursoris NUM 1615 , together with strain Cavy grass $6^{\mathrm{T}}$, were grown in BMY-G at $37^{\circ} \mathrm{C}$ for $24 \mathrm{~h}$ before testing with commercial API identification (test kits) systems (bioMérieux). Carbon assimilation and acid production from different carbohydrates were examined using API 50 CH and Rapid ID 32 STREP kits. Enzyme activity was profiled using Rapid ID 32 STREP and API ZYM kits. All tests were performed in duplicate following the manufacturers' instructions. Selected results that differentiate the strains are shown in Table 1. Additionally, fermentation tests of $20 \mathrm{mM}$ cellobiose, d-glucose, $0.5 \%$ (w/v) CM-cellulose, cellulose (CC41; Whatman), crystalline cellulose, dried grass, inulin, laminarin, lignin, pectin, soluble starch and xylan were tested with strain Cavy grass $6^{\mathrm{T}}$ and the type strains of $S$. devriesei, $S$. ratti and $S$. ursoris in liquid culture with BMY medium. With strain Cavy grass $6^{\mathrm{T}}$ and $\mathrm{S}$. devriesei, $20 \mathrm{mM} \mathrm{d}$-arabinose, d-arabitol, l-arabitol, dulcitol, d-fructose, d-galactose, dl-lactate, maltose, d-mannitol, d-mannose, raffinose, d-ribose, sucrose, d-sorbitol, l-sorbose, trehalose, xylitol, d-xylose and starch waste were tested in liquid culture with BMY. Cellulose-degrading properties, which we were looking for by studying guinea pig fecal samples, have not been found in this strain, nor in the three reference strains. The primary enrichment was performed with dried grass as the sole carbon source, and therefore strain Cavy grass $6^{\mathrm{T}}$ most probably uses the extracted products from the process of either cutting or autoclaving the grass as it could also grow in the grass extract after cutting and filtration through a $0.2 \mu \mathrm{m}$ sterile filter (Table S2). 
Strain Cavy grass $6^{\mathrm{T}}$ was able to grow on $20 \mathrm{mM}$ d-arabitol, cellobiose, dulcitol, dfructose, d-galactose, d-glucose, maltose, d-mannitol, d-mannose, raffinose, sucrose, d-sorbitol, lsorbose and trehalose, and $0.5 \%$ dried grass extract and inulin. The nature and ratio of organic acids produced differed depending on the substrate (Table S2). Results of API 50 CHB tests are shown in Table S3.

Based on the biochemical, physiological, chemotaxonomic and phylogenetic characteristics, strain Cavy grass $6^{\mathrm{T}}$ can be distinguished from other members of the genus Streptococcus. We suggest that strain Cavy grass $6^{\mathrm{T}}$ represents a novel species of the genus Streptococcus, family Streptococcaceae, order Lactobacillales, for which the name Streptococcus caviae sp. nov. is proposed. 
Table 1. Selected characteristics that differentiate strain Cavy grass $6^{\mathrm{T}}$ from related species strains: 1, Cavy grass 6 ${ }^{\mathrm{T}}$; 2, S. devriesei CCUG $47155^{\mathrm{T}} ; 3$, S. ratti ATCC $19645^{\mathrm{T}} ; 4$, S. ursoris NUM $1615^{\mathrm{T}}$. All data were obtained in this study except where indicated. +, Positive; -, negative; w+, weakly positive; nr, not reported.

\begin{tabular}{|c|c|c|c|c|}
\hline Characteristic & Cavy grass $6^{\mathrm{T}}$ & S. devriesei & S. ratti & S. ursoris \\
\hline Origin & $\begin{array}{l}\text { Guinea pig } \\
\text { feces }\end{array}$ & Horse teeth ${ }^{\mathrm{a}} \uparrow$ & $\begin{array}{c}\text { Rat, human } \\
\text { mouth }^{\mathrm{b}} \dagger\end{array}$ & Bear mouth ${ }^{\mathrm{c}} \dagger$ \\
\hline Gram-stain & + & $++^{\mathrm{a} \dagger}$ & $+{ }^{\mathrm{b}} \dagger$ & $+{ }^{c} \dagger$ \\
\hline Cell size $(\mu \mathrm{m})$ & $0.2 \times 0.2-0.7$ & $\mathrm{nr}$ & $0.5^{\mathrm{b}} \dagger$ & $0.5-0.7^{c} \dagger$ \\
\hline Temperature range/ Optimum $\left({ }^{\circ} \mathrm{C}\right)$ & $25-40 / 37$ & $\mathrm{nr} / \mathrm{nr}$ & $\mathrm{nr} / \mathrm{nr}$ & $\mathrm{nr} / \mathrm{nr}$ \\
\hline pH range / Optimum & $4.5-9.5 / 8.0$ & $\mathrm{nr} / \mathrm{nr}$ & $\mathrm{nr} / \mathrm{nr}$ & $\mathrm{nr} / \mathrm{nr}$ \\
\hline $\mathrm{G}+\mathrm{C}$ content $(\mathrm{mol} \%)$ & $42.6 \pm 0.3$ & $42.0^{a} \dagger$ & $41-43^{b} \dagger$ & $34^{c} \dagger$ \\
\hline Urease & + & - & $\mathrm{w}+$ & w+ \\
\hline Fermentation products from glucose $\mathrm{e}^{\#}$ & $\mathrm{~L}, \mathrm{~A}, \mathrm{~F}, \mathrm{E}$ & $\mathrm{L}, \mathrm{A}, \mathrm{F}, \mathrm{E}$ & $\mathrm{L}, \mathrm{a}, \mathrm{f}, \mathrm{e}$ & $\mathrm{L}, \mathrm{a}, \mathrm{F}, \mathrm{E}$ \\
\hline \multicolumn{5}{|l|}{ Fermentation of substrates: } \\
\hline D-Arabitol & + & + & $\mathrm{w}+$ & - \\
\hline Dulcitol & + & + & - & - \\
\hline Methyl- $\alpha$ D-mannopyranoside & - & - & $\mathrm{w}+$ & - \\
\hline Potassium gluconate & + & + & - & - \\
\hline D-Ribose & - & - & $\mathrm{w}+$ & - \\
\hline L-Sorbose & + & - & - & - \\
\hline \multicolumn{5}{|l|}{ Acidification from: } \\
\hline D-Arabitol & + & - & - & - \\
\hline D-Melibiose & + & - & - & - \\
\hline D-Melezitose & + & - & - & - \\
\hline Methyl- $\beta \mathrm{D}$ glucopyranoside & + & + & + & - \\
\hline D-Sorbitol & + & + & - & - \\
\hline \multicolumn{5}{|l|}{ Enzyme activities: } \\
\hline$\alpha$-Glucosidase & + & - & + & + \\
\hline$\beta$-Mannosidase & w+ & w+ & - & - \\
\hline Lipase $\left(\mathrm{C}_{14}\right)$ & + & + & - & - \\
\hline
\end{tabular}

All data were obtained in this study except $\uparrow$ ) taken from; a, Collins et al., 2004; b, Whiley \& Hardie, 2009; c, Shinozaki-Kuwahara et al., 2011.

+, positive; -, negative; w+, weakly positive; nr, not reported \#, L, Lactate; A, Acetate; F, Formate; E, Ethanol (small letter indicates minor amount $(<1 \mathrm{mM}))$

\section{Description of Streptococcus caviae sp. nov.}

Streptococcus caviae (ca'vi.ae. N.L. gen. n. caviae of Cavia or a guinea pig).

Cells are $0.5 \times 0.5-0.8 \mu \mathrm{m}$ in size and appear coccus- or oval-shaped (Fig. S4). Colonies on RCM agar are white, circular, convex, with smooth margins and $1-2 \mathrm{~mm}$ in diameter after $48 \mathrm{~h}$ of 
growth. Gram-stain-positive, non-motile, non-spore-forming, and catalase- and oxidase-negative. Grows at $25-40{ }^{\circ} \mathrm{C}$ (optimum $37^{\circ} \mathrm{C}$ ) and at $\mathrm{pH} 4.5-9.5$ (optimum 8.0). The generation time is $2.6 \mathrm{~h}$ in BMY-G at $37^{\circ} \mathrm{C}$ and $\mathrm{pH}$ 7.2. Facultatively anaerobic. Able to ferment d-arabitol, cellobiose, dulcitol, d-fructose, d-galactose, d-glucose, maltose, d-mannitol, d-mannose, raffinose, sucrose, dsorbitol, 1-sorbose, trehalose, dried grass extract and inulin, but could not use d-arabinose, larabitol, dl-lactate, d-ribose, xylitol, d-xylose, CM-cellulose, cellulose (CC41), crystalline cellulose, laminarin, lignin, pectin, soluble starch, starch waste or xylan as substrates in anaerobic bottles (Table S2). In API 50 CHB tests, produces acid from $N$-acetylglucosamine, amygdalin, d-arabitol, arbutin, dulcitol, aesculin ferric citrate, d-fructose, gentiobiose, d-lactose, melibiose, potassium gluconate, salicin and d-tagatose (Table S3). In Rapid ID 32 STREP tests, positive for $\alpha$ galactosidase, $\beta$-glucosidase, alanyl-phenylalanyl-proline arylamidase, arginine dihydrolase, acetoin production (Voges-Proskauer reaction), melezitose and methyl $\beta$-d-glucopyranoside and weakly positive for $\beta$-mannosidase and hydrolysis of hippurate (Table S4). In API ZYM tests, also positive for $\alpha$-glucosidase, acid phosphatase, cystine arylamidase, esterase (C4), esterase lipase (C8), lipase (C14), leucine arylamidase and naphthol-AS-BI-phosphohydrolase, and weakly positive for valine arylamidase (Table S5).

The type strain, Cavy grass $6^{\mathrm{T}}\left(=\right.$ TISTR $2371^{\mathrm{T}}=$ DSM $\left.102819^{\mathrm{T}}\right)$, was isolated from fecal samples of guinea pigs in the Netherlands. The DNA G+C content of the type strain is $42.6 \pm 0.3$ $\operatorname{mol} \%$.

\section{Acknowledgements}

This research was supported by a Royal Thai Government Scholarship, Thailand. The authors thank the technical staff of the Medisch Microbiologisch Laboratorium of the hospital 'de Gelderse Vallei' for performing the Lancefield group tests, Prof. A. J. M. Stams for stimulating discussions and M. Jarzembowska and A. H. van Gelder for technical support. 


\section{Supplmentary data}

Table S1. Cellular fatty acid composition of strain Cavy grass $6^{\mathrm{T}}$ and Streptococcus devriesei CCUG $47155^{\mathrm{T}}$. Values are percentages of total fatty acids. Fatty acids present at less than $0.5 \%$ in both strains are not shown. Major fatty acids $(>10 \%)$ are in bold.

\begin{tabular}{lll}
\hline Cellular fatty acids (\%) & Cavy grass $^{\mathbf{T}}$ & S. devriesei \\
\hline Saturated acids & & \\
$\mathrm{C}_{12: 0}$ & 0.7 & 0.2 \\
$\mathrm{C}_{14: 0}$ & 2.8 & 0.8 \\
$\mathrm{C}_{\mathbf{1 6}: 0}$ & $\mathbf{3 2 . 5}$ & $\mathbf{2 7 . 0}$ \\
$\mathrm{C}_{18: 0}$ & 7.8 & 9.3 \\
$\mathrm{C}_{20: 0}$ & 0.5 & 0.6 \\
Unsaturated acids & & \\
$\mathrm{C}_{16: 1 \omega 5 c}$ & 0.9 & 0.7 \\
$\mathrm{C}_{16: 1 \omega 9 c}$ & 3.1 & 2.8 \\
$\mathrm{C}_{18: 1 \omega 5 c}$ & 1.2 & 1.3 \\
$\mathrm{C}_{18: 1 \omega 9 c}$ & 4.8 & 5.3 \\
$\mathrm{C}_{20: 1}(\omega 7 c$ & 1.1 & 1.5 \\
$\mathrm{C}_{\mathbf{2 0}: 1 \omega \mathbf{9}}$ & $\mathbf{1 2 . 6}$ & $\mathbf{1 5 . 3}$ \\
Summed features* & & \\
3 & - & 0.8 \\
$\mathbf{8}$ & $\mathbf{3 0 . 3}$ & $\mathbf{3 3 . 7}$ \\
\hline
\end{tabular}

*Summed features refer to chromatographic peaks of fatty acids groups that were not separated.

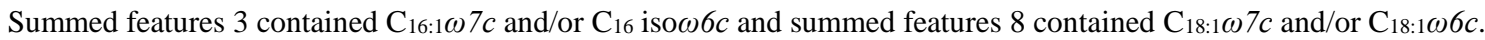


Table S2. Physiological characteristics of strain Cavy grass $6^{\mathrm{T}}$, Streptococcus devriesei CCUG $47155^{\mathrm{T}}$, Streptococcus ratti ATCC $19645^{\mathrm{T}}$, and Streptococcus ursoris NUM $1615^{\mathrm{T}}$ from different substrates.

\begin{tabular}{|c|c|c|c|c|}
\hline Characteristic / Strain & Cavy grass $6^{T}$ & S. devriesei & S. ratti & S. ursoris \\
\hline Carboxymethyl cellulose & - & - & - & - \\
\hline Cellulose (CC41) & - & - & - & - \\
\hline Crystalline cellulose & - & - & - & - \\
\hline Dried grass extract & $1, \mathrm{a}, \mathrm{f}^{\#}$ & $1, \mathrm{a}, \mathrm{f}$ & $1, \mathrm{a}, \mathrm{f}$ & $1, \mathrm{a}, \mathrm{f}$ \\
\hline Inulin & $\mathrm{L}, \mathrm{A}, \mathrm{F}, \mathrm{E}$ & $\mathrm{L}, \mathrm{a}, \mathrm{F}, \mathrm{E}$ & $\mathrm{L}, \mathrm{a}, \mathrm{e}$ & $\mathrm{L}, \mathrm{A}, \mathrm{F}, \mathrm{E}$ \\
\hline Laminarin & - & - & - & - \\
\hline Lignin & - & - & - & - \\
\hline Pectin & - & - & - & - \\
\hline Soluble starch & - & - & - & - \\
\hline Starch waste & - & - & nd & nd \\
\hline Xylan & - & - & - & - \\
\hline D-Arabinose & - & - & nd & nd \\
\hline D-Arabitol & $\mathrm{L}, \mathrm{A}, \mathrm{F}, \mathrm{E}$ & $\mathrm{L}, \mathrm{A}, \mathrm{F}, \mathrm{E}$ & nd & nd \\
\hline L-Arabitol & - & - & nd & nd \\
\hline D-Cellobiose & $\mathrm{L}, \mathrm{A}, \mathrm{F}, \mathrm{E}$ & $\mathrm{L}, \mathrm{a}, \mathrm{F}, \mathrm{e}$ & $\mathrm{L}, \mathrm{A}, \mathrm{F}, \mathrm{e}$ & $\mathrm{L}, \mathrm{A}, \mathrm{F}, \mathrm{e}$ \\
\hline Dulcitol & 1, a, F, E & $1, \mathrm{~A}, \mathrm{~F}, \mathrm{e}$ & nd & nd \\
\hline D-Fructose & $\mathrm{L}, \mathrm{a}, \mathrm{f}$ & $\mathrm{L}, \mathrm{a}, \mathrm{f}$ & nd & nd \\
\hline D-Galactose & $\mathrm{L}, \mathrm{A}, \mathrm{F}, \mathrm{E}$ & $\mathrm{L}, \mathrm{A}, \mathrm{F}, \mathrm{E}$ & nd & nd \\
\hline D-Glucose & $\mathrm{L}, \mathrm{A}, \mathrm{F}, \mathrm{E}$ & $\mathrm{L}, \mathrm{A}, \mathrm{F}, \mathrm{E}$ & $\mathrm{L}, \mathrm{a}, \mathrm{f}, \mathrm{e}$ & $\mathrm{L}, \mathrm{a}, \mathrm{F}, \mathrm{E}$ \\
\hline D, L-Lactate & - & - & nd & nd \\
\hline D-Maltose & $\mathrm{L}, \mathrm{a}, \mathrm{F}, \mathrm{e}$ & $\mathrm{L}, \mathrm{F}$ & nd & nd \\
\hline D-Mannitol & $\mathrm{L}, \mathrm{A}, \mathrm{F}, \mathrm{E}$ & $\mathrm{L}, \mathrm{a}, \mathrm{F}, \mathrm{E}$ & nd & nd \\
\hline D-Mannose & $\mathrm{L}, \mathrm{A}, \mathrm{F}, \mathrm{E}$ & $\mathrm{L}, \mathrm{A}, \mathrm{F}, \mathrm{e}$ & nd & nd \\
\hline D-Raffinose & $\mathrm{L}, \mathrm{a}, \mathrm{F}, \mathrm{e}$ & $\mathrm{L}, \mathrm{a}, \mathrm{f}, \mathrm{e}$ & nd & nd \\
\hline D-Ribose & - & - & nd & nd \\
\hline D-Saccharose & $\mathrm{L}, \mathrm{a}, \mathrm{F}, \mathrm{e}$ & $\mathrm{L}, \mathrm{f}$ & nd & nd \\
\hline D-Sorbitol & $\mathrm{L}, \mathrm{A}, \mathrm{F}, \mathrm{E}$ & $\mathrm{L}, \mathrm{a}, \mathrm{F}, \mathrm{E}$ & nd & nd \\
\hline L-Sorbose & $\mathrm{L}, \mathrm{A}, \mathrm{F}, \mathrm{E}$ & - & nd & nd \\
\hline D-Trehalose & $\mathrm{L}, \mathrm{a}, \mathrm{f}$ & $\mathrm{L}, \mathrm{f}$ & nd & nd \\
\hline Xylitol & - & - & nd & nd \\
\hline D-Xylose & - & - & nd & nd \\
\hline
\end{tabular}

All data were obtained in this study. -, negative; nd, not determined

\#, L, Lactate; A, Acetate; F, Formate; P, propionate; E, ethanol (small letter indicates minor amount $(<1 \mathrm{mM})$ ) 
Table S3. Characteristics of strain Cavy grass $6^{\mathrm{T}}$, Streptococcus devriesei CCUG $47155^{\mathrm{T}}$, Streptococcus ratti ATCC $19645^{\mathrm{T}}$ and Streptococcus ursoris NUM $1615^{\mathrm{T}}$ from the API 50 CH test. Differences between the strains are highlighted.

\begin{tabular}{|c|c|c|c|c|}
\hline Characteristic / Strain & Cavy grass $6^{T}$ & S. devriesei & S. ratti & S. ursoris \\
\hline \multicolumn{5}{|l|}{ Fermentation of substrates: } \\
\hline N-Acetylglucosamine & + & + & + & + \\
\hline D-Adonitol & - & - & - & - \\
\hline Amygdalin & + & + & + & + \\
\hline D-Arabinose & - & - & - & - \\
\hline L-Arabinose & - & - & - & - \\
\hline D-Arabitol & $\mathrm{w}+$ & $\mathrm{w}+$ & w+ & - \\
\hline L-Arabitol & - & - & - & - \\
\hline Arbutin & + & + & + & + \\
\hline D-Cellobiose & + & + & + & + \\
\hline Dulcitol & + & + & - & - \\
\hline Esculin ferric citrate & + & + & + & + \\
\hline Erythritol & - & - & - & - \\
\hline D-Fucose & - & - & - & - \\
\hline L-Fucose & - & - & - & - \\
\hline D-Fructose & + & + & + & + \\
\hline D-Galactose & + & + & + & + \\
\hline Gentiobiose & + & + & + & + \\
\hline D-Glucose & + & + & + & + \\
\hline Glycerol & - & - & - & - \\
\hline Glycogen & - & - & - & - \\
\hline Inositol & - & - & - & - \\
\hline Inulin & - & + & - & - \\
\hline D-Lactose & + & + & + & + \\
\hline D-Lyxose & - & - & - & - \\
\hline D-Maltose & + & + & + & + \\
\hline D-Mannitol & + & + & + & + \\
\hline D-Mannose & + & + & + & + \\
\hline D-Melezitose & - & - & - & - \\
\hline D-Melibiose & + & + & + & + \\
\hline Methyl- $\alpha \mathrm{D}$-glucopyranoside & - & - & - & - \\
\hline Methyl- $\alpha \mathrm{D}$-mannopyranoside & - & - & w+ & - \\
\hline Methyl- $\beta$ D-xylopyranoside & - & - & - & - \\
\hline Potassium gluconate & + & + & - & - \\
\hline Potassium 2-ketogluconate & - & - & - & - \\
\hline Potassium 5-ketogluconate & - & - & - & - \\
\hline D-Raffinose & + & + & + & + \\
\hline L-Rhamnose & - & - & - & - \\
\hline D-Ribose & - & - & w+ & - \\
\hline D-Saccharose (sucrose) & + & + & + & + \\
\hline Salicin & + & + & + & + \\
\hline D-Sorbitol & + & + & + & + \\
\hline L-Sorbose & w+ & - & - & - \\
\hline Starch & - & - & - & - \\
\hline D-Tagatose & + & + & + & + \\
\hline D-Trehalose & + & + & + & + \\
\hline D-Turanose & - & - & - & - \\
\hline Xylitol & - & - & - & - \\
\hline D-Xylose & - & - & - & - \\
\hline L-Xylose & - & - & - & - \\
\hline
\end{tabular}

All data were obtained in this study. +, positive; -, negative; w+, weakly positive 
Table S4. Characteristics of strain Cavy grass $6^{\mathrm{T}}$, Streptococcus devriesei CCUG $47155^{\mathrm{T}}$, Streptococcus ratti ATCC $19645^{\mathrm{T}}$ and Streptococcus ursoris NUM $1615^{\mathrm{T}}$ from the Rapid ID 32 STREP test.

Differences between the strains are highlighted.

\begin{tabular}{|c|c|c|c|c|}
\hline Characteristic / Strain & Cavy grass $6^{\mathrm{T}}$ & S. devriesei & S. ratti & S. ursoris \\
\hline$\alpha$-Galactosidase & + & + & + & + \\
\hline B-Galactosidase & - & - & - & - \\
\hline (2-naphthyl- BD-galactopyranoside) & & & & \\
\hline $\begin{array}{l}\text { B-Galactosidase } \\
\text { (resorufin-ßD-galactopyranoside) }\end{array}$ & - & - & - & - \\
\hline B-Glucosidase & + & + & + & + \\
\hline ß-Glucuronidase & - & - & - & - \\
\hline$\beta$-Mannosidase & $\mathrm{w}+$ & w+ & - & - \\
\hline $\mathrm{N}$-acetyl- $\beta$-glucosaminidase & - & - & - & - \\
\hline $\begin{array}{l}\text { Alanyl-phenylalanyl-proline } \\
\text { arylamidase }\end{array}$ & + & + & + & + \\
\hline Alkaline phosphatase & - & - & - & - \\
\hline Arginine dihydrolase & + & + & + & + \\
\hline Glycyl-tryptophan arylamidase & - & - & - & - \\
\hline Pyroglutamic acid arylamidase & - & - & - & - \\
\hline $\begin{array}{l}\text { Acetoin production } \\
\text { (Voges Proskauer) }\end{array}$ & + & + & + & + \\
\hline Hydrolysis of hippurate & $\mathrm{w}+$ & + & $\mathrm{w}+$ & $\mathrm{w}+$ \\
\hline Urease & + & - & $\mathrm{w}+$ & $\mathrm{w}+$ \\
\hline \multicolumn{5}{|l|}{ Acidification from: } \\
\hline D-Arabitol & + & - & - & - \\
\hline L-Arabinose & - & - & - & - \\
\hline$\alpha$-Cyclodextrin & - & - & - & - \\
\hline Glycogen & - & - & - & - \\
\hline D-Lactose & + & + & + & + \\
\hline D-Maltose & + & + & + & + \\
\hline D-Mannitol & + & + & + & + \\
\hline D-Melibiose & + & - & - & - \\
\hline D-Melezitose & + & - & - & - \\
\hline Methyl- $\beta \mathrm{D}$ glucopyranoside & + & + & + & - \\
\hline Pullulan & - & - & - & - \\
\hline D-Raffinose & + & + & + & + \\
\hline D-Ribose & - & - & - & - \\
\hline D-Saccharose (sucrose) & + & + & + & + \\
\hline D-Sorbitol & + & + & - & - \\
\hline D-Tagarose & - & + & $\mathrm{w}+$ & + \\
\hline D-Trehalose & + & + & + & + \\
\hline
\end{tabular}

All data were obtained in this study. +, positive; -, negative; w+, weakly positive 
Table S5. Characteristics of strain Cavy grass $6^{\mathrm{T}}$, Streptococcus devriesei CCUG $47155^{\mathrm{T}}$, Streptococcus ratti ATCC $19645^{\mathrm{T}}$ and Streptococcus ursoris NUM $1615^{\mathrm{T}}$ from the API ZYM test. Differences between the strains are highlighted.

\begin{tabular}{|c|c|c|c|c|}
\hline Characteristic / Strain & Cavy grass $6^{\mathrm{T}}$ & S. devriesei & S. ratti & S. ursoris \\
\hline$\alpha$-Chymotrypsin & - & - & - & - \\
\hline$\alpha$-Galactosidase & - & - & - & - \\
\hline B-Galactosidase & - & - & - & - \\
\hline$\alpha$-Glucosidase & + & - & + & + \\
\hline B-Glucosidase & + & + & + & w+ \\
\hline B-Glucuronidase & - & - & - & - \\
\hline$\alpha$-Fucosidase & - & - & - & - \\
\hline$\alpha$-Mannosidase & - & - & - & - \\
\hline $\mathrm{N}$-acetyl- $\beta$-glucosaminidase & - & - & - & - \\
\hline Acid phosphatase & + & + & + & + \\
\hline Alkaline phosphatase & - & - & - & - \\
\hline Cystine arylamidase & + & + & $\mathrm{w}+$ & $\mathrm{w}+$ \\
\hline Esterase $\left(\mathrm{C}_{4}\right)$ & + & + & + & $\mathrm{w}+$ \\
\hline Esterase lipase $\left(\mathrm{C}_{8}\right)$ & + & + & + & $\mathrm{w}+$ \\
\hline Lipase $\left(\mathrm{C}_{14}\right)$ & + & + & - & - \\
\hline Leucine arylamidase & + & + & + & + \\
\hline Naphthol-AS-BI-phosphohydrolase & + & + & + & + \\
\hline Trypsin & - & - & - & - \\
\hline Valine arylamidase & $\mathrm{w}+$ & + & $\mathrm{w}+$ & $\mathrm{w}+$ \\
\hline
\end{tabular}

All data were obtained in this study. +, positive; -, negative; w+, weakly positive 


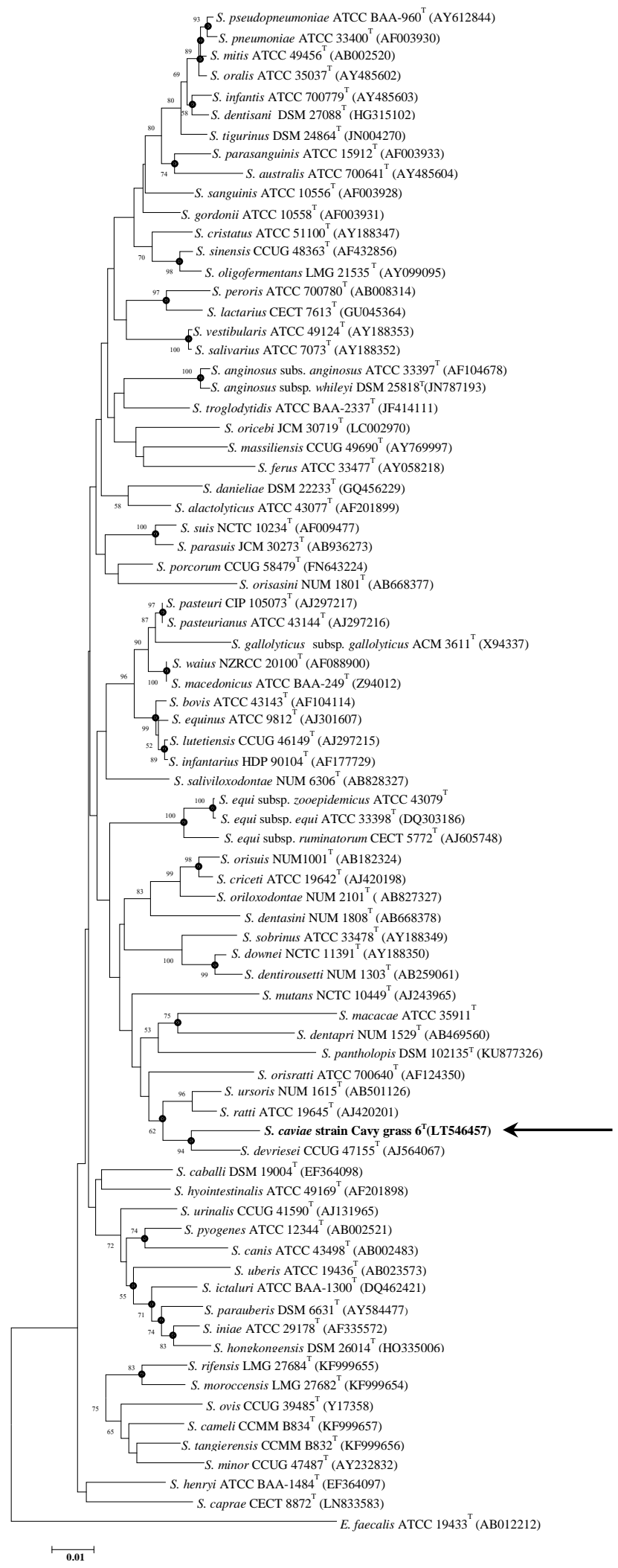

Fig. S1. Phylogenetic relationships between strain Cavy grass $6^{\mathrm{T}}$ and related species in the genus Streptococcus based on 16S rRNA gene sequences (approx. 1360 nucleotides) by the neighbor-joining method. Bootstrap values, which were higher than $50 \%$ based on 1000 replications, are shown at the branching points. Enterococcus faecalis ATCC $19433^{\mathrm{T}}$ was used as an out group. Filled circles indicate identical nodes generated by three methods (neighbor-joining, maximum-likelihood and maximum-parsimony). Gen Bank accession numbers of each strain are given in parentheses. Bar, $1 \%$ sequence divergence. 



\section{CHAPTER 7}

General discussion 


\section{Introduction}

There is considerable interest in the anaerobic digestion of organic waste into biogas and/or other economically relevant compounds, such as organic acids and biofuels, to close the carbon cycle. The hydrolysis step in this process is considered to be the rate-limiting step and hence substantial attention has been given to pre-treatment methods of physical, chemical, thermal and/or biological or enzymatic nature. These are applied to increase the hydrolysis rate, the overall biogas yield, and to increase the surface area accessibility of substrates for fermentative microorganisms as well as the anaerobic digestion efficiency (Monlau et al., 2013). Pre-treatment methods are applied depending on the different types of biomass and also result in different costs (Bosma et al., 2013). Organic acids, such as lactate, succinate, ethanol and acetate, are intermediate fermentation products that are formed after the acidogenesis step. The use of mixed microbial cultures for the fermentation of biopolymers into organic acids may also reduce the pre-treatment and hydrolysis costs. These strategies are embedded in the carboxylate platform which converts waste and/or biomass to produce carboxylates, including organic acids using anaerobic mixed cultures (Tamis et al., 2015; Agler et al., 2011).The carboxylate platform is environmental friendly not only helping to manage the organic waste problem by using as substrates but also producing organic acids which can further be applied to form chemicals and fuels to replace the use of fossil reserves and consequently lowering $\mathrm{CO}_{2}$ emission to the atmosphere. A similar system has been developed in nature in the rumen of cows and other herbivores and it has been established that the rumen is an excellent source of fermentative microorganisms with high hydrolytic activity.

In Chapter $\mathbf{2}$ starch waste and rumen fluid inocula were applied to investigate the conversion of organic waste to valuable products such as organic acids without a pre-treatment step. Organic acid production was studied in ex-situ conditions by using two different types of inoculum: i) rumen fluid from dairy cows from the Netherlands and Thailand and ii) fecal samples from two male domestic guinea pigs (Chapter 2 and 5). Foregut and hindgut animals in general have similar diets 
(grass or hay) but have a difference in the anatomy of their digestive track. Three novel gut bacteria (originating from cow, sheep and guinea pig) have been characterized and identified by the morphological, physiological chemical and genomic characteristics. Actinomyces succiniciruminis and Actinomyces glycerinitolerans were distinguished and presented in Chapter $\mathbf{3}$ and Streptococcus caviae was described in Chapter 6. The three novel bacteria that were obtained may be used for biotechnological organic acid production from organic materials in the future. Especially, the ability of $A$. succiniciruminis to form succinate as a main product in the fermentation of starch waste offers perspectives, when through genetic engineering the succinate yield can be further enhanced (Chapter 4).

\section{Substrate and inoculum in anaerobic reactor}

The type and the composition of the diet have a large impact on the microbial composition in the rumen as shown by the different microbial community of the Dutch and Thai rumen inoculum (Chapter 2). Similarly, the substrate determines the microbial community in the reactors as shown in Chapter 2 where starch waste enhanced the growth of lactic acid bacteria (LAB) especially members of the genus Streptococcus in the first stage of the fermentation resulting in lactate production. The microbial community changed in the second stage of the fermentation for both rumen inocula and the organic acid production profiles in both reactors were different.

The source of inoculum is also very important as shown in the Chapters $\mathbf{2}$ and $\mathbf{5}$ where two sources of gut inocula (rumen fluids and guinea pig fecal samples) were enriched on starch waste $(0.5 \% \mathrm{w} / \mathrm{v})$. We observed lactate to be the first primary product of starch waste fermentation by rumen microorganisms (Chapter 2). In contrast, acetate was the primary product of hindgut (caecum) microorganisms when degrading the same starch waste (Chapter 5). In another recent study with granular sludge from up-flow anaerobic sludge blanket (UASB) reactor treating potato factory waste, acetate was the major product formed from starch waste (Arslan et al., 2017). Our 
results show that it is feasible to obtain robust lactate production from starch waste by rumen microorganisms. However, it is challenging to further optimize this lactate production (Chapter 2).

When we analyzed the microbial communities involved in these starch waste and dried grass conversions, marked differences were observed that may explain the observed different key metabolites (Fig. 1). In the Fig. 1, the dominant microbial groups obtained from two different type inocula (rumen fluids and guinea pig fecal samples) are presented and the enrichment of selected substrates as well as the routes of isolated novel bacteria. This relates to the microbial inocula that are different and the microbial composition in the inocula were related to their animal feeds. For example, we only found Acetobacter and Lactobacillus members in the Thai rumen sample as the cows were fed with pineapple peel but was not detected in the Dutch rumen fluid. Various lactic acid bacteria including Lactobacillus were isolated from pineapple and acetic acid bacteria such as Acetobacter spp. are the cause of marbling disease; one of the common diseases in pineapple (Sipes et al., 2017) (Chapter 2). Members of the genus Fibrobacter, a well-known of cellulose degrader, were highly presented in the guinea pig fecal inoculum and the guinea pigs were fed mainly with fiber materials. In the starch waste enrichment, this substrate enriched lactic acid bacteria especially Streptococcus in both reactors (Dutch and Thai) even though it was abundant only less than $1 \%$ in both inocula. 


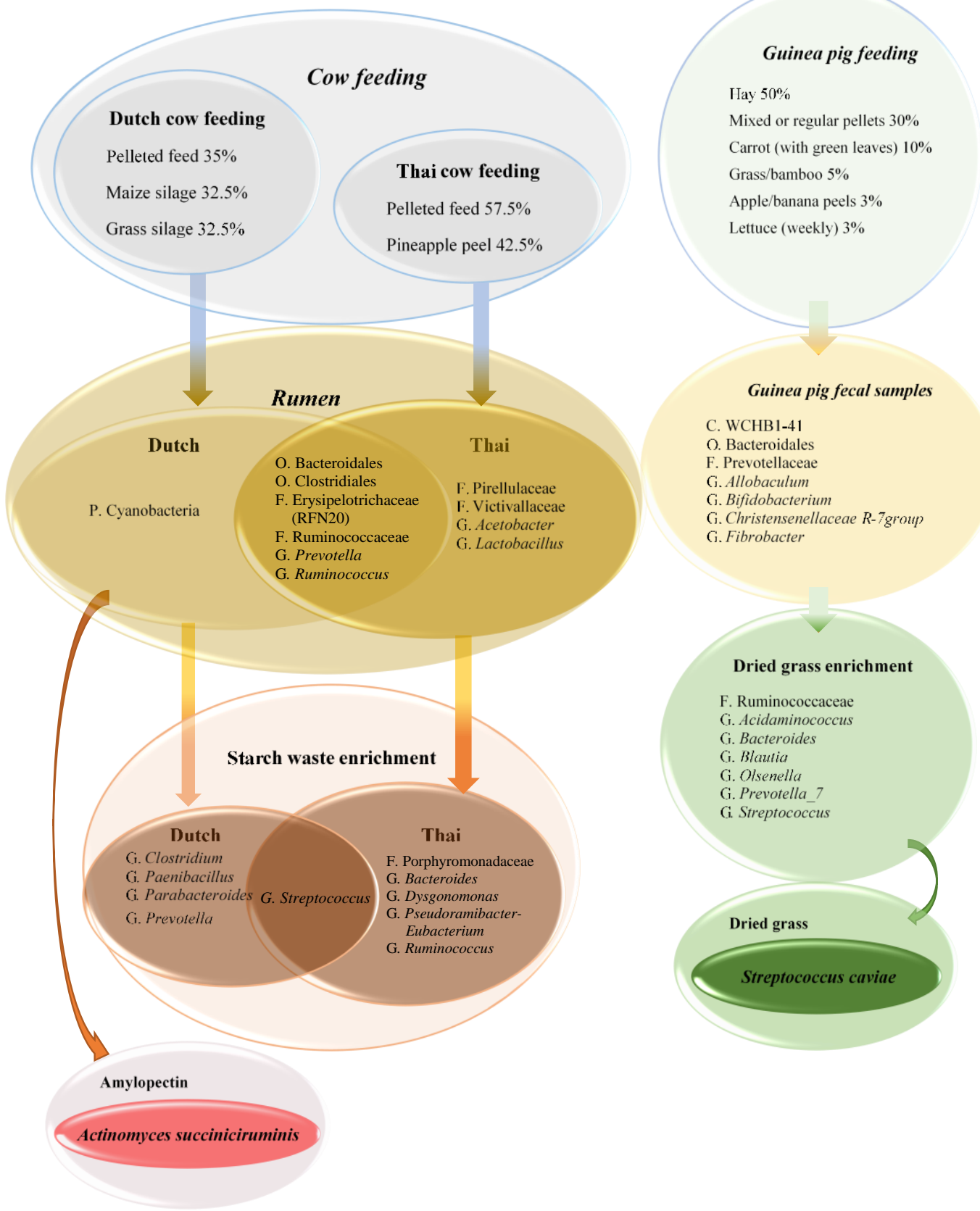

Fig. 1. Relationship of animal feed and principal microbial composition in guts (cow rumen and guinea pig fecal samples) and in the substrate enrichments (starch waste, amylopectin or dried grass). Capital letters mean taxonomic rank: P; phylum, C; class, O; order, F; family and G; genus.

In conclusion, substrate or diet drives the microbial community and the microbial community determines the organic acid production profile in the fermentation process and later the products regulate the microbial composition in the habitat. Therefore, substrate and inoculum selection are important factors in the carboxylate platform. This confirms an earlier suggestion that selection of 
substrate and microbial inoculum are important to achieve the efficient fermentation of turning renewable materials to valuable products (Wang et al., 2015).

\section{Starch waste as source for organic acid production}

Lactate has been produced by microorganisms at industrial scale for many years. It has been reported that the costs of raw materials contribute for approximately one third of the total manufacturing cost of bio-based lactate (Wang et al., 2015). In the current first-generation biolactate processes, edible biomass such as corn, tapioca, sugar cane and sugar beet are used as substrates to generate fermentable sugars (glucose and sucrose) for lactic acid bacteria (Bosma et al., 2013). Lactic acid bacteria are very efficient lactate producers, but they are usually fastidious and require mono-sugars which come from the biomass after the pre-treatment method. Renewable materials such as lignocellulose and starch are considered as an attractive substrate for organic acid production as they have zero or low value. Pre-treatment steps either by physical and/or chemical for lignocellulose for instant, is needed to make the (hemi) cellulose available for the saccharification step. Later the (hemi) cellulose polymers will be saccharified to monomeric sugars by enzymes and then will be fermented by microorganisms into products. In the case that that saccharification and fermentation occur in the same reactor these processes can be characterized into consolidated bioprocessing (CBP) or simultaneous saccharification and fermentation (SSF) (Bosma et al., 2013). In CBP microorganisms produce all necessary enzymes to hydrolyze the pre-treated biomass without additional enzyme requirement, whereas in SSF saccharification and fermentation are carried out in one reactor but requires addition of the hydrolysis enzymes to hydrolyze the biomass into mono-sugars (Bosma et al., 2013). The advantage of starchy waste over cellulose materials is that it is easier hydrolyzed to glucose. Starch is the world's second-most abundant carbohydrate, after cellulose, resulting in a large amounts of starch waste or starch residues

worldwide. Various plants contain mainly starch such as potatoes and cassava, or seeds of grains such as wheat, corn and rice. Potato waste is used as animal feed or to produce compost, but still 
much of it is discharged as waste (Suzuki et al., 2010). Starchy waste contains high amounts of carbohydrates (Chapter 2) which are suitable as growth substrate for microorganisms (Rakshit, 2004). In many starch fermentation studies using undefined mixed cultures, lactate is often reported as main product. For instance, in potato peel waste fermentation (Liang et. al, 2014; Liang et. al, 2015) and maize silage fermentation (Sträuber et. al, 2012). As previously mentioned, the oftenencountered bottleneck for bio-based lactate production from renewable materials is the costs of pre-treatment (Wang et al., 2015). We demonstrated that starch waste from a potato factory is suitable as an alternative substrate for fast organic acid production, especially lactate production, which occurs within one day using rumen inocula in batch reactors without the pre-treatment (Chapter 2). Lactate in nature, occurs in two optical isomers; D (-)- and L (+)- forms. Bio-lactate from microbial fermentation method is preferable over the synthesized lactate derived from petroleum resources due to the purity of lactate as the chemical synthesis always results in a racemic mixture of DL-lactate whereas optically pure D (-)- or L (+)-lactate can be obtained from the microbial fermentation (Wang et al., 2015). Among these two racemic forms, L (+)-lactate is preferred for the food and drug industries as only this isomer is adapted to be assimilated by the human body (Wang et al., 2015). Besides using mixed microorganisms to reduce the pre-treatment cost, exploring the microorganism that can directly utilize the biomass and/or less growth requirement is desirable. For example, in Chapter 4, Actinomyces succiniciruminis that isolated from the enrichment of amylopectin as shown in Fig. 1, could produce succinate directly from fresh starch that was only supplemented with some bicarbonate.

\section{Organic acid production from three sources: rumen of Thai and Dutch cows and guinea pig guts}

Herbivorous mammals including ruminants and rodents consume plant material as their main feed. Mammalian themselvescannot the complex substances, and therefore rely on the microorganisms in their gut to digest the food for survival (Flint et al., 2012). Foregut fermenters 
(ruminants) such as cows and sheep gain energy by consuming the microbial protein and organic acid produced by the anaerobic microorganisms in their guts (Flint et al., 2012). Hindgut fermenters or monogastric herbivores, such as horses and rodents benefit from the digestion and fermentation by microbes in their guts located in the enlarged cecum and proximal colon. Those microorganisms in foregut and hindgut digest and ferment the feed (plant cell walls) and form mainly organic acids such as acetate, lactate, propionate and butyrate. Yu et al. (2000) reported that the pattern of organic acids obtained from fecal and colon-rectal contents of ten guinea pigs was similar to that of rumen; acetate was the main product followed by propionate and then butyrate (Table 1) (Yu et al., 2000). However, this pattern is different for rodents (rats, hamsters and rabbits) where butyrate was higher than propionate (Yu et al., 2000). The difference of the major microbial groups between these two animals could not be traced back, because there was no microbial analysis in this work. In the bioreactors (ex-situ conditions) described in Chapter 2, the acetate:propionate:butyrate molar ratio (mol \%) from both reactors at day 1 are shown in Table 1 comparing with those ratio obtained from cow fed with high and low grain diets (Yu et al., 2000) and the from two fermented positions of guinea pig gut (Sofyan et al., 2017). The acetate:propionate:butyrate ratio in the reactor with Thai rumen fluid was similar to the percent ratio of the cows fed with grain diet as reported with 40:37:20 and when the cows were fed with hay diet the ratio was 65:20:12 (Chiba, 2014).

Table 1 Comparison of the organic acids (mol \%) production in reactors, foregut and hindgut

\begin{tabular}{|c|c|c|c|c|c|c|}
\hline \multirow{2}{*}{$\begin{array}{c}\text { Mole } \% \text { of } \\
\text { organic acid }\end{array}$} & \multicolumn{2}{|c|}{ Starch waste fermentation ${ }^{a}$} & \multicolumn{2}{|c|}{ Dairy cows (Foregut) ${ }^{\mathbf{b}}$} & \multicolumn{2}{|c|}{ Guinea pigs (Hindgut) ${ }^{c}$} \\
\hline & $\begin{array}{c}\text { Dutch } \\
\text { reactor }\end{array}$ & $\begin{array}{l}\text { Thai } \\
\text { reactor }\end{array}$ & $\begin{array}{l}\text { Low-yield } \\
\text { rumen }\end{array}$ & $\begin{array}{l}\text { High-yield } \\
\text { rumen }\end{array}$ & Caecum & $\begin{array}{l}\text { Colonic- } \\
\text { rectum }\end{array}$ \\
\hline Acetate $(\mathrm{C} 2)$ & $89.2 \pm 0.1$ & $71.0 \pm 0.1$ & $69.5 \pm 3.8$ & $71.0 \pm 2.1$ & $57.1 \pm 3.4$ & $58.3 \pm 10.1$ \\
\hline Propionate $(\mathrm{C} 3)$ & $6.7 \pm 0.1$ & $15.7 \pm 0.1$ & $18.2 \pm 1.2$ & $17.6 \pm 1.0$ & $24.3 \pm 3.2$ & $20.9 \pm 4.8$ \\
\hline Butyrate (C4) & $4.0 \pm 0.1$ & $13.3 \pm 0.1$ & $12.3 \pm 2.7$ & $11.4 \pm 1.6$ & $16.1 \pm 1.9$ & $17.8 \pm 7.7$ \\
\hline
\end{tabular}

${ }^{\mathrm{a}},{ }^{\mathrm{b}}$ and ${ }^{\mathrm{c}}$ obtained from Palakawong Na Ayudthaya et al., 2018 (Chapter 2), Sofyan et al., 2017 and Yu et al., 2000, respectively. 
There are many factors that determine the organic acid production profiles such as the animal diet, the type of animal, animal individuality and food digestion system. Cows or ruminants re-chew by re-taking their diet from their stomach back in their mouth, whereas guinea pigs eat their own feces (coprophagy). One of the main factors that determines the organic acid production profiles is the microbial community in those habitats. Please note that it is likely that calves are first inoculated the microbial community by their mother (de Vos 2013).

At the phylum level, the microbial community of all three studied gut microbiomes shared three phyla; Firmicutes, Bacteroides and Cyanobacteria, and these three phyla together was the majority of the microbiome $(93 \%, 78 \%, 78 \%$ and $84 \%$ relative abundances in Dutch rumen fluid, Thai rumen fluid, Guinea pig fecal sample 1 and Guinea pig fecal sample 2, respectively) (Fig. 2). Unclassified groups (in average $4 \%$ relative abundance) were detected only in the guinea pig fecal samples indicating that as-yet-uncultivated bacteria are present in this source. On the other hand, Candidate division TM7 was detected in the rumen fluid in small amount (in average $0.9 \%$ relative abundance).

The organic acid production profiles resulting from starch waste fermentation by rumen and guinea pig fecal samples were different. These may be the result of the different microbial community in rumen and guinea pig fecal samples. In the starch waste fermentation using rumen fluid as inoculum, lactic acid bacteria especially belonging to the genus Streptococcus played an important role in lactate production (Chapter 2) whereas using guinea pig fecal samples as inoculum, members of Bacteroides, Prevotella and Blautia were abundant. These may be responsible for the observed acetate production (Chapter 5). 


\section{Dutch rumen fluid Thai rumen fluid Guinea pig fecal sample 1 Guinea pig fecal sample 2}

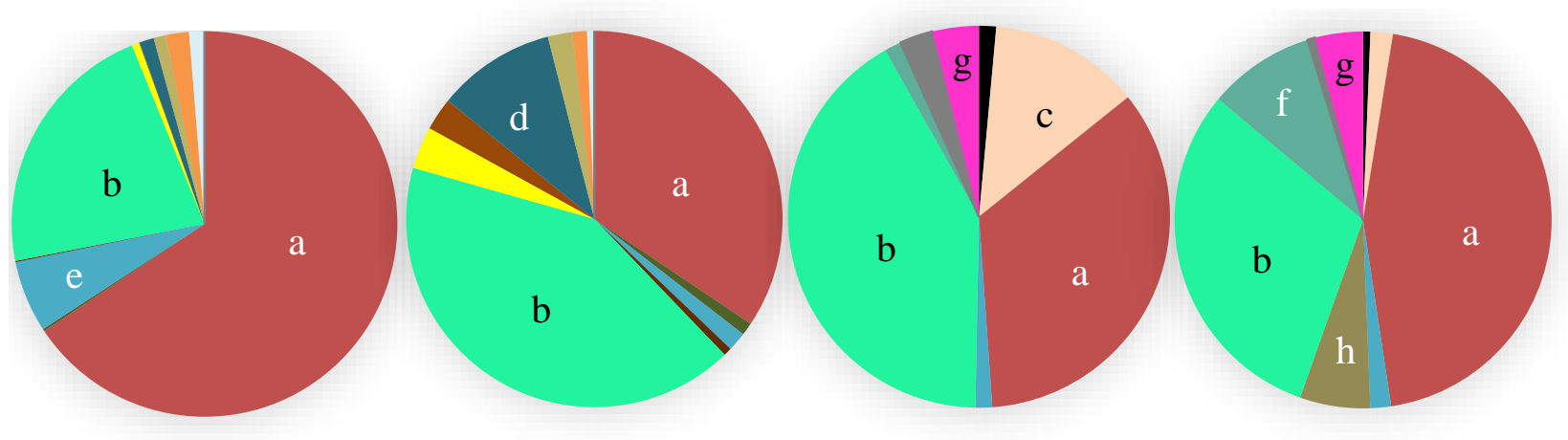

- K_Archaea; P_Euryarchaeota

(a) $\quad$ K__Bacteria; P_Bacteroidetes

(e) $\square$ K_Bacteria; $\mathbf{P} \_$Cyanobacteria

(h) $\square$ K__Bacteria; P_Fibrobacteres

K__Bacteria; P_Lentisphaerae

(d) $\square$ K__Bacteria; $\mathbf{P} \_$Proteobacteria

- K__Bacteria; P_Tenericutes

TM7

(g) $\square$ Unclassified (c) K_Bacteria; P_Actinobacteria - K_Bacteria; P_Chloroflexi - K__Bacteria; P_Elusimicrobia

(b) $\square$ K__Bacteria; $\mathbf{P}$ __Firmicutes - K__Bacteria; P_Planctomycetes K__Bacteria; P_Spirochaetes

(f) $\square$ K__Bacteria; $\mathbf{P} \_$Verrucomicrobia - Phylogenetic groups that contribute less than $1 \%$

Fig. 2 Relative abundance of gut microorganisms (at phylum level). Note: The microbial composition in Dutch and Thai rumen fluid was determined by $16 \mathrm{~S}$ rRNA amplicon pyrosequencing (Chapter 2) whereas the microbial composition of Guinea pig fecal sample 1 and 2 was determined by $16 \mathrm{~S}$ rRNA amplicon Miseq sequencing (Chapter 5). Capital letters mean taxonomic rank: K; Kingdom and P; phylum. The major phylum-level phylogenetic groupings from all samples were alphabetically listed as $\mathrm{a}-\mathrm{g}$.

\section{Novel organic acid producing bacteria and their characteristics for future application}

Some disadvantages of the carboxylate platform using mixed cultures are that the product concentration of organic acids and their purity may be lower than when pure cultures or engineered strains are used. Therefore, identifying and isolating novel organic acid-producing bacteria is important. In this study, three novel bacteria have been enriched, isolated and characterized as shown in the Fig. 1. Two strains belonging to the genus Actinomyces are described: A. succiniciruminis strain $\mathrm{Am} 4^{\mathrm{T}}$ isolated from Holstein cow rumen fluid in the Netherlands with amylopectin as 
substrate and A. glycerinitolerans strain $\mathrm{G} 10^{\mathrm{T}}$ isolated from sheep (Slovenskè merino breed) with glycerol (Chapter 3). The third novel strain belongs to the genus Streptococcus and was named S. caviae (Cavy grass $6^{\mathrm{T}}$ ). It was isolated from guinea pig fecal samples and enriched with dried grass as substrate (Chapter 5 and 6). As previously mentioned, bio-based succinate is one of the top 10 important organic acids for further use in the chemical industry. Both Actinomyces strains are rather robust as they tolerate adverse conditions such as at high level of $\mathrm{O}_{2}(20 \% \mathrm{v} / \mathrm{v})$ and glycerol (up to $25 \% \mathrm{w} / \mathrm{v}$ ) and they are to convert starch waste to succinate as product without pretreatment (Chapter 3). Therefore, A. succiniciruminis was further studied to optimize succinate production from starch waste (Chapter 4). S. caviae strain Cavy grass $6^{\mathrm{T}}$, a facultatively anaerobic bacterium utilizes and ferments a range of plant mono- and disaccharides as well as polymeric carbohydrates, including cellobiose, dulcitol, inulin, and dried grass extract. It forms lactate, formate, acetate and ethanol as main products (Chapter 6). All three novel isolated species directly converted the complex polymeric substrates to organic acids in one-step fermentation and no requirement of additional hydrolytic enzymes are required. Therefore, the novel strains are promising to consider as catalysts for biotechnological applications.

\section{The genus Actinomyces and A. scucciniciruminis}

It has been well acknowledged of the many remarkable characteristics of Actinobacteria such as production of antibiotics and/or secondary metabolites. Genus Actinomyces is a member of the Actinobacteria phylum and has many interesting characteristics for future application. For instance, A. succiniciruminis could utilize various substrates such as mono- di- and poly substrates including amylopectin, cellobiose, inulin, pectin, soluble starch, starch waste and xylan to mainly succinate, lactate and small amount of formate and acetate. However, not all members of Actinomyces can utilize the variety of carbohydrate, it is depended on the species differences. Genus Actinomyces is a mixed acid-producing bacterium. Not all Actinomyces spp. can utilize starch to organic acids and the end fermentation products from glucose are vary in the type and amount of acids (Schaal, 
and Yassin, 2012). For instant, Woo et al. reported that A. hongkongensis cannot produce acid from glucose and seems to be completely an asaccharolytic species (2003). The other example is $A$. nasicola that can produce acid from cellobiose, fructose and glucose but not form a large variety of carbohydrates (Hall et al., 2003). Moreover, we found an ADP-dependent glucokinase or ADPGK gene that uses ADP to convert glucose into glucose-6-phosphate encodes in the genome of strain Am4. Normally, other bacteria use ATP to convert glucose into glucose-6-phosphate. We also found this gene in the closely related Actinomyces such as in A. glycerinitolerans, A. ruminicola, A. israelii and A. massiliensis but the percent of sequence similarity are quite low $(91,81,64$ and $62 \%$, respectively). Using ADPGK instead of ATPGK in this step may help the cell to conserve energy. Chapter 4 describes that the strain in this genus could utilize starch waste and result mainly succinate in the conditions without medium (only supplemented with phosphate and bicarbonate) that is an interesting feature for biotechnological approach. Since the strain $\mathrm{Am} 4^{\mathrm{T}}$ is heterofermentative, genetic engineering is an interesting approach to further optimize SA production by block or reduce other organic acid products. Based on our knowledge, there is no genetic system reported for any Actinomyces species up to now. In 2015, Tong and others successfully developed a CRISPR-Cas 9 system to engineer the Actinomycetal genomes (Actinomycetales is the taxonomic order level of genus Actinomyces) (Tong et al., 2015). Moreover, other studies of Cobb and others and Huang and others proved that CRISPR/Cas9-mediated genome editing could be applied for multiplex editing of the Streptomyces genome and is promising for genome-modified application in Actinomyces species (Cobb et al., 2014; Huang et al., 2015). The development of these genome editing systems may accelerate genetic engineering in the genus Actinomyces and lead to an engineered A. succiniciruminis strain $\mathrm{Am} 4^{\mathrm{T}}$ to give even higher succinate yields from starch waste fermentation. 


\section{The genus Streptococcus and S. caviae}

More than 100 species are presently included in the genus Streptococcus. Members of this genus have been found in broad habitats including human and many other animals where they reside notably in the oral or gastrointestinal (GI) tract. The predominant fermentation product from carbohydrate of all streptococci is lactate while small amounts of acetate, formate, ethanol and $\mathrm{CO}_{2}$ are produced (Whiley and Hardie, 2009). Not all Streptococcus species can utilize cellebiose, such as S. downei, S. oligofermentans and S. oralis (Whiley and Hardie, 2009), while S. caviae and other species such as $S$. devriesei, $S$ ratti and $S$. ursoris can utilize the cellebiose to organic acids (Chapter 6). Moreover, S. caviae could utilize L-sorbose which most of the Streptococcus members could not utilize, only some variations of $S$. devriesei have been reported (Whiley and Hardie, 2009). Degrading and fermentation capacity are vary within the genus depending on the individual species.

\section{Conclusion remarks and future perspectives}

The carboxylate fermentation (using mixed cultures) is more attractive than pure culture fermentation as previously mention. The substrate costs are lower, no expensive sterilization process is required (Arslan et al., 2017) and no hydrolytic-enzymes need to be added which can be characterized as consolidated bioprocessing and has an advantage over the simultaneous saccharification and fermentation that needs the addition of the hydrolytic enzymes. Using a rumenderived inoculum, which harbours high microbial hydrolytic activities and has a very high microbial diversity, could reduce the pre-treatment costs in anaerobic digestion and utilizes a variety of organic wastes. In this study, the selection of starch waste and rumen fluid was successful especially in lactate production. High lactate concentrations were achieved in a short time period. Further optimization by changing fermentation parameters and investigate the product profile will result in the optimum conditions for the production of each organic acids. A challenging task is how to make 
rumen microorganisms as the commercial seed for industrial application. Synthetic microbialmixture seed may be the other challenging option which is more advantageous than authentic microbial-mixture seed in terms of its reproducibility, controllability and safety (de Vos, 2013). Moreover, a single culture that owns the hydrolytic enzymes which are needed to utilize the biomass together with the ability to ferment the result to products is also attractive. 


\section{Summary}

Global warming and depleting resources are currently main issues in our society. Consuming fossil fuels has become a significant concern not only because resources are depleting, but also because of the resulting pollution and carbon dioxide formation that contribute to the global warming. There is also a worldwide increasing energy demand as the world's population increases. Renewable instead of fossil resources to produce energy and biochemical building blocks are thus of interest. One the most important building blocks is succinate and its production is a process that uses carbon dioxide. Turning organic waste to valuable products such as organic acids including lactate and succinate is a promising strategy. Starch waste has no, or low-value and it does not compete with sources that can also be used for food production. Therefore, in Chapter 1, general information related to this approach is introduced and bio-based organic acids such as lactate and succinate are reviewed. The efficiency of the anaerobic digestion process (in terms of production and digestion yields) relies on many factors such as chemical parameters ( $\mathrm{pH}$, nutrient content), physical parameters (temperature, mixing) and biological factors (biomass). The choice of organic waste and substrate inoculum are also important factors. Rumen "a bioreactor" becomes an interesting source as it contains extreme high numbers and various degrading microorganisms. In this thesis, various materials and gut microorganisms were selected as substrate and inoculum to study organic acid production and the choices were presented in Chapter $\mathbf{2}$ and 5. In Chapter 2, starch waste from potato factory as the substrate and two different sources of rumen fluids (from Dutch and Thai dairy cows) as inoculum were investigated on the possibility of organic acid production. Organic acid production profiles and the microbial community change during the fermentation process from two rumen-fluid inoculum reactors were investigated and compared. Lactate is the first primary organic acid fermentation product (within one day) from both reactors and Streptococcus spp., amylolytic lactic acid bacteria, play an important role in this process as their relative abundance is $89 \%$. In the second fermentation stage, the community in both reactors 
changed and that resulted in different organic acid production profiles as result of the different origin of the inoculum. In the Dutch-rumen inoculum reactor, butyrate production coincided with a decrease in relative abundance of Streptococcus spp. and an increase in relative abundance of Parabacteroides, Sporanaerobacter, Helicobacteraceae, Peptostreptococcaceae and Porphyromonadaceae. In the Thai-rumen inoculum reactor (after day 3), acetate, propionate and butyrate were produced and showed significant positive correlations with bacteria belonging to five dominant groups, Bacteroides, Pseudoramibacter / Eubacterium, Dysgonomonas, Enterobacteriaceae and Porphyromonadaceae. In Chapter 5, a different gut-microbial source (guinea pig fecal samples) was tested as inoculum with various substrates including dried grass and starch waste. This is the first study in which guinea pig fecal samples have been used for organic acid production and microbial enrichments. Acetate was the predominant organic acid in all enrichments. Microbial community analysis of guinea pig fecal samples revealed that $\sim 68 \%$ of the community could not be classified at genus level, when using $16 \mathrm{~S}$ rRNA amplicon sequencing. This reveals that the guinea pig gut contains many as-yet-uncultivated bacteria that may be an appropriate target for future microbial studies. Eight phylogenetically different isolates were obtained, including a novel Streptococcus species, strain Cavy grass $6^{\mathrm{T}}$. Strain Cavy grass $6^{\mathrm{T}}$ was isolated from the dried grass enrichments (Chapter 6). This strain can utilize a range of plant mono- and disaccharides as well as polymeric carbohydrates including cellobiose, dulcitol, d-glucose, maltose, raffinose, sucrose, 1-sorbose, trehalose, inulin and dried grass extract, and forms lactate, formate, acetate and ethanol as products. The strain Cavy grass $6^{\mathrm{T}}$ was characterized and registered as a novel cellobiosedegrading and lactate-producing bacterium and named Streptococcus caviae. Two more novel organic acid producing bacteria belonging to genus Actinomyces were described in Chapter 3 . Strain $\mathrm{Am} 4^{\mathrm{T}}$ (Actinomyces succiniciruminis) and strain $\mathrm{G} 10^{\mathrm{T}}$ (Actinomyces glycerinitolerans) were isolated from rumen fluid of different ruminants: cow (Holstein-Friesian) and sheep (Slovenskè merino), respectively. They were isolated from different hosts and regions but showed 99.2\% similarity of the $16 \mathrm{~S}$ rRNA genes. Therefore, different techniques such as 16S rRNA gene sequence 
analysis, ANI, DDH, dDDH, AAI and MLSA, but also substrate utilization were applied to distinguish between these two species. One of the interesting characteristics that they can ferment starch waste forming succinate, which is an important organic acid in bio-based economy. Succinate production from starch waste by the strain $\mathrm{Am} 4^{\mathrm{T}}$ was further optimized in anaerobic bottles and bioreactors under various conditions as shown in Chapter 4. Addition of phosphate and bicarbonate to the growth medium enhanced succinate production from starch waste. No effect of oxygen, sulfate and nitrate on the succinate yield was observed. Nitrite completely inhibited the growth of the strain $\mathrm{Am} 4^{\mathrm{T}}$. Succinate production was highest $\left(118 \mathrm{mM} ; 1.48 \mathrm{mmol}\right.$ succinate $\mathrm{g}$ starch waste $\left.^{-1}\right)$ in batch reactors fed with $8 \%(\mathrm{w} / \mathrm{v})$ dried starch waste in a mineral-salt anaerobic medium supplemented with $150 \mathrm{mM}$ bicarbonate, $12 \mathrm{mM}$ phosphate buffer and $0.1 \mathrm{~g} \mathrm{l}^{-1}$ yeast extract and a headspace of $20 \% \mathrm{CO}_{2}: 79 \% \mathrm{~N}_{2}: 1 \% \mathrm{O}_{2}$. The findings of this thesis were discussed in Chapter 7 and future perspectives were presented.

In summary, starch waste and rumen fluid are the suitable for lactate and succinate production. Moreover, based on the number and diversity of rumen or hindgut microorganisms, these are good choices as the microbial source for organic acid production especially from organic waste. Three novel organic acid producing bacteria were obtained and some of them may have potential for applications in the future. 



\section{References}

Abdel-Rahman, M.A., Tashiro, Y. and Sonomoto, K. (2013) Recent advances in lactic acid production by microbial fermentation processes. Biotechnol. Adv. 31, 877e902.

Adsul, MG., Varma, AJ. and Gokhale, DV. (2007) Lactic acid production from waste sugarcane bagasse derived cellulose. Green Chem. 9, 58-62.

Agler, M.T., Wrenn, B.A., Zinder, S.H and Angenent L.T. (2011) Waste to bioproduct conversion with undefined mixed cultures: the carboxylate platform. Trends Biotechnol. 29, 70-78.

Alakomi, H.L., Skyttä, E., Saarela, M., Mattila-Sandholm, T., Latva-Kala, K. and Helander, I.M. (2000) Lactic acid permeabilizes gram-negative bacteria by disrupting the outer membrane. Appl. Environ. Microbiol. 66, 2001-2005.

An, D., Cai, S. and Dong, X. (2006) Actinomyces ruminicola sp. nov., isolated from cattle rumen. Int. J. Syst. Evol. Microbiol. 56, 2043-2048.

Arslan, D., Zhang, Y., Steinbusch, K.J.J., Diels, L., Hamelers, H.V.M., Buisman, C.J.N. and De Wever, H. (2017) In-situ carboxylate recovery and simultaneous $\mathrm{pH}$ control with tailorconfigured bipolar membrane electrodialysis during continuous mixed culture fermentation. Sep. Purif. Technol. 175, 27-35.

Aulitto, M., Contursi, P., Franzén, C., Fusco, S. and Bartolucci, S. (2017) Bacillus coagulans MA13: A promising thermophilic and cellulolytic strain for the production of lactic acid from lignocellulosic hydrolysate. Biotechnol. biofules. 10, 1-15.

Azman, S., Khadem, A.F., van Lier, J.B., Zeeman, G. and Plugge, C.M. (2015) Presence and role of anaerobic hydrolytic microbes in conversion of lignocellulosic biomass for biogas production. Crit. Rev. Environ. Sci Technol. 45, 2523-2564.

Bai, X., Xiong, Y., Lu, S., Jin, D., Lai, X., Yang, J., Niu, L., Hu, S., Meng, X., Pu, J., Ye, C. and $\mathrm{Xu}$, J. (2016) Streptococcus pantholopis sp. nov., isolated from faeces of the Tibetan antelope (Pantholops hodgsonii). Int. J. Syst. Evol. Microbiol. 66, 3281-3286.

Barnes, S.P. and Keller, J. (2004) Anaerobic rumen SBR for degradation of cellulosic material. Water Sci. Technol. 50, 305-311.

Biswas, S. and Rolain, J.-M. (2013) Use of MALDI-TOF mass spectrometry for identification of bacteria that are difficult to culture. J. Microb. Methods. 92, 14-24.

Bosma, E.F., van der Oost, J., de Vos, W.M. and van Kranenburg R. (2013) Sustainable production of bio-based chemicals by extremophiles. Curr. Biotechnol. 2, 360-379.

Bozell, J.J. and Petersen, G.R. (2010) Technology development for the production of biobased products from biorefinery carbohydrates - the US Department of Energy's "Top 10" revisited. Green Chem. 12, 539-554. 
Caporaso, J.G., Bittinger, K., Bushman, F.D., DeSantis, T.Z., Andersen, G.L. and Knight, R. (2010) PyNAST: a flexible tool for aligning sequences to a template alignment. Bioinformatics. 26, 266-267.

Caporaso, J.G., Kuczynski, J., Stombaugh, J., Bittinger, K., Bushman, F.D., Costello, E.K., Fierer, N., Peña, A.G., Goodrich, J.K., Gordon, J.I., Huttley, G.A., Kelley, S.T., Knights, D., Koenig, J.E., Ley, R.E., Lozupone, C.A., McDonald, D., Muegge, B.D., Pirrung, M., Reeder, J., Sevinsky, J.R., Turnbaugh, P.J., Walters, W.A., Widmann, J., Yatsunenko, T., Zaneveld, J. and Knight, R. (2010). QIIME allows analysis of high-throughput community sequencing data. J. Bacteriol. 7, 335-336.

Caporaso, J.G., Lauber, C.L., Walters, W.A., Berg-Lyons, D., Lozupone, C.A., Turnbaugh, P.J., Fierer, N. and Knight, R. (2011) Global patterns of 16S rRNA diversity at a depth of millions of sequences per sample. Proc. Natl. Acad. Sci. USA 108, 4516-4522.

Chassard, C., Delmas, E., Lawson, P.A. and Bernalier-Donadille, A. (2008) Bacteroides xylanisolvens sp. nov., a xylan-degrading bacterium isolated from human faeces. Int. J. Syst. Evol. Microbiol. 58, 1008-1013.

Chen, T., Long, W., Zhang, C., Liu, S., Zhao, L. and Hamaker, B.R. (2017) Fiber-utilizing capacity varies in Prevotella-versus Bacteroides-dominated gut microbiota. Sci. Rep. 7, 2594.

Chiba, L.I. (2014), Section 3: Rumen microbiology and fermentation. In: Animal nutrition handbook. Third edition.

pp. $57-81$. (http://www.ag.auburn.edu/ chibale/animalnutrition.html)

Christensen, J.J., Dargis, R., Hammer, M., Justesen, U.S., Nielsen, X.C. and Kemp, M. (2012) The Danish MALDI-TOF MS study group Matrix-assisted laser desorption ionization-time of flight mass spectrometry analysis of Gram-positive, catalase-negative cocci not belonging to the Streptococcus or Enterococcus genus and benefits of database extension. J. Clin. Microbiol. 50, 1787-1791.

Chun, J., Lee, J.-H., Jung, Y., Kim, M., Kim, S., Kim, B.K. and Lim, Y.-W. (2007) EzTaxon: a webbased tool for the identification of prokaryotes based on 16S ribosomal RNA gene sequences. Int. J. Syst. Evol. Microbiol. 57, 2259-2261.

Clark, J.H., Farmer, T.J., Hunt, A.J. and Sherwood, J. (2015) Opportunities for bio-based solvents created as petrochemical and fuel products transition towards renewable resources. Int. J. Mol. Sci. 16, 17101-17159.

Clavel, T., Charrier, C. and Haller, D. (2013) Streptococcus danieliae sp. nov., a novel bacterium isolated from the caecum of a mouse. Arch. Microbiol. 195, 43-49.

Cobb, R.E., Wang, Y. and Zhao, H. (2014) High-efficiency multiplex genome editing of Streptomyces species using an engineered CRISPR/Cas system. ACS Synth. Biol. 4, 723728.

Cobellis, G., Trabalza-Marinucci, M. and Yu, Z. (2016) Critical evaluation of essential oils as rumen modifiers in ruminant nutrition: a review. Sci. Total Environ. 545, 556-568. 
Collins, M.D., Lundström, T., Welinder-Olsson, C., Hansson, I., Wattle, O., Hudson, R.A. and Falsen, E. (2004) Streptococcus devriesei sp. nov., from equine teeth. Syst. Appl. Microbiol. 27, 146-150.

Colombo, B., Favini, F., Scaglia, B., Sciarria, T.P., D'Imporzano, G., Pognani, M., Alekseeva, A., Eisele, G., Cosentino, C. and Adani, F. (2017) Enhanced polyhydroxyalkanoate (PHA) production from the organic fraction of municipal solid waste by using mixed microbial culture. Biotechnol. Biofuels10, 201.

Comparetti, A., Febo, P., Greco, C. and Orlando, S. (2013) Current state and future of biogas and digestate production. Bulg. J. Agric. Sci. 19, 1-14.

Crowley, E.J., King, J.M., Wilkinson, T., Worgan, H.J., Huson, K.M., Rose, M.T. and McEwan, N.R. (2017) Comparison of the microbial population in rabbits and guinea pigs by next generation sequencing. PLoS ONE 12, e0165779.

Cukalovic, A. and Stevens, C.V. (2008) Feasibility of production methods for succinic acid derivatives: a marriage of renewable resources and chemical technology. Biofuel Bioprod. Bior. 2, 505-529.

Dahiya, S., Kumar, A.N., Shanthi, J.S., Chatterjee, S., Sarkar, O. and Mohan, S.V. (2018) Food waste biorefinery: Sustainable strategy for circular bioeconomy. Bioresour. Technol. 248, 2-12.

Daims, H., Brühl, A., Amann, R., Schleifer, K-H. and Wagner, M. (1999) The domain-specific probe EUB338 is insufficient for the detection of all Bacteria: development and evaluation of a more comprehensive probe set. Syst. Appl. Microbiol. 22, 434-444.

De Filippo, C., Cavalieri, D., Di Paola, M., Ramazzotti, M., Poullet, J.B., Massart, S., Collini, S., Pieraccini, G. and Lionetti, P. (2010) Impact of diet in shaping gut microbiota revealed by a comparative study in children from Europe and rural Africa. Proc. Natl. Acad. Sci. USA 107, 14691-14696.

de Vos, W.M. (2013) Fame and future of faecal transplantations - developing next generation therapies with synthetic microbiomes. Microbial Biotechnol. 6, 316-325.

Der Werf, M.V., Guettler, M.V., Jain, M.K. and Zeikus, J.G. (1997) Environmental and physiological factors affecting the succinate product ratio during carbohydrate fermentation by Actinobacillus sp. 130Z. Arch. of Microbiol. 167, 332-342.

Dishaw, L.J., Flores-Torres, J., Lax, S., Gemayel, K., Leigh, B., Melillo, D., Mueller, M.G., Natale, L., Zucchetti, I., De Santis, R., Pinto, M.R., Litman, G.W. and Gilbert, J.A. (2014) The gut of geographically disparate Ciona intestinalis harbors a core microbiota. PLoS ONE 9, e93386.

Domingo, M., Huletsky, A., Boissinot, M., Bernard, K., Picard, F. and Bergeron, M. (2008) Ruminococcus gauvreauii sp. nov., a glycopeptide-resistant species isolated from a human faecal specimen. Int. J. Syst. Evol. Microbiol. 58, 1393-1397. 
Edgar, R.C. (2010) Search and clustering orders of magnitude faster than BLAST. Bioinformatics. 26, 2460-2461.

Edwards, J.E., Huws, S.A., Kim, E.J., Lee, M.R.F., Kingston-Smith, A.H. and Scollan, N.D. (2008) Advances in microbial ecosystem concepts and their consequences for ruminant agriculture. Animal 2, 653-660.

European Communities. (EPA): http://ec.europa.eu/environment/waste/target_review.htm (16-12018)

Felsenstein, J. (1981) Evolutionary trees from DNA sequences: a maximum likelihood approach. J. Mol. Evol. 17, 368-376.

Felsenstein, J. (1985) Confidence limits on phylogenies: an approach using the bootstrap. Evolution 39, 783-791.

Ferreira, L., Sánchez-Juanes, F., Muñoz-Bellido, J.L. and González-Buitrago, J.M. (2011) Rapid method for direct identification of bacteria in urine and blood culture samples by matrixassisted laser desorption ionization time-of-flight mass spectrometry: intact cell vs. extraction method Clin. Microbiol. Infect. 17, 1007-1012.

Fiorentino, G. and Ripa, M. (2017) Chemicals from biomass: technological versus environmental feasibility. A review. Biofuels, Bioprod. Bioref. 11, 195-214.

Flint, H.J., Duncan, S.H., Scott, K.P. and Louis, P. (2015) Links between diet, gut microbiota composition and gut metabolism. Proc. Nutr. Soc. 74, 13-22.

Flint, H.J., Scott, K.P., Duncan, S.H., Louis, P. and Forano, E. (2012) Microbial degradation of complex carbohydrates in the gut. Gut Microbes. 3, 289-306.

Fouts, D.E., Szpakowski, S., Purushe, J., Torralba, M., Waterman, R.C., MacNeil, M.D., Alexander, L.J. and Nelson, K.E. (2012) Next generation sequencing to define prokaryotic and fungal diversity in the bovine rumen. PLoS ONE 7, e48289.

Franz, R., Soliva, C. R., Kreuzer, M., Hummel, J. and Clauss, M. (2011) Methane output of rabbits (Oryctolagus cuniculus) and guinea pigs (Cavia porcellus) fed a hay-only diet: Implications for the scaling of methane production with body mass in non-ruminant mammalian herbivores. Comp. Biochem. Physiol. Part. A. Mol. Integr. Physiol. 158, 177-181.

Gao, C., Ma, C. and Xu, P. (2011) Biotechnological routes based on lactic acid production from biomass. Biotechnol. Adv. 29, 930-939.

Garcia, E.F., Luciano, W.A., Xavier, D.E., da Costa, W.C., de Sousa Oliveira, K., Franco, O.L., de Morais Júnior, M.A., Lucena, B.T., Picão, R.C., Magnani, M., Saarela, M. and de Souza, E.L. (2016) Identification of lactic acid bacteria in fruit pulp processing byproducts and potential probiotic properties of selected Lactobacillus strains. Front Microbiol. 7, 1-11. 
Garde, A., Jonsson, G., Schmidt, A.S. and Ahring, B.K. (2002) Lactic acid production from wheat straw hemicellulose hydrolysate by Lactobacillus pentosus and Lactobacillus brevis. Bioresour. Technol. 81, 217-223.

Ghaffar, T., Irshad, M., Anwar, Z., Aqil, T., Zulifqar, Z., Tariq, A., Kamran, M., Ehsan, N. and Mehmood, S. (2014) Recent trends in lactic acid biotechnology: A brief review on production to purification. J. Radiat. Res. Appl. Sci. 7, 222-229.

Glassner, D.A. and Datta, R. (1992) Process for the production and purification of succinic acid. Patent US5143834.

Goris, J., Konstantinidis, K.T., Klappenbach, J.A., Coenye, T., Vandamme, P. and Tiedje, J.M. (2007) DNA-DNA hybridization values and their relationship to whole-genome sequence similarities. Int. J. Syst. Evol. Microbiol. 57, 81-91.

Gou, M., Zeng, J., Wang, H., Tang, Y., Shigematsu, T., Morimura, S. and Kida, K. (2016) Microbial community structure and dynamics of starch-fed and glucose-fed chemostats during two years of continuous operation. Front Env. Sci. Eng. 10, 368-380.

Greetham, H.L., Gibson, G.R., Giffard, C., Hippe, H., Merkhoffer, B., Steiner, U., Falsen, E. and Collins, M.D. (2004) Allobaculum stercoricanis gen. nov., sp. nov., isolated from canine faeces. Anaerobe 10, 301-307.

Gregory, E.M., Moore, W.E. and Holdeman, L.V. (1978) Superoxide dismutase in anaerobes: survey. Appl. Environ. Microbiol. 35, 988-991.

Guettler, M.V., Jain, M.K. and Rumler, D. (1996) Method for making succinic acid, bacterial variants for use in the process, and methods for obtaining variants. Patent US5573931.

Guettler, M.V., Jain, M.K. and Soni, B.K. (1998) Process for making succinic acid, microorganisms for use in the process and methods of obtaining the microorganisms. Patent US5723322.

Guyot, J.P., Calderon, M. and Morlon-Guyot, J. (2000) Effect of pH control on lactic acid fermentation of starch by Lactobacillus manihotivorans LMG $18010^{\mathrm{T}}$. J. Appl. Microbiol. $88,176-182$.

Haas, B.J., Gevers, D., Earl, A.M., Feldgarden, M., Ward, D.V., Giannoukos, G., Ciulla, D., Tabbaa, D., Highlander, S.K., Sodergren, E., Methé, B., DeSantis, T.Z., Petrosino, J.F., Knight, R., Birren, B.W. and Human Microbiome Consortium. (2011) Chimeric 16S rRNA sequence formation and detection in Sanger and 454-pyrosequenced PCR amplicons. Genome Res. 21, 494-504.

Hall, T.A. (1999) BioEdit: a user-friendly biological sequence alignment editor and analysis program for windows 95/98/NT. Nucl. Acids Symp. Ser. 41, 95-98.

Hall, V., Collins, M.D., Hutson, R.A., Inganäs, E., Falsen, E. and Duerden, B.I. (2003) Actinomyces oricola sp. nov., from a human dental abscess. Int. J. Syst. Evol. Microbiol. 53, 1515-1518.

Hall, V., Collins, M.D., Lawson, P.A., Falsen, E. and Duerden, B.I. (2005) Actinomyces dentalis sp. nov., from a human dental abscess. Int. J. Syst. Evol. Microbiol. 55, 427-431. 
Hamady, M., Lozupone, C. and Knight, R. (2010) Fast UniFrac: facilitating high-throughput phylogenetic analyses of microbial communities including analysis of pyrosequencing and PhyloChip data. ISME. J. 4, 17-27.

Hamady, M., Walker, J.J., Harris, J.K., Gold, N.J. and Knight, R. (2008) Error-correcting barcoded primers for pyrosequencing hundreds of samples in multiplex. Nat. Methods 5, 235-237.

Herrmann, E., Young, W., Rosendale, D., Reichert-Grimm, V., Riedel, C.U., Conrad, R. and Egert, M. (2017) RNA-based stable isotope probing suggests Allobaculum spp. as particularly active glucose assimilators in a complex murine microbiota cultured in vitro. Biomed. Res. Int. Article ID. 1829685.

Hess, A., Holländer, R. and Mannheim, W. (1979) Lipoquinones of some spore-forming rods, lactic-acid bacteria and Actinomycetes. Microbiology 115, 247-252.

Hijazin, M., Alber, J., Lämmler, C., Kämpfer, P., Glaeser, S.P., Busse, H.-J., Kassmannhuber, J., Prenger-Berninghoff, E., FÖrnges, T., Hassan, A.A., Abdulmawjood, A. and ZschÖck M. (2012) Actinomyces weissii sp. nov., isolated from dogs. Int. J. Syst. Evol. Microbiol. 62, 1755-1760.

Hildebrand, F., Ebersbach, T., Nielsen, H.B., Li, X., Sonne, S.B., Bertalan, M., Dimitrov, P., Madsen, L., Qin, J. Wang, J., Raes, J., Kristiansen, K. and Licht, T.R. (2012) A comparative analysis of the intestinal metagenomes present in guinea pigs (Cavia porcellus) and humans (Homo sapiens). BMC Genomics 13, 514.

Hofvendahl, K. and Hahn-Hägerdal, B. (1997) L-lactic acid production from whole wheat flour hydrolysate using strains of Lactobacilli and Lactococci. Enzyme 20, 301e307.

Hofvendahl, K. and Hahn-Hägerdal, B. (2000) Factors affecting the fermentative lactic acid production from renewable resources. Enzyme Microb. Technol. 26, 87-107.

Hofvendahl, K., Hahn-Hägerdal, B., Åkerberg, C. and Zacchi, G. (1999) Simultaneous enzymatic wheat starch saccharification and fermentation to lactic acid by Lactococcus lactis. Appl. Microbiol. Biotechnol. 52, 163-169.

Huang, H., Zheng, G., Jiang, W., Hu, H. and Lu, Y. (2015) One-step high-efficiency CRISPR/Cas9mediated genome editing in Streptomyces. Acta Biochim. Biophys Sin. 47, 231-243.

Huang, L.P., Jin, B. and Lant, P. (2005) Direct fermentation of potato starch wastewater to lactic acid by Rhizopus oryzae and Rhizopus arrhizus. Bioprocess Biosyst. Eng. 27, 229-238.

Huss, V.A.R., Festl, H. and Schleifer, K.H. (1983) Studies on the spectrophotometric determination of DNA hybridization from renaturation rates. Syst. Appl. Microbiol. 4, 184-192.

IEA (2017). Key World energy statistics 2017 edition. International Energy Agency OECD/IEA, Paris.

Ivarsson, E., Roos, S., Liu, H.Y. and Lindberg, J.E. (2014) Fermentable non-starch polysaccharides increases the abundance of Bacteroides-Prevotella-Porphyromonas in ileal microbial community of growing pigs. Animal 8, 1777-1787. 
Jami, E., Israel, A., Kotser, A. and Mizrahi, I. (2013) Exploring the bovine rumen bacterial community from birth to adulthood. ISME J. 7, 1069-1079.

Jang, Y.S., Kim, B., Shin, J. H., Choi, Y. J., Choi, S., Song, C. W., Lee, J., Park, H. G and Lee, S.Y. (2012) Bio-based production of C2-C6 platform chemicals. Biotechnol. Bioeng. 109, 24372459.

Jiang, X., Li, B., Su, Y. and Zhu, W. (2013) Shifts in bacterial community compositions during in vitro fermentation of amylopectin and resistant starch by colonic inocula of pigs. Food Nutr. Res. 1, 156-163.

John, R.P., Nampoothiri, K.M. and Pandey (2006) A. Simultaneous saccharification and fermentation of cassava bagasse for L-(+)-lactic acid production using Lactobacilli. Appl. Biochem. Biotechnol. 134, 263-272.

Juturu, V. and Wu, J.C. (2016) Microbial production of lactic acid: the latest development. Crit. Rev. Biotechnol. 36, 967-977.

Kajaste, R. (2014) Chemicals from biomass - managing greenhouse gas emissions in biorefinery production chains - a review. J. Clean. Prod. 75, 1-10.

Kambam, P.K.R. and Henson, M.A. (2010) Engineering bacterial processes for cellulosic ethanol production. Biofuels 1, 729-743.

Kamra, D.N. (2005) Rumen microbial ecosystem. Curr. Sci. 89, 124-135.

Keegan, D., Kretschmer, B., Elbersen, B. and Panoutsou, C. (2013) Cascading use: a systematic approach to biomass beyond the energy sector. Biofuels Bioprod. Biorefin. 7, 193-206.

Khor, K., Sawisit, A., Chan, S., Kanchanatawee, S., Jantama, S.S. and Jantama, K. (2016) High production yield and specific productivity of succinate from cassava starch by metabolicallyengineered Escherichia coli KJ122. J. Chem. Technol. Biotechnol. 91, 2834-2841.

Kiely, P.D., Regan, J.M. and Logan, B.E. (2011) The electric picnic: synergistic requirements for exoelectrogenic microbial communities. Curr. Opin. Biotechnol. 22, 378-385.

Kim, M., Oh, H.S., Park, S.C. and Chun, J. (2014) Towards a taxonomic coherence between average nucleotide identity and 16S rRNA gene sequence similarity for species demarcation of prokaryotes. Int J. Syst. Evol. Microbiol. 64, 346-351.

Kim, O.-S., Cho, Y.-J., Lee, K., Yoon, S.-H., Kim, M., Na, H., Park, S.-C., Jeon, Y.S., Lee, J.-H., Yi, H., Won, S. and Chun, J. (2012) Introducing EzTaxon-e: a prokaryotic 16S rRNA gene sequence database with phylotypes that represent uncultured species. Int. J. Syst. Evol. Microbiol. 62, 716-721.

Kimura, M. (1980) A simple method for estimating evolutionary rates of base substitutions through comparative studies of nucleotide sequences. J. Mol. Evol. 16, 111-120.

Kopylova, E., Noe, L. and Touzet, H. (2012) SortMeRNA: fast and accurate filtering of ribosomal RNAs in metatranscriptomic data. Bioinformatics. 28, 3211-3217. 
Kovács, A., van Hartskamp, M., Kuipers, O., and van Kranenburg, R. (2010) Genetic tool development for a new host for biotechnology, the thermotolerant bacterium Bacillus coagulans. Appl. Environ. Microbiol. 76, 4085-4088.

Krause, D.O., Denman, S.E., Mackie, R.I., Morrison, M., Rae, A.L., Attwood, G.T. and McSweeney, C.S. (2003) Opportunities to improve fiber degradation in the rumen: microbiology, ecology, and genomics. FEMS Microbiol. 27, 663-693.

Krause, M., Beauchemin, K.A., Rode, L.M. Farr, B.I. and Nørgaard, P. (1998) Fibrolytic enzyme treatment of barley grain and source of forage in high-grain diets fed to growing cattle. J. Anim. Sci. 76, 2912-2920.

Kumar, R., Singh, S. and Singh, O.V. (2008) Bioconversion of lignocellulosic biomass: biochemical and molecular perspectives. J. Ind. Microbiol. Biotechnol. 35, 377-391.

Lamed, R. and Zeikus, J.G. (1980) Glucose Fermentation Pathway of Thermoanaerobium brockii. J. Bacteriol. 141, 1251-1257.

Lane, D.J. (1991)16S/23S rRNA sequencing. In: Stackebrandt, E. and Goodfellow, M. (editors). Nucleic acid techniques in bacterial systematics. Chichester: Wiley \& Sons. pp. 115-175.

Lange, A., Becker, J., Schulze, D., Cahoreau, E., Portais, J., Haefner, S., Krawczyk, J., Zelder, O. and Wittmann, C. (2017) Bio-based succinate from sucrose: High-resolution 13C metabolic flux analysis and metabolic engineering of the rumen bacterium Basfia succiniciproducens. Metab. Eng. 44, 198-212.

Laopaiboon, P., Thani, A., Leelavatcharamas, V. and Laopaiboon, L. (2010) Acid hydrolysis of sugarcane bagasse for lactic acid production. Bioresour. Technol. 101, 1036-1043.

Law, J.Y. and Mohammad, A.W. (2017) Separation of succinate from organic acid salts using nanofiltration membranes. Chem. Eng. Trans. 56, 1705-1710.

Lee, J.Y., Kang, C.D., Lee, S.H., Park, Y.K. and Cho, K.M. (2015) Engineering cellular redox balance in Saccharomyces cerevisiae for improved production of L-lactic acid. Biotechnol. Bioeng. 112, 751-758.

Lee, I., Kim, Y.O., Park, S.C. and Chun, J. (2016) OrthoANI: an improved algorithm and software for calculating average nucleotide identity. Int. J. Syst. Evol. Microbiol. 66, 1100-1103.

Lewin, G.R., Johnson, A.L., Soto, R.D.M., Perry, K., Book, A.J., Horn, H.A., Pinto-Tomás, A.A. and Currie, C.R. (2016) Cellulose-enriched microbial communities from leaf-cutter ant (Atta colombica) refuse dumps vary in taxonomic composition and degradation ability. PloS ONE 11, e0151840.

Ley, J.D., Cattoir, H. and Reynaerts, A. (1970) The quantitative measurement of DNA hybridization from renaturation rates. J. Mol. Evol. 12, 133-142.

Li, J., Jiang, M., Chen, K.Q., Ye, Q., Shang, L.A., Wei, P., Ying, H-J. and Chang, H.N. (2010ª) Effect of redox potential regulation on succinic acid production by Actinobacillus succinogenes. Bioprocess Biosyst. Eng. 33, 911-920. 
Li, Q. and Xing, J. (2015) Microbial succinic acid production using different bacteria species. In: Kamm, B. (editor) Microorganisms in biorefineries. Microbiology Monographs, Vol. 26. Springer, Berlin, Heidelberg.

Li, Q., Wang, D., Song, Z.Y., Zhou, W., Wu, Y., Xing, J.M. and Su, Z.G. (2010 ${ }^{\text {b }}$ Dual-phase fermentation enables Actinobacillus succinogenes $130 \mathrm{Z}^{\mathrm{T}}$ to be a potential role for high-level lactate production from the bioresource. Bioresour. Technol. 101, 7665-7667.

Li, Q., Wang, D., Wu, Y., Li, W.L., Zhang, Y.J., Xing, J.M. and Su, Z.G. (2010) One step recovery of succinic acid from fermentation broths by crystallization. Sep. Purif. Technol. 72, 294300 .

Li, Q., Yang, M.H., Wang, D., Li, W.L., Wu, Y., Zhang, Y.J., Xing, J.M. and Su, Z.G. (2010 ${ }^{\text {d }}$ Efficient conversion of crop stalk wastes into succinic acid production by Actinobacillus succinogenes. Bioresour. Technol. 101, 3292-3294.

Liang, S., Gliniewicz, K., Mendes-Soares, H., Settles, M.L., Forney, L.J., Coats, E.R. and McDonald, A.G. (2015). Comparative analysis of microbial community of novel lactic acid fermentation inoculated with different undefined mixed cultures. Bioresour. Technol. 179, $268-274$.

Liang, S., McDonald, A.G. and Coats, E.R. (2014) Lactic acid production with undefined mixed culture fermentation of potato peel waste. Waste Manag. 34, 2022-2027.

Lin, H., Bennett, G.N. and San, K.Y. (2005) Fed-batch culture of a metabolically engineered Escherichia coli strain designed for high-level succinate production and yield under aerobic conditions. Biotechnol. Bioeng. 90, 775-779.

Lin, W.C., Coppi, M.V. and Lovley, D.R. (2004) Geobacter sulfurreducens can grow with oxygen as a terminal electron acceptor. Appl. Environ. Microbiol. 70, 2525-2528.

Linko, Y. and Javanainen, P. (1996). Simultaneous liquefaction, saccharification, and lactic acid fermentation on barley starch. Enzyme, 19, $118 \mathrm{e} 123$.

Liu, C., Finegold, S. M., Song, Y. and Lawson, P.A. (2008) Reclassification of Clostridium coccoides, Ruminococcus hansenii, Ruminococcus hydrogenotrophicus, Ruminococcus luti, Ruminococcus productus and Ruminococcus schinkii as Blautia coccoides gen. nov., comb. nov., Blautia hansenii comb. nov., Blautia hydrogenotrophica comb. nov., Blautia luti comb. nov., Blautia producta comb. nov., Blautia schinkii comb. nov. and description of Blautia wexlerae sp. nov., isolated from human faeces. Int. J. Syst. Evol. Microbiol. 58, 1896-1902.

Lopes, W.S., Leite, V.D. and Prasad, S. (2004) Influence of inoculum on performance of anaerobic reactors for treating municipal solid waste. Bioresour. Technol. 94, 261-266.

Ma, J., Frear, C., Wang, Z., Yu, L., Zhao, Q., Li, X. and Chen, S. (2013) A simple methodology for rate-limiting step determination for anaerobic digestion of complex substrates and effect of microbial community ratio. Bioresour. Technol. 134, 391-395.

Macfarlane, G.T. and Macfarlane, S. (1993) Factors affecting fermentation reactions in the large bowel. Proc. Nutr. Soc. 52, 367-373. 
Martín, R., Heilig, G., Zoetendal, E., Smidt, H. and Rodríguez, J. (2007) Diversity of the Lactobacillus group in breast milk and vagina of healthy women and potential role in the colonization of the infant gut. J. Appl. Microbiol. 103, 2638-2644.

Martínez, I., Wallace, G., Zhang, C., Legge, R., Benson, A.K., Carr, T.P., Moriyama, E.N. and Walter, J. (2009) Diet-induced metabolic improvements in a hamster model of hypercholesterolemia are strongly linked to alterations of the gut microbiota. Appl. Environ. Microbiol. 75, 4175-4184.

Matsakas, L., Kekos, D., Loizidou, M. and Christakopoulos, P. (2014) Utilization of household food waste for the production of ethanol at high dry material content. Biotechnol. Biofuels 7, 412.

Meier-Kolthoff, J.P., Auch, A.F., Klenk, H.-P. and Göker, M. (2013) Genome sequence-based species delimitation with confidence intervals and improved distance functions. BMC Bioinformatics 14, 1.

Meng, J., Wang, B., Liu, D., Chen, T., Wang, Z. and Zhao, X. (2016) High-yield anaerobic succinate production by strategically regulating multiple metabolic pathways based on stoichiometric maximum in Escherichia coli. Microb. Cell Fac. 15, 141.

Monlau, F., Barakat, A., Trably, E., Dumas, C., Steyer, J-P. and Carrère, H. (2013) Lignocellulosic materials into biohydrogen and biomethane: impact of structural features and pretreatment. Crit. Rev. Environ. Sci. Technol. 43, 260-322.

Moore, L., Moore, E., Murray, R., Stackebrandt, E. and Starr, M. (1987) Report of the ad hoc committee on reconciliation of approaches to bacterial systematics. Int. J. Syst. Bacteriol. 37, $463-464$

Mougiakos, I., Bosma, E.F., de Vos, W.M., van Kranenburg, R. and van der Oost, J. (2016) Next generation prokaryotic engineering: the CRISPR-Cas toolkit. Trends Biotechnol. 34, 575587.

Murto, M., Björnsson, L. and Mattiasson, B. (2004) Impact of food industrial waste on anaerobic co-digestion of sewage sludge and pig manure. J. Environ. Manage 70, 101-107.

Nagarjun, P.A., Rao, R.S., Rajesham, S. and Rao, L.V. (2005) Optimization of lactic acid production in SSF by Lactobacillus amylovorus NRRL B-4542 using Taguchi methodology. J. Microbiol 43, 38-43.

Narita, J., Nakahara, S., Fukuda, H. and Kondo, A. (2004) Efficient production of L-(+)-lactic acid from raw starch by Streptococcus bovis 148. J. Biosci. Bioeng. 97, 423-425.

Neuendorf, E., Gajer, P., Bowlin, A.K., Marques, Patricia, X.M, Ma B., Yang, H., Fu, L., Humphrys, M.S., Forney, L.J., Myers, G.S.A., Bavoil, P.M., Rank, R.G. and Ravel, J. (2015) Chlamydia caviae infection alters abundance but not composition of the guinea pig vaginal microbiota. Pathog. Dis. 73, 1-12.

Nguyen, T.L.A., Vieira-Silva, S., Liston, A. and Raes, J. (2015) How informative is the mouse for human gut microbiota research? Dis. Model. Mech. 8, 1-16. 
NPC, (2012) National Potato Council 2012, Potato Statistical Yearbook. (http://www.nationalpotatocouncil.org/files/1613/3926/5517/FINAL_2012Statbook_smalle rfilesizeforweb.pdf)

Nübel, U., Engelen, B., Felske, A., Snaidr, J., Wieshuber, A., Amann, R.I., Ludwig, W. and Backhaus, H. (1996) Sequence heterogeneities of genes encoding $16 \mathrm{~S}$ rRNAs in Paenibacillus polymyxa detected by temperature gradient gel electrophoresis. J. Bacteriol. 178, 5636-5643.

Oda, Y., Saito, K., Yamauchi, H. and Mori, M. (2002) Lactic acid fermentation of potato pulp by the fungus Rhizopus oryzae. Curr. Microbiol. 45, 1-4.

Oh, H., Wee, Y.-J., Yun, J.-S., Ho Han, S., Jung, S. and Ryu, H.-W. (2005) Lactic acid production from agricultural resources as cheap raw materials. Bioresour. Technol. 96, 1492e1498.

Ohta, H., Fukui, K. and Kato, K. (1989) Effect of bicarbonate on the growth of Actinobacillus actinomycetemcomitans in anaerobic fructose-limited chemostat culture. Microbiology 135, $3485-3495$.

Okano, K., Kimura, S., Narita, J., Fukuda, H. and Kondo, A. (2007) Improvement in lactic acid production from starch using $\alpha$-amylase-secreting Lactococcus lactis cells adapted to maltose or starch. Appl. Microbiol. Biotechnol. 75, 1007-1013.

Okano, K., Tanaka, T., Ogino, C., Fukuda. H. and Kondo, A. (2010) Biotechnological production of enantiomeric pure lactic acid from renewable resources: recent achievements, perspectives, and limits. Appl. Microbiol. Biotechnol. 85, 413-423.

Okano, K., Yoshida, S., Yamda, R., Tanaka, T., Ogino, C., Fukuda H and Kondo A. (2009a) Improved production of homo-D-lactic acid via xylose fermentation by introduction of xylose assimilation genes and redirection of the phosphoketolase pathway to pentose phosphate pathway in L-lactate dehydrogenase gene-deficient Lactobacillus plantarum. Appl. Environ. Microbiol.75, 7858-7861.

Okano, K., Zhang, Q., Shinkawa, S., Yoshida, S., Tanaka, T., Fukuda, H. and Kondo, A. (2009 ${ }^{\text {b }}$ Efficient production of optically pure D-lactic acid from raw corn starch by using genetically modified L-lactate dehydrogenase gene-deficient and $\alpha$-amylase-secreting Lactobacillus plantarum strain. Appl. Environ. Microbiol.75, 462-467.

Okino, S., Inui, M. and Yukawa, H. (2005) Production of organic acids by Corynebacterium glutamicum under oxygen deprivation. Appl. Microbiol. Biotechnol. 68, 475-480.

Palakawong Na Ayudthaya, S., Hilderink, L.J., van der Oost, J., de Vos, W.M. and Plugge, C.M. $\left(2017^{\mathrm{a}}\right)$ Streptococcus caviae sp. nov., isolated from guinea pig faecal samples. Int. J. Syst. Evol. Microbiol. 67, 1551-1556.

Palakawong Na Ayudthaya, S., Hornung, B., Varadarajan, A.R., Plugge, W. and Plugge, C.M. (2017 ${ }^{\text {) }}$ Draft genome sequence of Actinomyces succiniciruminis strain $\mathrm{Am}^{\mathrm{T}}$, isolated from cow rumen fluid. Genome announc. 5, e01587-16. 
Palakawong Na Ayudthaya, S., Pristaš, P., Hrehová, L., Javorský, P., Stams, A. J. M. and Plugge, C.M. (2016) Actinomyces succiniciruminis sp. nov. and Actinomyces glycerinitolerans sp. nov., two novel organic acid-producing bacteria isolated from rumen. Syst. Appl. Microbiol. 39, 445-452.

Palakawong Na Ayudthaya, S., van de Weijer, A.H.P., van Gelder, A.H., Stams, A.J.M., de Vos, W.M. and Plugge, C.M. (2018) Organic acid production from potato starch waste fermentation by rumen microbial communities from Dutch and Thai dairy cows. Biotechnol. Biofuels 11, 13.

Parada, A.E., Needham, D.M. and Fuhrman, J.A. (2016) Every base matters: assessing small subunit rRNA primers for marine microbiomes with mock communities, time series and global field samples. Environ. Microbiol. 18, 1403-1414.

Parawira, W., Murto, M., Read, J.S. and Mattiasson, B. (2004) Volatile fatty acid production during anaerobic mesophilic digestion of solid potato waste. J. Chem. Technol. Biotechnol. 79, 673-677.

Pateraki, C., Patsalou, M., Vlysidis, A., Kopsahelis, N., Webb, C., Koutinas, A.A. and Koutinas, M. (2016) Actinobacillus succinogenes: advances on succinic acid production and prospects for development of integrated biorefineries. Biochem. Eng. J. 112, 285-303.

Paul, S.S., Dey, A., Baro, D. and Punia, B.S. (2017) Comparative community structure of archaea in rumen of buffaloes and cattle. J. Sci. Food Agric. 97, 3284-3293.

Pitt, R.E., VanKessel, J.S., Fox, D.G., Pell, A.N., Barry, M.C. and VanSoest, P.J. (1996) Prediction of ruminal volatile fatty acids and $\mathrm{pH}$ within the net carbohydrate and protein system. J. Anim. Sci. 74, 226-244.

Pitta, D.W., Kumar, S., Vecchiarelli, B., Shirley, D.J., Bittinger, K., Baker, L.D., Ferguson, J.D. and Thomsen, N. (2014) Temporal dynamics in the ruminal microbiome of dairy cows during the transition period. J. Anim. Sci. 92, 4014-4022.

Pleissner, D., Dietz, D., van Duuren, J.B.J.H., Wittmann, C., Yang, X., Lin, C.S.K. and Venus, J. (2017) Biotechnological production of organic acids from renewable resources. Adv. Biochem. Eng. Biotechnol. 1-38.

Plugge, C.M. (2005) Anoxic media design, preparation, and considerations. Methods Enzymol. 397, $3-16$.

Plugge, C.M., Zoetendal, E.G. and Stams, A.J.M. (2000) Caloramator coolhaasii sp. nov., a glutamate-degrading, moderately thermophilic anaerobe. Int. J. Syst. Evol. Microbiol. 50, $1155-1162$.

Porro, D., Brambilla, L., Ranzi, B.M., Martegani, E. and Alberghina, L. (1995) Development of metabolically engineered Saccharomyces cerevisiae cells for the production of lactic acid. Biotechnol. Prog. 11, 294-298.

Poyart, C., Quesne, G. and Trieu-Cuot, P. (2002) Taxonomic dissection of the Streptococcus bovis group by analysis of manganese-dependent superoxide dismutase gene ( $\operatorname{sodA}$ ) sequences: reclassification of Streptococcus infantarius subsp. coli as Streptococcus lutetiensis sp. nov. and of Streptococcus bovis biotype 11.2 as Streptococcus pasteurianus sp. nov. Int. J. Syst. Evol. Microbiol. 52, 1247-1255. 
Puniya, A.K., Singh, R. and Kamra, D.N. (editors) (2015) Rumen microbiology: from evolution to revolution. Springer India, New Delhi. pp. 379.

Quast, C., Pruesse, E., Yilmaz, P., Gerken, J., Schweer, T., Yarza, P., Peplies, J. and Glöckner, F.O. (2013) The SILVA ribosomal RNA gene database project: improved data processing and web-based tools. Nucleic Acids. Res. 41, D590-D596.

Rakshit S.K. (2004) Biopolymer applications. In: Pandey, A. (editor) Concise encyclopedia of bioresource technology. The Haworth Press, New York pp. 179.

Ramiro-Garcia, J., Hermes, G.D.A., Giatsis, C., Sipkema, D, Zoetendal, E.G., Schaap, P.J. and Smidt, H. (2016) NG-Tax, a highly accurate and validated pipeline for analysis of 16S rRNA amplicons from complex biomes [version 1; referees: 2 approved with reservations, 1 not approved]. F1000Research 5, 1791.

Rao, J.U., Rash, B.A., Nobre, M.F., Da Costa, M.S., Rainey, F.A. and Moe, W.M. (2012). Actinomyces naturae sp. nov., the first Actinomyces sp. isolated from a non-human or animal source. Antonie Leeuwenhoek. 101, 155-168.

Ray, R.C., Sharma, P. and Panda, S.H. (2009). Lactic acid production from cassava fibrous residue using Lactobacillus plantarum MTCC 1407. J. Env. Biol. 30, 847-852.

Reddy, G., Altaf, M.D., Naveena, B.J., Venkateshwar, M. and Kumar, E.V. (2008) Amylolytic bacterial lactic acid fermentation-a review. Biotechnol. Adv. 26, 22-34.

Renvoise, A., Raoult, D. and Roux, V. (2009) Actinomyces massiliensis sp. nov., isolated from a patient blood culture. Int. J. Syst. Evol. Microbiol. 59, 540-544.

Richardson, V.C.G. (2000) Diseases of domestic guinea pigs. Second edition, Blackwell Science Ltd., London, England. pp. 144.

Richter, M. and Rosselló-Móra, R. (2009) Shifting the genomic gold standard for the prokaryotic species definition. Proc. Natl. Acad. Sci. USA. 106, 19126-19131.

Rosselló-Móra, R. and Amann, R. (2015) Past and future species definitions for bacteria and archaea. Syst. Appl. Microbiol. 38, 209-216.

Ryu, H-W., Yun, J-S. and Wee, Y-J (2004) Lactic acid. In: Pandey, A. (editor). Concise encyclopedia of bioresource technology. New York: The Haworth Press. pp. 635-644.

Saini, A., Aggarwal, N.K., Sharma, A. and Yadav, A. (2015) Actinomycetes: a source of lignocellulolytic enzymes. Enzyme Res. pp. 1-15.

Saitou, N. and Nei, M. (1987) The neighbor-joining method: a new method for reconstructing phylogenetic trees. Mol. Biol. Evol. 4, 406-425.

Sakaguchi, E. and Nabata, A. (1992) Comparison of fibre digestion and digesta retention time between nutrias (Myocaster coypus) and guinea-pigs (Cavia porcellus). Comp. Biochem. Physiol. a Comp. Physiol. 103, 601-604. 
Salvachúa, D., Mohagheghi, A., Smith, H., Bradfield, M.F., Nicol, W., Black, B.A., Biddy, M.J., Dowe, N. and Beckham, G.T. (2016) Succinic acid production on xylose-enriched biorefinery streams by Actinobacillus succinogenes in batch fermentation. Biotechnol. Biofuels 9, 28.

Samuel, B.S., Hansen, E.E., Manchester, J.K., Coutinho, P.M., Henrissat, Fulton, R., Latreille, P., Kim, K., Wilson, R.K. and Gordon, J.I. (2007) Genomic and metabolic adaptations of Methanobrevibacter smithii to the human gut. Proc. Natl. Acad. Sci. USA. 104, 1064310648.

Sanguinetti, C.J., Neto, E.D. and Simpson, A.J.G. (1994) Rapid silver staining and recovery of PCR products separated on polyacrylamide gels. Biotechniques. 17, 914-921.

Sauer, M., Porro, D., Mattanovich, D. and Branduardi, P. (2008) Microbial production of organic acids: expanding the markets. Trends Biotechnol. 26, 100-108.

Sauer, S., Freiwald, A., Maier, T., Kube, M., Reinhardt, R., Kostrzewa, M. and Geider, K. (2008). Classification and identification of bacteria by mass spectrometry and computational analysis. PLoS ONE 3, e2843.

Schaal, K.P. and Yassin A.F. (2012) Family I. Actinomycetaceae. In. Goodfellow, M., Peter, K., Busse, H.J., Trujillo, M.E., Suzuki, K.I., Ludwig, W.,

Whitman, W.B. and Parte, A. (editors). Bergey's Manual of Systematic Bacteriology: Volume 5: The Actinobacteria, Part A and B. Springer, New York. pp. 36-108.

Schink, B. and Stams, A.J.M. (2006) Syntrophism among Prokaryotes. The Prokaryotes. 2, 309335.

Schlegel, L., Grimont, F., Ageron, E., Grimont, P.A. and Bouvet, A. (2003) Reappraisal of the taxonomy of the Streptococcus bovis/Streptococcus equinus complex and related species: description of Streptococcus gallolyticus subsp. gallolyticus subsp. nov., S. gallolyticus subsp. macedonicus subsp. nov. and S. gallolyticus subsp. pasteurianus subsp. nov. Int. J. Syst. Evol. Microbiol. 53, 631-645.

Schumann, P. and Maier, T. (2014) MALDI-TOF mass spectrometry applied to classification and identification of bacteria. Methods Microbiol. 41, 275-306.

Serrano-Silva, N., Sarria-Guzmán, Y., Dendooven, L. and Luna-Guido, M. (2014) Methanogenesis and methanotrophy in soil: a review. Pedosphere. 24, 291-307.

Sharma, M. (2014). Actinomycetes: source, identification, and their applications. Int. J. Curr. Microbiol. Appl. Sci. 3, 801-832

Shinozaki-Kuwahara, N., Takada, K. and Hirasawa, M. (2011) Streptococcus ursoris sp. nov., isolated from the oral cavities of bears. Int. J. Syst. Evol. Microbiol. 61, 40-44.

Sipes, B. and Wang, K-H. (2017) Pests, diseases and weeds. In: Lobo, M.G. and Paull, R.E. (editors). Handbook of pineapple technology: production, postharvest science, processing and nutrition. Chichester: Wiley \& Sons. pp. 62-88. 
Smerilli, M., Neureiter, M., Wurz, S., Haas, C., Frühauf, S. and Fuchs, W. (2015) Direct fermentation of potato starch and potato residues to lactic acid by Geobacillus stearothermophilus under non-sterile conditions. J. Chem. Technol. Biotechnol. 90, 648657.

Šmilauer, P. and Lepš, J. (2014) Multivariate analysis of ecological data using CANOCO 5. Cambridge: Cambridge University Press.

Sofyan, A, Mitsumori, M., Ohmori, H., Uyeno, Y., Hasunama, T., Akiyama, K., Yamamoto, H., Yokokawa, H., Yamaguchi, T., Shinkai, T., Hirako, M. and Kushibiki, S. (2017) Differences in rumen fermentation characteristics between low-yield and high-yield dairy cows in early lactation. Anim. Sci. J. 88, 974-982.

Sonnewald, U. and J. Kossmann (2013) Starches_-from current models to genetic engineering. Plant Biotechnol J. 11, 223-232.

Sreethawong, T., Chatsiriwatana, S., Rangsunvigit, P. and Chavadej, S. (2010) Hydrogen production from cassava wastewater using an anaerobic sequencing batch reactor: effects of operational parameters, COD: N ratio, and organic acid composition. Int. J. Hydrogen Energy. 35, 40924102.

Stackebrandt, E. and Ebers, J. (2006) Taxonomic parameters revisited: tarnished gold standards. Microbiol. Today 8, 6-9.

Stams, A.J.M., van Dijk, J.B., Dijkema, C. and Plugge, C.M. (1993) Growth of syntrophic propionateoxidizing bacteria with fumarate in the absence of methanogenic bacteria. Appl. Environ. Microbiol. 59, 1114-1119.

Steinbusch, K.J.J., Hamelers, H.V.M., Plugge, C.M. and Buisman, C.J.N. (2011) Biological formation of caproate and caprylate from acetate: fuel and chemical production from low grade biomass. Energy Env. 4, 216-224.

Stenmarck, Å., Jensen, C., Quested, T., Moates, G., Buksti, M., Balázs, C., Juul, S.; Parry, A., Politano, A., Redlingshofer, B. Scherhaufer, S., Silvennoinen, K., Soethoudt, H., Zübert, C. and Östergren, K. (2016) Estimates of European food waste levels. Stockholm: Swedish Environmental Research Institute. (http://www.eufusions.org/phocadownload/Publications/Estimates\%20of\%20European\%20food\%20waste \%20levels.pdf).

Stingu, C.S., Borgmann, T., Rodloff, A.C., Vielkind, P., Jentsch, H., Schellenberger, W. and Eschrich, K. (2015). Rapid identification of oral Actinomyces species cultivated from subgingival biofilm by MALDI-TOF-MS. J. Oral Microbiol. 7, 1-6.

Sträuber, H., Schröder, M. and Kleinsteuber, S. (2012) Metabolic and microbial community dynamics during the hydrolytic and acidogenic fermentation in a leach-bed process. Energy Sustain. Soc. 2, 13. 
Strepis, N., Sánchez-Andrea, I., van Gelder, A.H., van Kruistum, H., Shapiro, N., Kyrpides, N., Göker, M., Klenk, H.P., Schaap, P., Stams, A.J.M. and Sousa, D.Z. (2016). Description of Trichococcus ilyis sp. nov. by combined physiological and in silico genome hybridization analyses. Int. J. Syst. Evol. Microbiol. 66, 3963-3963.

Suzuki, S., Fukuoka, M., Sawaki, T.A.D.A., Matsushita-Morita, M., Hattori, R., Kitamoto, N. and Kusumoto, K.I. (2010) Production of polygalacturonase by recombinant Aspergillus oryzae in solid-state fermentation using potato pulp. Food Sci. Technol. Res. 16, 517-521.

Sykes, G. and Skinner, F.A. (1973) Actinomycetales: characteristics and practical importance. Academic Press Inc, London. pp. 1-339.

Takahashi, N., Kalfas, S. and Yamada, T. (1995) Phosphorylating enzymes involved in glucose fermentation of Actinomyces naeslundii. J. Bacteriol. 177, 5806-5811.

Tally, F.P., Stewart, P.R., Sutter, V.L. and Rosenblatt, J. (1975). Oxygen tolerance of fresh clinical anaerobic bacteria. J. Clin. Microbiol. 1, 161-164

Tamaoka, J. and Komagata, K. (1984) Determination of DNA base composition by reversed-phase high-performance liquid chromatography. FEMS Microbiol. Lett. 25, 125-128.

Tamis, J., Joosse B.M., van Loosdrecht, M.C.M. and Kleerebezem, R. (2015) High-rate volatile fatty acid (VFA) production by a granular sludge process at low $\mathrm{pH}$. Biotechnol. Bioeng. 112, $2248-2255$.

Tamura, K., Peterson, D., Peterson, N., Stecher, G., Nei, M. and Kumar, S. (2011). MEGA5: molecular evolutionary genetics analysis using maximum likelihood, evolutionary distance, and maximum parsimony methods. Mol. Biol. Evol. 28, 2731-2739.

Tan, J.P., Md Jahim, J., Wu, T.Y., Harun, S. and Mumtaz, T. (2017) The effects of reducing power from metal carbonates on succinic acid production using Actinobacillus succinogenes. Jurnal. Teknologi. 79, 61-65.

Tanaka, T., Hoshina, M., Tanabe, S., Sakai, K., Ohtsubo, S. and Taniguchi, M. (2006) Production of D-lactic acid from defatted rice bran by simultaneous saccharification and fermentation. Bioresour. Technol. 97, 211-217.

Taskila, S. and Ojamo, H. (2013) The current status and future expectations in industrial production of lactic acid bacteria. In Kongo, D.J.M. (editors) Lactic acid bacteria-R and D for food, health and livestock purposes. Intech, Rijeka, pp. 615-632.

Thoetkiattikul, H., Mhuantong, W., Laothanachareon, T., Tangphatsornruang, S., Pattarajinda, V., Eurwilaichitr, L. and Champreda, V. (2013) Comparative analysis of microbial profiles in cow rumen fed with different dietary fiber by tagged $16 \mathrm{~S}$ rRNA gene pyrosequencing. Curr. Microbiol. 67, 130-137.

Thompson, C.C., Vicente, A.C.P., Souza, R.C., Vasconcelos, A.T.R, Vesth, T., Alves, N., Ussery, D.W., Iida, T. and Thompson, F.L. (2009). Genomic taxonomy of Vibrios. BMC Evol. Biol. 9, 1. 
Thompson, J.D., Gibson, T.J., Plewniak, F., Jeanmougin, F. and Higgins, D.G. (1997) The CLUSTAL_X windows interface: flexible strategies for multiple sequence alignment aided by quality analysis tools. Nucleic Acids Res. 25, 4876-4882.

Thompson, J.D., Higgins, D.G. and Gibson, T.J. (1994) CLUSTAL W: improving the sensitivity of progressive multiple sequence alignment through sequence weighting, position-specific gap penalties and weight matrix choice. Nucleic Acids Res. 22, 4673-4680.

Timmers, P.H., Suarez-Zuluaga, D.A., van Rossem, M., Diender, M., Stams, A.J. and Plugge, C.M. (2015) Anaerobic oxidation of methane associated with sulfate reduction in a natural freshwater gas source. ISME. J. 10, 1400-1412.

Tong, Y., Charusanti, P., Zhang, L., Weber, T. and Lee, S.Y. (2015) CRISPR-Cas9 based engineering of actinomycetal genomes. ACS Synth. Biol. 4, 1020-1029.

Van den Abbeele, P., Belzer, C., Goossens, M., Kleerebezem, M., De Vos, W.M., Thas, O, De Weirdt, R., Kerckhof, F.M. and Van de Wiele, T. (2013) Butyrate-producing Clostridium cluster XIVa species specifically colonize mucins in an in vitro gut model. ISME. J. 7, 949.

Van den Bogert, B., de Vos, W.M., Zoetendal, E.G. and Kleerebezem, M. (2011) Microarray analysis and barcoded pyrosequencing provide consistent microbial profiles depending on the source of human intestinal samples. Appl. Environ. Microbiol. 77, 2071-2080.

Van Gelder, A.H., Aydin, R., Alves, M.M. and Stams, A.J.M. (2012) 1,3-Propanediol production from glycerol by a newly isolated Trichococcus strain. Microb. Biotechnol. 5, 573-578.

Van Lingen, H.J., Edwards, J.E., Vaidya, J.D., van Gastelen, S., Saccenti, E., van den Bogert, B., Saccenti, E., Bannink, A., Smidt, H., Plugge, C.M. and Dijkstra, J. (2017) Diurnal dynamics of gaseous and dissolved metabolites and microbiota composition in the bovine rumen. Front. Microbiol. 8, 425.

Vandžurová, A., Bódy, G., Javorský, P. and Pristaš, P. (2013) Actinomyces ruminicola G10-the rumen bacterium recovered from glycerol enriched cultivation media. Nov. Biotechnol. Chim., 12, 39-45.

Vanikova, S., Noskova, A., Pristas, P., Judova, J. and Javorsky, P. (2015) Heterotrophic bacteria associated with Varroa destructor mite. Apidologie. 46, 369-379.

Varghese, N.J., Mukherjee, S., Ivanova, N., Konstantinidis, K.T., $\quad$ Mavrommatis, K., Kyrpides, N.C. and Pati, A. (2015) Microbial species delineation using whole genome sequences. Nucleic Acids Res. pgkv657.

Vavilin, V.A., Fernandez, B., Palatsi, J. and Flotats, X. (2008) Hydrolysis kinetics in anaerobic degradation of particulate organic material: an overview. Waste Manag. 28, 939-951.

Veeken, A., Kalyuzhnyi, S., Scharff, H., and Hamelers, B. (2000) Effect pH and on hydrolysis of organic solid waste. J. Environ. Eng. 172, 1076-1081. 
Velikova, P., Stoyanov, A., Blagoeva, G., Popova, L., Petrov, K., Gotcheva, V., Angelov, A. and Petrova, P. (2016) Starch utilization routes in lactic acid bacteria: new insight by gene expression assay. Starch/Stärke. 68, 953-960.

Ventorino, V., Robertiello, A., Cimini, D., Argenzio, O., Schiraldi, C., Montella, S., Faraco, V., Ambrosanio, A., Viscardi, S. and Pepe, O. (2017) Bio-Based succinate production from Arundo donax hydrolysate with the new natural succinic acid-producing strain Basfia succiniciproducens BPP7. Bioenerg. Res. 10, 488-498.

Venus, J., Fiore, S., Demichelis, F. and Pleissner, D. (2018) Centralized and decentralized utilization of organic residues for lactic acid production. J. Clean. Prod. 172, 778-785.

Vishnu, C., Seenayya, G. and Reddy, G. (2002). Direct fermentation of various pure and crude starchy substrates to L(p)-lactic acid using Lactobacillus amylophilus GV6. World J. Microbiol. Biotechnol. 18, 429e433.

Vital, M., Howe, A.C. and Tiedje, J.M. (2014) Revealing the bacterial butyrate synthesis pathways by analyzing (meta)genomic data. MBio. 5, e00889-14.

Wang, Y., Tashiro, Y. and Sonomoto, K. (2015) Fermentative production of lactic acid from renewable materials: Recent achievements, prospects, and limits. J. Biosci. Bioeng. 119, 1018.

Wayne, L.G., Brenner, D.J., Colwell, R.R., Grimont, P.A.D., Kandler, O., Krichevsky, M.I., Moore, L.H., Moore, W.E.C., Murray, R.G.E., Stackebrandt, E., Starr, M.P. and Trüper, H.G. (1987) Report of the ad hoc committee on reconciliation of approaches to bacterial systematics. Int. J. Syst. Evol. Microbiol. 37, 463-464.

Wee, Y.J., Kim, J.N. and Ryu, H.W. (2006) Biotechnological production of lactic acid and its recent applications. Food Technol. Biotechnol. 44, 163-172.

Weusthuis, R.A., Mars, A.E., Springer, J., Wolbert, E.J., van der Wal, H., de Vrije, T.G., Levisson, M., Leprince, A., Houweling-Tan, G.B., Pha Moers, A., Hendriks, S.N., Mendes, O., Griekspoor, Y., Werten, M.W., Schaap, P.J., van der Oost, J. and Eggink, G. (2017) Monascus ruber as cell factory for lactic acid production at low pH. Metab. Eng. 42, 66-73.

Whiley, A.R. and Hardie, M.J. (2009) Family VI. Streptococcaceae. In. de Vos, P., Garrity, G.M., Jones, D., Krieg, N.R., Ludwig, W., Rainey, F.A., Schleifer, K-H. and Whitman, W.B. (editors). Bergey's manual of systematic bacteriology volume 3: the firmicutes. New york: Springer. pp. 655-710.

Wilson, D.B. (2011) Microbial diversity of cellulose hydrolysis. Curr. Opin. Microbiol. 14, 259263.

Woo, P.C.Y., Fung, A.M.Y., Lau, S.K.P., Teng, J.L.L., Wong, B.H.L., Wong, M.K.M., Hon, E., Tang, G.W.K. and Yuen, K-Y. (2003). Actinomyces hongkongensis sp. nov. a novel Actinomyces species isolated from a patient with pelvic actinomycosis. Syst. Appl. Microbiol. 26: 518-522. 
Wright, E.S., Yilmaz, L.S. and Noguera, D.R. (2012) DECIPHER, a search-based approach to chimera identification for $16 \mathrm{~S}$ rRNA sequences. Appl. Environ. Microbiol. 78, 717-725.

Xiaodong, W., Xuan, G. and Rakshit, S.K. (1997) Direct fermentative production of lactic acid on cassava and other starch substrates. Biotechnol. Lett. 19, 841-843.

Yan, B.H., Selvam, A. and Wong, J.W. (2014) Application of rumen microbes to enhance food waste hydrolysis in acidogenic leach-bed reactors. Bioresour. Technol. 168, 64-71.

Yarza, P. Yilmaz, P., Pruesse, E., Glöckner F.O., Ludwig, W., Schleifer, K-H., Whitman, W.B., Euzéby, J., Amann, R. and Rosselló-Móra., R. (2014) Uniting the classification of cultured and uncultured bacteria and archaea using 16S rRNA gene sequences. Nature. Rev. Microbiol. 12, 635-645.

Yen, H-W and Kang, J-L. (2010) Lactic acid production directly from starch in a starch-controlled fed-batch operation using Lactobacillus amylophilus. Bioprocess Biosyst. Eng. 33, 10171023.

Yu, B., Chiou, W-S. and Kuo, C-Y. (2000) Comparison of digestive function among rabbits, guineapigs, rats and hamsters. II. Digestive enzymes and hindgut fermentation Asian-Australas. J. Anim. Sci. 13, 1508-1513.

Yu, Z., García-González, R., Schanbacher, F.L. and Morrison, M. (2008) Evaluations of different hypervariable regions of archaeal $16 \mathrm{~S}$ rRNA genes in profiling of methanogens by Archaeaspecific PCR and denaturing gradient gel electrophoresis. Appl. Environ. Microbiol. 74, 889-893.

Yue, Z.B., Li, W.W. and Yu, H.Q. (2013) Application of rumen microorganisms for anaerobic bioconversion of lignocellulosic biomass. Bioresour. Technol. 128, 738-744.

Yun, J.S., Wee, Y.J., Kim, J.N. and Ryu, H.W. (2004) Fermentative production of DL-lactic acid from amylase-treated rice and wheat brans hydrolyzate by a novel lactic acid bacterium, Lactobacillus sp. Biotechnol. lett. 26, 1613-1616.

Zeikus, J.G., Jain, M.K. and Elankovan, P. (1999) Biotechnology of succinic acid production and markets for derived industrial products. Appl. Microbiol. Biotechnol. 51, 545-552.

Zhang, L., Zhang, K., Gao, W., Zhai, Z., Liang, J., Du, L. and Feng, X. (2016) Influence of temperature and $\mathrm{pH}$ on methanogenic digestion in two-phase anaerobic co-digestion of pig manure with maize straw. J. Residuals. Sci. Tech. 13, S27-S32.

Zheng, Z., Chen, T., Zhao, M., Wang, Z. and Zhao, X. (2012) Engineering Escherichia coli for succinate production from hemicellulose via consolidated bioprocessing. 11, 37.

Zhi, W., Ge, Z., He, Z. and Zhang, H. (2014) Methods for understanding microbial community structures and functions in microbial fuel cells: a review. Bioresour. Technol. 171, 461-468. 
Zhu, H., Stadnyk, A., Béland, M. and Seto, P. (2008) Co-production of hydrogen and methane from potato waste using a two-stage anaerobic digestion process. Bioresour. Technol. 99, 50785084.

Zou, W., Zhu, L-W, Li, H-M. and Tang, Y-J. (2011) Significance of $\mathrm{CO}_{2}$ donor on the production of succinic acid by Actinobacillus succinogenes ATCC 55618. Microb. Cell Fact. 10, 87. 


\section{List of publications/Book chapter}

Palakawong Na Ayudthaya, S., Pristaš, P., Hrehová, L., Javorský, P., Stams, A.J.M. and Plugge, C.M. (2016). Actinomyces succiniciruminis sp. nov. and Actinomyces glycerinitolerans sp. nov., two novel organic acid-producing bacteria isolated from rumen Systematic and Applied Microbiology. 39, 445-452.

Palakawong Na Ayudthaya, S.*, Strepis, N.*, Pristaš, P. and Plugge, C.M. (2017). Draft genome of Actinomyces glycerinitolerans $G 10^{T}$, isolated from sheep rumen fluid. Genome Announcements 5, e01589-16.

Palakawong Na Ayudthaya, S.*, Hornung, B.*, Varadarajan, A.R., Plugge, W. and Plugge, C.M. (2017). Draft genome sequence of Actinomyces succiniciruminis strain Am4 $4^{T}$, isolated from cow rumen fluid. Genome Announcements 5, e01587-16.

Palakawong Na Ayudthaya, S., Hilderink, L.J., van der Oost, J., de Vos, W.M. and Plugge, C.M. (2017). Streptococcus caviae sp. nov., isolated from guinea pig faecal samples. International Journal of Systematic and Evolutionary Microbiology 67, 1551-1556.

Palakawong Na Ayudthaya, S., Marshall, I.P., Schreiber, L. and Plugge, C.M. (2017). Draft Genome Sequence of Streptococcus caviae strain cavy grass $6^{T}$, isolated from domesticated guinea pig fecal samples. Genome Announcements 5, e00080-17.

Palakawong Na Ayudthaya, S., van de Weijer, A.H.P., van Gelder, A.H., Stams, A.J.M., de Vos, W.M. and Plugge, C.M. (2018) Organic acid production from potato starch waste fermentation by rumen microbial communities from Dutch and Thai dairy cows. Biotechnology for Biofules. 11, 13.

Liu, D., Puigros, M.R., Caizan-Juanarena, L., Geppert, F., Palakawong Na Ayudthaya, S., Buisman, C. and Heijne, A.T. (2018) Granular Carbon-based Electrodes as Cathodes in Methane-Producing Bioelectrochemical Systems. Front. Bioeng. Biotechnol. | doi: 10.3389/fbioe.2018.00078.

Palakawong Na Ayudthaya, S., van der Oost, H., van der Oost, J., van Vliet, D.M. and Plugge, C.M. Microbial diversity and organic acid production of guinea pig faecal samples. (Submitted)

Palakawong Na Ayudthaya, S., Guo, X. and Plugge, C.M. Optimization of succinate production from potato starch waste by Actinomyces succiniciruminis strain Am4 $4^{T}$.

* Equal Contribution 


\section{Co-author affiliations}

Alfons J. M. Stams, Antonie H. van Gelder, Antonius H. P. van de Weijer, Caroline M. Plugge, Daan M. van Vliet, Hans van der Oost, John van der Oost, Loes J. Hilderink, Susakul Palakawong Na Ayudthaya, Nicolaos Strepis and Xiaohan Guo.

Laboratory of Microbiology, Wageningen University \& Research, Stippeneng 4, 6708 WE Wageningen, The Netherlands.

\section{Alfons J. M. Stams}

Centre of Biological Engineering, University of Minho, Campus de Gualtar 4710-057 Braga, Portugal.

\section{Bastian Hornung and Nicolaos Strepis}

Laboratory of Systems and Synthethic Biology, Wageningen University \& Research, Stippeneng 4, 6708 WE Wageningen, The Netherlands.

\section{Dandan Liu, Marta Roca-Puigros, Leire Caizán-Juanarena, Cees Buisman and Annemiek ter} Heijne

Sub-Department of Environmental Technology, Wageningen University \& Research, Bornse Weilanden 9, 6700 AA Wageningen Wageningen, The Netherlands.

\section{Florian Geppert}

Fraunhofer Institute for Environmental, Safety, and Energy Technology UMSICHT, Osterfelder Straße 3, 46047 Oberhausen, Germany.

\section{Ian P. G. Marshall and Lars Schreiber}

Center for Geomicrobiology, Department of Bioscience, Aarhus University, Ny Munkegade 114, 8000 Aarhus, Denmark.

\section{Ludmila Hrehovác and Peter Pristaš}

Institute of Biology and Ecology, Pavol Jozef Šafárik University, Šrobárova 2, SK-04180 Košice, Slovak Republic

\section{Peter Javorský and Peter Pristaš}

Institute of Animal Physiology, Slovak Academy of Sciences, Šoltésovej 4-6, SK-04001 Košice, Slovak Republic.

\section{Susakul Palakawong Na Ayudthaya}

Biodiversity Research Centre, Thailand Institute of Scientific and Technological Research, 35 Moo 3, Tambon Khlong Ha, Amphoe Khlong Luang, Pathum Thani, 12120 Thailand.

Willem M. de Vos

Immunobiology Research Program, Department of Bacteriology and Immunology, University of Helsinki, Haartmaninkatu 3 FI-00014 Finland. 


\section{About the author}

Susakul Palakawong Na Ayudthaya was born on October $17^{\text {th }}, 1974$, in Bangkok, Thailand. She obtained her bachelor's degree in Microbiology from Kasetsart University in 1996. In the same year she started working her first job as a quality control staff at Nisho Nipro Corporation LTD. Since 1997, she has been working at Thailand Institute of Scientific and Technological Research (TISTR) until now.

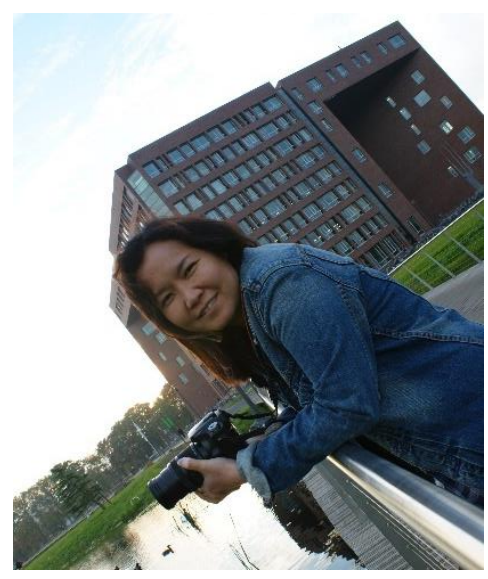

During her work at TISTR, she received the Royal Thai Government scholarship to presue her Master Degree at Colorado State University-Pueblo, The United State of America. Her master thesis entitled "Heavy metal concentration and microbial profile of topsoil in Pueblo, Colorado" in 2006. After that she went back to Thailand and had been continued her work as a researcher at TISTR until she got a scholarship from TISTR once again for her Ph.D. degree. In 2012, she started her study at Microbial Physiology group, Laboratory of Microbiology, Wageningen University, The Netherlands. She will defense her thesis at Wageningen to finish her PhD in September, 2018. 



\section{Acknowledgements}

I believe in the sentence that "everything happens for a reason". Therefore, there might be a reason for us to meet and become colleagues, friends or families; and that includes you, who are reading my thesis right now. At this point, it might be the end of $\mathrm{PhD}$ learning period, however, I am sure that our friendship will never be over. Along this journey, many people, some of them are now spread over many countries, got involved and contributed to my PhD accomplishment. I deeply appreciate your kindness and friendships. Although all my gratitude might not completely fit in these paragraphs, it has been written in my heart and memories.

First of all, I would like to give all the knowledge I have obtained to my father and mother, who have given me my life and made me the person I am now. Their infinite love and care are my backbone. Thank you so much for all and for being my first and forever teachers. You taught me to be brave, to do the right things, and to be kind to the people. Because of you, I am now able to do many things, have had chances to explore this great world, meet fantastic people and have wonderful friendships.

I would like to acknowledge the Royal Thai government scholarship via Ministry of Science and Technology and Thailand Institute of Scientific and Technological Research for fully granting me scholarships for both of my MSc education in US and PhD education in The Netherlands.

Importantly, without all the support from my beloved daily supervisor, Caroline, I could not be able to accomplish my $\mathrm{PhD}$. You have been teaching me and taking care of me not only on my work, but also on my personal life since I arrived in The Netherlands. You have shown me how to be a great scientist. I couldn't ask for a better supervisor. I really appreciate your care and kindness. You were my beloved teacher and have become my forever sister. I am very happy to be your student and have you as my model of scientist.

I would like to express my cordial gratitude to my dear promotors Fons and Willem. I am very happy to have two super idol scientists as my promotors. Thank you very much for your kindness and support. Fons, your door is always open for all the questions I have, and your opinion is very valuable for me. Willem, thank you so much for giving me the great opportunity to be your student and be a part of Laboratory of Microbiology at Wageningen University. Since the day that I got your acceptant e-mail, you have been caring and supporting. I will never forget you and will follow the inspirations in Science, just as you do.

I would like to thank John for your fantastic curiosity for Henk and Jaap, his guinea pigs, eating habits. Because of his initiative and the help of my first student, his son Hans, two nice stories 
have been added to my thesis. Thank you for all your contributions. I would like to thank all of my co-authors and my students Hans, Loes and Xiaohans. It was very nice to work with all of you. Your contributions are very valuable to me.

I would like to express my special thanks to Anja and Carolien for their kind support and help during these years. I would like to thank all of MIB/SSB technicians, Bart, Tom van der Weijer, Hans, Tom Schonewille, Wilma, Steven, Ineke, Philippe and Sjon for all technical supports especially Monika, Ton van Gelder and Wim. Ton, thank you so much for always being a brother, for your help and support, and for the nice talks about everything. You make MicFys lab a warm and secure space to everyone. Many thanks to Wim for all you have done, your support and help to all MIB members. I admire you, especially for your IT and problem-solving skills. You are a part of my successful PhD. I would like to thank Detmer for teaching me how to analyze the pyrosequencing data; thanks, Samet for being my first teacher in the lab; Gerben, Lennart, Floor and Yue for supporting me with the Canoco analysis; Daan for the Miseq analysis. Janneke, it was very nice experience to join you organizing a course.

My dear paranymphs, dear Nam who I have shared Vietnamese descent with. Thank you so much for all your help from the first week of my $\mathrm{PhD}$ until now. I have learned a lot from you and I will keep our friendship forever. Monika, thank you for sharing many things with me, especially the food. I am so proud of your increased tolerance to spicy food. I could feel our friendship from the first day we met in the meeting room, and I was right! Our friendship has no boundary!

My dear fantastic Anna, I am so happy to meet a nice and kind person as you. Thank you so much for your friendship and your help. I will never forget that we had spent good times (writing thesis day and night and having dinner) together for those months. You are always there when I need help and support. Thank you so much.

I would like to thank all my officemates Nam, Peer, Michael, Yuan, Jueeli, Daan, Moro (Giulio), Denny, Conell, Lara, Catalina and Iame for the nice conversations, sharing knowledge and all the support. Peer, it was nice to start my PhD life in the same office as you. Thanks for sharing the interesting stories with me. Moro, I will not forget our friendship. Daan, I was happy and enjoyed being in the same office as you in my last period. Thank you for all the nice things you shared. Jueeli, thank you for sharing (rumen) work and time together.

Dear Micfys members, I am very happy to be part of this team. It was my pleasure to meet and spend time with all of you: Fons, Caroline, Diana, Irene, Ton, Monika, Iame, Nam, Anna, 
Rik, Roy, Daan, Lot, Peer, Jueeli, Martijn, Nikolas, Yuan, Nohemi, Michael, Ana, Joana, Vicente, Derya, Monir, Samet, Rozeline, Petra, Martin, Lara, Florian, Cristina, Catalina, Denny, Moro, Conell, Ahmad, Marjet and Sabina. Thank you very much. Dear Diana, thank you so much for all your kindness and support. I appreciated your organization for my farewell. Rik, I was nice to know you myfriend! Irene, thanks for the working and fun times we had together. Martijn, thanks for being super (man) Martijn in Micfys. You always help everyone. Lot, it was very nice the time we spent together chatting, especially about cooking. Are you still cooking Thai food? You are my hope to maintain Thai food in the Micfys dinner!

I would like to thank all my friends and colleagues from the MIB/SSB/WUR family. It was my pleasure to meet all of you. Thank you so much for all fun times and your support. Special thanks to Teresita, LooWee, Charmaine, Thomas, Ying, Naim, Zephyr, Bastian, Yue, Jing, Siavash, Javi, Yifan, Dennis, Nico, Tika, Indra, Aleks, Sudashan, Kyle, Peng Peng, Romy, Momo, Dandan, Aura, Adihi, Nacho, Marta, Aziza, Rozani, and Audrey for your help and friendships.

My dear beloved friend, Lenny, I am so happy I met you and have you as my friend in my life. Thank you so much for your friendship and for all your help and sharing. You are an amazing person who can manage everything perfectly. Thanks for being my lovely colleague (painting job), my consultant, friend and sister.

Dear Kees and P' Weaw, my second farther and mother, thank you both of you so much for your kindness and for being my warm family in The Netherlands. Thank you so much for all fresh and clean fruits and vegetables from your garden. You are like the dad and mom for the Thai community. ขอบคุณพี่แหววและเกสมากๆ นะคะ สำหรับทุกสิ่งทุกอย่างที่พี่ทำให้กู๊ดและน้องๆคนไทย ขอบคุณ ที่รักและเอ็นดูกู๊ดเหมือนลูกเสมอมา กู๊ดจะไม่ลืมพระคุณเลยค่ะ

I would like to thank my Thai family in Wageningen. During these years, I have discovered a second family right here. Thanks for being my sisters and brothers and thank for all of your care and support.

Last, I would like to thank my beloved sisters, friends and Thai colleagues in Thailand for all your love, care, and support along these years.

With my best regards, 


\section{SENSE}

Netherlands Research School for the

Socio-Economic and Natural Sciences of the Environment

\section{I P L O M A}

For specialised PhD training

The Netherlands Research School for the Socio-Economic and Natural Sciences of the Environment

(SENSE) declares that

\section{Susakul Palakawong Na Ayudthaya}

born on 17 October 1974 in Bangkok, Thailand

has successfully fulfilled all requirements of the Educational Programme of SENSE.

Wageningen, 7 September 2018

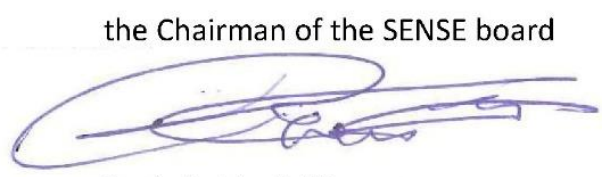

Prof. dr. Huub Rijnaarts

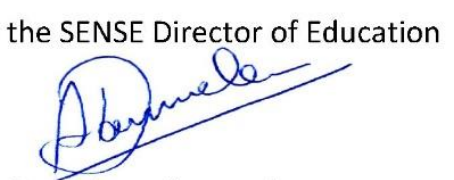

Dr. Ad van Dommelen

The SENSE Research School has been accredited by the Royal Netherlands Academy of Arts and Sciences (KNAW)

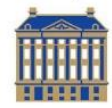

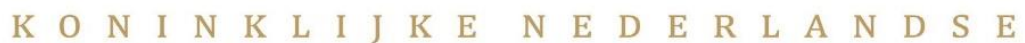

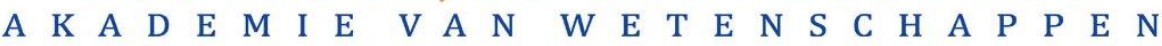




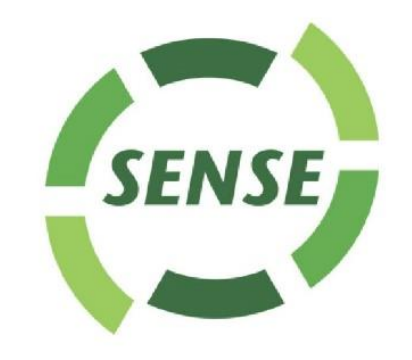

The SENSE Research School declares that Ms Susakul Palakawong Na Ayudthaya has successfully fulfilled all requirements of the Educational PhD Programme of SENSE with a work load of $50.5 \mathrm{EC}$, including the following activities:

\section{SENSE PhD Courses}

- Environmental research in context (2012)

- Research methodology I (2012)

- Program for basic ARB/SILVA training (2014)

- Research in context activity: 'Organising a course "Program for Basic ARB/SILVA Training' (2014)

- SENSE Writing week (2015)

\section{Other PhD and Advanced MSc Courses}

- Microbial physiology, Wageningen University (2012)

- Biorefining training, Wageningen University (2012)

- Bioreactor design and operation, Wageningen University (2012)

- Project and Time Management (2012)

- Scientific writing, Wageningen University (2013)

- Scientific publishing workshop, Wageningen University (2014)

- Multivariate analysis for food data/scientists, Wageningen University (2014)

\section{External training at a foreign research institute}

- RumicOmics summer school, Università Cattolica del Sacro Cuore (2014)

- Genomics in Environmental Microbiology, Aarhus University, Denmark (2016)

\section{Management and Didactic Skills Training}

- Supervising BSc student with thesis entitled 'Characterization of a novel grass degrading bacterium isolated from guinea pig faecal sample' (2015)

- Supervising MSc student with thesis entitled 'Optimizing succinic acid production using starch waste by Actinomyces strain Am4' (2015-2016)

- Assisting practical of the BSc course 'Microbial Physiology' (2012-2016)

\section{Oral Presentations}

- The rumen as bioreactor for renewable volatile fatty acid (VFA) production. International Conference on Anaerobic Digestion, 3-6 February 2015, Chiang-mai, Thailand

- Organic acid production from starchy waste by rumen derived microbial communities. Microbiology Centennial Symposium (Pitch), 18-20 October 2017, Wageningen, The Netherlands

SENSE Coordinator PhD Education

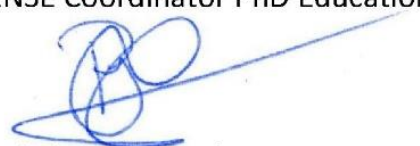

Dr. ir. P.J. Vermeulen 
The research described in this thesis was financially supported by The Royal Thai government scholarship, Ministry of Science and Technology, Thailand.

Financial support from the Laboratory of Microbiology (Wageningen University \& Research) for printing this thesis is gratefully acknowledged.

Cover design by Pathitta Sirirerkratana | Susakul Palakawong Na Ayudthaya and was sponsored by Dr. Pattong Sawadikiat

Thesis layout by Susakul Palakawong Na Ayudthaya

Thesis printing by Proefschriftmaken.nl || DigiForce Vianen 